\title{
Learning through Talk
}

Citation for published version (APA):

Eppich, W. J. (2018). Learning through Talk: the Role of Discourse in Medical Education. [Doctoral Thesis, Maastricht University]. Maastricht University. https://doi.org/10.26481/dis.20181010we

Document status and date:

Published: 01/01/2018

DOI:

10.26481/dis.20181010we

Document Version:

Publisher's PDF, also known as Version of record

\section{Please check the document version of this publication:}

- A submitted manuscript is the version of the article upon submission and before peer-review. There can be important differences between the submitted version and the official published version of record.

People interested in the research are advised to contact the author for the final version of the publication, or visit the DOI to the publisher's website.

- The final author version and the galley proof are versions of the publication after peer review.

- The final published version features the final layout of the paper including the volume, issue and page numbers.

Link to publication

\footnotetext{
General rights rights.

- You may freely distribute the URL identifying the publication in the public portal. please follow below link for the End User Agreement:

www.umlib.nl/taverne-license

Take down policy

If you believe that this document breaches copyright please contact us at:

repository@maastrichtuniversity.nl

providing details and we will investigate your claim.
}

Copyright and moral rights for the publications made accessible in the public portal are retained by the authors and/or other copyright owners and it is a condition of accessing publications that users recognise and abide by the legal requirements associated with these

- Users may download and print one copy of any publication from the public portal for the purpose of private study or research.

- You may not further distribute the material or use it for any profit-making activity or commercial gain

If the publication is distributed under the terms of Article $25 \mathrm{fa}$ of the Dutch Copyright Act, indicated by the "Taverne" license above, 


\section{Learning through Talk:}

The Role of Discourse in Medical Education 
The research reported here was carried out at

Maastricht University in Leaning!

in the School of Health Professions Education

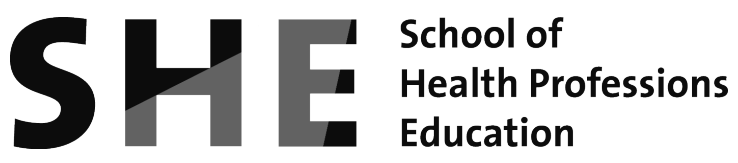

(C) Walter J. Eppich, Maastricht 2018

ISBN: 978-94-9301-471-8

Printing by Gildeprint 


\title{
Learning through Talk:
}

The Role of Discourse in Medical Education

\author{
Dissertation
}

to obtain the degree of Doctor at Maastricht University,

on the authority of the Rector Prof. dr. Rianne M. Letschert, in accordance with the decision of the Board of Deans, to be defended in public

on Wednesday $10^{\text {th }}$ October 2018 , at 1600 hours

by

Walter John Eppich 


\section{Supervisors}

Prof.dr. P.W. Teunissen

Prof.dr. T. Dornan

Prof.dr. J.J. Rethans

\section{Assessment Committee}

Prof.dr. D.H.J.M. Dolmans (chair)

Prof.dr. P.L.P. Brand (Universiteit Groningen)

dr. A. de la Croix (Vrije Universiteit Amsterdam)

Prof.dr. W.N.K.A. van Mook

dr. R.J.M.W. Rennenberg 


\section{Table of Contents}

$\begin{array}{lll}\text { Chapter } 1 & \text { Introduction } & 7\end{array}$

Chapter 2 Learning to work together through talk: Continuing professional 19 development medicine

Published in: Supporting Learning Across Working Life. Vol 16.

Professional and Practice-based Learning. Cham: Springer

International Publishing, 2016:47-73.

Chapter 3 Promoting Excellence and Reflective Learning in Simulation

(PEARLS) Development and rationale for a blended approach to health care simulation debriefing

Published in: Simulation in Healthcare, 2015;10(2):106-115.

Chapter 4 Structuring feedback and debriefing to achieve mastery learning goals

Published in: Academic Medicine, 2015;90(11):1501-1508.

Chapter 5 A rater training protocol to assess team performance

Published in: Journal of Continuing Education in the Health

Professions, 2015;35(2):83-90.

Chapter 6 "Learning the lingo": A grounded theory study of telephone talk in

clinical education

Under peer review

Chapter 7 Learning how to learn using simulation: Unpacking disguised

feedback using a qualitative analysis of doctors' telephone talk

Published in: Medical Teacher, 2018;40(7):661-667.

Chapter 8 Promoting learning and patient care through shared reflection: A conceptual framework for team reflexivity in health care

Published in: Academic Medicine, 2017;92(11):1555-1563.

Chapter 9 Discussion

Summary

Samenvatting

173

Valorisation

177

Acknowledgements

181

Curriculum vitae 


\section{CHAPTER 1}

Introduction 


\section{'Communication' in modern clinical education}

In order to meet the challenges of $21^{\text {st }}$ century healthcare, we must prepare physicians to care for patients whilst working in highly interdependent team-based settings. ${ }^{1}$ This realization manifests in a logical emphasis on 'communicative competence' ${ }^{2}$ in order to enable interprofessional collaboration ${ }^{3}$ and teamwork, ${ }^{4}$ while minimizing error and patient harm due to miscommunication. ${ }^{5,6}$ The 'work' in clinical practice includes two important components: ${ }^{7}$ (a) taskwork, which involves what needs to happen for patient care in terms of assessment and management, and (b) teamwork, which denotes how team members work together to achieve patient care, including communication, coordination, etc. Therefore, teamwork serves to support completion of taskwork.

This development has wide-reaching implications for physician education. "Communication skills" comprise several core competencies in graduate medical education, as evidenced by the CanMeds roles of 'Collaborator' and 'Communicator' from the Royal College of Physicians and Surgeons of Canada. ${ }^{8}$ The Accreditation Council on Graduate Medical Education from the United States (US) also provides developmental milestones as assessment guidelines for many medical specialties. ${ }^{9}$ For example, general pediatric trainees ${ }^{10}$ in the US must achieve milestones in a number of domains for which 'communicative competence' is reflected wholly or in part by core competencies related to managing interpersonal communications ${ }^{11}$ and working in interprofessional teams. ${ }^{12}$

\section{The problem}

This necessary emphasis on 'communicative competency' at the same time deemphasizes the fundamental contribution of discourse in medical education. Hicks refers to discourse as a "dialectic of both linguistic form and social communicative practices."13 Thus, discourse, or 'talk', not only enables the work required for safe patient care but also mediates the learning required to engage in that work in team settings. Psychological and sociocultural theorists support this view. ${ }^{13-17}$ This fundamental role of talk in medicine makes learning inseparable from patient care. As Burke (1935) noted, "a way of seeing is also a way of not seeing" (p. 70). ${ }^{18}$ The current focus on communicative competence shifts attention to skills in talking and away from the essential contribution of healthcare talk to medical education, what Wells refers to as "the role of language in knowing and coming to know"(p. 140). ${ }^{17}$ By viewing talk primarily as an individual outcome of learning (i.e. communicative competency), medical educators may overlook talk itself as an important social medium of learning in graduate medical education. We may be losing opportunities to augment and accelerate clinical education since related theory and conceptual frameworks of healthcare talk remain underdeveloped. 


\section{Purpose of this thesis}

Talk plays a prominent role in both clinical workplaces and supplemental curricular elements such as healthcare simulation. Therefore, this thesis explores talk from two vantage points: (a) talk and learning for practice in formal educational settings, and (b) talk and learning from practice in the workplace. Better understanding of how talk contributes to learning in these settings has two potential benefits: (a) to identify lessons from these respective settings that might inform each other, and (b) to articulate practical strategies to steer healthcare talk in order to promote both meaningful learning and patient care. My thesis explores the following overarching research question with an eye towards pragmatic implications for educational practice: How does 'talk' contribute to learning in clinical education?

\section{Overview of introductory chapter}

Chapter 1 introduces the main ideas; Chapter 2 expands on these ideas and serves as a comprehensive literature review that anchors the remainder of the thesis. This introductory chapter has six sections:

1. What is talk and why does it matter?

2. Talk in the main scholarly perspectives of learning

3. Talk and learning from clinical work

4. Talk and learning in simulation

5. Statement of reflexivity

6. Thesis overview

\section{What is 'talk' and why it does matter?}

We can view 'talk' as joint activity between conversation partners ${ }^{19,20}$ comprised by its verbal and nonverbal content as well its social implications. Talk encompasses the terms "discourse", "dialogue", and "conversation" depending on the field of literature. Given the ubiquitous nature of talk in settings inside and outside of work, medical educators can lose sight of its integral role in a variety of processes beyond 'communication'.

While healthcare simulation and workplace learning research has focused primarily on how students and residents learn from 'doing', ${ }^{21-24}$ much of their clinical practice involves 'talking' not only with patients but with other clinicians as part of interprofessional, multi-disciplinary teams. Therefore, 'learning by doing' is often 'learning by talking'. As in other occupations, ${ }^{25,26}$ talk comprises an integral aspect of clinical work for doctors-in-training. In teaching hospitals, "spoken performances are 
constitutive of the work" (p. 5). ${ }^{27}$ Examples of 'talk as work' include giving oral patient presentations in a variety of contexts, handing off patients to other providers, talking with subspecialists on the telephone to seek patient care advice, or communicating with team members while caring for deteriorating patients. Talk not only reflects the discursive work of patient care, talk contributes to the learning process of becoming a doctor.

Medical discourse has garnered attention both as an essential vehicle for socialization in medicine and a means of socially constructing medical knowledge. ${ }^{27-34}$ Young doctors gain competence while also learning to don a 'cloak of competence' as part of their professionalization. ${ }^{35}$ Further, Haas and Shaffir (1977) noted that early year medical students confront difficulties when beginning "to communicate in the symbolic system that defines medical work and workers" (p. 73, emphasis added). ${ }^{35}$ They must manipulate "the symbols of the profession", including language, to create "an imagery of authoritativeness and competence" (p. 85-86). ${ }^{35}$ In Medical Talk and Medical Work, Atkinson refers to "discursive acts" (p. 39) and socially organized practices around talk in medicine, which comprise the work of medical knowledge production within clinician teams. ${ }^{27}$ Hunter viewed ritualistic case presentations as "central to the discourse of medicine" and "the medium of clinical thought and communication" (p. 56) since medical knowledge achieves structure through narratives. ${ }^{28}$ Further, Erickson explored the tensions junior doctors face when learning to present patients-and thus one's self-competently to their clinical supervisors. ${ }^{36}$ Junior doctors must put aside the rigid presentation style of the medical student and present one's self as "both tough and casual in the face of difficult circumstances of professional work" (p. 123) by balancing the use of formal and informal language. ${ }^{36}$ These uses of language and ways of talking both contribute to and reflect the hidden curriculum in medical training. ${ }^{37}$ Chapter 2 examines research on how medical students learn to perform case presentations. ${ }^{38-41}$

In summary, talk reflects discursive work that shapes socialization in medicine; talk contributes fundamentally to patient care; and talk as 'communication' can be viewed both as a team process and a learning outcome. Finally, talk is inseparable from the process of learning and patient care. The following overview explores the place of talk in main scholarly perspectives of learning.

\section{Talk in main scholarly perspectives of learning}

Two metaphors of learning provide a valuable lens to view the roles of language in learning, namely 'learning as acquisition' and 'learning as participation'. ${ }^{42}$ The acquisition metaphor highlights cognitive processes that lead to knowing and personal enrichment. Thus, talk serves to convey knowledge to be processed and acquired by learners. Reddy (1979) referred to a conduit metaphor that captured the conception 
that language transmits thought. ${ }^{43}$ Other expressions of 'learning as acquisition' from experiential learning ${ }^{44}$ and reflective practice ${ }^{45}$ highlight the supportive role educators can play in the reflective dialogue of both 'in' and 'on' action. Swanwick pointed out that these cognitive perspectives view the functioning of the mind as independent from social contexts. ${ }^{46}$

At the other end of the spectrum, 'learning as participation' views knowing as a process of "belonging, participating, communicating" (p. 7). ${ }^{42}$ Participatory forms of learning in workplaces exemplify sociocultural theories, foregrounding the role of discourse within specific social contexts. ${ }^{47-50}$ Thought and the symbols used to mediate that thought interrelate during goal-oriented joint activity. ${ }^{14,15,17}$ Language represents a highly versatile system of symbols that significantly influences this process of semiotic mediation. ${ }^{17}$ Talk as joint social action manifests within specific contexts, making learning a highly situated and social process. ${ }^{47,48}$ Further, three dimensions contribute to learning within communities of practice: ${ }^{48}$ mutual engagement in the work, joint enterprise borne of shared purpose, and a shared repertoire. ${ }^{50}$ This shared repertoire includes ways of talking within the community. As Lave and Wenger described, newcomers gain access to the community though participation in legitimate activities commensurate with their newcomer status. ${ }^{48}$ For example, junior doctors often call subspecialists on the telephone to seek advice, which represents a prime example of this legitimate peripheral participation in authentic clinical workplace activities ${ }^{48}$ since the most junior doctors often take on this work. Thus, in these participation frameworks, ${ }^{50}$ 'learning to talk' plays a vital role as both social and cultural practice that provides access to the community and allows newcomers to move from peripheral to central members. As a result, talk drives socialization in medicine and ways of talking become reified or formalized as "the way things are done around here". These reifications ${ }^{50}$ capture cultural practices within a community. Highly contextualized and reified ways of talking shape culture, thinking, and knowing in various settings with powerful influences on physicians' clinical education. ${ }^{24}$

\section{Talk and learning from clinical work}

Talk represents discursive work and contributes significantly to both learning and patient care. Since physicians-in-training spend a vast majority of their time engaged in authentic patient care experiences, I now present several key considerations about workplace-based learning that touch on aspects of learning 'by acquisition' and 'by participation'. Clinical education encompasses both formal and informal aspects, requiring clear distinction between each. Formal learning takes place in institutions and classrooms; since educators direct the learning, high degrees of structure characterize it. ${ }^{51}$ Examples during clinical education include lunch-hour teaching conferences or simulation-based training sessions in which medical learners 'acquire' specific medical 
knowledge and skills articulated by objectives to be achieved. Informal learning, on the other hand, is highly context-specific, driven by learners themselves and takes various forms. Learning can be 'incidental' or a by-product of other activities, ${ }^{51}$ as in learning about power and hierarchy in healthcare during resuscitations of critically ill patients. If this learning fails to reach awareness, it remains implicit and taken for granted. ${ }^{52-54}$ Such tacit learning abounds in medicine, part of which contributes to the 'hidden curriculum' in medical training. ${ }^{55}$ Alternately, informal learning can have intentional elements, either reactively in response to emergent learning opportunities or deliberately in learning for future patient care episodes. ${ }^{52}$ Since participation in patient care activities comprises nearly all of the workplace curriculum, ${ }^{56,57}$ sociocultural perspectives have great relevance for learning from clinical work since learning is embedded within social relationships. ${ }^{14,46,49}$ Wenger noted that talk represents a means of acting in the world, thus comprising participatory skills that enable access to social interactions in communities of practice. ${ }^{50}$ Chapter 2 expands on these notions, specifically the participatory practices in team-based healthcare and the centrality of talk to clinical workplace learning.

\section{Talk and learning in simulation-based education}

The Institute of Medicine report "To Err is Human" (2000) recommended team training and the use of simulation whenever possible, ${ }^{5}$ greatly expanding uptake of this educational modality. ${ }^{58,59}$ Seminal work in obstetrics demonstrated the benefit of simulation-based team and communication training on clinically important outcomes, namely a reduction in neonatal morbidity and mortality in instances of difficult newborn delivery caused by shoulder dystocia. ${ }^{60}$ Such work demonstrating clinical impact supports simulation-based strategies to promote teamwork, communication and interprofessional collaboration. Talk features prominently in simulation-based team training (SBTT). First, SBTT promotes team-level 'communicative competence'. ${ }^{61-63}$ Second, post-simulation debriefings also epitomize an important discursive meeting place in which educators and simulation participants explore meanings and implications of simulated experiences for future performance. ${ }^{64,65}$ Evidence shows improved learning outcomes related to the quality of debriefing conversations. ${ }^{66}$ Baker, Jensen and Kolb have conceptualized conversations themselves as experiential learning. ${ }^{67}$

A critique of simulation-based education in healthcare, however, questions whether "learning by simulation can become a simulation of learning" (p. 606). ${ }^{68}$ Bligh and Bleakley observed that simulation may in some instances no longer accurately reflect actual clinical practice. The authors called for greater dialogue between work-based learning and simulation-based learning, pointing out that the "work-based learning movement can benefit from studying how the simulation culture structures the learning environment, where scaffolding and feedback are regularly employed" (p. 607). ${ }^{68}$ Talk 
represents one unifying element that plays an integral role in learning from both workplaces and simulation. I see potential synergies arising from an exploration of talk in both the workplace and formal educational settings such as simulation-based healthcare debriefing.

\section{Statement of reflexivity}

Reflexivity constitutes a fundamentally important aspect of research, ${ }^{69,70}$ especially given my primarily constructivist stance in exploring my main research question. Therefore, I provide the following relevant considerations. The papers included in my thesis represent contemporaneous collaborations with a number of research teams from the domains of workplace learning, simulation-based education, and psychology. The common thread through my body of work reflects the contribution of talk to learning and how steering talk might enhance learning.

As a pediatric emergency medicine physician, I care for patients with a spectrum of acute conditions, including life-threatening childhood illness and injury. These experiences lead me to immerse myself in healthcare simulation as an educational strategy to prepare myself and my emergency teams to care for these young patients. Over time I became very interested in healthcare debriefing and sought advanced training in specific debriefing and communication strategies to help participants in simulation make sense of and learn from their simulated patient care episodes. These experiences stoked not only my interest in talk in educational settings but also in workplace talk. I found that approaches I had honed during healthcare debriefing also had relevance for my work in two areas: (a) as faculty development lead at my medical school, (b) as a clinical supervisor in the workplace. Increasingly, I became fascinated in workplace talk in larger team. My PhD journey has become an exploration of talk as the logical intersection between healthcare simulation debriefing and workplace talk.

\section{Thesis outline}

This $\mathrm{PhD}$ thesis addresses the following overarching research question using various methodological approaches: "How does 'talk' contribute to learning in clinical education?" Three specific instances of healthcare talk serve as the point of departure to explore the role of talk in both learning for work and learning from work. I theorize how learning through work and through simulation might meaningfully inform each other. Four main sections comprise this thesis:

I. PART I includes this opening Chapter 1, which previews the thesis and introduces the main ideas. Chapter 2, a published chapter in a book on lifelong learning from work, represents a literature review that expands on this overview 
and provides a deeper exploration of talk as a medium of learning throughout professional life as a physician.

II. PART II explores learning through talk for clinical practice and uses healthcare simulation debriefing as specific instance of educational talk. Chapter 3 examines healthcare debriefing and presents a novel conceptual framework for debriefing to assist simulation educators in structuring and facilitating these learning conversations. Chapter $\mathbf{4}$ uses pediatric and adult advanced life support training as a case study to clarify how to approach feedback and debriefings for resuscitation education, highlighting the need for performance assessment to inform feedback and debriefing. Chapter $\mathbf{5}$ proposes a comprehensive rater training protocol to generate reliable performance assessment of healthcare resuscitation teams that can inform feedback and debriefing.

III. PART III examines how talk contributes to learning from clinical practice with a focus on talk with patient care as the primary goal and learning as a by-product. Chapter 6 explores the intrinsic learning potential of doctors' workplace telephone talk using constructivist grounded theory to solicit and analyze learners' perceptions about this social phenomenon. Chapter 7 reports a targeted needs assessment based on a qualitative analysis of doctors' workplace telephone talk and discusses implications for simulation-based strategies to sensitize learners to the affordances of workplace talk in their clinical education. Chapter $\mathbf{8}$ describes how team interactions can promote learning from practice during patient care and introduces a novel conceptual model for team reflexivity in healthcare with relevance for clinical event debriefing.

IV. PART IV presents summary discussions about the theoretical contributions of this work as well as practical implications for medical education in both the workplace and healthcare simulation. Chapter 9 discusses my PhD research in its entirety. Chapter 10 presents a summary of findings.

\section{References}

1. Edmondson AC. Teaming: How Organizations Learn, Innovate, and Compete in the Knowledge Economy. San Francisco: John Wiley \& Sons, Inc; 2012.

2. Hymes DH. On Communicative Competence. Sociolinguistics: Selected Readings, (Eds.) by John Bernard Pride \& Janet Holmes, 269-293. 1972.

3. Hammick M, Olckers L, Campion-Smith C. Learning in interprofessional teams: AMEE Guide no 38. Med Teach. 2009;31(1):1-12.

4. Salas E, Diazgranados D, Weaver SJ, King H. Does Team Training Work? Principles for Health Care. Academic Emergency Medicine. 2008;15(11):1002-1009.

5. Kohn SC, Corrigan J, Donaldson M. To Err Is Human: Building a Safer Health System. Washington, D.C.: National Academy Press; 2000. 
6. Sutcliffe KM, Lewton E, Rosenthal MM. Communication failures: an insidious contributor to medical mishaps. Acad Med. 2004;79(2):186-194.

7. Bowers C, Braun CC, Morgan BB. Team workload: its meaning and measurement. In: Brannick MT, Salas E, Prince C, eds. Team Performance Assessment and Measurement: Theory, Methods, and Applications. Mahwah, NJ; 1997:85-108.

8. CanMeds Framework. Royal College of Physicians and Surgeons of Canada. http://www.royalcollege.ca/rcsite/canmeds/canmeds-framework-e Accessed May 20, 2018.

9. ACGME Milestones by Specialty. Accreditation Council on Graduate Medical Education. http://www.acgme.org/What-We-Do/Accreditation/Milestones/Milestones-by-Specialty Accessed May 20, 2018.

10. The Pediatric Milestones Project. Accreditation Council on Graduate Medical Education and American Board of Pediatrics. http://www.acgme.org/Portals/0/PDFs/Milestones/PediatricsMilestones.pdf?ver=2017-07-24-124802340 Accessed May 20, 2018.

11. Benson BJ. Domain of competence: Interpersonal and communication skills. Acad Pediatr. 2014;14(2 Suppl):S55-S65.

12. Guralnick S, Ludwig S, Englander R. Domain of competence: Systems-based practice. Acad Pediatr. 2014;14(2 Suppl):S70-S79.

13. Hicks D. Discourse, Learning, and Teaching. Review of Research in Education. 1995;21(1):49-95.

14. Vygotsky LS. Mind in Society. (Cole M, John-Steiner V, Scriber S, Souberman E, eds.). Cambridge: Harvard University Press; 1978.

15. Vygotsky LS. Thought and Language (Rev. Ed.). Cambridge, Massachusetts: The MIT Press; 1986.

16. Wells G, Wells J. Learning to talk and talking to learn. Theory Into Practice. 1984;23(3):190-197.

17. Wells G. Language and education: reconceptualizing education as dialogue. In: Language Use in Professional Contexts. Vol 19. Cambridge: Annual Review of Applied Linguistics; 1999:135-155.

18. Burke K. Permanence and Change: an Anatomy of Purpose. New York: New Republic. 1936.

19. Clark HH. Using Language. Cambridge: Cambridge University Press; 1996:1-436.

20. Garrod S, Pickering MJ. Why is conversation so easy? Trends Cogn Sci (Regul Ed). 2004;8(1):8-11.

21. Dornan T, Boshuizen H, King N, Scherpbier A. Experience-based learning: a model linking the processes and outcomes of medical students' workplace learning. Med Educ. 2007;41(1):84-91.

22. Yardley S, Teunissen PW, Dornan T. Experiential learning: AMEE Guide No. 63. Med Teach. 2012;34(2):e102-e115. doi:10.3109/0142159X.2012.650741.

23. Teunissen PW, Scheele F, Scherpbier AJJA, et al. How residents learn: qualitative evidence for the pivotal role of clinical activities. Med Educ. 2007;41(8):763-770.

24. Teunissen PW. Experience, trajectories, and reifications: an emerging framework of practice-based learning in healthcare workplaces. Adv in Health Sci Educ. 2015;20(4):843-856.

25. Scheeres $\mathrm{H}$. Learning to talk: from manual work to discourse work as self-regulating practice. Journal of Workplace Learning. 2003;15(7/8):332-337.

26. ledema R, Scheeres H. From doing work to talking work: Renegotiating knowing, doing, and identity. Applied linguistics. 2003;24(3):316-337.

27. Atkinson P. Medical Work and Medical Talk: The Liturgy of the Clinic. London: Sage Publications; 1995.

28. Hunter KM. Doctors' Stories: The Narrative Structure of Medical Knowledge. Princeton, New Jersey: Princeton University Press; 1991.

29. Cohen MD, Hilligoss B, Kajdacsy-Balla Amaral AC. A handoff is not a telegram: an understanding of the patient is co-constructed. Crit Care. 2012;16(1):303.

30. Hilligoss B, Moffatt-Bruce SD. The limits of checklists: handoff and narrative thinking. BMJ Qual Saf. 2014;23(7):528-533.

31. Arluke A. Social control rituals in medicine: the case of death rounds. In: Dingwall R, Heath C, Reid M, Stacey M, eds. New York: Prodist; 1977.

32. Anspach RR. Notes on the sociology of medical discourse: the language of case presentation. Journal of Health and Social Behavior. 1988;29(4):357-375. 


\section{Chapter 1}

33. Sarangi S, Roberts C. The dynamics of interactional and institutional orders in work-related settings. In: Sarangi S, Roberts C, eds. Talk, Work, and Institutional Order. New York: Mouton de Gruyter; 1999:1-57.

34. Atkinson P. Medical discourse, evidentiality and the construction of professional responsibility. In: Talk, Work, and Institutional Order. New York: Mouton de Gruyter; 1999:75-107.

35. Haas J, Shaffir W. The Professionalization of Medical Students: Developing Competence And A Cloak of Competence. Symbolic Interaction. 1977;1(1):71-88.

36. Erickson F. Appropriation of voice and presentation of self as a fellow physician: aspects of a discourse of apprenticeship in medicine. In: Sarangi S, Roberts C, eds. Talk, Work, and Institutional Order. New York: Mouton de Gruyter; 1999:109-143.

37. Haas J, Shaffir W. Ritual evaluation of competence: the hidden curriculum of professionalization in an innovative medical school program. Work and Occupations. 1982;9(2):131-154.

38. Haber RJ, Lingard LA. Learning oral presentation skills: a rhetorical analysis with pedagogical and professional implications. J Gen Intern Med. 2001;16(5):308-314.

39. Lingard L, Haber RJ. Teaching and learning communication in medicine: a rhetorical approach. Acad Med. 1999;74(5):507-510.

40. Lingard L, Garwood K, Schryer CF, Spafford MM. A certain art of uncertainty: case presentation and the development of professional identity. Soc Sci Med. 2003;56(3):603-616.

41. Lingard L, Schryer C, Garwood K, Spafford M. "Talking the talk": school and workplace genre tension in clerkship case presentations. Med Educ. 2003;37(7):612-620.

42. Sfard A. On two metaphors for learning and the dangers of choosing just one. Educational Researcher. 1998;27(2):4-13.

43. Reddy MJ. The conduit metaphor--a case for frame conflict in our language about language. In: Ortony A, ed. Metaphor and Thought. Cambridge: Cambridge University Press; 1979:284-324.

44. Kolb D. Experiential Learning: Experience as the Source of Learning and Development. Saddle River, NJ: Prentice Hall; 1984.

45. Schon DA. The Reflective Practitioner. New York: Harper \& Collins; 1983.

46. Swanwick T. Informal learning in postgraduate medical education: from cognitivism to 'culturism'. Med Educ. 2005;39(8):859-865.

47. Brown JS, Collins A, Duguid P. Situated cognition and the culture of learning. Educational Researcher. 1989;18(1):32-42.

48. Lave J, Wenger E. Situated Learning: Legitimate Peripheral Participation. New York: Cambridge University Press; 1991.

49. Rogoff B. Apprenticeship in Thinking. New York: Oxford University Press; 1990.

50. Wenger E. Communities of Practice: Learning, Meaning, and Identity. New York: Cambridge University Press; 1998.

51. Marsick VJ, Watkins KE. Informal and Incidental Learning in the Workplace. New York: Routledge; 1990.

52. Eraut M. Non-formal learning and tacit knowledge in professional work. Br J Educ Psychol. 2000;70:113136.

53. Eraut M. Informal learning in the workplace. Studies in continuing education. 2004;26(2):247-273.

54. Reber AS. Implicit learning and tacit knowledge. Journal of experimental psychology: General. 1989;118(3):219-235.

55. Hafferty FW, Franks R. The hidden curriculum, ethics teaching, and the structure of medical education. Acad Med. 1994;69(11):861-871.

56. Billett S. Guided learning at work. Journal of Workplace Learning. 2000;12(7):272-285.

57. Billett $\mathrm{S}$. Towards a model of workplace learning: the learning curriculum. Studies in continuing education. 1996;18(1):43-58.

58. Eppich WJ, Nypaver MM, Mahajan P, et al. The Role of High-Fidelity Simulation in Training Pediatric Emergency Medicine Fellows in the United States and Canada. Pediatr Emerg Care. 2013;29(1):1-7.

59. Okuda Y, Bond W, Bonfante G, et al. National Growth in Simulation Training within Emergency Medicine Residency Programs, 2003-2008. Acad Emerg Med. 2008;15(11):1113-1116.

60. Draycott TJ, Crofts JF, Ash JP, et al. Improving neonatal outcome through practical shoulder dystocia training. Obstetrics and gynecology. 2008;112(1):14-20. 
Introduction

61. Weaver SJ, Salas E, Lyons R, et al. Simulation-based team training at the sharp end: A qualitative study of simulation-based team training design, implementation, and evaluation in healthcare. 2010;3(4):369-377.

62. Eppich W, Howard V, Vozenilek J, Curran I. Simulation-based team training in healthcare. Simul Healthc. 2011;6 Suppl:S14-S19.

63. Weaver SJ, Rosen MA, Salas E, Baum KD, King HB. Integrating the science of team training: guidelines for continuing education. J Contin Educ Health Prof. 2010;30(4):208-220.

64. Rudolph JW, Simon R, Raemer DB, Eppich WJ. Debriefing as formative assessment: closing performance gaps in medical education. Acad Emerg Med. 2008;15(11):1010-1016.

65. Sawyer T, Eppich W, Brett-Fleegler M, Grant V, Cheng A. More Than One Way to Debrief: A Critical Review of Healthcare Simulation Debriefing Methods. Simul Healthc. 2016;11(3):209-217.

66. Cheng A, Hunt EA, Donoghue $A$, et al. Examining pediatric resuscitation education using simulation and scripted debriefing: a multicenter randomized trial. JAMA Pediatr. 2013;167(6):528-536.

67. Baker AC, Jensen PJ, Kolb DA. Conversation as experiential learning. Management Learning. 2005;36(4):411-427.

68. Bligh J, Bleakley A. Distributing menus to hungry learners: can learning by simulation become simulation of learning? Med Teach. 2006;28(7):606-613.

69. Watling CJ, Lingard L. Grounded theory in medical education research: AMEE Guide No. 70. Med Teach. 2012;34(10):850-861. doi:10.3109/0142159X.2012.704439.

70. Charmaz K. Constructing Grounded Theory. 2nd ed. London: SAGE Publications Ltd; 2014. 


\section{Chapter 1}




\section{CHAPTER 2}

\section{Learning to Work Together Through Talk:}

\section{Continuing Professional Development in Medicine}

Published as: Eppich W, Rethans JJ, Teunissen PW, Dornan T. Learning to Work Together Through Talk: Continuing Professional Development in Medicine. In: Supporting Learning Across Working Life. Vol 16. Professional and Practice-based Learning. Cham: Springer International Publishing; 2016:47-73. 


\section{Introduction}

Becoming a physician is a lengthy process. The trajectory begins after secondary school, may include a general university degree before entering 4-6 years of medical school, and ends with some form of structured graduate training program. The latter can last from 3 to more than 10 years, after which physicians must continue to learn throughout their professional lives. They need not only to stay abreast of the evidence that informs practice, but also to translate evidence into action within the social context of clinical environments. In discussing how all of this might progress, this chapter has three main sections. In the first one, we focus on learning from work when becoming a doctor and explore an emerging framework for practice-based learning in healthcare. We highlight the essential role of 'talk' as a mediator of learning and how it informs communication practices. We address limitations of learning from work, including social structures that promote communication breakdowns. In the second section, we outline the current state of formal continuing professional development (CPD) in medicine, the stated goal of which is to maintain or further develop physicians' competence. In doing so, we highlight the paradox between: (a) how CPD is currently organized around activities that promote decontextualized knowledge and skill acquisition, and (b) the evolving understanding that learning and participation in authentic workplace activities are inextricably linked. We explore the limitations of formal CPD by addressing the primary factor that threatens patient safety: breakdowns in communication among healthcare professionals. Since current CPD models foreground individual competence, the competence of healthcare teams-and patient care-likely suffer. In the final section, we explore recent developments in healthcare education discourse relevant to clinical practice since collaboration and communication across professional and disciplinary boundaries are prerequisites for safe patient care. We then envision a world in which workplace learning plays a central role in certified CPD, and how foregrounding talk as a medium for collaboration and learning can enhance practice.

\section{Section I: Becoming a doctor}

Medicine is one of many health professions. Undergraduate medical education consists of mostly uni-professional training programs, which are accredited by govern- mental and/or local medical regulatory bodies. These training curricula are not the focus of this chapter; see "Educating Physicians: A Call for Reform of Medical School and Residency" for an overview. ${ }^{1}$ After undergraduate medical studies, medical students emerge as doctors and enter the second phase of clinical training, or graduate medical education, termed 'residency'. After residency, doctors become independent practitioners. ${ }^{1}$ In primary care settings, as well as in hospitals, they work in teams usually composed of several fully-trained doctors and a complement of nurses and other providers. In teaching hospitals, teams might also include a number of doctors in training (i.e. 
residents) and perhaps undergraduate medical students if the institution is affiliated with a medical school. A newly qualified doctor might enter a 1 or 2-year period of foundational training in a broad area such as internal medicine or surgery with the aim of pursuing focused training in general practice, internal medicine, obstetrics and gynaecology, surgery, paediatrics, or emergency medicine. Not infrequently, physicians pursue further specialized training to master the nuances of a specific area within their specialty. ${ }^{1}$ Examples include:

- Internal medicine: e.g. endocrinology, cardiology, gastroenterology

- Surgery: e.g. colo-rectal surgery, heart surgery, neurosurgery

- Paediatrics: e.g. cardiology, critical care, neonatology, emergency medicine

\section{Practising medicine requires more than acquiring knowledge}

We can apply two metaphors of learning to doctors' education: 'learning as acquisition' and 'learning as participation'. ${ }^{2}$ Medical education requires learners to command large amounts of codified propositional knowledge. A 'knowledge as competence' discourse emphasizes knowledge mastery as an indicator of competence ${ }^{3}$ and foregrounds formal classroom learning, embodied by the metaphor 'learning as acquisition'. ${ }^{2}$ Although learning from clinical practice alongside more experienced clinicians in a classic apprenticeship model ${ }^{4,5}$ is a time-honored form of physician training, recent trends towards the 'learning as participation' metaphor explicitly recognize the social nature of healthcare. ${ }^{2}$ Lave and Wenger (1991) popularized the notion of learning by engaging in situated social activity in 'communities of practice'. ${ }^{6}$ Medical learners, thus, prepare for independent practice not only through acquiring knowledge by reading books or attending lectures, but by gaining access to healthcare communities-through legitimate peripheral participation-in order to work and learn with and from others, and consequently develop their professional identities. ${ }^{6-8}$ There is, accordingly, a movement to promote earlier clinical experiences within undergraduate medical curricula. ${ }^{9-12}$

In contrast to formal curricula focused on knowledge acquisition, Eraut (2004) outlines four categories of work-based learning: (a) participation in group activities; (b) working with others; (c) assuming challenging tasks; and (d) working with clients [or patients], ${ }^{13}$ all of which apply to healthcare. Eraut (2000) also proposes various forms of non-formal learning at work, including: (a) unconscious implicit learning that may never reach awareness, such as how to interpret social cues, (b) conscious reactive learning that is spontaneous and responds to emergent learning opportunities, such as unexpected changes in patients' conditions, and (c) deliberative learning, which involves actively reviewing past events and experiences and planning for future learning, ${ }^{14}$ as, for example, when debriefing after clinical events. As he notes, learning at work is mostly invisible and, thus, easily taken for granted. ${ }^{14}$ Hence, the resulting knowledge is 
acquired without awareness and remains tacit. ${ }^{14,15}$ Billett (2001), however, views the differentiation between formal and informal learning critically since it suggests a situational determinism that de-emphasizes the role of human agency in the constructive processes of thinking-acting-learning. ${ }^{16}$ To the contrary, workplaces are characterized by participatory practices ${ }^{17}$ that afford opportunities for individuals to engage in work activities ${ }^{18}$ within a guided learning workplace curriculum. ${ }^{19-21}$ Despite tendencies to emphasize formalized components of medical education, recognition that the social nature of clinical work environments affords both tacit and explicit learning has refocused clinical training on authentic patient care experiences.

\section{Learning to practise medicine involves participating in patient care}

Sociocultural learning theories stress the importance of both context and social interactions within those contexts as prerequisites for individual and collective learning ${ }^{6,22-25}$ and highlight learning by doing, or experience-based learning., 7,8,26 Features of curricula, such as predetermined learning objectives on the one hand and, on the other hand, social interactions between medical learners and nurses, doctors, patients, and peers while engaged in supported participation in authentic environments, combine to promote competence and a sense of readiness for practice. ${ }^{7}$ Importantly, feeling invited to participate and engage with a team is essential to initiate and maintain meaningful participation. ${ }^{27}$

Indeed, Teunissen (2015) claims that the key strength of learning from practice is that it enables people to learn how to perform, think, and interact in ways appropriate for their specific work setting. ${ }^{28}$ Further, health care settings are particularly challenging as workplace learning environments since not only are they highly contextual, they are also structured primarily for patient care rather than learning. In exploring this tension, he outlines an empirically-based framework for practice-based learning in healthcare workplaces. $^{28}$ In conceptualizing those who participate in healthcare, including patients, as learners, he also views learning as a process of constructing meaning that is both situated in specific contexts at individual and social levels. Learning may be visible if it leads to changes in future behaviour, making it easier to describe and study. However, learning often represents reinforcing or slightly modifying existing knowledge or behaviours, making it difficult to recognize or observe. The utility of Teunissen's experiences-trajectories-reifications (ETR) framework is to explore how individual and collective effects contribute to acting and learning in workplaces. ${ }^{28}$ First, learners engage in acts within specific situations embedded in social and cultural systems, select and make sense of information, and then adapt their behaviour, which leads to personal experiences. They can be helped in this process when clinical teachers maximize the affordances of workplaces, support learning, and help create meaning from participation in clinical work activities. ${ }^{29}$ Of course, different learners will experience situations-and draw meaning from them-differently, because of their unique 
personal histories. These collections and combinations of personal experiences lead to trajectories over time-for multiple individuals, whose trajectories intertwine as their professional and social identities evolve. Indeed, Teunissen also asserts that because many aspects of individuals' experiences and trajectories are shared with others, norms and conventions develop, hierarchies are established and exercised, and specific tools are invented, and a shared understanding of the situational requirements for performance emerges. ${ }^{28}$ Examples of these reifications are standard operating procedures, practice guidelines, tools, ways of talking, and structured communication strategies. Given the importance of talk and communication in healthcare work- places for both learning and patient care, we will give these aspects special attention.

\section{Talk is central to learning from clinical practice}

Learning from work can be seen as a by-product of engaging in work activities through social interactions with patients and other members of healthcare teams, highlighting the important role of talk in learning. ${ }^{30,31}$ Both formal and informal opportunities to engage in conversation, including interactions over coffee with more experienced clinicians, contribute in important ways that promote learning and encourage professional thinking. ${ }^{27}$ Indeed, "learning to talk", represents the shift in modern societies away from "manual work to discourse work" (p. 332) ) $^{32}$ in which talking has become one of the main components of the work. ${ }^{33}$ Thus, although talk has always played a role in the work of healthcare, rather than a supporting role, we argue here that talk, as discourse, now plays a central role since it is a core activity in learning and in caring for patients.

Oral case presentations are a prominent example of healthcare talk through which medical students legitimately participate in patient care. During oral presentations, medical learners verbally summarize and present information gathered through interviewing patients/families, examining patients, and-importantly-interpret what it means in terms of diagnosis and/or management. In general, giving an oral case presentation to colleagues represents a fundamental communication skill for all physicians, not only to report key findings of patient assessments and diagnostic evaluations, but also to demonstrate an ability to process, prioritize, and synthesize information, formulate possible diagnoses, and outline steps in patient management. The key is to include only what is relevant to the listener in a given setting. Haber and colleagues used rhetorical analysis to explore how medical students learn oral case presentation skills. ${ }^{34}$ Students struggle to tailor presentations to the context, in contrast to more experienced physicians who view the rhetoric of their presentations as fluid and dependent on patient, time, and situational factors. ${ }^{34}$ In short, physicians must master oral case presentations. Lingard and colleagues (2003) note that socialization involves learning to speak like other community members, both learning to talk with and about patients. ${ }^{35}$ Indeed, professional identities are "constructed and co- 
constructed through talk" (p. 40). ${ }^{36}$ In addition to demonstrating an ability to synthesize and integrate patient information, medical students shape their professional identifies though oral case presentations, particularly in learning to deal with and convey uncertainty. ${ }^{37}$ For example, students observe more experienced doctors using modal auxiliaries (e.g. can, could, may, might must, shall, etc.) and adverbs (e.g. perhaps, maybe, etc.) in oral case presentations to manage uncertainty in a skilful manner. ${ }^{37}$ Thus, oral case presentations represent a textual form of talk that comprises a significant form of work for many physicians, one that has important implications for both learning and patient care in all career phases.

The discourse of clinical teaching is, like case presentations, an important example of talk in medicine for which learning is an explicit goal. Supervising or attending physicians are more experienced and fully qualified doctors who oversee medical trainees and are ultimately accountable for patients' care. These more senior physicians often use questions to assess trainee competence during oral case presentations. ${ }^{38}$ For example, supervising physicians often pose clarifying questions to support their own understanding of the case. In addition, three other forms of question help assess trainee competence: (a) case-related probing questions to explore the trainee's understanding of diagnostic decision-making or management plans, (b) knowledge-related probing questions to assess medical knowledge, and (c) challenging questions to test the trainee's assumptions of shared knowledge that emerge during case presentations. Thus, oral presentations reflect a "regular discursive meeting place" (p. S14) for medical trainees and supervising physicians that plays an important role in how trainees develop and demonstrate evolving competence and thus earn progressive autonomy. ${ }^{38}$ Further, a critical discourse analysis explored descriptions that both medical students and physician supervisors provided about their moments of interaction supplemented by follow-up student debriefing interviews. ${ }^{39}$ The authors identified various discourses within the Question-Answer dynamic between physician supervisors and medical learners. These included discourses related to a 'power game', 'distance' and 'equality and reciprocity' between educators and learners. Importantly, this analysis revealed affordances of student-doctor relationships conceptualized as 'developmental spaces' that generate positive learning momentum for students and doctors and 'developmental vacuums', which stifle learning. Another study examining the audio diaries of seven general practitioners (GPs) during a 10-week-long clinical placement uncovered trajectories of developing relationships through evolution of dialogue. ${ }^{40}$ Doctors in the study used dialogue to define and shape their discourses of good medical practice, both influencing and depending on students' learning trajectories.

Supervising physicians often view their questioning practices as activities that serve both teaching and patient care. However, Goldszmidt and colleagues (2012) found that supervisors' interruptions to pose questions or make teaching points led to detours 
from the standard case presentation format that disrupt critical information sharing. ${ }^{41}$ There is also a form of questioning known in medical circles as 'pimping', which is a slang term ${ }^{42}$ referring to the practice of posing a rapid series of ever-more difficult questions ${ }^{43}$ in a manner that can be interpreted as intimidating or even humiliating to junior medical trainees. ${ }^{44}$ In 'pimping' we see an example of the 'power game', ${ }^{39}$ which is, ultimately, pedagogically unproductive. Indeed, as a manifestation of inherent hierarchical structures within healthcare, 'pimping' may have negative impacts on medical students and junior doctors, such as fostering future disrespectful behaviour (as a doctor) towards nurses, trainees, colleagues, and patients. ${ }^{45}$ And, yet, both senior surgeons and resident physicians said that intimidation and harassment could have legitimate educational value. ${ }^{46}$

Talk plays a central a role in learning, identity formation, and socialization of doctors(to-be) as well as being a core mechanism of patient care. The dialogical nature of interactions within healthcare teams and with patients has numerous positive benefits and, in many ways, reflects the shift to 'discourse work' seen in other professions. Given the complexity of healthcare settings in which it occurs, however, talk also has the potential to amplify less favourable social structures and practices that impede learning and patient care. These insights highlight the need to understand the positive and negative impact of talk in clinical practice so that we can better design strategies to improve communication for patient care and learning.

\section{Shortcomings of practice-based learning in medicine: When communication breaks down, learning breaks down}

The achievements of modern healthcare are, unfortunately, accompanied by errors that have the potential to harm patients. A majority of them result from breakdowns in communication, which we are only beginning to understand. These relate to a number of factors, including authority gradients and power differentials, ${ }^{47,48}$ conflict, $^{49}$ incomplete information sharing,,$^{50,51}$ and failures to speak up about questions or concerns. ${ }^{52,53}$ Team communication in operating rooms (ORs), for example, was characterized by 'high-tension' events that impacted whole teams including trainees ${ }^{54}$ and led trainees either to disengage from the communication or mimic their senior colleagues whose behaviour contributed to the tension. Thirty percent of over 400 communication events in ORs reflected communication failures, which compromised patient safety. ${ }^{55}$ These failures included not sharing information at all or giving inaccurate information, failing to take account of important contextual issues, and communication without clear purpose. Effects included delays, inefficiency, patient inconvenience, procedural error, and tension.

Accurate information sharing is particularly important at times of transition of care, such as patient handoffs or handovers, which are highly contextualized forms of oral 
case presentations. A handoff is the verbal exchange of information between health professionals when responsibility for patient care changes hands. ${ }^{56}$ This verbal communication occurs in person or by phone and is called handover or handoff-both are interchangeable terms. An example would be a physician or team of providers handing over care of patients at the end of a shift to a new physician or team before leaving the hospital, thus passing the baton of accountability. Handoffs are also essential when patients are transferred from one area of a hospital to another, such transfer from intensive care units to hospital wards when life-threatening illness has improved. Factors that predict handoff quality include conveying clear, reliable, and salient information, developing shared understanding, and having a supportive working atmosphere. ${ }^{57}$ An effective handoff includes a clear assessment of a patient's status and anticipated problems ${ }^{58}$ with the goal of co-constructing a shared understanding of the patient. ${ }^{59}$ In surveys, however, residents in emergency medicine report receiving little training in effective handoff practices, increasing the likelihood of communication errors; standardized handoff tools are rarely used. ${ }^{60,61}$ There are several essential needs: enhancing our conceptual understanding of handoff communication ${ }^{62-64}$ and then developing comprehensive strategies to promote effective communication. ${ }^{65}$

In high-risk settings of emergency departments (EDs), despite the best intentions, information can be erroneous or omitted altogether when one physician hands over patients to another at change of shift. ${ }^{51}$ In addition to within-unit handoffs, which are generally planned and involve team members from the same unit who know each other, between-unit handoffs require particular negotiation and coordination skills, such as when patients require hospital admission from the ED to the ward for ongoing care. Patient admission handoffs are more complex due to differences between health professions in their orientations towards illness and treatment, unequal power distribution, and lack of established relationships. ${ }^{48,66}$ During handoff from ED doctors to inpatient teams, a particularly crass discourse is 'selling' patients; in other words, to persuade the inpatient surgical or medical teams to accept patients for hospital admission by minimizing and/or embellishing aspects of their cases. ${ }^{67}$ The goal is procuring inpatient beds expeditiously in order to maintain the flow of patients out of $E D s,{ }^{68}$ especially when waiting rooms are full of patients still needing care. Selling patients is but one of four metaphors for handoffs between doctors in EDs, who are hospital gatekeepers, and physicians who care for patients after admission. Three others are: 69

1. Sports and games: handoffs as competition

2. Packaging: handoffs as expectation matching

3. Teamwork and conversation: handoffs as collaboration

These metaphors highlight that handoffs represent more than just information transmission. Handoffs are social interactions in which conversation partners co- 
construct meaning in the heat of clinical care. ${ }^{59,64}$ This explains why simple technical fixes such as handoff tools to structure information exchange are insufficient to prevent communication breakdowns. Importantly, the social nature of such dialogues develops professional identity ${ }^{70}$ and a tribe mentality. ${ }^{71}$ There is an interesting relationship, moreover, between those dialogues and the media through which they take place. Inperson compared with telephone conversations, for example, are differently shaped by their social contexts in ways that are familiar to all physicians but currently illunderstood by researchers. ${ }^{72}$

An insidious and pervasive communication deficit is a failure to 'speak up', or raise concerns to colleagues or supervisors; ${ }^{52}$ in other words, giving 'voice' ${ }^{73}$ to information, ideas, and opinions. ${ }^{74}$ In contrast to communication lapses that represent honest mistakes, ${ }^{75}$ not speaking up and giving voice to concerns represent deliberate choices to remain silent ${ }^{76}$ about poor and unsafe patient care or deficient actions by healthcare team members. Factors influencing whether or not providers speak up include: ${ }^{52}$ (a) being motivated by a perceived risk to patients depending on how clear the clinical situation appears and what needs to happen; (b) contextual factors such as relationships among team members, attitudes of leaders/supervisors, and organizational support; (c) individual factors such as confidence in skills and education and feelings of responsibility toward patients; (d) feeling that speaking up will make a difference, and (e) the perceived impact of speaking up, for example, fear of reprisals or being made to feel incompetent. The ability to ask questions, express concerns or admit mistakes - thus taking risks - is part of learning. ${ }^{77}$ An important counterpart to trainees feeling empowered to speak up is supervisors being sensitive to unease in colleagues, such as nursing staff, and creating spaces where concerns can be voiced. ${ }^{30}$ Being able to speak up is related to the climate of learning environments ${ }^{78}$ and the approachability of clinical supervisors, ${ }^{79}$ which influence willingness to seek support when help is needed ${ }^{80}$ and ask for feedback. ${ }^{81}$ When viewed through a lens of 'feeling safe to speak up', the harassment and intimidation that is regarded as legitimate and of educational value in surgery, ${ }^{46}$ 'pimping' by clinical supervisors, ${ }^{42,43}$ 'tense' communication in $\mathrm{ORs}^{54}$ and witnessing rude behaviour ${ }^{82,83}$ are threats to learning and safe practice because they inhibit a workplace culture of speaking up. These factors influence the internal tension providers face when faced with choosing 'voice' over 'silence'. ${ }^{84}$

As an example of how social milieus contribute to communication breakdowns, we explore some factors that impacted the activation of rapid response teams (RRTs) in four Australian hospitals. ${ }^{85}$ RRTs are comprised of physicians and nurses who provide expert support to colleagues when a patient's clinical status deteriorates. In one-third of patients whose clinical status warranted RRT activation, issues of hierarchy between treating physicians and nurses, discrepant perceptions about who makes ultimate 
decisions, and barriers to interprofessional communication prevented RRTs from being called. ${ }^{85}$ The opposite also occurred: nurses activated RRTs as 'work arounds' to compensate for breakdowns in collaboration with doctors. Together, those two types of shortcomings represent collective incompetence. ${ }^{85}$ Unfortunately, however, the dominant discourse of competence is an individualistic one, which deflects attention from relational issues like power dynamics or inability to adapt collaborative strategies to new or changing situations. ${ }^{86}$

To summarise, this section shows that learning to become a doctor is more than just acquiring knowledge. Learning and doing are part of the same process, ${ }^{28}$ and participating in authentic patient care within the social context of healthcare teams is essential for learning. Shared activities in these social contexts are structured through verbal and non-verbal communication ${ }^{87}$ enacted during work activities. Thus, talk is the vehicle to co-construct the meaning of shared experiences and is central to learning from practice. Now that we have explored the role of talk in learning, we turn our attention to the current state of continuing professional development.

\section{Section II: The current state of continuing professional development}

After completing residency and subspecialty training, doctors become independent licensed practitioners alongside nurses and other health professionals. Doctors must, however, participate in educational programs for the rest of their careers. Continuing professional development (CPD) helps them acquire and maintain specialty-specific knowledge and skills, which meet the needs of their patients. ${ }^{88}$ Participation in approved programs of CPD allows them to remain licensed, ${ }^{89}$ maintain their specialty certification, ${ }^{90-92}$ and be 'revalidated' as practitioners who are fit for purpose. ${ }^{93}$

The United Kingdom's General Medical Council (GMC) defines CPD in this way:

CPD is any learning outside of undergraduate education or postgraduate training that helps [physicians] maintain and improve [their] performance. It covers the development of... knowledge, skills, attitudes and behaviours across all areas of...professional practice. It includes both formal and informal learning activities (p. 7)..$^{94}$

Traditionally, CPD focuses on the maintenance and development of medical knowledge and skills that are specific to an individual doctor's specialty practice ${ }^{88,95,96}$ and takes various forms. ${ }^{97,98}$ Unfortunately, however, it targets relatively low order cognitive skills of remembering and understanding ${ }^{99}$ rather than behaviour change, which is more likely to impact clinical practice. CPD is largely decontextualized from workplaces, thus divorcing learning from the social context of clinical practice and minimizing the 
complexity of the learning experience. ${ }^{29}$ 'Knowing in practice', which is an essential element of vocational expertise, ${ }^{100}$ plays only a secondary role in CPD.

Likewise, interprofessional and multidisciplinary working, which is ubiquitous in clinical workplaces, is largely ignored by contemporary CPD. Current frameworks privilege individual over collective accomplishment because they are profession-specific, constrained by regulatory bodies ${ }^{101}$ and removed from the talk between different health workers, which is necessary for safe, effective patient care. While the metaphor of 'learning as acquisition' ${ }^{2}$ has at least some place, traditional CPD foregrounds 'acquisition' over 'participation' disproportionately. The work of Lingard (2012), ${ }^{86}$ which contrasts individualist and collectivist discourses of medical competence, supports that interpretation. The individualist discourse views competence as a construct which individuals acquire and possess, is context-free, and represents a state to be achieved. In the collectivist discourse, competence evolves from participation in authentic situations, is situated across networks of persons and artefacts, and manifests in interconnected behaviours occurring within time and space. ${ }^{86}$ Lingard notes that "competent individuals can come together to form an incompetent team" (p. 44). ${ }^{86}$ Therefore, individualistic CPD is not well aligned with patients' needs. ${ }^{102,103}$ It does little to combat tribal conflict between providers from different disciplines, whose values and cultural norms diverge. ${ }^{71}$ It seems reasonable to conclude that siloed initial and ongoing health professions education ${ }^{104}$ contributes to collective incompetence.

Collective incompetence is a serious problem because, according to the 2000 United States (US)-based Institute of Medicine (IOM) Report To Err is Human, over $70 \%$ of medical errors are caused by communication breakdowns within healthcare teams. ${ }^{104}$ Medical errors are a leading cause of death, estimated at 210,000-400,000 deaths/year in 2013 in the US. ${ }^{105}$ Communication within and amongst healthcare teams is a critical medium for enacting knowledge and forms the basis for teamwork, ${ }^{106}$ interprofessional collaboration and learning ${ }^{107}$ and safe patient care. Communication breakdowns involve verbal, non-verbal, and written communication during patient handoffs, communication with patients, and failures to speak up with concerns. ${ }^{108}$

Interprofessional education (IPE), enacted "when members (or students) of two or more health and/or social care professions engage in interactive learning activities to improve collaboration and/or the delivery of care" (p. xiv), ${ }^{109}$ is one potential antidote to collective incompetence. But it is, at best, a partial solution. IPE, continuing education, and workplace learning intersect ${ }^{110}$ as do quality improvement, patient safety, and continuing education. ${ }^{111}$ In contrast to uni-professional, off-the-job education, work is the primary medium for learning interprofessional collaboration and communication. The next section explores how physicians and other healthcare professional can enhance their clinical practice by the way they work, talk, and learn together around the central task of giving patients high quality care. 


\section{Section III: Aligning workplace learning, CPD, and improved care quality}

We now envision a world in which workplace learning plays a central role in certified CPD and enhances practice through quality improvement. We focus on three examples of fundamental structural changes, which support collective team learning and enhance communicative practice. Each example exemplifies Teunissen's (2015) ETR framework ${ }^{28}$ by representing concrete experiences and trajectories of activities, shared between individuals and groups over time. Each structural change focuses on a mechanism for steering the talk of practice through reifications, which promote collective learning and are inextricably linked to patient care. In each instance, learning also benefited patients. These examples include: (a) interdisciplinary and family-centred rounds (b) patient handoffs in a children's hospital, and (c) use of checklists in surgery and for central venous catheter insertion.

\section{Improving patient care through enhanced interdisciplinary collaboration on ward rounds}

When patients are admitted to hospital, a team of physicians, nurses, and other allied health professionals cares for them. Each day, physicians review patients' status and responses to treatment, and modify care plans during what is known as a 'ward round'. It is in this setting that medical learners give oral presentations about their patients in order to inform the team about patients' status and contribute to plan care. Given the sheer number of providers involved, there is great potential for miscommunication. Indeed, doctors and nurses may not communicate clearly with each other or even agree about the care plan. ${ }^{112}$ In response to these findings, O'Leary and colleagues reengineered ward rounds into structured interdisciplinary rounds (SIDR) on both units with medical trainees ${ }^{113}$ and those units without trainees. ${ }^{114}$ They standardised where and when SIDRs took place, who participated, and how long rounds lasted. Nurses' perceptions of collaboration and teamwork subsequently improved. Importantly, key safety measures got better: ${ }^{114}$ patients hospitalized on units with medical trainees had significantly lower rates of preventable adverse events. ${ }^{115}$ In a subsequent study, preparing physicians and nurses to share leadership within SIDRs improved teamwork and communication, as measured by a Safety Attitudes Questionnaire. ${ }^{116}$ Stein and colleagues (2015) built on this work and reorganized the workflow of a hospital ward to create what they call an accountable care unit. ${ }^{117}$ In doing so, they integrated: (a) unitbased teams, (b) structured interdisciplinary bedside rounds, (c) unit-level performance reporting, and (d) unit-level nurse and physician co-leadership. Similar to the work by O'Leary and colleagues (2014), ${ }^{116}$ Stein and team (2015) structured rounds to include interdisciplinary input and shared leadership structures. ${ }^{117}$ Dissimilar was the location of rounds themselves; Stein and team conducted rounds at the bedside with a standard communication protocol that also engaged the patient. All participants prepared in 
advance to promote efficient and accurate information exchange. A preset choreography allowed each actor to play their role, from unit charge nurse, bedside nurse, junior physician, medical students, to allied health professionals. The protocol included daily review of a quality safety checklist. Health professionals, patients and families all reviewed the plan of care together to ensure shared understanding. Importantly, restructuring the hospital ward into an accountable care unit enhanced communication and work climate whilst reducing unadjusted mortality rates by half (from 2.3 to $1.1 \%$ ). Examples of family-centred rounds exist also in paediatrics. ${ }^{118}$ These innovations worked in part because they brought together interprofessional teams in both time and space, which served to facilitate the talk of collaborative clinical practice and harmonize patient care.

\section{Improving patient handoffs}

Given the variable size, weight, and developmental stage of sick and injured children, ${ }^{119}$ paediatric units are at particularly high-risk of communication errors. ${ }^{104}$ Some attempts to standardize handoffs, focusing solely on information transfer, have not yielded the expected benefits ${ }^{59}$ but more comprehensively designed handoffs have been successful. Starmer and colleagues (2012) developed a mnemonic to standardize verbal handoffs called I-PASS, ${ }^{120}$ whose elements were:

- I: Illness severity in terms of patient stability or potential for deterioration

- P: Patient summary of key events, ongoing assessment/plan

- A: Action list of key to-do items

- S: Situation awareness and contingency planning

- S: Synthesis by receiver to summarize key elements, ask questions, restate key to-do items

Beyond clear and accurate information transfer, this model encourages providers to process what they have heard, repeat back key elements, and speak up with questions or concerns. This process helps them understand what to anticipate and what tasks they must complete. In other words, this form of handoff provides a space for coconstructing meaning. Rates of medical error and preventable adverse events in hospitalized children fell significantly after the handoff tool was implemented, which also comprised training and structured changes to where handoffs occurred and who attended them. ${ }^{121}$ The training included workshops, simulation exercises, faculty development tools, and materials to influence institutional culture. It addressed individual, organizational, and contextual factors linked to both care processes and patient outcomes. ${ }^{122,123}$ Involvement of nine hospitals in the research provided a multicentre view of how improved resident handoff could reduce medical errors, preventable adverse events, and communication failures). ${ }^{122,123}$ In 10,740 patient admissions, the rates of medical error and preventable adverse events decreased 
significantly without increasing the time required to complete handoffs. These results show how structured processes can shape social and organization culture, shift the discourse of a high-risk event, and improve patient outcomes. Similarly, adapting standardized handoff approaches to local practice in 23 children's hospitals significantly reduced handoff failures, ${ }^{124}$ highlighting how important it is to contextualize such interventions to institutional cultures. Shared understanding among 'sender' and 'receiver' during ED patient handoffs and structuring the input of nurses provide space for dialogue is gaining traction. ${ }^{125}$

\section{Maximizing the potential of using safety checklists}

The use of checklists also improves patient safety. For example, a surgery safety checklist implemented in hospitals in many different countries reduced rates of death and complications significantly, ${ }^{126}$ although social factors such as the collaborative competence of individual teams ${ }^{127}$ influence uptake and effectiveness. Similar contextual issues ${ }^{128,129}$ affect the uptake of measures to reduce the rate of potentially lethal bloodstream infections ${ }^{130,131}$ associated with insertion of long catheters into the veins of the neck or upper chest in patients in intensive care units to administer medications and fluids. As Bosk and colleagues (2009) note, it is a mistake to view checklists as simple technical solutions for complex sociocultural problems. ${ }^{132}$ Indeed, use of checklists may have unintended consequences when implemented in a top-down fashion. Building checklists for interprofessional contexts requires understanding of the politics and complex local power structures as well as cultural and relational factors of stakeholder groups. ${ }^{133}$ We conclude that both handoff tools and checklists are powerful mechanisms to improve communication and practice-based learning if they are designed and implemented with local context and social factors in mind.

\section{Common themes relevant for workplace learning, quality improvement, and CPD}

The positive patient outcomes demonstrated in quality improvement initiatives linked to interdisciplinary rounds, handoffs, and the effective use of checklists highlight several key themes of practice-based learning. These include collective competence, ${ }^{86}$ intersubjectivity ${ }^{134,135}$ and reciprocal interdependence. ${ }^{30}$ Talk links these themes because it intertwines learning and working within the social fabric of workplaces. Collective competence involves making collective sense of workplace events, developing and using a collective knowledge base, and cultivating a sense of interdependency. ${ }^{136}$ Thus, groups negotiate competence collectively through work and talk. ${ }^{86}$ Viewing effective clinical practice through the lens of collective competence, it becomes clear that quality improvement work brings trainees and practicing clinicians together and nurtures meaningful collaboration and communication by focusing on patient outcomes achieved by the collective rather than on the competence of individuals. When teams have successfully implemented interdisciplinary rounds, an 
important component of their intervention has been co- leadership by physicians and nurses, ${ }^{116,117}$ which mitigated the tradition of dominance by doctors and made space for truly interprofessional care. ${ }^{137}$ They shifted "multi-professionalism to interprofessionalism" (p. 461) ${ }^{138}$ and co-promoted collaborative learning and patientcenteredness. $^{29}$ Although entailing communication between physicians only, the effective practices orchestrated by Starmer and colleagues ${ }^{120-123}$ reframed handoffs as collective events that integrated socio-cultural and adaptive elements of healthcare environments. When checklists are implemented as part of a care bundle, they promote dialogue by opening channels of communication that make health workers collectively responsible for outcomes.

The term intersubjectivity means that people working together share common understanding. ${ }^{134}$ This understanding involves sensing what others intend, think, and feel as well as imagining what impact their actions may have on those around them. Interactions are fundamental for creating shared realities. ${ }^{135}$ Further, intersubjectivity helps explain how members of established healthcare teams understand and make sense of individual preferences and idiosyncrasies. This makes constant negotiation for routine tasks unnecessary while reserving it for grappling with non-routine or novel problems. ${ }^{27}$ One can envision high degrees of intersubjectivity on medical wards with nurse-physician co-leadership and processes that promote collaboration. Billett (2014) highlights that intersubjectivity itself can be viewed as a desirable learning outcome among interprofessional teams. ${ }^{134}$

Edmondson (2012) advocates reciprocal interdependence, which denotes a shared understanding that professionals cannot work and learn without each other. ${ }^{30}$ This notion is at the very core of interprofessional practice. Specifically, she states that healthcare is at times so complex that processes must constantly adapt to the unique needs of patients, providers, and workplace contexts. As all of these are in constant flux, providers need to work together to promote collective learning on a daily basis. Edmondson's conceptual model uses the term 'teaming' to highlight the behaviours rather than the people. ${ }^{30}$ Notions of complexity ${ }^{139}$ and team working ${ }^{140}$ as 'liquid' and 'fluid'141 support this approach. Individuals coming together to solve collective problems should engage in 'teaming behaviours' to 'organize-to-learn' rather than 'learning to execute'. ${ }^{30}$ Those behaviours include:

- Explicitly framing activities as learning opportunities

- Making it safe to learn

- Learning from failure

- Spanning occupational and cultural boundaries

These behaviours are enacted through the discourse of workplaces; specifically, by asking questions, sharing information, seeking help, talking about mistakes, and seeking 
feedback. Leaders in Edmondson's 'teaming' model-lead nurses and doctors-frame their own roles in the process by espousing reciprocal interdependence and acknowledging their own fallibility in the service of psychological safety. Feeling safe to learn means feeling safe to disagree, to question, to be wrong, ${ }^{30}$ which is not typical of clinical practice. Indeed, even when we feel safe, we still engage in self-censorship and often remain silent, which inhibits knowledge sharing and group learning. ${ }^{142}$ Although we have focused on talk here, silence is discourse too, ${ }^{143}$ especially when it comes to 'speaking up' and giving voice to ideas or concerns. ${ }^{74,84,144}$ The teaming behaviours outlined by Edmondson promote discourses of collective competence, intersubjectivity, and reciprocal interdependence. We now discuss ways forward by exploring how to enhance productive discourse in clinical practice to address communication breakdowns.

\section{Use of simulation to promote productive discourse}

The 2000 Institute of Medicine report recommended team training in simulated settings, ${ }^{104}$ which promoted simulation-based education. ${ }^{145}$ The team training literature, in general ${ }^{146}$ and simulation-based team training (SBTT) in particular ${ }^{147}$ is beginning to show that simulation is effective in domains such as obstetrics. ${ }^{148}$ This work has supported the expanded use of SBTT to promote teamwork and interprofessional collaboration. ${ }^{149}$ More robust needs assessment is required to ensure that simulation-based experiences align with the demands of clinical practices that depend upon interprofessional communication and collaboration. ${ }^{150}$ Recent trends emphasize the importance of an interprofessional approach. ${ }^{151-153}$ We see potential for learners in team and interprofessional simulations to engage in types of talk that promote collaboration and teamworking and the forms of communication that comprise substantive elements of the work. ${ }^{32,33}$ Exploring simulation experiences in post-event debriefings ${ }^{154-156}$ prepares health care providers to reflect on critical events in clinical settings, ${ }^{157}$ which has been beneficial in paediatric intensive care units. ${ }^{158}$ Voices are emerging that call for the greater integration of simulation-based strategies in the educational paradigm of clinical practice, ${ }^{71,159}$ while ensuring that sufficient theory guides practice and integrates simulation within existing curriculum. ${ }^{29}$ So although healthcare simulation holds promise, it is not a panacea. How to best design and implement simulation-based activities during medical school and clinical training needs further study.

\section{Aligning simulation and workplace learning}

It has been suggested that "learning by simulation can become a simulation of learning" (p. 606) and that simulation may, in some instances, no longer accurately reflect actual clinical practice. ${ }^{160}$ These authors call for greater dialogue between practitioners in work-based learning and simulation-based learning, noting that advocates of work- 
based learning may glean important lessons from strategies simulation educators use to structure learning environments, integrate scaffolding, and facilitate feedback. ${ }^{160}$ Team research could usefully address concerns about complexity including the need to study interprofessional teams in clinical settings during patient care. ${ }^{106} \mathrm{~A}$ pressing research agenda is to explore how healthcare providers learn collaborative practice and the personal and situational factors that influence this capability. ${ }^{161}$

Mechanisms to incorporate sociological factors such as hierarchy, power relations, professional identity, and interprofessional conflict ${ }^{87,162}$ in interprofessional team simulations are relatively underexplored. Some authors point out that current approaches to SBTT focus primarily on enhancing individuals' team orientation, and propose increased emphasis on collaboration, negotiation, and communication skills. ${ }^{163}$ One strategy to align simulation with workplace learning is to rely less on resourceintensive simulations using computer-controlled manikins and expand the use of simulated patient methodologies. The latter approach uses real people trained to mimic patient conditions to recreate clinical events. ${ }^{164}$ Using such trained people to serve as unannounced or 'incognito' simulated patients in real primary care practice ${ }^{165}$ and for phone consultations ${ }^{166}$ demonstrates promise. Unobtrusive data collection in actual clinical practice can serve as a starting point for simulation scenario building and inform subsequent feedback/debriefing. More targeted work is needed in this area; and it seems particularly promising to align the needs of practitioners and their patients with an educational strategy to improve discursive practice.

\section{Summary}

In outlining learners' paths towards becoming doctors, this chapter has highlighted the essential role of discourse in learning, identity formation, and patient care. Shared understanding and co-construction of clinical experiences-and learning-are mediated through talk. We have argued that most forms of CPD, which focus on the 'learning as acquisition' rather than the 'learning as participation' paradigm, are divorced from authentic clinical practice. We have provided examples of structures that strengthen collective learning processes--the space, the actors, the talk-and steer the discourse of practice in productive directions. Although adding structure may reduce agency, ${ }^{28}$ it likely augments learning from practice. We suggest that patient-focused quality improvement projects and simulations aligned to workplace needs could meet requirements for continuous professional development are both measurable and linked to authentic practice. Future work could usefully further explore how steering the talk of practice can promote learning. 


\section{Chapter 2}

\section{References}

1. Cooke M, Irby DM, O’Brien BC. Educating Physicians: a Call for Reform of Medical School and Residency. San Francisco: Josey-Bass; 2010.

2. Sfard A. On two metaphors for learning and the dangers of choosing just one. Educational Researcher. 1998;27(2):4-13. 3.

3. Hodges B. Medical education and the maintenance of incompetence. Med Teach. 2006;28(8):690-696.

4. Dornan T. Osler, Flexner, apprenticeship and "the new medical education." Journal of the Royal Society of Medicine. 2005;98:91-95.

5. Swanwick T. Informal learning in postgraduate medical education: from cognitivism to 'culturism'. Med Educ. 2005;39(8):859-865.

6. Lave J, Wenger E. Situated Learning: Legitimate Peripheral Participation. New York: Cambridge University Press; 1991.

7. Dornan T, Boshuizen H, King N, Scherpbier A. Experience-based learning: a model linking the processes and outcomes of medical students' workplace learning. Med Educ. 2007;41(1):84-91.

8. Teunissen PW, Scheele F, Scherpbier AJJA, et al. How residents learn: qualitative evidence for the pivotal role of clinical activities. Med Educ. 2007;41(8):763-770.

9. Diemers AD, Dolmans DHJM, Van Santen M, Van Luijk SJ, Janssen-Noordman AMB, Scherpbier AJJA. Students' perceptions of early patient encounters in a PBL curriculum: a first evaluation of the Maastricht experience. Med Teach. 2007;29(2-3):135-142.

10. Dornan T, Bundy C. What can experience add to early medical education? Consensus survey. BMJ. 2004;329(7470):834.

11. Dornan T, Littlewood S, Margolis SA, Scherpbier A, Spencer J, Ypinazar V. How can experience in clinical and community settings contribute to early medical education? A BEME systematic review. Med Teach. 2006;28(1):3-18.

12. Littlewood S, Ypinazar V, Margolis SA, Scherpbier A, Spencer J, Dornan T. Early practical experience and the social responsiveness of clinical education: systematic review. BMJ. 2005;331(7513):387-391.

13. Eraut M. Informal learning in the workplace. Stud Cont Ed. 2004;26(2):247-273.

14. Eraut M. Non-formal learning and tacit knowledge in professional work. Br J Educ Psychol. 2000;70:113136.

15. Reber AS. Implicit learning and tacit knowledge. J Exp Psych. 1989;118(3):219-235.

16. Billett S. Critiquing workplace learning discourses: participation and continuity at work. January 2001:117. Paper presented at the Context, Power, and Perspective: Confronting Challenges to Improving Attainment in Learning at Work. Joint Network/SKOPE/TLRP International Workshop November 8-10, 2001., Sunley Management Centre, University College of Northampton. Retrieved from http://www.infed.org/archives/e-texts/billett_workplace_learn- ing.htm

17. Billett S. Workplace participatory practices: conceptualising workplaces as learning environments. Journal of Workplace Learning. 2004;16(6):312-324.

18. Billett S. Learning through work: workplace affordances and individual engagement. Journal of Workplace Learning. 2001;13(5):209-214.

19. Billett $\mathrm{S}$. Towards a model of workplace learning: the learning curriculum. Studies in continuing education. 1996;18(1):43-58.

20. Dornan T, Arno M, Hadfield J, Scherpbier A, Boshuizen H. Student evaluation of the clinical 'curriculum in action'. Med Educ. 2006;40(7):667-674.

21. Billett S. Guided learning at work. Journal of Workplace Learning. 2000;12(7):272-285.

22. Brown JS, Collins A, Duguid P. Situated cognition and the culture of learning. Educational Researcher. 1989;18(1):32-42.

23. Durning SJ, Artino AR. Situativity theory: a perspective on how participants and the environment can interact: AMEE Guide no. 52. Med Teach. 2011;33(3):188-199. doi:10.3109/0142159X.2011.550965.

24. Eraut M. Learning from other people in the workplace. Oxford Review of Education. 2007;33(4):403-422.

25. Yardley S, Teunissen PW, Dornan T. Experiential learning: AMEE Guide No. 63. Med Teach. 2012;34(2):e102-e115. 
26. Ashley P, Rhodes N, Sari-Kouzel H, Mukherjee A, Dornan T. 'They've all got to learn“. Medical students" learning from patients in ambulatory (outpatient and general practice) consultations. Med Teach. 2009;31(2):e24-e31.

27. Sheehan D, Wilkinson TJ, Billett S. Interns' participation and learning in clinical environments in a New Zealand hospital. Acad Med. 2005;80(3):302-308.

28. Teunissen PW. Experience, trajectories, and reifications: an emerging framework of practice-based learning in healthcare workplaces. Adv in Health Sci Educ. 2015;20(4):843-856.

29. Bleakley A, Bligh J, Browne J. Medical Education for the Future: Identity, Power and Location. Dordrecht, The Netherlands: Springer Science+Business Media B.V.; 2011.

30. Edmondson AC. Teaming: How Organizations Learn, Innovate, and Compete in the Knowledge Economy. San Francisco: John Wiley \& Sons, Inc; 2012.

31. Steven K, Wenger E, Boshuizen H, Scherpbier A, Dornan T. How clerkship students learn from real patients in practice settings. Acad Med. 2014;89(3):469-476.

32. Scheeres H. Learning to talk: from manual work to discourse work as self-regulating practice. Journal of Workplace Learning. 2003;15(7/8):332-337.

33. ledema R, Scheeres H. From doing work to talking work: Renegotiating knowing, doing, and identity. Applied linguistics. 2003;24(3):316-337.

34. Haber RJ, Lingard LA. Learning oral presentation skills: a rhetorical analysis with pedagogical and professional implications. J Gen Intern Med. 2001;16(5):308-314.

35. Lingard L, Schryer C, Garwood K, Spafford M. "Talking the talk": school and workplace genre tension in clerkship case presentations. Med Educ. 2003;37(7):612-620.

36. Monrouxe LV. Identity, identification and medical education: why should we care? Med Educ. 2010;44(1):40-49.

37. Lingard L, Garwood K, Schryer CF, Spafford MM. A certain art of uncertainty: case presentation and the development of professional identity. Soc Sci Med. 2003;56(3):603-616.

38. Kennedy TJT, Lingard LA. Questioning competence: a discourse analysis of attending physicians' use of questions to assess trainee competence. Acad Med. 2007;82(10 Suppl):S12-S15.

39. van der Zwet J, la Croix de A, de Jonge LPJWM, Stalmeijer RE, Scherpbier AJJA, Teunissen PW. The power of questions: a discourse analysis about doctor-student interaction. Med Educ. 2014;48(8):806-819.

40. van der Zwet J, Dornan T, Teunissen PW, de Jonge LPJWM, Scherpbier AJJA. Making sense of how physician preceptors interact with medical students: discourses of dialogue, good medical practice, and relationship trajectories. Adv in Health Sci Educ. 2014;19(1):85-98.

41. Goldszmidt M, Aziz N, Lingard L. Taking a detour: positive and negative effects of supervisors' interruptions during admission case review discussions. Acad Med. 2012;87(10):1382-1388.

42. Kost $A$, Chen FM. Socrates was not a pimp: changing the paradigm of questioning in medical education. Acad Med. 2015;90(1):20-24.

43. Brancati FL. The art of pimping. JAMA. 1989;262(1):89-90.

44. Martin GC, Wells DM. Nothing artful about the term 'pimping'. Med Educ. 2014;48(10):1028. doi:10.1111/medu.12528.

45. Leape LL, Shore MF, Dienstag JL, et al. Perspective: A Culture of Respect, Part 1: The Nature and Causes of Disrespectful Behavior by Physicians. Acad Med. 2012;87(7):845-852.

46. Musselman LJ, MacRae HM, Reznick RK, Lingard LA. "You learn better under the gun": intimidation and harassment in surgical education. Med Educ. 2005;39(9):926-934.

47. Cosby KS, Croskerry P. Profiles in patient safety: authority gradients in medical error. Acad Emerg Med. 2004;11(12):1341-1345.

48. Nugus P, Greenfield D, Travaglia J, Westbrook J, Braithwaite J. How and where clinicians exercise power: interprofessional relations in health care. Soc Sci Med. 2010;71(5):898-909.

49. Janss R, Rispens $S$, Segers M, Jehn KA. What is happening under the surface? Power, conflict and the performance of medical teams. Med Educ. 2012;46(9):838-849.

50. Manser T. Minding the gaps: moving handover research forward. Eur J Anaesthesiol. 2011;28(9):613615. 


\section{Chapter 2}

51. Maughan BC, Lei L, Cydulka RK. ED handoffs: observed practices and communication errors. Am J Emerg Med. 2011;29(5):502-511.

52. Okuyama A, Wagner C, Bijnen B. Speaking up for patient safety by hospital-based health care professionals: a literature review. BMC health services research. 2014;14(1):1-8.

53. Rainer J. Speaking up: factors and issues in nurses advocating for patients when patients are in jeopardy. J Nurs Care Qual. 2015;30(1):53-62.

54. Lingard L, Reznick R, Espin S, Regehr G, DeVito I. Team communications in the operating room: talk patterns, sites of tension, and implications for novices. Acad Med. 2002;77(3):232-237.

55. Lingard L, Espin S, Whyte $S$, et al. Communication failures in the operating room: an observational classification of recurrent types and effects. Quality and Safety in Health Care. 2004;13(5):330-334.

56. Cohen MD, Hilligoss PB. The published literature on handoffs in hospitals: deficiencies identified in an extensive review. Quality and Safety in Health Care. 2010;19(6):493-497.

57. Manser T, Foster S, Gisin S, Jaeckel D, Ummenhofer W. Assessing the quality of patient handoffs at care transitions. Quality and Safety in Health Care. 2010;19(6):e44.

58. Manser T, Foster S, Flin R, Patey R. Team communication during patient handover from the operating room: more than facts and figures. Human factors. 2013;55(1):138-156.

59. Cohen MD, Hilligoss B, Kajdacsy-Balla Amaral AC. A handoff is not a telegram: an understanding of the patient is co-constructed. Crit Care. 2012;16(1):303.

60. Kessler C, Shakeel F, Hern HG, et al. A survey of handoff practices in emergency medicine. American Journal of Medical Quality. 2014;29(5):408-414.

61. Kessler C, Scott NL, Siedsma M, Jordan J, Beach C, Coletti CM. Interunit handoffs of patients and transfers of information: a survey of current practices. Annals of emergency medicine. 2014;64(4):343349.e345.

62. Beach C, Cheung DS, Apker J, et al. Improving interunit transitions of care between emergency physicians and hospital medicine physicians: a conceptual approach. Acad Emerg Med. 2012;19(10):1188-1195.

63. Patterson ES, Wears RL. Beyond "communication failure". Annals of emergency medicine. 2009;53(6):711-712.

64. Patterson ES, Wears RL. Patient handoffs: standardized and reliable measurement tools remain elusive. Joint Commission journal on quality and patient safety / Joint Commission Resources. 2010;36(2):52-61.

65. Cheung DS, Kelly JJ, Beach C, et al. Improving handoffs in the emergency department. Annals of Emergency Medicine. 2010;55(2):171-180.

66. Hilligoss B, Cohen MD. The unappreciated challenges of between-unit handoffs: negotiating and coordinating across boundaries. Annals of emergency medicine. 2013;61(2):155-160.

67. Nugus $P$, Selling patients. BMJ. 2009;339:b5201.

68. Nugus $P$, Forero R. Understanding interdepartmental and organizational work in the emergency department: an ethnographic approach. Int Emerg Nurs. 2011;19(2):69-74.

69. Hilligoss B. Selling patients and other metaphors: a discourse analysis of the interpretive frames that shape emergency department admission handoffs. Soc Sci Med. 2014;102(C):119-128.

70. Burford B. Group processes in medical education: learning from social identity theory. Med Educ. 2012;46(2):143-152.

71. Weller J, Boyd M, Cumin D. Teams, tribes and patient safety: overcoming barriers to effective teamwork in healthcare. 2014;90(1061):149-154.

72. Henn P, Power D, Smith SD, et al. A metric-based analysis of structure and content of telephone consultations of final-year medical students in a high-fidelity emergency medicine simulation. BMJ Open. 2012;2(5).

73. Morrison EW. Employee Voice Behavior: Integration and Directions for Future Research. The Academy of Management Annals. 2011;5(1):373-412.

74. Van Dyne L, Ang S, Botero IC. Conceptualizing Employee Silence and Employee Voice as Multidimensional Constructs*. Journal of Management Studies. 2003;40(6):1359-1392.

75. Reason J. Human error: models and management. BMJ. 2000;320(7237):768-770. 
76. Maxfield D, Grenny J, Lavandero R, Groah L. The Silent Treatment: Why Safety Tools and Checklists Aren't Enough To Save Lives. VitalSmarts, AORN \& AACN. 2011.

77. Edmondson A. Psychological safety and learning behavior in work teams. Administrative Science Quarterly. 1999:350-383.

78. Boor K, van der Vleuten C, Teunissen P, Scherpbier A, Scheele F. Development and analysis of D-RECT, an instrument measuring residents' learning climate. Med Teach. 2011;33(10):820-827.

79. Boor K, Scheele F, Van Der Vleuten CPM, Teunissen PW, Breejen den EME, Scherpbier AJJA. How undergraduate clinical learning climates differ: a multi-method case study. Med Educ. 2008;42(10):10291036.

80. Kennedy TJ, Regehr G, Baker GR, Lingard L. Preserving professional credibility: grounded theory study of medical trainees' requests for clinical support. BMJ. 2009;338.

81. Bok HGJ, Teunissen PW, Spruijt A, et al. Clarifying students' feedback-seeking behaviour in clinical clerkships. Med Educ. 2013;47(3):282-291.

82. Flin R. Rudeness at work. BMJ. 2010;340:c2480.

83. Porath CL, Erez A. Overlooked but not untouched: How rudeness reduces onlookers' performance on routine and creative tasks. Organizational Behavior and Human Decision Processes. 2009;109(1):29-44.

84. Eppich W. "Speaking Up" for Patient Safety in the Pediatric Emergency Department. Clinical Pediatric Emergency Medicine. 2015;16(2):83-89.

85. Kitto S, Marshall SD, McMillan SE, et al. Rapid response systems and collective (in)competence: an exploratory analysis of intraprofessional and interprofessional activation factors. J Interprof Care. 2014;29(4):340-346.

86. Lingard L. Rethinking competence in the context of teamwork. In: Hodges B, Lingard L, eds. Ithaca, NY; 2012:42-69.

87. Lingard L, Reznick R, DeVito I, Espin S. Forming professional identities on the health care team: discursive constructions of the "other" in the operating room. Med Educ. 2002;36(8):728-734.

88. Peck C, McCall M, McLaren B, Rotem T. Continuing medical education and continuing professional development: international comparisons. BMJ. 2000;320(7232):432-435.

89. Solé M, Panteli D, Risso-Gill I, et al. How do medical doctors in the European Union demonstrate that they continue to meet criteria for registration and licencing? Clin Med. 2014;14(6):633-639.

90. Campbell CM, Parboosingh J. The Royal College experience and plans for the maintenance of certification program. J Contin Educ Health Prof. 2013;33 Suppl 1:S36-S47.

91. Hawkins RE, Lipner RS, Ham HP, Wagner R, Holmboe ES. American Board of Medical Specialties Maintenance of Certification: theory and evidence regarding the current framework. J Contin Educ Health Prof. 2013;33 Suppl 1:S7-S19.

92. Holmboe ES. Maintenance of certification, revalidation, and professional self-regulation. J Contin Educ Health Prof. 2013;33 Suppl 1(S1):S63-S66.

93. Archer J, de Bere SR. The United Kingdom's experience with and future plans for revalidation. J Contin Educ Health Prof. 2013;33 Suppl 1:S48-S53.

94. General Medical Council (UK). Continuing professional development: Guidance for all doctors. June 2012:1-32.

95. Davis N, Davis D, Bloch R. Continuing medical education: AMEE Education Guide No 35. Med Teach. 2008;30(7):652-666. doi:10.1080/01421590802108323.

96. O'Neil KM, Addrizzo-Harris DJ, American College of Chest Physicians Health and Science Policy Committee. Continuing medical education effect on physician knowledge application and psychomotor skills: effectiveness of continuing medical education: American College of Chest Physicians EvidenceBased Educational Guidelines. Chest. 2009;135(3 Suppl):37S-41S. doi:10.1378/chest.08-2516.

97. Davis D, O'Brien MA, Freemantle N, Wolf FM, Mazmanian P, Taylor-Vaisey A. Impact of formal continuing medical education: do conferences, workshops, rounds, and other traditional continuing education activities change physician behavior or health care outcomes? JAMA. 1999;282(9):867-874.

98. Mazmanian PE, Davis DA, Galbraith R, American College of Chest Physicians Health and Science Policy Committee. Continuing medical education effect on clinical outcomes: effectiveness of continuing 


\section{Chapter 2}

medical education: American College of Chest Physicians Evidence-Based Educational Guidelines. Chest. 2009;135(3 Suppl):49S-55S.

99. Légaré $F$, Freitas $A$, Thompson-Leduc $P$, et al. The Majority of Accredited Continuing Professional Development Activities Do Not Target Clinical Behavior Change. Acad Med. 2014;90(2):197-202.

100. Billett S. Knowing in practice: Re-conceptualising vocational expertise. Learning and Instruction. 2001;11(6):431-452.

101. Barr H. An anatomy of continuing interprofessional education. J Contin Educ Health Prof. 2009;29(3):147-150.

102. Kitto S, Bell M, Peller J, et al. Positioning continuing education: boundaries and intersections between the domains continuing education, knowledge translation, patient safety and quality improvement. Adv in Health Sci Educ. 2013;18(1):141-156.

103. Rowland P, Kitto S. Patient safety and professional discourses: implications for interprofessionalism. J Interprof Care. 2014;28(4):331-338.

104. Kohn SC, Corrigan J, Donaldson M. To Err Is Human: Building a Safer Health System. Washington, D.C.: National Academy Press; 2000.

105. James JT. A new, evidence-based estimate of patient harms associated with hospital care. J Patient Saf. 2013;9(3):122-128.

106. Salas E, Cooke NJ, Rosen MA. On teams, teamwork, and team performance: discoveries and developments. Human Factors. 2008;50(3):540-547.

107. Hammick M, Olckers L, Campion-Smith C. Learning in interprofessional teams: AMEE Guide no 38. Med Teach. 2009;31(1):1-12.

108. Sutcliffe KM, Lewton E, Rosenthal MM. Communication failures: an insidious contributor to medical mishaps. Acad Med. 2004;79(2):186-194.

109. Reeves S, Lewin S, Espin S, Zwarenstein M. Interprofessional Teamwork for Health and Social Care. Chichester, UK: Blackwell Publishing Ltd.; 2010.

110. Kitto S, Goldman J, Schmitt MH, Olson CA. Examining the intersections between continuing education, interprofessional education and workplace learning. J Interprof Care. 2014;28(3):183-185.

111. Kitto S, Goldman J, Etchells E, et al. Quality improvement, patient safety, and continuing education: a qualitative study of the current boundaries and opportunities for collaboration between these domains. Acad Med. 2015;90(2):240-245.

112. O'Leary KJ, Thompson JA, Landler MP, et al. Patterns of nurse-physician communication and agreement on the plan of care. Quality and Safety in Health Care. 2010;19(3):195-199.

113. O'Leary KJ, Wayne DB, Haviley C, Slade ME, Lee J, Williams MV. Improving teamwork: impact of structured interdisciplinary rounds on a medical teaching unit. J Gen Int Med. 2010;25(8):826-832.

114. O'Leary KJ, Haviley C, Slade ME, Shah HM, Lee J, Williams MV. Improving teamwork: impact of structured interdisciplinary rounds on a hospitalist unit. J Hosp Med (Online). 2011;6(2):88-93.

115. O'Leary KJ, Buck R, Fligiel HM, et al. Structured interdisciplinary rounds in a medical teaching unit: improving patient safety. Arch Int Med. 2011;171(7):678-684.

116. O'Leary KJ, Creden AJ, Slade ME, et al. Implementation of Unit-Based Interventions to Improve Teamwork and Patient Safety on a Medical Service. Am J Med Qual. 2014;30(5):409-416.

117. Stein J, Payne C, Methvin A, et al. Reorganizing a hospital ward as an accountable care unit. J Hosp Med (Online). 2015;10(1):36-40.

118. Muething SE, Kotagal UR, Schoettker PJ, del Rey JG, DeWitt TG. Family-Centered Bedside Rounds: A New Approach to Patient Care and Teaching. Pediatrics. 2007;119(4):829-832.

119. Luten R, Wears RL, Broselow J, Croskerry P, Joseph MM, Frush K. Managing the unique size-related issues of pediatric resuscitation: reducing cognitive load with resuscitation aids. Acad Emerg Med. 2002;9(8):840-847.

120. Starmer AJ, Spector ND, Srivastava R, et al. I-pass, a mnemonic to standardize verbal handoffs. Pediatrics. 2012;129(2):201-204.

121. Starmer AJ, Sectish TC, Simon DW, et al. Rates of medical errors and preventable adverse events among hospitalized children following implementation of a resident handoff bundle. JAMA. 2013;310(21):22622270. 
122. Starmer AJ, O'Toole JK, Rosenbluth G, et al. Development, implementation, and dissemination of the IPASS handoff curriculum: A multisite educational intervention to improve patient handoffs. Acad Med. 2014;89(6):876-884.

123. Starmer AJ, Spector ND, Srivastava R, et al. Changes in medical errors after implementation of a handoff program. N Engl J Med. 2014;371(19):1803-1812.

124. Bigham MT, Logsdon TR, Manicone PE, et al. Decreasing handoff-related care failures in children's hospitals. Pediatrics. 2014;134(2):e572-e579.

125. Gopwani PR, Brown KM, Quinn MJ, Dorosz EJ, Chamberlain JM. SOUND: a structured handoff tool improves patient handoffs in a pediatric emergency department. Pediatr Emerg Care. 2015;31(2):83-87.

126. Haynes AB, Weiser TG, Berry WR, et al. A surgical safety checklist to reduce morbidity and mortality in a global population. N Engl J Med. 2009;360(5):491-499.

127. Kitto S, Grant R. Revisiting evidence-based checklists: interprofessionalism, safety culture and collective competence. J Interprof Care. 2014;28(5):390-392.

128. Dixon-Woods M, Leslie M, Tarrant C, Bion J. Explaining Matching Michigan: an ethnographic study of a patient safety program. Implement Sci. 2013;8(1):1-1.

129. Dixon-Woods M, Bosk CL, Aveling EL, Goeschel CA, Pronovost PJ. Explaining Michigan: developing an ex post theory of a quality improvement program. Milbank Q. 2011;89(2):167-205.

130. Pronovost P. Interventions to decrease catheter-related bloodstream infections in the ICU: the Keystone Intensive Care Unit Project. Am J Infect Control. 2008;36(10):S171.e1-e5.

131. Pronovost $P$, Needham $D$, Berenholtz $S$, et al. An intervention to decrease catheter-related bloodstream infections in the ICU. N Engl J Med. 2006;355(26):2725-2732.

132. Bosk CL, Dixon-Woods M, Goeschel CA, Pronovost PJ. Reality check for checklists. Lancet. August 8 , 2009:444-445.

133. Kitto S. Evidence-based checklists: intended and unintended consequences for interprofessional care. J Interprof Care. 2010;24(6):609-611.

134. Billett SR. Securing intersubjectivity through interprofessional workplace learning experiences. J Interprof Care. 2014;28(3):206-211.

135. Teunissen PW. When I say ... intersubjectivity. Med Educ. 2014;48(4):349-350.

136. Boreham N. A theory of collective competence: challenging the neo-liberal individualisation of performance at work. British Journal of Educational Studies. 2004;52(1):5-17.

137. Bleakley A. The dislocation of medical dominance: making space for interprofessional care. J Interprof Care. 2013;27 Suppl 2:24-30.

138. Bleakley A, Boyden J, Hobbs A, Walsh L, Allard J. Improving teamwork climate in operating theatres: the shift from multiprofessionalismto interprofessionalism. J Interprof Care. 2006;20(5):461-470.

139. Lingard L, McDougall A, Levstik M, Chandok N, Spafford MM, Schryer C. Representing complexity well: a story about teamwork, with implications for how we teach collaboration. Med Educ. 2012;46(9):869877.

140. Bleakley A. Broadening conceptions of learning in medical education: the message from teamworking. Med Educ. 2006;40(2):150-157.

141. Bleakley A. Working in "teams" in an era of 'liquid' healthcare: What is the use of theory? J Interprof Care. 2013;27(1):18-26.

142. Detert J, Edmondson A. Implicit Voice Theories: Taken-for-Granted Rules of Self-Censorship at Work. Academy of Management Journal. 2011;54(3):461-488.

143. Lingard L. Language matters: towards an understanding of silence and humour in medical education. Med Educ. 2012;47(1):40-48.

144. Milliken FJ, Morrison EW. Shades of silence: Emerging themes and future directions for research on silence in organizations. Journal of Management Studies. 2003;40(6):1563-1568.

145. Eppich WJ, Nypaver MM, Mahajan P, et al. The Role of High-Fidelity Simulation in Training Pediatric Emergency Medicine Fellows in the United States and Canada. Pediatr Emerg Care. 2013;29(1):1-7.

146. Weaver SJ, Rosen MA, Salas E, Baum KD, King HB. Integrating the science of team training: guidelines for continuing education. J Contin Educ Health Prof. 2010;30(4):208-220. 


\section{Chapter 2}

147. Weaver SJ, Salas E, Lyons R, et al. Simulation-based team training at the sharp end: A qualitative study of simulation-based team training design, implementation, and evaluation in healthcare. Journal of Emergencies, Trauma, and Shock. 2010;3(4):369-377.

148. Draycott TJ, Crofts JF, Ash JP, et al. Improving neonatal outcome through practical shoulder dystocia training. Obstetrics and Gynecology. 2008;112(1):14-20.

149. Tofil NM, Morris JL, Peterson DT, et al. Interprofessional simulation training improves knowledge and teamwork in nursing and medical students during internal medicine clerkship. Journal of hospital medicine (Online). 2014;9(3):189-192.

150. Eppich W, Howard V, Vozenilek J, Curran I. Simulation-based team training in healthcare. Simul Healthc. 2011;6 Suppl:S14-S19.

151. Hammick M, Freeth D, Koppel I, Reeves S, Barr H. A best evidence systematic review of interprofessional education: BEME Guide no. 9. Med Teach. 2009;29(8):735-751.

152. Thistlethwaite J, Davies H, Dornan T, Greenhalgh T, Hammick M, Scalese R. What is evidence? Reflections on the AMEE symposium, Vienna, August 2011. Med Teach. 2012;34(6):454-457.

153. World Heath Organization. Framework for Action on Interprofessional Education \& Collaborative Practice. 2010:1-64.

154. Cheng A, Eppich W, Grant V, Sherbino J, Zendejas B, Cook DA. Debriefing for technology-enhanced simulation: a systematic review and meta-analysis. Med Educ. 2014;48(7):657-666.

155. Eppich W, Cheng A. Promoting Excellence and Reflective Learning in Simulation (PEARLS): development and rationale for a blended approach to health care simulation debriefing. Simul Healthc. 2015;10(2):106-115.

156. Fanning RM, Gaba DM. The role of debriefing in simulation-based learning. Simul Healthc. 2007;2(2):115-125.

157. Kessler DO, Cheng A, Mullan PC. Debriefing in the emergency department after clinical events: a practical guide. Ann Emerg Med. 2015;65(6):690-698.

158. Wolfe H, Zebuhr C, Topjian AA, et al. Interdisciplinary ICU cardiac arrest debriefing improves survival outcomes. Crit Care Med. 2014;42(7):1688-1695.

159. O'Leary KJ, Woods DM. Making the potential benefit of teamwork training a reality. J Hosp Med(Online). 2014;9(3):201-202.

160. Bligh J, Bleakley A. Distributing menus to hungry learners: can learning by simulation become simulation of learning? Med Teach. 2006;28(7):606-613.

161. Thistlethwaite J. Interprofessional education: a review of context, learning and the research agenda. Med Educ. 2012;46(1):58-70.

162. Kitto SC, Gruen RL, Smith JA. Imagining a continuing interprofessional education program (CIPE) within surgical training. J Contin Educ Health Prof. 2009;29(3):185-189.

163. Sharma S, Boet S, Kitto S, Reeves S. Interprofessional simulated learning: the need for 'sociological fidelity'. J Interprof Care. 2011;25(2):81-83.

164. Cleland JA, Abe K, Rethans J-J. The use of simulated patients in medical education: AMEE Guide No 42. Med Teach. 2009;31(6):477-486.

165. Rethans J-J, Gorter S, Bokken L, Morrison L. Unannounced standardised patients in real practice: a systematic literature review. Med Educ. 2007;41(6):537-549.

166. Derkx H, Rethans JJ, Maiburg B, Winkens R, Knottnerus A. New methodology for using incognito standardised patients for telephone consultation in primary care. Med Educ. 2009;43(1):82-88. 


\section{Chapter 3}

Promoting Excellence and Reflective Learning in Simulation (PEARLS):

Development and Rationale for a Blended Approach to Health Care Simulation Debriefing

Published as: Eppich W, Cheng A. Promoting Excellence and Reflective Learning in Simulation (PEARLS): development and rationale for a blended approach to health care simulation debriefing. Simulation in Healthcare. 2015;10(2):106-115. 
Chapter 3

\begin{abstract}
We describe an integrated conceptual framework for a blended approach to debriefing called PEARLS (Promoting Excellence And Reflective Learning in Simulation). We provide a rationale for scripted debriefing and introduce a PEARLS debriefing tool designed to facilitate implementation of the new framework. The PEARLS framework integrates 3 common educational strategies used during debriefing, namely (1) learner self-assessment, (2) facilitating focused discussion, and (3) providing information in the form of directive feedback and/or teaching. The PEARLS debriefing tool incorporates scripted language to guide the debriefing, depending on the strategy chosen. The PEARLS framework and debriefing script fill a need for many health care educators learning to facilitate debriefings in simulation-based education. The PEARLS offers a structured framework adaptable for debriefing simulations with a variety of goals, including clinical decision making, improving technical skills, teamwork training, and interprofessional collaboration.
\end{abstract}




\section{Introduction}

Health care educators have recognized the essential role of debriefing in simulation learning contexts ${ }^{1-8}$ to help transform experience into learning through reflection. ${ }^{9-}$ 12 Debriefing is a facilitated reflection in the cycle of experiential learning ${ }^{3}$ to help identify and close gaps in knowledge and skills. ${ }^{13}$ Debriefing includes the following essential elements ${ }^{14}:(a)$ active participation with more than just the passive receipt of feedback; $(b)$ developmental intent focused on learning and improvement (more than a performance review); (c) discussion of specific events; and (d) input from multiple sources. Whereby debriefing represents a conversation between simulation participants and educator(s), feedback is the specific information about an observed performance compared with a standard. ${ }^{15}$ Effective debriefings can provide a forum for feedback that is essential for performance improvement ${ }^{14-21}$ and deliberate practice that promotes expertise. ${ }^{22-27}$ The notion of performance gaps is important for individuals and teams. A performance gap is the difference between the desired and actual observed performance ${ }^{28}$ and can form the basis for separate lines of questioning in the debriefing. For this article, we will refer to performance gaps as areas in need of improvement. However, simulation educators should also debrief areas of exceptional performance ${ }^{29}$ because lessons can be drawn from both successful and failed experiences. ${ }^{30}$ We use the term learner to indicate all participants irrespective of stage of training or career. Moreover, although debriefing may occur during or after the simulation, ${ }^{31-33}$ our focus is postsimulation debriefing.

Evidence is emerging about what makes debriefing effective $\mathrm{e}^{6,34,35}$ and how to assess its quality. ${ }^{36,37}$ Wide agreement exists about the importance of a supportive learning environment as a prerequisite for successful simulation-based education and debriefing $21,28,31,38$ and what contributes to it. $6,37-40$ How educators facilitate debriefings, however, is highly variable ${ }^{14}$ and in practice may stray from the ideal. ${ }^{5,34}$ For example, although simulation participants seem to value an honest, nonthreatening approach, ${ }^{6}$ educators often hesitate to share critical performance feedback to avoid being seen as harsh ${ }^{4,41}$ and because of perceived potential negative effects on the learner. ${ }^{42-46}$ Simulation educators, especially novices, can be overwhelmed by the complexity of facilitating debriefings, and practical guidance is needed. Our initial work on scripted debriefing ${ }^{47}$ has shown promise in promoting debriefing quality for less experienced educators in the narrow scope of resuscitation training. Indeed, scripted debriefing approaches have been integrated into standardized advanced life support courses. ${ }^{48}$ Educators, however, need additional support. We seek to fill this gap by presenting a debriefing script paired with a novel blended approach to debriefing called PEARLS [Promoting Excellence and Reflective Learning in Simulation]. In this article, we define a blended approach to debriefing as 
the selective and deliberate use of more than one debriefing strategy, guided by context and learner need, within a single debriefing event.

The purposes of this article are as follows: (1) to provide a rationale for scripted debriefing; (2) to discuss a rationale for a blended approach to debriefing based on challenges to be addressed and debriefing method; (3) to present a PEARLS debriefing framework and guidance for its application; and (4) to offer early experiences of implementing the framework in simulation educator courses.

\section{A rationale for scripted debriefing}

Despite the critical role of debriefing in experiential learning contexts, $2,3,38,41,49-$ 52 simulation educators may struggle to learn and master this essential skill. An area of increasing focus is how debriefing best practice translates into practical, easy-toimplement strategies.8,53,56 Structured and scripted debriefing in clinical contexts ${ }^{53,54}$ and simulation-based education ${ }^{47}$ may counter the variability in debriefing style and structure. For example, the EXPRESS [Examining Pediatric Resuscitation Education using Simulation and Scripting] trial aimed to standardize debriefings in the Pediatric Advanced Life Support (PALS) course by assessing the effect of a scripted debriefing tool used by novice instructors on learning and performance outcomes. ${ }^{47}$ Novice instructors using a debriefing script were more effective at increasing learners' knowledge acquisition and team leader behavioral skills compared with those educators who did not use a script. Building on the experiences gained from the EXPRESS study, the authors of this article collaborated with the American Heart Association (AHA) to help develop a new debriefing tool for both the PALS and Advanced Cardiac Life Support (ACLS) course. ${ }^{48}$ The AHA debriefing tool used the "Gather, Analyze and Summarize (GAS)" debriefing model ${ }^{48}$ and was developed to be generalizable to all PALS and ACLS scenarios. The tool provided educators with specific phrases to help facilitate learning and was ultimately incorporated into the 2011 PALS and ACLS instructor materials. Unfortunately, both the EXPRESS and AHA debriefing tools used only one strategy for debriefing, thus providing limited flexibility and guidance for educators struggling to adapt dynamically to learner needs and time constraints.

Of the debriefing tools being developed, some are designed for expediency, ${ }^{53,54,56}$ some may be suitable only for more experienced simulation educators, ${ }^{55}$ and some have limitations because they focus on only one debriefing strategy. To address these issues, we have developed a novel debriefing script. The PEARLS debriefing script is a cognitive aid that may promote faculty development efforts and augment debriefing skills particularly in those educators who are still solidifying their debriefing expertise. The use of select video sequences from the simulation scenario, time and technology 
permitting, may also promote learning ${ }^{57,58}$ but may not be essential, ${ }^{59,60}$ so we have not emphasized this aspect. Further research describing the optimal use of video during debriefing is required to help guide optimal integration of video into the PEARLS debriefing framework.

\section{A rationale for a blended approach to debriefing}

Although we have drawn from the education and simulation literature, including empiric evidence where available, we also relied on our own combined debriefing experience and simulation faculty development work. Most expert simulation educators deliberately meld several educational strategies during debriefings based on context or specific debriefing goal rather than adhering rigidly to one particular strategy. ${ }^{5,52}$ Many options, however, may overwhelm novice debriefers.

Although various strategies exist, we have distilled these into 3 broad categories as follows: $(a)$ learner self-assessment, ${ }^{3,49,52-54}(b)$ focused facilitation to promote critical reflection and deeper understanding of events, 2,4,31,50-52,57,61,62 and (c) and providing information through directive performance feedback ${ }^{63,64}$ and/or focused teaching. ${ }^{5,51}$ Each category of commonly used approaches has its own potential advantages and disadvantages in the context of health care debriefing (see Table, Supplemental Digital Content $1 \mathrm{http}: / /$ links.Iww.com/SIH/A174 for advantages and disadvantages of commonly used educational strategies; included as Appendix 1 at end of Chapter 3).

In merging these 3 broad educational strategies into a blended debriefing framework, we have kept key learning principles in mind, namely, that learning should be active, collaborative, and self-directed ${ }^{65}$ and learner-centered. ${ }^{66}$ The framework helps guide practical decision making for targeted selection of an educational strategy during the analysis phase of the debriefing. For example, educators can engage learners and promote self-assessment of their performance by querying what they think went well and what they would change about their performance using a plus/delta technique ${ }^{3}$ or what went well/not so well and why (e.g., SHARP technique) ${ }^{54}$ or what was "easy" versus "challenging." 52 Although self-assessment is prone to inaccuracy, ${ }^{67-69}$ educators can use learner self-assessment approaches to identify areas for further inquiry that learners find important. Other general facilitation techniques ${ }^{70}$ or more specific questioning methods $4,55,71,72$ may lead to high-yield discussion and learning. For example, when using advocacy-inquiry, educators seek to uncover learners' rationale for action or mental models by stating a concrete observation and sharing their point of view or judgment about it before inquiring about the learners' perspective. ${ }^{4,41}$ Similarly, exploring alternatives and their pros and cons of clinical decisions, management options, or other areas of performance can yield rich discussion and learning. ${ }^{52}$ Additional methods are emerging, which have great potential to add to 
educators' debriefing repertoire, ${ }^{71,72}$ and Kolbe et al ${ }^{55}$ provide a comprehensive discussion. These focused facilitation methods share the goal of helping learners' surface and explore their mental models and/or thought processes. Once mental models have been made explicit, educators and learners can work together to reframe their thinking or encourage effective cognitive routines. ${ }^{28}$ Such facilitated discussions can be particularly fruitful when debriefing interprofessional and multidisciplinary teams. Finally, educators often provide information in the form of clear directive performance feedback and/or focused teaching when indicated, ${ }^{57,64}$ ideally delivered in an honest but nonthreatening manner. ${ }^{6,37}$ The blending of strategies while addressing a given learning objective may be quite appropriate; as an example, all educational strategies may serve a role during exploration of complex clinical decision-making processes (global self-assessment first, then focused facilitation about decision making, then providing information based on learning needs).

\section{PEARLS debriefing script}

The PEARLS debriefing script assists both novice and experienced simulation educators to effectively implement the PEARLS framework of debriefing. The use of the script assumes that educators have adequately prepared learners to participate in the simulated learning encounter; creating a sense of psychological safety is essential. ${ }^{28,52,73}$ The PEARLS debriefing script supports simulation educators in 3 main areas as follows: (1) setting the stage for the debriefing; (2) organizing the debriefing to include initial participant reactions followed by a description of relevant case elements, an analysis of positive and suboptimal areas of performance using the PEARLS framework to select a debriefing approach, and finally a summary of lessons learned; and (3) formulating questions that empower educators to share clearly their honest point of view about events. Table 1 provides an overview of the PEARLS debriefing framework with suggested wording for each phrase and strategy (see Table, Supplemental Digital Content 2 http://links.Iww.com/SIH/A175, guides the educator through the advocacy-inquiry model of debriefing, for use when selected; included as Appendix 2 at end of Chapter 3).

\section{PEARLS debriefing framework}

The PEARLS debriefing framework integrates commonly used strategies during debriefings and provides guidance on their implementation, depending on target learner group or debriefing environment. Context-specific factors influence the choice of approach, including time available, whether learners' rationale for action is clear, and whether the learning objective/performance gap are related to knowledge, skills, or behaviors. 
PEARLS outlines 4 distinct phases of the debriefing process, ${ }^{2,28,61}$ although its novel focus is the blended approach in the analysis phase (Figure 1). The 4 phases are the reactions, description, analysis, and summary phases. For further details, see Table 1 (PEARLS Debriefing Script).

The reactions phase begins with an open-ended question such as "How are you feeling?" to allow learners to vent and express their initial thoughts and feelings. 3,6,8,28,57 When only 1 or 2 learners respond to the initial question, a follow-up question such as "Other initial reactions?" or "How are the rest of you feeling?" followed by silence often prompts additional reactions. This ensures that all participants have a chance to vent if they choose.

In the description phase, ${ }^{2}$ it can be helpful to invite someone to summarize their perspective of key events or major medical problems faced during the case to make sure that educator(s) and participants are on the same page. ${ }^{61}$ If team members are not on the same page about major issues or events, it can be a useful springboard for later discussion. To avoid a time-consuming and at times inefficient recounting of all events during the case, it can help to focus this portion on main issues. During these opening phases, astute educators make a note of particular learner concerns that may represent important issues to address later in the debriefing.

\section{PEARLS and the analysis phase: specific decision support}

In applying the PEARLS framework, educators select the strategy suited for each particular aspect of performance in the analysis phase of the debriefing (Figure 1). Before the start of the debriefing session, educators should reflect on the level of insight and experience of the participants, along with his or her own debriefing experience, because these may influence which educational strategies to use during the debriefing (Table 2). To determine the ideal strategy for each particular aspect of performance, educators should pose the following questions (Table 2):

1. Is the rationale for the performance gap clear (ie, it is clear if the participant states, "I did not know what to do next," thus signifying an underlying knowledge gap)?

2. How much time is available?

3. Does the performance clearly represent cognitive (e.g., knowledge, clinical decision making), technical (e.g., procedural skills), or behavioral domains (e.g., team dynamics, interprofessional collaboration, leadership, communication)? 


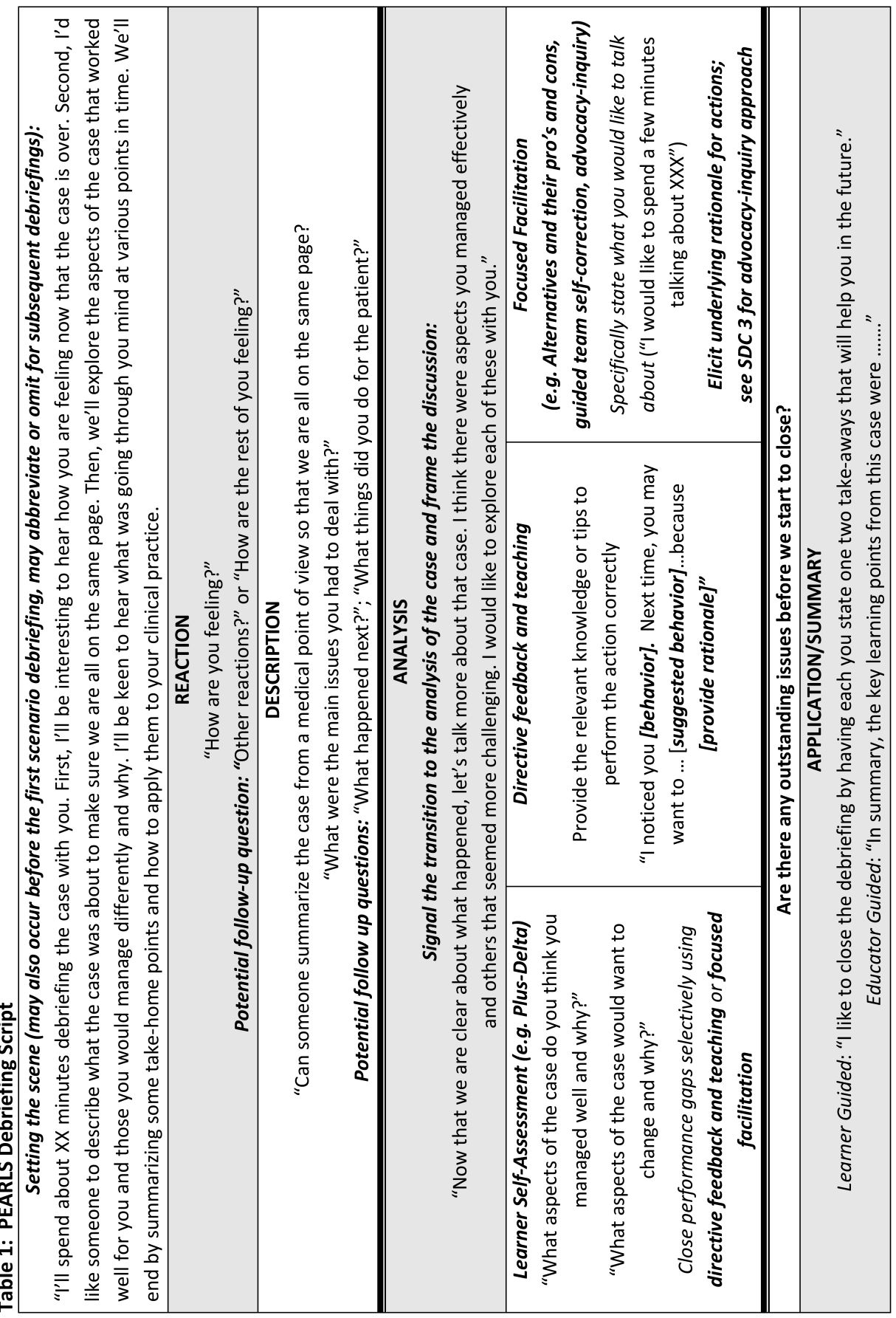


Figure 1 PEARLS debriefing framework

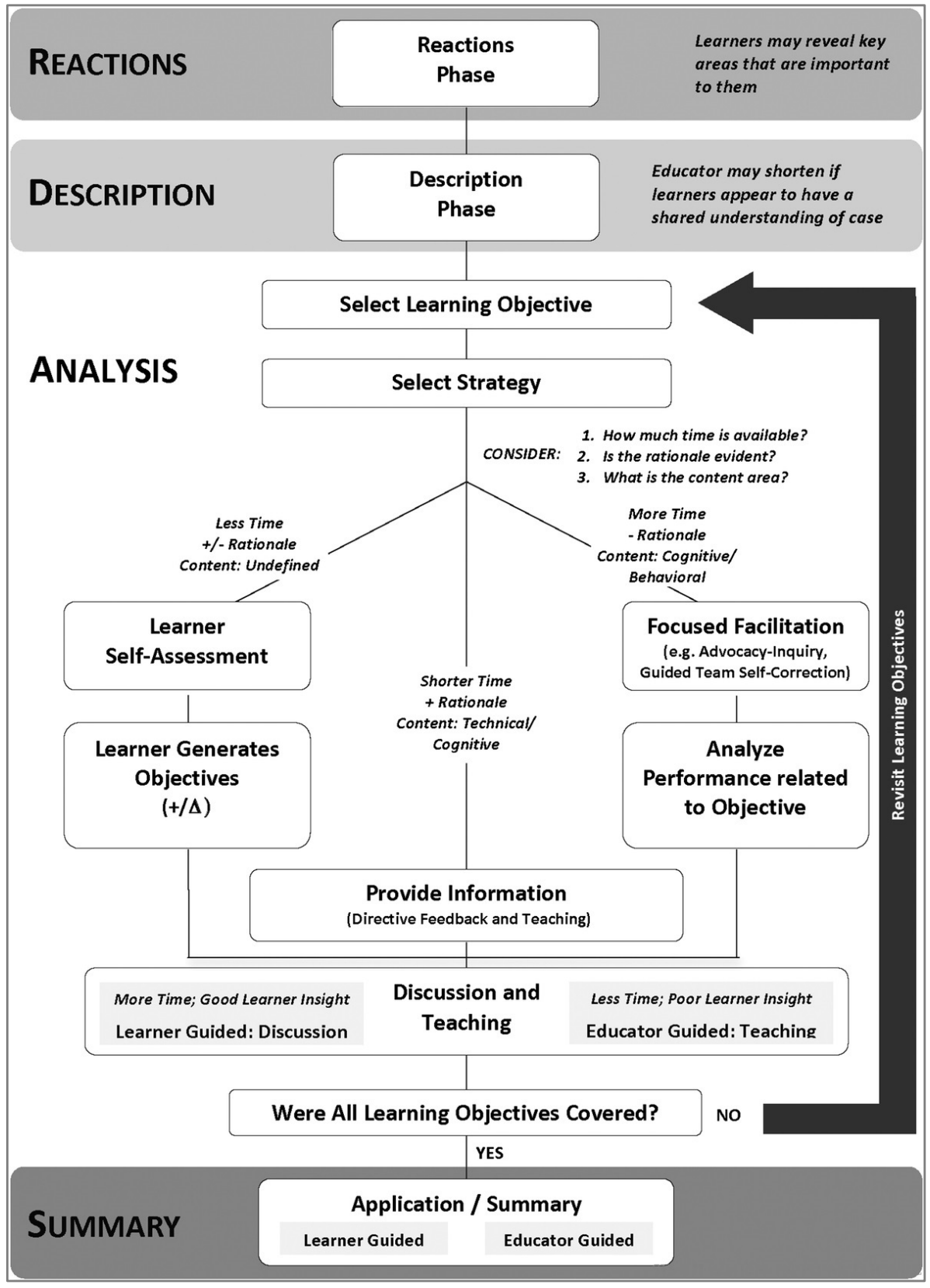




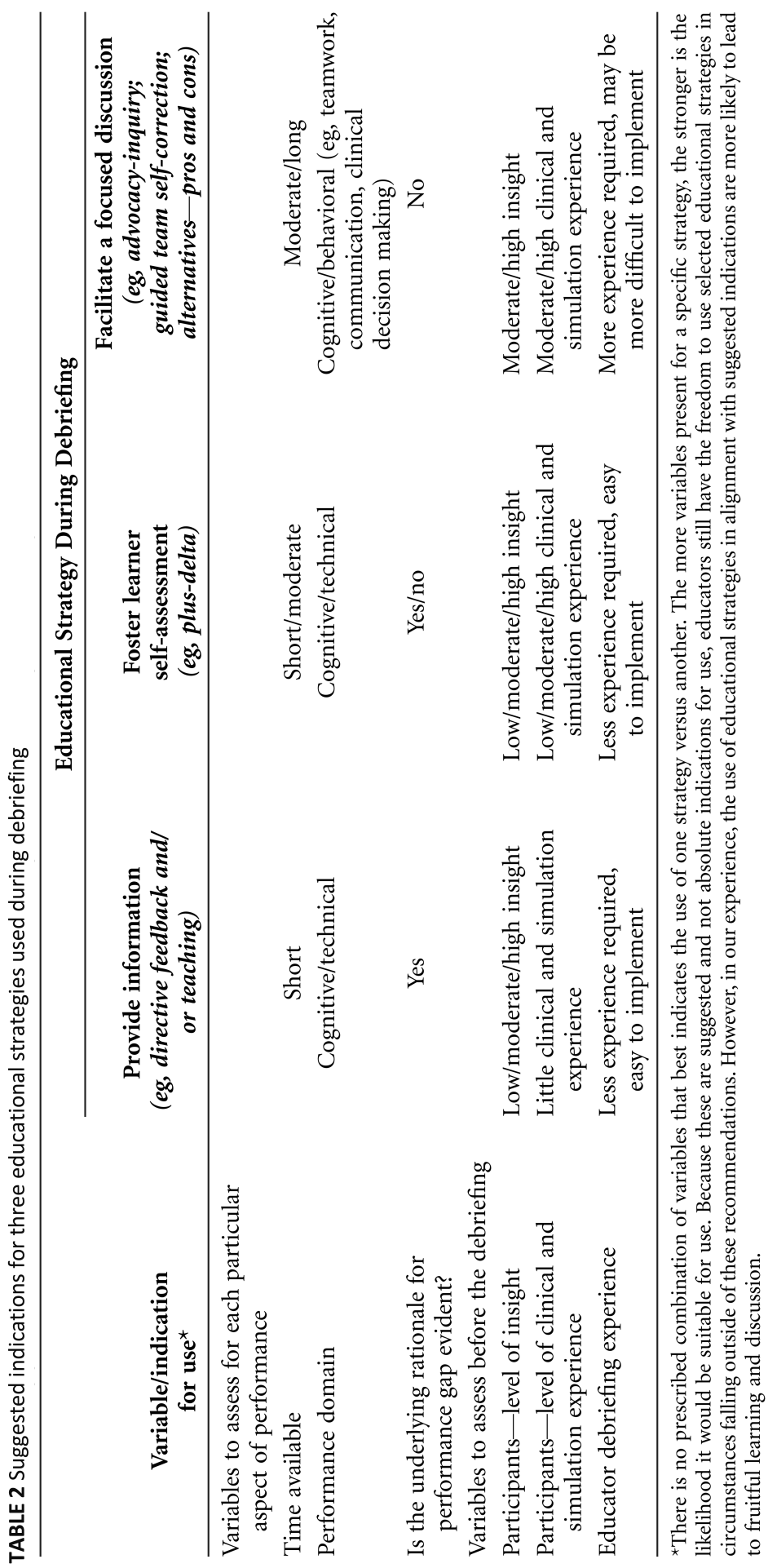




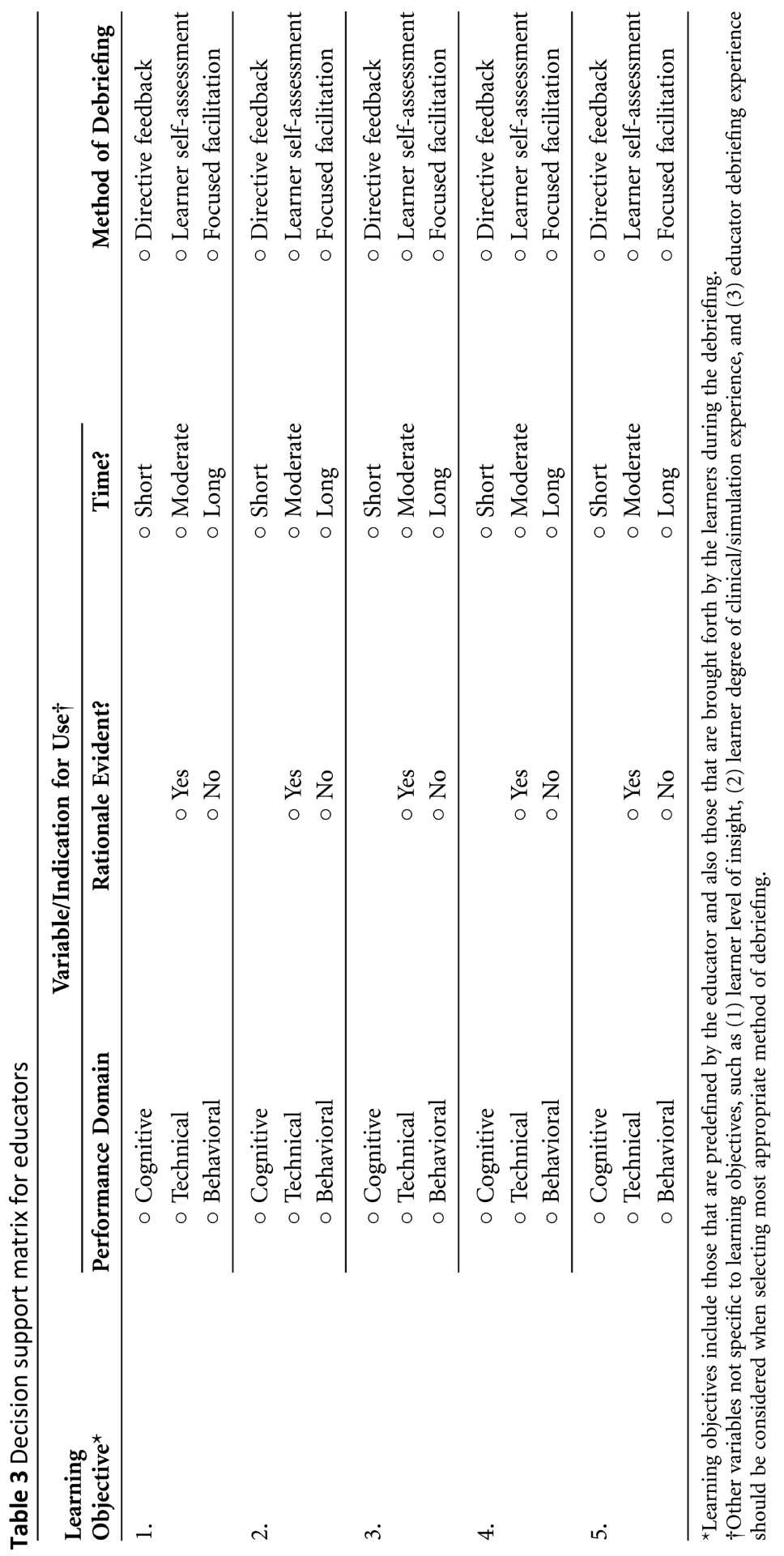


Using these screening questions (Table 2) and Figure 1 for guidance, educators can choose a strategy for each relevant aspect of performance. Although no prescribed combination of variables best indicates use of one educational strategy over another, we suggest that the more variables that support use of a specific strategy, the greater is the likelihood that it would be suitable in that particular context. We have designed a decision support matrix for educators to use while observing a simulation event (Table 3 ). Educators simply populate the learning objectives and then sequentially consider the 3 screening questions mentioned earlier to help them select the educational strategy best suited for that specific performance gap or objective. This process is not meant to be overly rigid; it becomes more refined with experience implementing and debriefing a given scenario.

Self-assessment strategies (what went well/what would you change?;3,53 what went well/did not go well and why?:54 what was easy, what was challenging ${ }^{52}$ ) are well suited at the outset of the analysis phase if time is limited or if the participants did not share their thoughts and/or emotions during the reactions phase. Often major issues can be raised in a short period and may provide insight as to what topics are important to participants. Once issues are identified, the educator can selectively use focused facilitation techniques to promote more in-depth discussion or strive to close performance gaps through directive feedback and teaching as appropriate. Selfassessment strategies are more learner centered; indeed, with sufficient time, highlevel groups may debrief themselves to a large extent and make the necessary connections to their future clinical practice, whereas groups with less insight/experience may require more guidance. ${ }^{70}$

Probing deeper using focused facilitation methods can be used to explore specific issues. For example, advocacy-inquiry is appropriate when the underlying rationale for action is not obvious to the educator (or other learners) ${ }^{4}$ and when sufficient time is available. Similarly, taking the time to explore alternatives and their pros and cons of decision making, management options, and team behaviors encourages participantfocused discussion and acts to depersonalize the performance. ${ }^{52}$ Irrespective of debriefing approach, careful listening and flexibility about debriefing topic helps identify and address key issues that are important to trainees.

In a more direct, highly educator-driven approach, educators provide information, that is, the "solution" to the problem. Liberal use of instruction or lectures, especially early in the debriefing, represents a pitfall for novice educators who often simply teach irrespective of situation ("The educator who does all the talking"). Providing information judiciously in the form of directive feedback ${ }^{64}$ and/or teaching may be preferred if time is very short and performance gaps are highly technical (e.g., holding a laryngoscope in the wrong hand) or the underlying reason for the deficient 
performance is clear (e.g., due to knowledge gap when a learner says "I could not remember the steps of the algorithm"). In these instances, educators can switch to teaching mode (e.g., "Try holding the laryngoscope in the other hand next time" or "Let us review the algorithm"). Figure 2 provides an example of how the PEARLS framework can be applied to various performance domains with a simulated scenario.

As time permits, educators ideally address critical performance issues fully before moving on to the discussion of the next issue to avoid disjointed or superficial discussions. When there are a large number of issues to address, educators often struggle deciding how to prioritize these topics of discussion. Learners typically bring up issues that are important to them (i.e., learner agenda) during the reactions phase or of a self-assessment during the debriefing. Determining overlap between the learner agenda and predefined learning objectives will help the educator identify issues that are important to both the learner and the educator (i.e., common agenda). We generally recommend prioritizing the common agenda as high-yield topics for discussion earlier in the analysis phase, before moving on to discuss topics that are important only to the learner and/or educator.

In helping trainees reflect on performance, simulation educators can either drive the process or facilitate a learner-driven discussion. Once an issue has been adequately addressed, educators should ask, "Have all learning objectives been covered?" If not, then the next aspect of performance should be addressed using an appropriate strategy (see Table 3 and screening questions for guidance). Once essential learning objectives have been addressed, the educator can inquire if any other outstanding issues remain before moving on to the summary phase of the debriefing.

The summary phase of the debriefing may be conducted in 1 of 2 ways. In a learnerguided manner, the learners are asked to state their main take-home message(s) and perhaps even anticipate enablers and barriers to enact change in their setting. This step also has benefit of allowing the educator to confirm if the learner's take-home messages align with the predetermined learning objectives of the session. Conducting the summary phase in this fashion usually takes more time, and learners occasionally will introduce new topics for discussion while the educator is trying to facilitate a summary. Although we favor the learner-guided approach, alternatively the educator can summarize by providing a succinct review of the main take-home messages (as perceived by the educator). By conducting the summary in this manner, the educator has more control over when the debriefing will end but is unable to determine if the learner's take-home messages align with the learning objectives of the session. It is best to manage time during a debriefing to provide sufficient opportunity for learners to formulate their own take-home messages. 


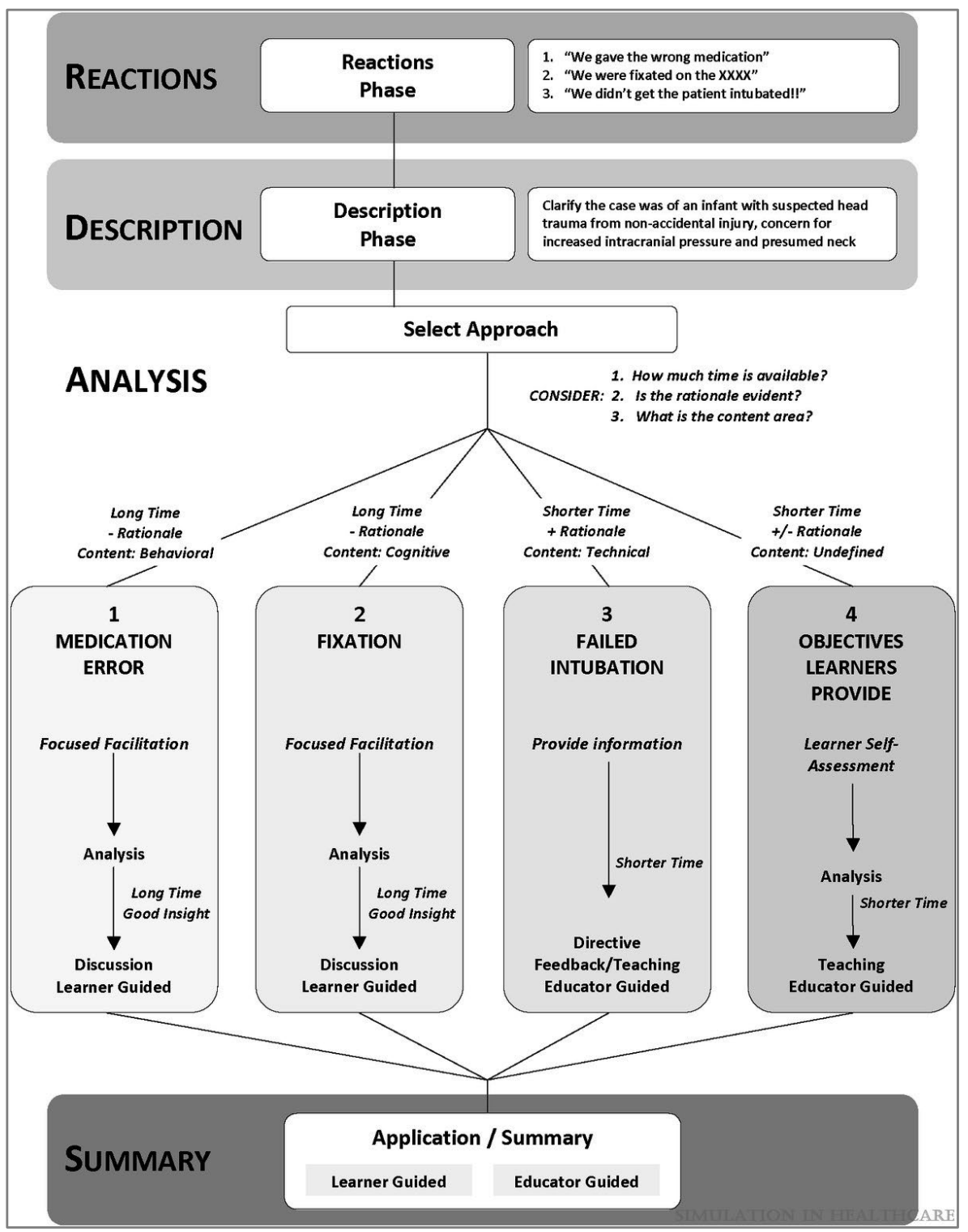

FIGURE 2 Application of the PEARLS debriefing framework to address various types of learning objectives. In this sample debriefing, the educator explores a hypothetical case of an infant with head trauma caused by nonaccidental injury. Performance gaps relate to a medication error, a fixation error, and failed intubation. Here, we see how an educator might select an educational strategy during the analysis phase of the debriefing based on key considerations with each objective/performance gap. 


\section{Development and pilot testing the PEARLS debriefing framework and debriefing script}

The PEARLS debriefing framework and script was developed over a 3-year period via a multistep process involving a comprehensive review of the literature, integration of our own debriefing faculty development experience, and pilot testing with iterative revisions. Table 4 provides an overview of the development process.

Early anecdotal experiences from teaching the PEARLS approach at multiple debriefing workshops at simulation and education conferences and faculty development courses in North America and Europe are quite positive. Our workshop and course participants note the following:

- The debriefing script is easy to follow but requires some preorientation and familiarization for optimal use.

- A description of the rationale behind the use of the script supports effective implementation.

- It helps novice facilitators to use the scripted phrases verbatim initially; once they become familiar with the flow and content, then they become more comfortable adding their own personal touch to wording of questions/phrases.

- Even experienced facilitators still benefit from using the PEARLS framework and script as a guide.

- The use of the debriefing script as a faculty development tool during simulation educator training anecdotally seems to accelerate the learning curve for acquisition of debriefing skills.

TABLE 4 Development steps of PEARLS debriefing framework and script

Step 1: Literature review to identify strategies used during a postsimulation debriefing

Step 2: Review of existing debriefing scripts (EXPRESS, AHA, SHARP, DISCERN)

Step 3: Development-integration of our own experience in debriefing and teaching simulation faculty development courses and workshops (3 mo)

a. PEARLS framework

b. PEARLS debriefing script: design, format, representative scripted language

Step 4: Pilot testing (24 mo)

a. Framework and debriefing script shared and pilot tested with simulation educators from the KidSIM program at Alberta Children's Hospital, the kidSTAR program at Ann and Robert Lurie Children's Hospital, and the Royal College of Physicians and Surgeons of Canada. Elements reviewed and trialed with the PAEDSIM collaborative in Europe.

b. Debriefing workshops at multiple simulation and education conferences in North America and Europe.

Step 5: Iterative revisions to framework and script based on educator and end-user feedback

Step 6: Integration of emerging literature as appropriate (6 mo) 


\section{Discussion}

Debriefing plays a central role in experiential learning contexts such as health care simulation. Although some frameworks have been adapted from other arenas such as the US Army after-action review, ${ }^{56}$ limited evidence guides our practice. ${ }^{13}$ The PEARLS framework and PEARLS debriefing script represent a novel contribution to the simulation literature. PEARLS fills an important gap by conceptualizing a framework for integrating 3 common educational strategies used during debriefings and providing guidance on their implementation. We realize that as authors, our debriefing styles and faculty development experiences have informed the development of PEARLS; throughout, we have tried to build on what is known from the literature and expert consensus but acknowledge that both science and art contribute to the complex skill of debriefing. We have articulated and operationalized a blended framework that incorporates what many health care simulation educators already do. As such, we believe the PEARLS framework is adaptable and suitable for various learner groups across professions and disciplines and for different debriefing environments. Finally, we have developed and described a debriefing script that will help educators apply the PEARLS framework to their debriefing.

The debriefing script may provide valuable scaffolding for health care simulation educators who are learning to debrief; it naturally adapts to their needs because they may refer to it at their discretion. In our experience, the PEARLS framework and debriefing script promote faculty development efforts because not only specific steps of debriefing are made explicit but also representative phrases are provided to guide possible wording choices. Specifically, we hope to empower educators to make informed decisions about their debriefing practices until guidance from more rigorous study emerges.

Despite the spread of health care simulation and debriefing, many educators have little or no previous formal training in debriefing and still struggle to facilitate effectively, ${ }^{5}$ and few, if any, practical guides to improve debriefing skills exist. Obstacles to effective debriefing likely include relatively high cost of simulation educator training, limited debriefing experience, and lack of experienced simulation educators to provide the ongoing mentoring that helps improve debriefing skills. Inadequate debriefing expertise may ultimately have a negative impact on knowledge and skill acquisition as well as attitudes in the learners. From the authors' experience, novice simulation educators are challenged by observing and codifying events of the simulation, organizing their thoughts and meaningfully structuring the debriefing to encourage engaging discussions, promote critical reflection, and provide open and honest performance feedback. Often novice educators struggle to think of their next question, which impedes the effective listening skills that are so important to 
effective debriefing. Debriefing scripts are one strategy to reduce an educator's cognitive load, ${ }^{74}$ provided that educators familiarize themselves with the script before use.

During the development of PEARLS, the authors weighed the advantages and disadvantages of developing a debriefing script that offered a structure and helpful sample phrases but might seem prescriptive in its format and suggested language. Much like any communication guide or template, rigid adherence to the debriefing script is neither desirable nor the ultimate goal. Ideally, educators follow the framework and the script while increasingly modifying the language as they practice and their experience grows. Indeed, the script only offers structure and guidance. We agree that educators should avoid formulaic speech and tokenisms ${ }^{75}$ as well as linguistic rituals $^{76}$ by being curious and authentic; educators need to find and speak with their voice. The ultimate goal of debriefing is for learners to reflect on and make sense of their simulation experience and generate meaningful learning that translates to clinical practice. We believe that the PEARLS framework and debriefing script can support this ultimate goal and may also promote consistency within simulation programs while allowing flexibility as to style and approach. For example, although we identify time as a factor, a skilled and experienced educator may be highly efficient in the use of questions and our guidance regarding time constraints may be less appropriate. Moreover, some educators may place greater weight on learner selfassessment or prefer facilitating a focused discussion. With increasing experience and expertise, simulation educators develop the flexibility and individuality in facilitating debriefings that are both suited to the context and learner group.

\section{Conclusions}

The PEARLS framework and debriefing script incorporate what is known about effective debriefing practices by formulating a new framework for debriefing using existing educational strategies and designing a debriefing script to help support its implementation in a variety of settings. Future directions include empiric study of the PEARLS debriefing framework and debriefing script. Areas of focus include the role of PEARLS in debriefing skill acquisition and the development of debriefing expertise, the role of the framework and script on debriefing quality, and how the framework and script impact faculty development efforts.

\section{References}

1. Dreifuerst KT. The essentials of debriefing in simulation learning: a concept analysis. Nurs Educ Perspect 2009; 30 (2): 109-114.

2. Steinwachs B. How to facilitate a debriefing. Simul Gaming 1992; 23: 186-195. 


\section{Chapter 3}

3. Fanning RM, Gaba DM. The role of debriefing in simulation-based learning. Simul Healthc 2007; 2 (2): 115-125.

4. Rudolph JW, Simon R, Dufresne RL, Raemer DB. There's no such thing as "nonjudgmental" debriefing: a theory and method for debriefing with good judgment. Simul Healthc 2006; 1 (1): 49-55.

5. Dieckmann P, Molin Friis S, Lippert A, Ostergaard D. The art and science of debriefing in simulation: ideal and practice. Med Teach 2009; 31 (7): e287-e294.

6. Ahmed M, Sevdalis N, Paige J, Paragi-Gururaja R, Nestel D, Arora S. Identifying best practice

7. Arafeh JM, Hansen SS, Nichols A. Debriefing in simulated-based learning: facilitating a reflective discussion. J Perinat Neonatal Nurs 2010; 24 (4): 302-309.

8. Zigmont JJ, Kappus LJ, Sudikoff SN. The 3D model of debriefing: defusing, discovering, and deepening. Semin Perinatol 2011; 35 (2): 52-58.

9. Yardley S, Teunissen PW, Dornan T. Experiential learning: AMEE guide no. 63. Med Teach 2012; 34 (2): e102-e115.

10. Kolb D. Experiential Learning: Experience as a Source of Learning and Development. Upper Saddle River, NJ: Prentice Hall; 1984.

11. Jarvis P. Adult and Continuing Education: Theory and Practice. 2nd ed. New York: Routledge; 1999.

12. Yardley S, Teunissen PW, Dornan T. Experiential learning: transforming theory into practice. Med Teach 2012; 34 (2): 161-164.

13. Raemer D, Anderson M, Cheng A, Fanning R, Nadkarni V, Savoldelli G. Research regarding debriefing as part of the learning process. Simul Healthc 2011; 6 (suppl): S52-S57.

14. Tannenbaum SI, Cerasoli CP. Do team and individual debriefs enhance performance? A metaanalysis. Hum Factors 2013; 55 (1): 231-245.

15. van de Ridder JM, Stokking KM, McGaghie WC, ten Cate OT. What is feedback in clinical education? Med Educ 2008; 42 (2): 189-197.

16. Issenberg SB, McGaghie WC, Petrusa ER, Lee Gordon D, Scalese RJ. Features and uses of high-fidelity medical simulations that lead to effective learning: a BEME systematic review. Med Teach 2005; 27 (1): 10-28.

17. McGaghie WC, Issenberg SB, Petrusa ER, Scalese RJ. A critical review of simulation-based medical education research: 2003-2009. Med Educ 2010; 44 (1): 50-63.

18. Edelson DP, Litzinger B, Arora $\mathrm{V}$, et al. Improving in-hospital cardiac arrest process and outcomes with performance debriefing. Arch Intern Med 2008; 168 (10): 1063-1069.

19. Edelson DP, Lafond CM. Deconstructing debriefing for simulation-based education. JAMA Pediatr 2013; 167: 586-587.

20. Morrison JE, Meliza LL. Foundations of the After Action Review Process (Special Report 42). Alexandria, VA: US Army Research Institute for Behavioral and Social Sciences; 1999: 42.

21. Salas $E$, Klein $C$, King $H$, et al. Debriefing medical teams: 12 evidence-based best practices and tips. Jt Comm J Qual Patient Saf 2008; 34 (9): 518-527.

22. Ericsson KA. Deliberate practice and acquisition of expert performance: a general overview. Acad Emerg Med 2008; 15 (11): 988-994.

23. McGaghie WC. Research opportunities in simulation-based medical education using deliberate practice. Acad Emerg Med 2008; 15 (11): 995-1001.

24. Siassakos D, Bristowe $K$, Draycott $T$, et al. Clinical efficiency in a simulated emergency and relationship to team behaviours: a multisite cross-sectional study. BJOG 2011; 118 (5): 596-607.

25. Hunt EA, Fiedor-Hamilton M, Eppich WJ. Resuscitation education: narrowing the gap between evidencebased resuscitation guidelines and performance using best educational practices. Pediatr Clin North Am 2008; 55 (4): 1025-1050 xii.

26. McGaghie WC, Issenberg SB, Cohen ER, Barsuk JH, Wayne DB. Does simulation-based medical education with deliberate practice yield better results than traditional clinical education? A meta-analytic comparative review of the evidence. Acad Med2011; 86 (6): 706-711.

27. Ericsson KA. Deliberate practice and the acquisition and maintenance of expert performance in medicine and related domains. Acad Med 2004; 79 (suppl 10): S70-S81. 
28. Rudolph JW, Simon R, Raemer DB, Eppich WJ. Debriefing as formative assessment: closing performance gaps in medical education. Acad Emerg Med 2008; 15 (11): 1010-1016.

29. Salas E, DiazGranados D, Klein C, et al. Does team training improve team performance? A metaanalysis. Hum Factors 2008; 50 (6): 903-933.

30. Ellis S, Davidi I. After-event reviews: drawing lessons from successful and failed experience. J Appl Psychol 2005; 90 (5): 857-871.

31. Flanagan B. Debriefing: theory and techniques. In: Riley RH, ed. A Manual of Simulation in Healthcare. New York: Oxford University Press USA; 2008: 155-170.

32. Van Heukelom JN, Begaz $T$, Treat R. Comparison of postsimulation debriefing versus insimulation debriefing in medical simulation. Simul Healthc 2010; 5 (2): 91-97.

33. Walsh CM, Ling SC, Wang CS, Carnahan H. Concurrent versus terminal feedback: it may be better to wait. Acad Med 2009; 84 (suppl 10): S54-S57.

34. Ahmed M, Sevdalis N, Vincent C, Arora S. Actual vs perceived performance debriefing in surgery: practice far from perfect. Am J Surg 2013; 205 (4): 434-440.

35. Husebo SE, Dieckmann P, Rystedt H, Soreide E, Friberg F. The relationship between facilitators' questions and the level of reflection in postsimulation debriefing. Simul Healthc 2013; 8(3): 135-142.

36. Brett-Fleegler M, Rudolph J, Eppich W, et al. Debriefing assessment for simulation in healthcare: development and psychometric properties. Simul Healthc 2012; 7 (5): 288-294.

37. Arora S, Ahmed M, Paige J, et al. Objective structured assessment of debriefing: bringing science to the art of debriefing in surgery. Ann Surg 2012; 256 (6): 982-988.

38. Dieckmann P. Simulation settings for learning in acute medical care. In: Dieckmann $P$, ed. Using Simulations for Education, Training, and Research. Lengerich: Pabst; 2009.

39. Simon R, Raemer D, B, Rudolph JW. Debriefing assessment for simulation in healthcare: rater handbook. 2009. From https://harvardmedsim.org/_media/DASH.handbook.2010.Final.Rev.2.pdf. Accessed September 27, 2012.

40. Wickers MP. Establishing a climate for a successful debriefing. Clin Simul Nurs 2010; 6: e83-e86.

41. Rudolph JW, Simon R, Rivard P, Dufresne RL, Raemer DB. Debriefing with good judgment: combining rigorous feedback with genuine inquiry. Anesthesiol Clin 2007; 25 (2): 361-376.

42. Rall M, Manser T, Howard SK. Key elements of debriefing for simulator training. Eur J Anaesthesiol 2000; 17 (8): 516-517.

43. Baron RA. Negative effects of destructive criticism: impact on conflict, self-efficacy, and task performance. J Appl Psychol 1988; 73 (2): 199-207.

44. Ende J. Feedback in clinical medical education. JAMA 1983; 250 (6): 777-781.

45. Eva $\mathrm{KW}$, Armson $\mathrm{H}$, Holmboe $\mathrm{E}$, et al. Factors influencing responsiveness to feedback: on the interplay between fear, confidence, and reasoning processes. Adv Health Sci Educ Theory Pract 2012; 17 (1): 1526.

46. Kluger AN, Van Dijk D. Feedback, the various tasks of the doctor, and the feedforward alternative. Med Educ 2010; 44 (12): 1166-1174.

47. Cheng $A$, Hunt EA, Donoghue $A$, et al. Examining pediatric resuscitation education using simulation and scripted debriefing: a multicenter randomized trial. JAMA Pediatr 2013; 167: 1-9.

48. Cheng A, Rodgers DL, van der Jagt E, Eppich W, O'Donnell J. Evolution of the Pediatric Advanced Life Support course: enhanced learning with a new debriefing tool and Web-based module for Pediatric Advanced Life Support instructors*. Pediatr Crit Care Med 2012; 13 (5): 589-595.

49. Gaba DM, Howard SK, Fish KJ, Smith BE, Sowb YA. Simulation-based training in anesthesia crisis resource management: a decade of experience. Simul Gaming 2001; 32 (2): 175-193.

50. Lederman LC. Debriefing: toward a systematic assessment of theory and practice. Simul Gaming 1992; 23 : 145-160.

51. Dismukes RK, Gaba DM, Howard SK. So many roads: facilitated debriefing in healthcare. Simul Healthc 2006; 1 (1): 23-25.

52. Fanning RM, Gaba DM. Debriefing. In: Gaba DM, Fish KJ, Howard SK, Burden AR, eds. Crisis Management in Anesthesiology. 2nd ed. Philadelphia, PA: Elsevier Saunders; 2015: 65-78. 


\section{Chapter 3}

53. Mullan PC, Wuestner E, Kerr TD, Christopher DP, Patel B. Implementation of an in situ qualitative debriefing tool for resuscitations. Resuscitation 2013; 84 (7): 946-951.

54. Ahmed M, Arora S, Russ S, Darzi A, Vincent C, Sevdalis N. Operation debrief: a SHARP improvement in performance feedback in the operating room. Ann Surg 2013; 258 (6): 958-963.

55. Kolbe $M$, Weiss $M$, Grote $G$, et al. TeamGAINS: a tool for structured debriefings for simulation-based team trainings. BMJ Qual Saf 2013; 22 (7): 541-553.

56. Sawyer TL, Deering S. Adaptation of the US Army's After-Action Review for simulation debriefing in healthcare. Simul Healthc2013; 8 (6): 388-397.

57. Dieckmann $\mathrm{P}$, Reddersen $\mathrm{S}$, Zieger J, Rall M. Video-assisted debriefing in simulation-based training of crisis resource management. In: Kyle RR, Murray WB, eds. Clinical Simulation: Operations, Engineering, and Management. Burlington: Academic Press; 2008: 667-676.

58. Hamilton NA, Kieninger AN, Woodhouse J, Freeman BD, Murray D, Klingensmith ME. Video review using a reliable evaluation metric improves team function in high-fidelity simulated trauma resuscitation. J Surg Educ 2012; 69 (3): 428-431.

59. Savoldelli GL, Naik VN, Park J, Joo HS, Chow R, Hamstra SJ. Value of debriefing during simulated crisis management: oral versus video-assisted oral feedback. Anesthesiology 2006; 105 (2): 279-285.

60. Sawyer T, Sierocka-Castaneda A, Chan D, Berg B, Lustik M, Thompson M. The effectiveness of videoassisted debriefingversus oral debriefing alone at improving neonatal resuscitation performance: a randomized trial. Simul Healthc 2012; 7 (4): 213-221.

61. Eppich W, O'Connor L, Adler M. Providing effective simulation activities. In: Forrest K, McKimm J, Edgar S, eds. Essential Simulation in Clinical Education. Chichester: Wiley-Blackwell; 2013: 213-234.

62. Dieckmann P. Debriefing olympics-a workshop concept to stimulate the adaptation of debriefings to learning contexts. Simul Healthc 2012; 7 (3): 176-182.

63. Hewson MG, Little ML. Giving feedback in medical education: verification of recommended techniques. J Gen Intern Med1998; 13 (2): 111-116.

64. Archer JC. State of the science in health professional education: effective feedback. Med Educ 2010; 44 (1): 101-108.

65. Dolmans DH, De Grave W, Wolfhagen IH, van der Vleuten CP. Problem-based learning: future challenges for educational practice and research. Med Educ 2005; 39 (7): 732-741.

66. Estes C. Promoting student-centered learning in experiential education. J Experiential Educ 2004; 27 (2): 141-160.

67. Davis DA, Mazmanian PE, Fordis M, Van Harrison R, Thorpe KE, Perrier L. Accuracy of physician selfassessment compared with observed measures of competence: a systematic review. JAMA 2006; 296 (9): 1094-1102.

68. Duffy FD, Holmboe ES. Self-assessment in lifelong learning and improving performance in practice: physician know thyself. JAMA 2006; 296 (9): 1137-1139.

69. Eva KW, Regehr G. Self-assessment in the health professions: a reformulation and research agenda. Acad Med 2005; 80 (suppl 10): S46-S54.

70. McDonnell LK, Jobe KK, Dismukes RK. Facilitating LOS Debriefings: A Training Manual. Moffett Field, CA. National Aeronautical and Space Administration; 1997.

71. Smith-Jentsch KA, Cannon-Bowers JA, Tannenbaum SI, Salas E. Guided team self-correction: impacts on team mental models, processes, and effectiveness. Small Group Research 2008; 39 (3): 303-327.

72. Kriz WC. A systemic-constructivist approach to facilitation and debriefing of simulations and games. Simul Gaming 2008; 41 (5): 663-680.

73. Rudolph JW, Raemer DB, Simon R. Establishing a safe container for learning in simulation: the role of the presimulation briefing. Simul Healthc 2014; 9(6): 339-349.

74. van Merrienboer JJ, Sweller J. Cognitive load theory in health professional education: design principles and strategies. Med Educ 2010; 44 (1): 85-93.

75. Bearman M, Ajjawi R. Avoiding tokenism in health professional education. Med Educ 2013; 47 (1): 9-11.

76. Molloy E, Borrell-Carrio F, Epstein R. The impact of emotions in feedback. In: Boud D, Molloy E, eds. Feedback in Higher and Professional Education: Understanding It and Doing It Well. London and New York: Routledge; 2013: 50-71. 
Appendix 1 Advantages and disadvantages of three educational strategies used in debriefings

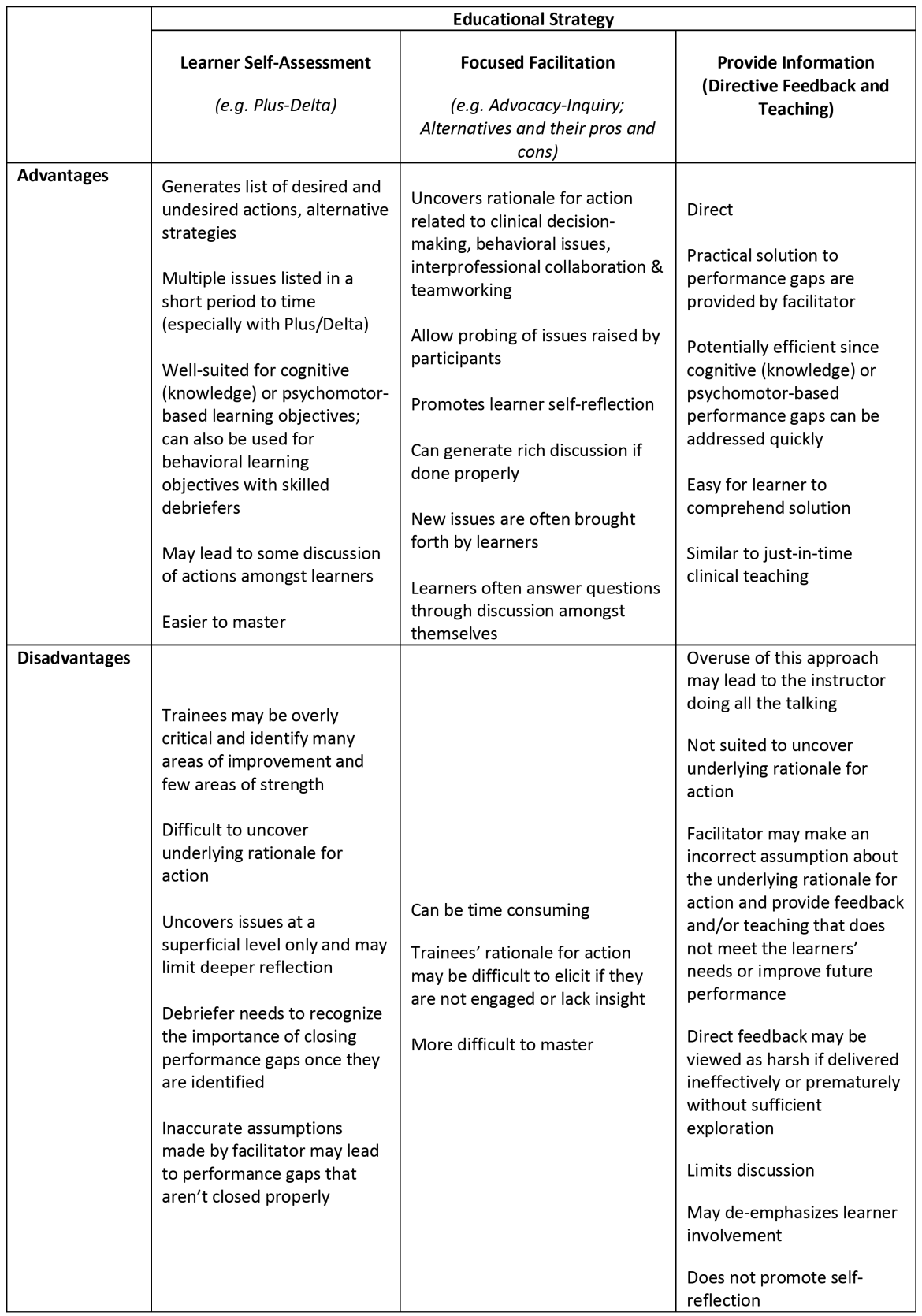




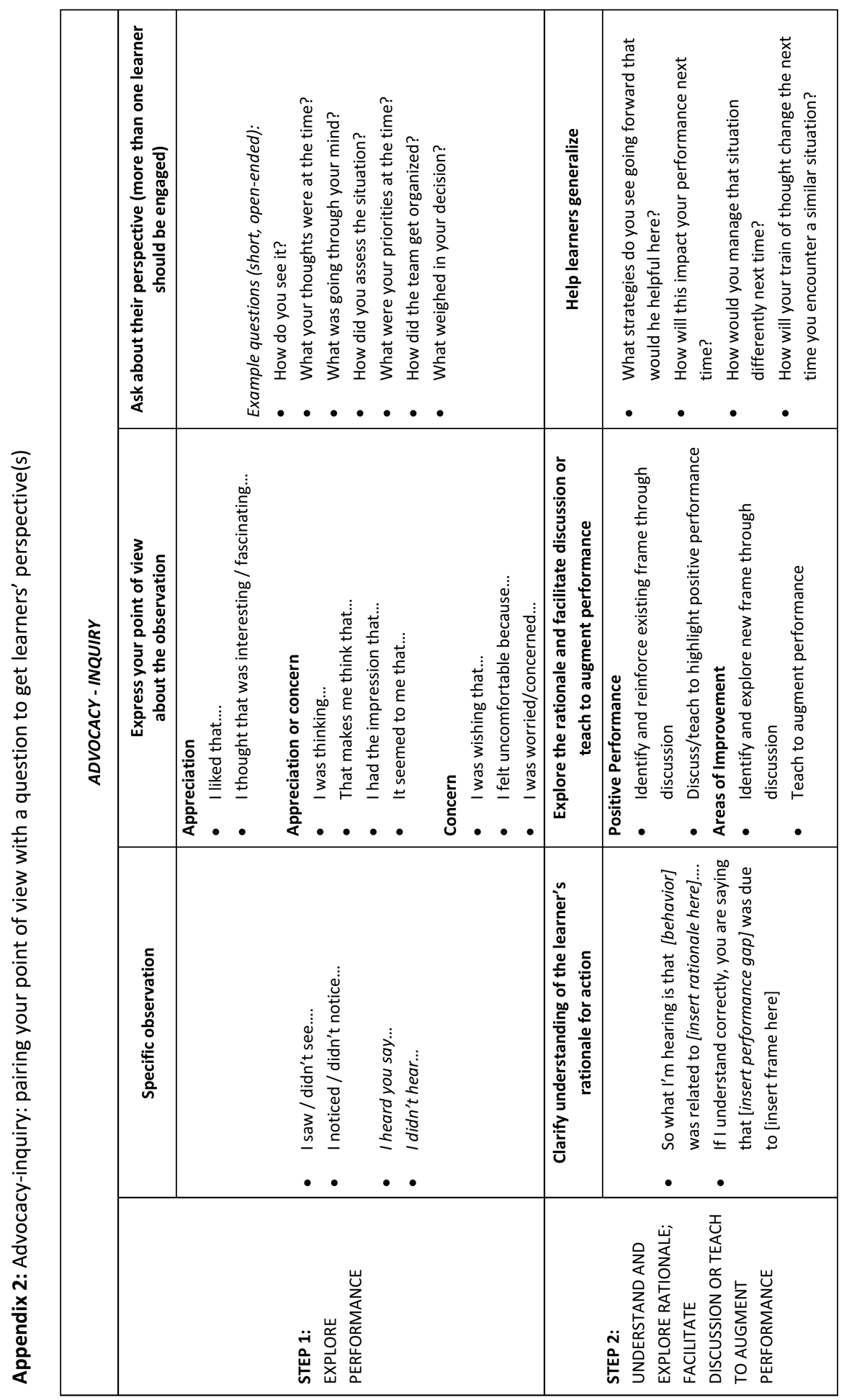




\section{CHAPTER 4}

Structuring Feedback and Debriefing to Achieve Mastery Learning Goals

Published as: Eppich WJ, Hunt EA, Duval-Arnould JM, Siddall VJ, Cheng A. Structuring feedback and debriefing to achieve mastery learning goals. Academic Medicine. 2015;90(11):1501-1508. 


\section{Abstract}

Mastery learning is a powerful educational strategy in which learners gain knowledge and skills that are rigorously measured against predetermined mastery standards with different learners needing variable time to reach uniform outcomes. Central to mastery learning are repetitive deliberate practice and robust feedback that promote performance improvement. Traditional health care simulation involves a simulation exercise followed by a facilitated postevent debriefing in which learners discuss what went well and what they should do differently next time, usually without additional opportunities to apply the specific new knowledge. Mastery learning approaches enable learners to "try again" until they master the skill in question. Despite the growing body of health care simulation literature documenting the efficacy of mastery learning models, to date insufficient details have been reported on how to design and implement the feedback and debriefing components of deliberate practice-based educational interventions. Using simulation-based training for adult and pediatric advanced life support as case studies, this article focuses on how to prepare learners for feedback and debriefing by establishing a supportive yet challenging learning environment; how to implement educational interventions that maximize opportunities for deliberate practice with feedback and reflection during debriefing; describing the role of within-event debriefing or "microdebriefing" (i.e., during a pause in the simulation scenario or during ongoing case management without interruption), as a strategy to promote performance improvement; and highlighting directions for future research in feedback and debriefing for mastery learning. 


\section{Introduction}

Because of its powerful impact, mastery learning has found increasing applications in medical education, ${ }^{1,2}$ such as advanced cardiac life support $(A C L S)^{3}$ and procedural skills training ${ }^{4}$ as well as intern boot camps. ${ }^{5}$ This trend will likely expand within competencybased medical education models. ${ }^{6}$ Mastery learning has several complementary features $^{2,7}$ : baseline assessment; clear learning objectives, organized in educational units of increasing difficulty; engagement in powerful educational activities (e.g., deliberate practice) focused on attaining the objectives; set minimum passing standards (MPSs) (e.g., checklist percentages) for each educational unit; assessment to determine unit completion at the MPS for mastery; progression to the next educational unit if the MPS is achieved; and continued practice or study on an educational unit until the mastery standard is achieved. In mastery learning models all learners achieve all educational objectives with little or no variation in outcome; what varies is the amount of time learners need to reach a unit's educational objectives. ${ }^{2,7}$ Although evidence supports the effectiveness of mastery learning in health care simulation-based education, ${ }^{1,2}$ precisely how educators should integrate feedback and debriefing into this educational model is less clear.

Deliberate practice with performance feedback within mastery learning models helps learners progress toward meeting performance standards in well-defined tasks. ${ }^{8,9}$ Feedback is "specific information about the comparison between a trainee's observed performance and a standard, given with the intent to improve the trainee's performance." ${ }^{10}$ Whereas feedback is information, debriefing is an interactive discussion or conversation to reflect on performance. ${ }^{11}$ Traditionally, debriefing occurs post event with clear phases ${ }^{12-17}$ during which learners may receive performance feedback. Debriefing also occurs in a "pause and discuss" manner during an activity such as a simulation scenario ${ }^{18}$ to provide directive feedback ${ }^{19}$ and/or explore rationale(s) for action. ${ }^{14}$ Debriefing post event or during "pause and discuss" fosters reflection-onaction after events have occurred, ${ }^{20}$ whereas reflection-in-action occurs as events unfold. ${ }^{20}$ In this article we refer to episodes of within-event debriefing (during a pause or during ongoing case management) as "microdebriefing" to highlight their brief and focused nature. See Figure 1 for an overview of feedback and debriefing characteristics. Several debriefing models $s^{12,13,15}$ and recommendations for practice exist, ${ }^{21-23}$ but the link between debriefing models and learning outcomes is only beginning to emerge.

Although deliberate practice is core to simulation-based mastery learning ${ }^{1,24}$ and can yield better results than traditional clinical education, ${ }^{25}$ details about how to design and implement deliberate-practice-based educational interventions are lacking. Several studies have described the positive impact of deliberate practice on resuscitation skills, but word count limits prohibit publication of details needed to replicate the curricula. 
For example, in a seminal study on simulation-based mastery learning for ACLS skills, ${ }^{3}$ the description of feedback and debriefing components of deliberate practice is sparse, specifically regarding timing, content, duration, and frequency of feedback, as well as debriefing method. We seek to fill this gap by providing more explicit details specifically about how to structure feedback and debriefing for deliberate-practicebased educational interventions.

Figure 1 Overview of feedback and debriefing characteristics to achieve mastery learning goals

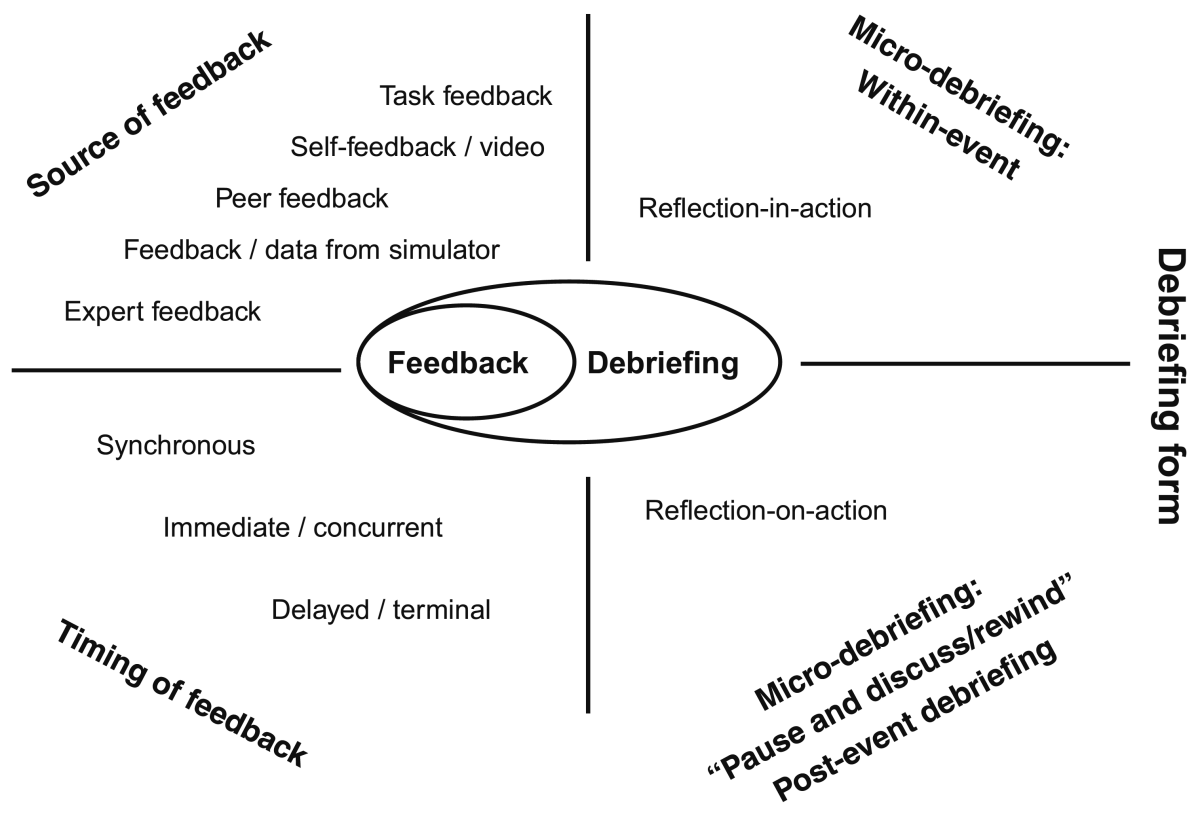

We use ACLS and pediatric advanced life support (PALS) as case studies to explore elements essential for mastery learning curricula: supportive learning environments that prepare learners for effortful practice and feedback; integrating feedback and debriefing into deliberate-practice-based educational interventions; and within-event debriefing or "microdebriefing." We also offer directions for future research.

\section{Designing the Educational Intervention}

Effective feedback and debriefing begin with curriculum design. ${ }^{26,27}$ Central to mastery learning models ${ }^{2}$ is the use of performance measures ${ }^{28}$ and determination of MPSs, ${ }^{29}$ for which standard setting guidelines exist. ${ }^{29}$ Although curriculum design and performance measures are important, we focus on structuring feedback and debriefing for mastery learning. When designing educational interventions, educators should specifically consider key feedback characteristics, including type, source, and timing ${ }^{30}$ in 
planning how and when feedback and debriefing will occur. See Figure 1 for examples of feedback sources. Feedback from multiple sources promotes learning ${ }^{31}$ and should be planned in advance.

\section{Establishing a Supportive Learning Environment}

Supportive learning environments are essential prerequisites for simulation-based educational strategies, ${ }^{15,22,32}$ particularly for deliberate practice approaches. Psychological safety fosters individual risk taking ${ }^{33}$ and helps learners to accept challenges. ${ }^{34}$ Although steps educators can take to engender psychological safety, mutual respect, and trust have been outlined elsewhere, ${ }^{32}$ we provide additional considerations for deliberate-practice-based interventions:

- Explicitly discuss the role of debriefing, how and when learners will receive feedback, ${ }^{26}$ and the significance of specific, honest yet nonthreatening feedback, ${ }^{23}$ much like coaching world-class athletes. ${ }^{35}$

- Explain that the goal is not perfection from the start, but being challenged, learning from mistakes, and improving. ${ }^{17}$ Acknowledge that honest feedback may feel unpleasant and trigger defensiveness but is necessary for improvement.

- Tell learners that they may be interrupted during the simulation so that they can briefly reflect on their progress and receive feedback before rewinding/resuming the case for more practice.

- Explicitly explain that learners may provide feedback to peers and the value of this process.

\section{Case Studies: ACLS and PALS Resuscitation Training}

Although mastery learning has been applied in various domains, here we use simulation-based advanced life support (ALS) training as an exemplar for our discussion for several key reasons: Clear performance guidelines exist for adult and pediatric ALS; resuscitation skills are relevant across health care professions and patient populations, and thus of interest to many readers; resuscitation skills combine cognitive processes and procedural components with team and communication skills; and two coauthors of this article were principal educators in published studies documenting the benefit of deliberate practice for ACLS (VIS) ${ }^{3}$ and PALS skills (EAH). ${ }^{35}$ See Table 1 for a summary of the primary studies on ACLS and PALS skills including key findings. Based on input from these two authors, what follows is a detailed description of how these educational sessions were structured and facilitated with a focus on feedback and debriefing components of deliberate practice. 


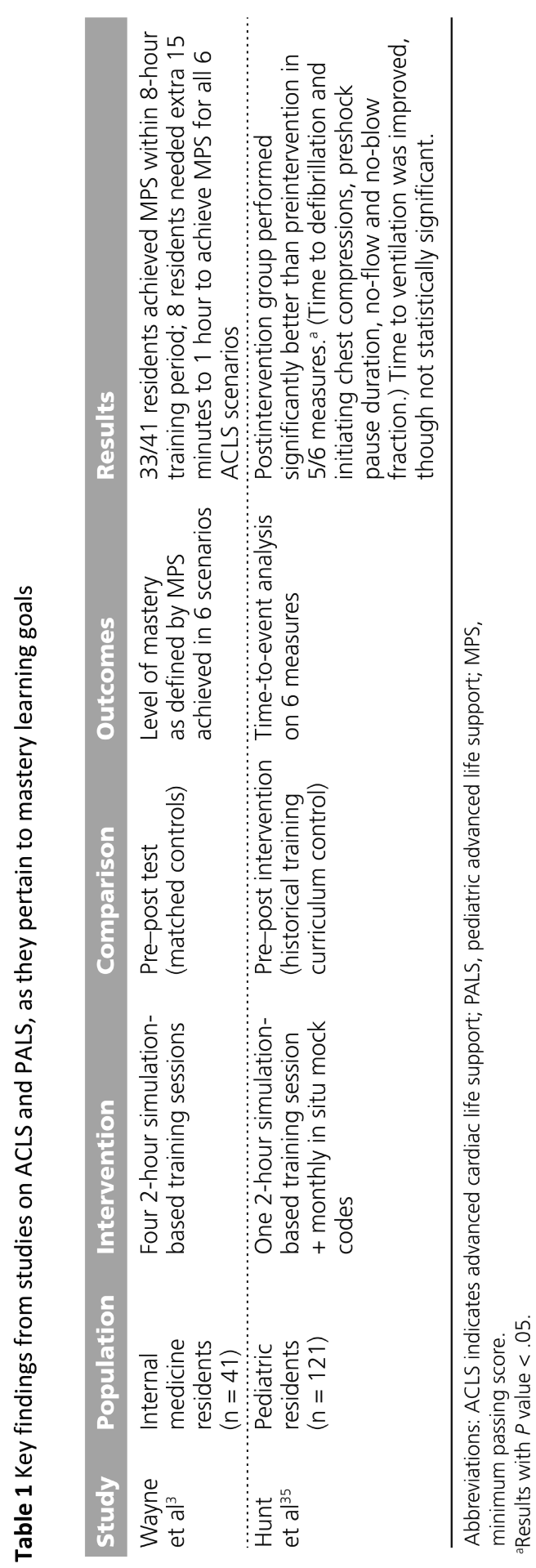




\section{Using deliberate practice in mastery learning of ACLS skills}

In a simulation-based study of ACLS mastery learning, second-year internal medicine residents participated in educational sessions facilitated by a nonphysician, ACLScertified instructor (VJS) to improve their ability to lead a resuscitation. ${ }^{3}$ The first twohour session focused on procedural skills (not embedded in simulation scenarios), including bag-mask ventilation (BMV), intubation, chest compressions, and defibrillation with emphasis on technical proficiency. During deliberate skills practice, the educator provided hands-on feedback as needed. More important, to augment the learners' abilities to observe and correct performance in their future roles as resuscitation team leaders, the educator encouraged peer-to-peer feedback (both giving as team leaders and receiving as team members). For example, residents reflected on the following questions to improve their observational skills in preparation for providing team members with performance feedback (e.g., adequacy of BMV or chest compressions):

- When the skill is performed correctly, what characterizes effective performance?

- If a skill is not performed correctly, what characterizes ineffective performance? What would need to change to ensure correct performance?

Clinical scenarios for the three subsequent two-hour sessions were grouped as follows: pulseless arrhythmias, tachyarrhythmias, and bradycardias. The primary outcome was the residents' ability to serve as team leaders, adhere to ACLS guidelines, and make critical decisions. Residents assigned to other roles practiced resuscitation skills, such as BMV, chest compressions, defibrillation, and administering medications and received performance feedback.

Before each scenario, residents received case information and assigned roles including team leader. During the scenario, the educator stood just behind the team leader, who was positioned at the foot of the bed. The educator quietly posed reflective questions to the team leader to prompt reflection-in-action (microdebriefing) during the active resuscitation-without pause-depending on the team leader and team member performance. For example, if an element of basic life support (BLS) or ALS was inadequate, the educator directed the team leader's attention to that element through reflective questions such as "Is BMV being performed adequately?" and "If not, what needs to change to improve it?" If BMV needed improvement, the team leader provided performance feedback as the resuscitation proceeded. As another example, if the team leader seemed to struggle with the next management step, the educator posed questions to prompt reflection-in-action (microdebriefing), such as "What are you seeing/hearing right now?" and "What are you thinking?" 
In scenarios involving pulseless electrical activity, if the resident was slow to work through the possible reversible causes, the educator prompted the team leader to assess BLS quality, reassured him/her that high-quality BLS provided time to think, and then posed reflective questions/provided feedback to direct management to the desired outcome. The educator focused on empowering the team leader to guide the team to improved performance, to provide peer feedback as needed during ongoing resuscitative efforts, and to understand the rationale for key actions and maneuvers.

After the scenario, the educator facilitated a short bedside postevent debriefing using a plus-delta technique with the team: what went well, what could have gone better, what should change for the next time. The educator encouraged peer-to-peer feedback and also provided clarification and feedback on troublesome aspects of performance herself as needed (e.g., critical decision making) to promote iterative improvement.

During the two-hour sessions, each resident served as team leader for each scenario type. Scenarios and debriefings were brief, with most of the session dedicated to deliberate practice in up to 15 scenarios with each resident completing multiple turns as team leader. The amount of support the educator provided to the team leader in the form of within-event microdebriefing decreased as each team leader's ability to lead the team improved during the session.

After completing all practice sessions, residents were assessed using six testing scenarios and guideline-specific checklists. ${ }^{3}$ If a resident did not achieve mastery standards for leading the team in accordance with resuscitation guidelines in any of the testing scenarios, she or he completed additional deliberate practice on those scenarios until mastery was achieved (see Table 1).

\section{Rapid cycle deliberate practice}

Pediatric residents participated in a novel rapid cycle deliberate practice (RCDP) simulation-based curriculum to improve PALS procedural and team skills within the first five minutes of an event. ${ }^{35}$ Central to RCDP is the selection and sequencing of cases that afford deliberate practice of core skills required to manage clinical scenarios based on their prevalence in clinical practice. In pediatrics, for example, respiratory failure requiring $B M V$ is more frequent than ventricular fibrillation requiring defibrillation, so $B M V$ is integrated in all scenarios. See Figure 2 for case sequencing of scenarios and embedded tasks within a two-hour RCDP session for PALS skills. Unlike other curricula described in the literature that provide little specific detail about how feedback and debriefing occur in simulation, ${ }^{11}$ the RCDP methodology provides a context (cases 
sequenced based on increasing difficulty) for rapid cycles of deliberate practice with clear strategies for structuring feedback and debriefing within the individual cases.

During RCDP, the educator observed the performance and paused the learners at various times to give directive feedback ${ }^{19}$ on exactly what aspect of the performance went well or what needed improvement. During the microdebriefing, the educator focused on the issue that prompted the interruption by linking the observed performance with a brief rationale of why improvement was needed. For example, if the objective was minimizing pauses in compressions immediately prior to defibrillation, the educator stopped the scenario when the pause in compressions exceeded the standard (e.g., < 10 seconds). In this case, when compressions were paused for more than 10 seconds, the educator said "time out" or "let's pause," highlighted the breached standard, and provided a brief rationale regarding its importance. After the educator succinctly stated his/her observation, she gave explicit directions on what to do differently next time and why to complete the task properly. These brief, focused explanations (i.e., suggested team choreography or expert modeling of skills) were followed by additional practice attempts until learners performed the task correctly. See Box 1 for examples of educator comments during a microdebriefing.

Box 1 Examples of microdebriefing to promote reflection-in-action in RCDP, demonstrating educator pausing after a breached performance standard and an exemplary performance

\section{Breached standard}

(pause before defibrillation $<10$ seconds)

"Okay guys, we just paused compressions for 15 seconds before the defibrillation, and remember the AHA standard is no pause longer than 10 seconds AND Dana Edelson's paper [referenced by E.A.H. for feedback] demonstrated that each 5-second decrease in preshock pause is associated with a $86 \%$ increase in defibrillation success rate ... so let me give you some strategies on how to shrink that pause, and then we will rewind you and can try again."

\section{Exemplary performance}

(closed-loop communication)

"Let's pause. I would like to highlight that beautiful use of closed-loop communication. I noticed our leader caught herself saying, 'Can "someone" tell me the dose of amiodarone?' and after the second time, you looked around the room and touched the pharmacist on his shoulder and said, 'Mike, can you tell me the dose of amiodarone?' and Mike looked up and said, 'Yes, amiodarone is $5 \mathrm{mg} / \mathrm{kg}$, I will prepare the drug and let you know when it is ready.' That was fabulous ... do you want to add anything?"

Abbreviations: RCDP indicates rapid cycle deliberate practice ${ }^{32}$; AHA, American Heart Association.

During initial iterations of a scenario (e.g., respiratory failure in which BMV is difficult, requiring advanced maneuvers such as two-person technique), learners engaged in a period of uninterrupted practice before a microdebriefing with performance feedback. As the teaching session progressed, when learners repeated an error or substandard performance that had been addressed previously (e.g., proper use of two-person technique if $\mathrm{BMV}$ is difficult), the educator paused again to provide specific, direct 
feedback, "rewound" the scenario 10 seconds, and resumed the scenario to allow repeated practice on the troublesome aspect of the task. The scenario did not progress to the next phase until learners demonstrated proficiency at that task (see Figure 2). Breaches in performance standards applied for individuals (e.g., the person performing $\mathrm{BMV}$ ) or the team as a whole (e.g., team choreography to place backboard under patient with minimal interruptions in chest compressions). For instances of inadequate performance despite multiple cycles of directive feedback, the educator spent more time during a microdebriefing exploring the learner's understanding of the issue at hand. The goal was for learners to experience successful application of key knowledge and essential skills as they worked toward meeting performance standards.

Figure 2 Case sequencing of scenarios and embedded tasks within a two-hour rapid cycle deliberate practice session for pediatric advanced life support skills.

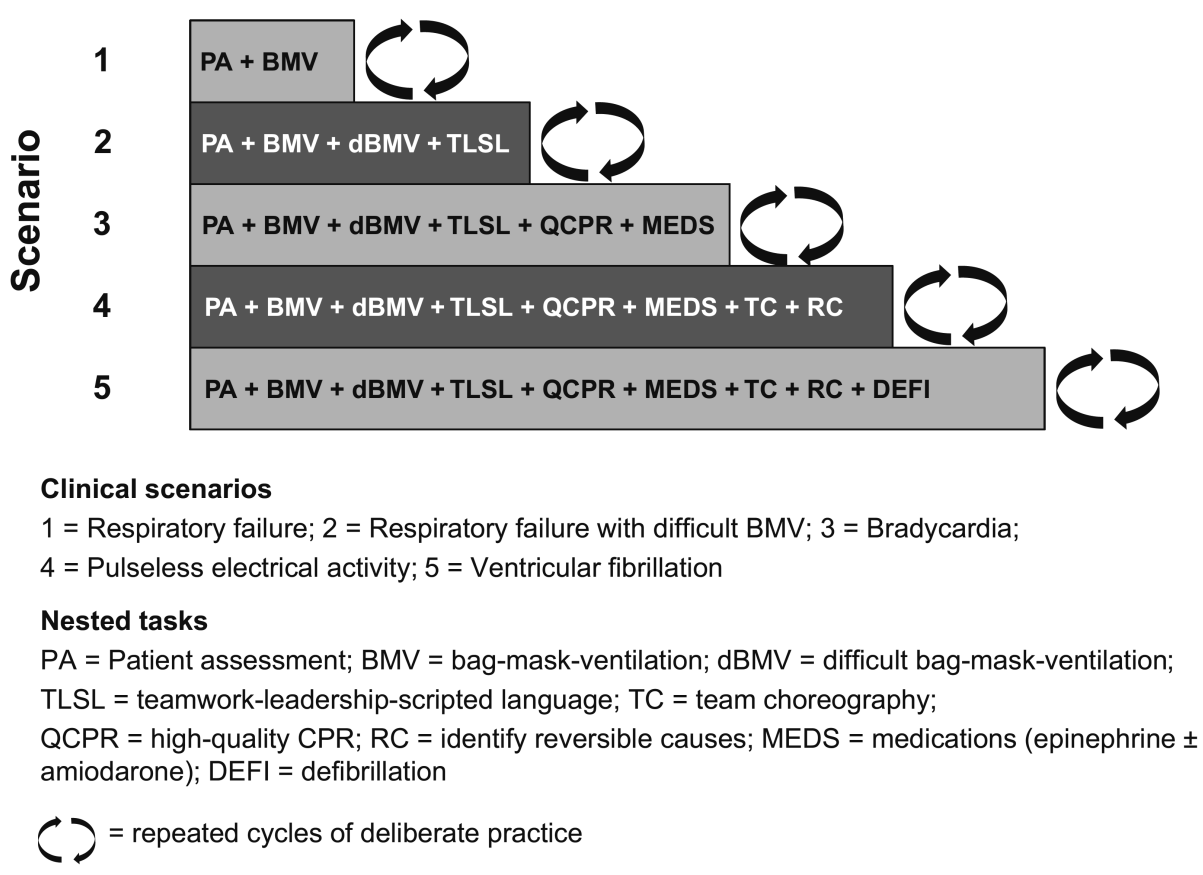

As learners progressed through the scenarios and achieved target performance on component skills, the simulated patient responded positively to correct interventions (e.g., chest rise with $\mathrm{BMV}$ ), which reinforced desired behaviors through task-related feedback. RCDP appears particularly well suited for simulation-based sessions devoted to individual and team-based resuscitation skills with established evidence-based guidelines or expert opinion that forms the basis for clear performance standards. ${ }^{35}$ See Supplemental Digital List 1 at http://links.Iww.com/ACADMED/A302 for examples of essential resuscitation skills amenable to a simulation-based RCDP approach (included as Appendix at the end of Chapter 4). 


\section{Using performance data as sources of feedback for deliberate practice}

Sources and types of data available can accurately determine whether learners achieve performance standards. These data need to be objective, quantifiable, and presented so that learners can understand them. Educators can use data from simulations as a mechanism for setting expectations, assessing performance, and providing meaningful feedback to help learners monitor and improve their performance. For example, patient simulators log important detail about the quality of chest compressions such as depth, rate, and recoil. ${ }^{35-38}$

Other sources of data include peer observation and video performance review. Peer observation using checklists and video performance review can capture key tasks and promote collaborative learning. Use of checklist-based measurement requires skilled observers; it can be error prone with the potential of influencing feedback accuracy. For summative assessment of performance, rater training and calibration are essential. ${ }^{39,40}$ Use of these strategies for mastery learning should be balanced with time and rater training considerations. In mastery learning models, outcome measurement is an essential component to determine whether learners have achieved mastery standards or whether they require additional practice. ${ }^{2}$

\section{Discussion: Key Lessons}

Deliberate practice promotes performance improvement. ${ }^{3,35}$ This article fills a gap in the literature by describing in detail how various feedback and debriefing strategies support mastery learning and deliberate practice in health care simulation. Insights offered here also raise additional questions that can guide future inquiry.

We glean several key lessons for structuring feedback and debriefing from the description of the deliberate practice interventions for ALS skills by Wayne et $\mathrm{al}^{3}$ and Hunt et $\mathrm{al}^{35}$ given the demonstrated learning benefits in terms of resuscitation skills (see Table 1). The first lesson relates to the notion of training for success. In both studies, resident physicians achieved proficiency in the predefined tasks. According to self-determination theory, promoting feelings of competence augments internal motivation ${ }^{41}$; during deliberate practice, learners see themselves improve and welcome the feedback that makes this possible. This stands in stark contrast to more traditional models of simulation-based education in which a simulation is followed by a debriefing; learners may discuss how to improve in the postevent debriefing, but then either the session ends or learners move on to a different case. Even a single opportunity to repeat the scenario shows benefit. ${ }^{42}$ The interventions described by Wayne et al and Hunt et al afforded learners many opportunities to engage in deliberate practice. 
The second lesson relates to the role of reflection, both in-action or on-action. ${ }^{20}$ The "pause and discuss" or microdebriefing strategy used in RCDP ${ }^{35}$ relies on the principle of reflection-on-action ${ }^{20}$ like more traditional debriefing strategies. ${ }^{12,13}$ Recent work has highlighted the advantage of terminal (after the event) over concurrent (immediately during the event) feedback, ${ }^{11,31}$ although further clarification would be helpful because in the RCDP model, microdebriefings with immediate feedback for repeat errors was a key strategy. The facilitation approach exemplified by VJS in coaching the resident team leaders through a mixture of reflective questions ("What are you seeing?" "What are you thinking?") and targeted feedback during ongoing resuscitation efforts leverages reflection-in-action. ${ }^{20}$ To our knowledge, this notion of a "coach" supporting team leaders during simulated resuscitations is not widespread and represents a novel and potentially powerful educational intervention. While coaching the team leader during the scenario, VJS offered scaffolding that was slowly withdrawn with successive rounds of deliberate practice. The relative impacts of reflection-inaction prompted by facilitative "within-event microdebriefing" and scaffolded learning during simulation scenarios demands further study-for instance, frequency and duration of microdebriefings, timing and content, adaptations based on learner training level, and learning objectives suited for this approach, educator training, and transfer of these strategies to supervision of trainees in clinical practice.

A third key lesson is the role of peer-assisted learning in the ACLS study, with team leaders providing performance feedback to other residents in scenarios when appropriate. It is notable that in both $\mathrm{ACLS}^{3}$ and $\mathrm{PALS}^{35}$ studies, all learners were resident physicians. Evidence suggests that matched peers or "status equals" are necessary for effective peer-assisted learning, ${ }^{43}$ although within-team debriefings after simulations for interprofessional teams show potential as well. ${ }^{44}$ Social comparison among peers is also an added factor. ${ }^{45,46}$ Particularly in the study of ACLS skills, ${ }^{3}$ all residents took their turns as leaders and team members; they experienced both giving and receiving feedback and likely felt pressure to "measure up" in comparison to peers, which may have facilitated learning.

Finally, identifying outcome measures and reliable data sources, such as time-to-event analysis, offers objective performance feedback, ensuring that feedback, microdebriefing, and postevent debriefing are anchored in accurate observations. Recent work demonstrates the power of objective performance feedback after actual resuscitation to improve patient outcomes. ${ }^{47}$ When appropriate, time-to-event analysis provides performance indicators that assess individual and team functioning for complex skills. Educators should survey the breadth of data sources relevant to the predetermined learning objectives and identify those that are best suited for integration into deliberate practice curricula. 
Although we explicate much needed detail on how to design and implement educational interventions based on deliberate practice using ACLS and PALS as case studies, we realize that other feedback and debriefing approaches may be more suitable for other domains of clinical performance. For example, postevent debriefing ${ }^{12,13,16}$ may have clear advantages when intended learning outcomes involve complex clinical decision making or social interactions. This may be particularly true when no clear performance standards exist and multiple strategies are appropriate; ${ }^{48}$ more traditional forms of postevent debriefing are likely still of great benefit. The relative merits of various approaches to feedback, microdebriefing, and debriefing speak to a need for educators to strive for a blended approach. ${ }^{49}$ See Table 2 for a comparison of giving feedback, microdebriefing, and postevent debriefing.

Although mastery learning may be limited in clinical environments because of patient safety concerns, some components of structured feedback and debriefing presented here may apply to clinical practice. In particular, the form of microdebriefing during active clinical management, much as when a supervising physician might stand behind a trainee physician who is learning to lead a resuscitation, may provide useful scaffolding. Further research will characterize success factors that assist clinical supervisors in managing their dual roles as educators and patient care providers and the benefit for trainees of such a microdebriefing strategy.

Although Wayne et $\mathrm{al}^{3}$ and Hunt et $\mathrm{al}^{35}$ ascribe the benefit of their educational intervention to deliberate practice, future research needs to clarify what elements of deliberate practice are most important, and which feedback characteristics such as source/timing and debriefing approach have the most impact for specific learner groups and learning objectives. To what extent reflection-in-action strategies such as withinevent microdebriefing and peer-assisted learning augment deliberate practice is not clear. What is clear is that the deliberate-practice-based mastery learning intervention for ACLS skills by Wayne et al $^{3}$ was powerful, leading to long-term skill retention ${ }^{50}$ and enhanced performance when trained residents led code teams during actual cardiac arrest medical team responses. ${ }^{51,52}$

Effortful practice has been shown to promote learning, ${ }^{53}$ making feedback frequency, content, and timing in deliberate practice models related to particular skills an interesting area of inquiry. Also, most published work on mastery learning and the deliberate practice approach includes resident physicians. Studies are ongoing to explore whether the RCDP approach will be effective with other learner groups (e.g., practicing nurses, medical students).

We hope this article offers health care educators the stimulus to reevaluate their educational practice and consider the full spectrum of debriefing strategies, including 


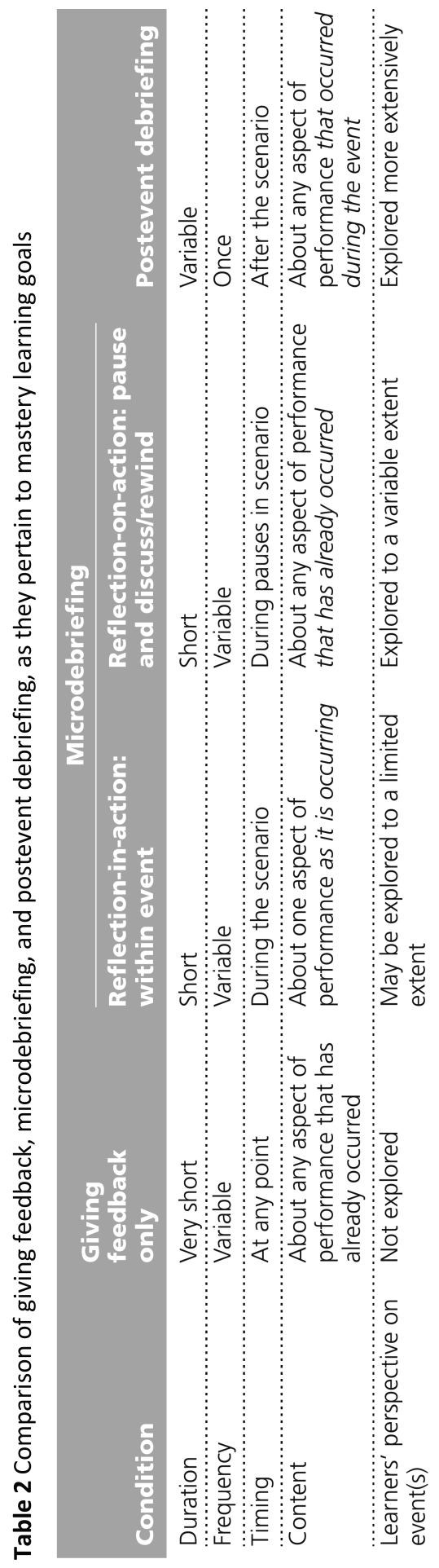


both microdebriefing and postevent debriefing as tools to reach educational objectives. Dissemination of innovation in health care is challenging, ${ }^{54}$ and our hope is that this report will contribute to the adoption of deliberate practice and mastery learning models in health care education.

\section{References}

1. Cook DA, Brydges R, Zendejas B, Hamstra SJ, Hatala R. Mastery learning for health professionals using technology-enhanced simulation: A systematic review and meta-analysis. Acad Med. 2013;88:1178-1186.

2. McGaghie WC, Issenberg SB, Barsuk JH, Wayne DB. A critical review of simulation-based mastery learning with translational outcomes. Med Educ. 2014;48:375-385.

3. Wayne DB, Butter J, Siddall VJ, et al. Mastery learning of advanced cardiac life support skills by internal medicine residents using simulation technology and deliberate practice. J Gen Intern Med. 2006;21:251256.

4. Barsuk JH, McGaghie WC, Cohen ER, Balachandran JS, Wayne DB. Use of simulation-based mastery learning to improve the quality of central venous catheter placement in a medical intensive care unit. J Hosp Med. 2009;4:397-403.

5. Cohen ER, Barsuk JH, Moazed F, et al. Making July safer: Simulation-based mastery learning during intern boot camp. Acad Med. 2013;88:233-239.

6. Frank JR, Snell LS, ten Cate O, et al. Competency-based medical education: Theory to practice. Med Teach. 2010;32:638-645.

7. McGaghie WC, Siddall VJ, Mazmanian PE, Myers JAmerican College of Chest Physicians Health and Science Policy Committee. Lessons for continuing medical education from simulation research in undergraduate and graduate medical education: Effectiveness of continuing medical education: American College of Chest Physicians Evidence-Based Educational Guidelines. Chest. 2009;135(3 suppl):S62-S68.

8. Ericsson KA, Krampe RT, Tesch-Romer C. The role of deliberate practice in the acquisition of expert performance. Psychol Rev. 1993;100:363-406.

9. Ericsson KA. Deliberate practice and acquisition of expert performance: A general overview. Acad Emerg Med. 2008;15:988-994.

10. van de Ridder JM, Stokking KM, McGaghie WC, ten Cate OT. What is feedback in clinical education? Med Educ. 2008;42:189-197.

11. Cheng A, Eppich W, Grant V, Sherbino J, Zendejas B, Cook DA. Debriefing for technology-enhanced simulation: A systematic review and meta-analysis. Med Educ. 2014;48:657-666.

12. Steinwachs B. How to facilitate a debriefing. Simul Gaming. 1992;23:186-195.

13. Zigmont JJ, Kappus $\sqcup$, Sudikoff SN. The 3D model of debriefing: Defusing, discovering, and deepening. Semin Perinatol. 2011;35:52-58.

14. Rudolph JW, Simon R, Dufresne RL, Raemer DB. There's no such thing as "nonjudgmental" debriefing: A theory and method for debriefing with good judgment. Simul Healthc. 2006;1:49-55.

15. Rudolph JW, Simon R, Raemer DB, Eppich WJ. Debriefing as formative assessment: Closing performance gaps in medical education. Acad Emerg Med. 2008;15:1010-1016.

16. Kolbe $M$, Weiss $M$, Grote $G$, et al. TeamGAINS: A tool for structured debriefings for simulation-based team trainings. BMJ Qual Saf. 2013;22:541-553.

17. Eppich WJ, O'Connor L, Adler MD, Forrest K, McKimm J, Edgar S. Providing effective simulation activities. Essential Simulation in Clinical Education. Chichester, UK Wiley-Blackwell; 2013:213-234.

18. Flanagan B, Riley RH. Debriefing: Theory and techniques. A Manual of Simulation in Healthcare. 2008 New York, NY Oxford University Press USA:155-170.

19. Archer JC. State of the science in health professional education: Effective feedback. Med Educ. 2010;44:101-108.

20. Schön D The Reflective Practitioner. New York, NY Basic Books;1983. 


\section{Chapter 4}

21. Ahmed M, Sevdalis N, Paige J, Paragi-Gururaja R, Nestel D, Arora S. Identifying best practice guidelines for debriefing in surgery: A tri-continental study. Am J Surg. 2012;203:523-529.

22. Brett-Fleegler M, Rudolph J, Eppich W, et al. Debriefing assessment for simulation in healthcare: Development and psychometric properties. Simul Healthc. 2012;7:288-294.

23. Arora S, Ahmed M, Paige J, et al. Objective structured assessment of debriefing: Bringing science to the art of debriefing in surgery. Ann Surg. 2012;256:982-988.

24. McGaghie WC, Issenberg SB, Petrusa ER, Scalese RJ. A critical review of simulation-based medical education research: 2003-2009. Med Educ. 2010;44:50-63.

25. McGaghie WC, Issenberg SB, Cohen ER, Barsuk JH, Wayne DB. Does simulation-based medical education with deliberate practice yield better results than traditional clinical education? A meta-analytic comparative review of the evidence. Acad Med. 2011;86:706-711.

26. Molloy E, Boud D. Changing conceptions of feedback. Feedback in Higher and Professional Education: Undertanding It and Doing It Well. London, UK Routledge; 2013:11-33.

27. Kern DE, Thomas PA, Hughes MT Curriculum Development for Medical Education: A Six-Step Approach. 2nd ed Baltimore, Md Johns Hopkins University Press; 2009.

28. Schmutz J, Eppich WJ, Hoffmann F, Heimberg E, Manser T. Five steps to develop checklists for evaluating clinical performance: An integrative approach. Acad Med. 2014;89:996-1005.

29. Wayne DB, Fudala MJ, Butter J, et al. Comparison of two standard-setting methods for advanced cardiac life support training. Acad Med. 2005;80(10 suppl):S63-S66.

30. Chiniara G, Cole G, Brisbin K, et al. Canadian Network for Simulation in Healthcare, Guidelines Working Group. Simulation in healthcare: A taxonomy and a conceptual framework for instructional design and media selection. Med Teach. 2013;35:e1380-e1395.

31. Hatala R, Cook DA, Zendejas B, Hamstra SJ, Brydges R. Feedback for simulation-based procedural skills training: A meta-analysis and critical narrative synthesis. Adv Health Sci Educ Theory Pract. 2014;19:251272.

32. Rudolph JW, Raemer DB, Simon R. Establishing a safe container for learning in simulation: The role of the presimulation briefing. Simul Healthc. 2014;9:339-349.

33. Edmondson AC. Psychological safety and learning behavior in work teams. Adm Sci Q. 1999;44:350-383.

34. Edmondson AC. The competitive imperative of learning. Harv Bus Rev. 2008;86:60-67, 160.

35. Hunt EA, Duval-Arnould JM, Nelson-McMillan KL, et al. Pediatric resident resuscitation skills improve after "rapid cycle deliberate practice" training. Resuscitation. 2014;85:945-951.

36. Berg RA, Hemphill R, Abella BS, et al. Part 5: Adult basic life support: 2010 American Heart Association Guidelines for Cardiopulmonary Resuscitation and Emergency Cardiovascular Care. Circulation. 2010;122(18 suppl 3):S685-S705.

37. Kleinman ME, Chameides L, Schexnayder SM, et al. Part 14: Pediatric advanced life support: 2010 American Heart Association guidelines for cardiopulmonary resuscitation and emergency cardiovascular care. Circulation. 2010;122(18 suppl 3):S876-S908.

38. Mancini ME, Soar J, Bhanji F, et al.Education, Implementation, and Teams Chapter Collaborators. Part 12: Education, implementation, and teams: 2010 international consensus on cardiopulmonary resuscitation and emergency cardiovascular care science with treatment recommendations. Circulation. 2010;122(16 suppl 2):S539-S581.

39. Feldman M, Lazzara EH, Vanderbilt AA, DiazGranados D. Rater training to support high-stakes simulationbased assessments. J Contin Educ Health Prof. 2012;32:279-286.

40. Eppich W, Nannicelli AP, Seivert NP, et al. A rater training protocol to assess team performance. J Contin Educ Health Prof. 2015;35:83-90.

41. Ten Cate TJ, Kusurkar RA, Williams GC. How self-determination theory can assist our understanding of the teaching and learning processes in medical education. AMEE guide no. 59. Med Teach. 2011;33:961-973.

42. Auerbach M, Kessler D, Foltin JC. Repetitive pediatric simulation resuscitation training. Pediatr Emerg Care. 2011;27:29-31.

43. Topping KJ. Trends in peer learning. Educ Psychol. 2005;25:631-645.

44. Boet S, Bould MD, Sharma B, et al. Within-team debriefing versus instructor-led debriefing for simulationbased education: A randomized controlled trial. Ann Surg. 2013;258:53-58. 
45. Raat J, Kuks J, Cohen-Schotanus J. Learning in clinical practice: Stimulating and discouraging response to social comparison. Med Teach. 2010;32:899-904.

46. Bleakley A. Social comparison, peer learning and democracy in medical education. Med Teach. 2010;32:878-879.

47. Wolfe $\mathrm{H}$, Zebuhr $\mathrm{C}$, Topjian AA, et al. Interdisciplinary ICU cardiac arrest debriefing improves survival outcomes. Crit Care Med. 2014;42:1688-1695.

48. Fanning RM, Gaba DMGaba DM, Fish KJ, Howard SK, Burden AR. Debriefing. Crisis Management in Anesthesiology. 20152nd ed. Philadelphia, Pa Elsevier Saunders:65-78.

49. Eppich W, Cheng A. Promoting excellence and reflective learning in simulation (PEARLS): Development and rationale for a blended approach to health care simulation debriefing. Simul Healthc. 2015;10:106115.

50. Wayne DB, Siddall VJ, Butter J, et al. A longitudinal study of internal medicine residents' retention of advanced cardiac life support skills. Acad Med. 2006;81(10 suppl):S9-S12.

51. Wayne DB, Didwania A, Feinglass J, Fudala MJ, Barsuk JH, McGaghie WC. Simulation-based education improves quality of care during cardiac arrest team responses at an academic teaching hospital: A casecontrol study. Chest. 2008;133:56-61.

52. Didwania A, McGaghie WC, Cohen ER, et al. Progress toward improving the quality of cardiac arrest medical team responses at an academic teaching hospital. J Grad Med Educ. 2011;3:211-216.

53. Bjork RAMetcalfe J, Shinamura A. Memory and metamemory considerations in the training of human beings. Metacognition: Knowing About Knowing. Cambridge, Mass MIT Press;1994:185-205.

54. Berwick DM. Disseminating innovations in health care. JAMA. 2003;289:1969-1975. 


\section{Chapter 4}

Appendix Examples of resuscitation skills amenable to a simulation-based Rapid Cycle Deliberate Practice

- Assess patient, identify pulselessness and initiate chest compressions in $\leq 10$ seconds

- Demonstrate team choreography to place backboard under patient correctly but to minimize pause in chest compressions to $\leq 10$ seconds (ideally $\leq 5$ seconds)

- Demonstrate team choreography for switching chest compressors every 2 minutes while minimizing pauses in compressions

- Defibrillate patients with shockable rhythm within 2 minutes

- Minimize peri-shock pauses surrounding defibrillation to $\leq 10$ seconds

- Modify chest compressions to optimize quality and maintain end tidal carbon dioxide $\geq 20$ $\mathrm{mm} \mathrm{Hg}$ and diastolic blood pressure $\geq 25 \mathrm{~mm} \mathrm{Hg}$ (depends on simulation technology used)

- Team leader explicitly shares mental model so that all team members know what life support algorithm applies for the patient, what reversible causes of the arrest are being considered and how each reversible cause is being excluded or addressed.

- Use of closed loop communication when achieving the above goals 


\section{CHAPTER 5}

\section{A Rater Training Protocol to Assess Team Performance}

Published as: Eppich W, Nannicelli AP, Seivert NP, et al. A rater training protocol to assess team performance. Journal of Continuing Education in the Health Professions. 2015;35(2):83-90. 


\section{Abstract}

Introduction: Simulation-based methodologies are increasingly used to assess teamwork and communication skills and provide team training. Formative feedback regarding team performance is an essential component. While effective use of simulation for assessment or training requires accurate rating of team performance, examples of rater-training programs in health care are scarce. We describe our rater training program and report interrater reliability during phases of training and independent rating.

Methods: We selected an assessment tool shown to yield valid and reliable results and developed a rater training protocol with an accompanying rater training handbook. The rater training program was modeled after previously described high-stakes assessments in the setting of 3 facilitated training sessions. Adjacent agreement was used to measure interrater reliability between raters.

Results: Nine raters with a background in health care and/or patient safety evaluated team performance of 42 in-situ simulations using post-hoc video review. Adjacent agreement increased from the second training session (83.6\%) to the third training session (85.6\%) when evaluating the same video segments. Adjacent agreement for the rating of overall team performance was $78.3 \%$, which was added for the third training session. Adjacent agreement was $97 \% 4$ weeks posttraining and $90.6 \%$ at the end of independent rating of all simulation videos.

Discussion: Rater training is an important element in team performance assessment and providing examples of rater training programs is essential. Articulating key rating anchors promotes adequate interrater reliability. In addition, using adjacent agreement as a measure allows differentiation between high- and low-performing teams on video review. 


\section{Introduction}

Advances in patient safety highlight the critical role of teamwork and communication within interprofessional health care teams for safe and effective patient care. ${ }^{1-3}$ Simulation-based methodologies are increasingly used to assess teamwork and communication skills and provide team training by presenting formative team performance feedback. ${ }^{4,5}$ However, effective use of simulation for training requires accurate observational team performance assessment, either in real time or through post-hoc video review. To achieve high reliability when assessing teamwork skills, two key elements are required: (1) selection of a psychometrically sound rating tool and (2) robust rater training for use of the tool. ${ }^{5-8}$ Although the importance of rater training has been established and there are training strategies to reduce errors, increase rating accuracy, and improve validity of observational performance assessments, ${ }^{5,7,9,10}$ detailed examples of rater training programs are lacking in the health care education and training literature. ${ }^{11}$

We provide a robust description of a rater training program to assess and rate teamwork skills and behaviors, team communication, and overall team performance through posthoc video review. The training was necessary in order to rate team performance in 42 in-situ simulation videos previously conducted for a funded research project. For this project, in situ simulations took place in actual hospital environments where interprofessional health care teams (eg, attending physician, bedside nurse) perform their clinical duties with access to clinical systems and processes (e.g., electronic health record, laboratory results, medical images). ${ }^{12}$

The objectives of the overall in-situ simulation project were to (1) develop risk-informed simulation scenarios, (2) conduct risk-informed in-situ simulations using the scenarios, and (3) evaluate the impact of in-situ simulation and subsequent video-assisted debriefing regarding teamwork skills as an intervention to improve health care teamwork. The simulation scenarios lasted approximately 45 minutes and focused on emergency transfers of pediatric patients from a referring emergency department (ED) to a receiving pediatric ED or pediatric intensive care unit (PICU). A multidisciplinary team of clinicians from participating hospitals designed the simulation scenarios using the AHRQ's Team-STEPPS training model as a framework for scenario development and to guide formative debriefing. ${ }^{13}$ The project was conducted at 5 hospitals with comprehensive pediatric services in the greater area of Chicago, Illinois. Institutional Review Board approval was obtained at each participating site.

The specific goals of this article are to (1) describe the development and implementation of a rater training program using an observational assessment tool to rate team performance through post-hoc video review, (2) report interrater reliability during phases of training and subsequent independent rating, and (3) discuss the role of reliability in rating team performance through observational assessments.

\section{Methods}

The necessary components to develop and implement a robust rater training program to rate team performance through post-hoc video review include (1) tool selection, (2) 
development of a rater training handbook, (3) rater selection, (4) rater training sessions for rater recalibration, (5) independent rating pilot test, (6) random video assignment and independent rating, and (7) assessment of interrater reliability at key time points. We now provide further detail on each of these components.

\section{Tool Selection}

First, the research team searched for observational tools to assess team performance. Multiple approaches were used to identify relevant existing tools, including (1) keyword searches in PubMed and Google Scholar using the following terms and all possible combinations: health care, teams, teamwork, assessment, clinical teamwork, and simulation; (2) review of the identified peer-reviewed literature for additional references of team assessment tools; and (3) direct e-mail and verbal communications with established simulation and teamwork experts, including lead authors on pertinent teamwork publications and a simulation expert with a clinical background, to ensure that no relevant tools were excluded.

Next, the research team identified eight team performance assessment tools that were potentially applicable to the project and considered for use (Table 1). Although TeamSTEPPS was used as a framework for scenario development and formative participant feedback, the assessment tool provided with the curriculum-the Team Performance Observation Tool (TPOT)-had not been evaluated psychometrically at the time of our study (HB King, personal communication, 2012) and thus was not considered.

Finally, the Team Emergency Assessment Measure (TEAM) ${ }^{14}$ was selected for several key reasons: (1) prior research showed that the tool yielded adequately valid and reliable results, (2) ease of use, and (3) contextual relevance to the project. Further, Cooper et al describe that the TEAM was created with consideration of other similar, previously published team performance assessment measures. ${ }^{14-16}$

Among identified tools with reported psychometric data, the TEAM had a modest number of items (12) suggesting relative ease of use. Although subsequent work has demonstrated validity and reliability of data generated through use of the TEAM, ${ }^{17}$ an observational tool is only as reliable and valid as the observer using it. 5,18 Therefore, rater training is a key component of establishing assessment reliability. However, none of the identified tools included explicit details of a rater training program to apply the tool, including the peer-reviewed publication about the TEAM. ${ }^{14}$ This lack of well described rater training models in the medical education and training literature exists despite recognition of the importance of strong interrater reliability for assessments. ${ }^{5,11}$ 
Table 1 Team performance assessment tools

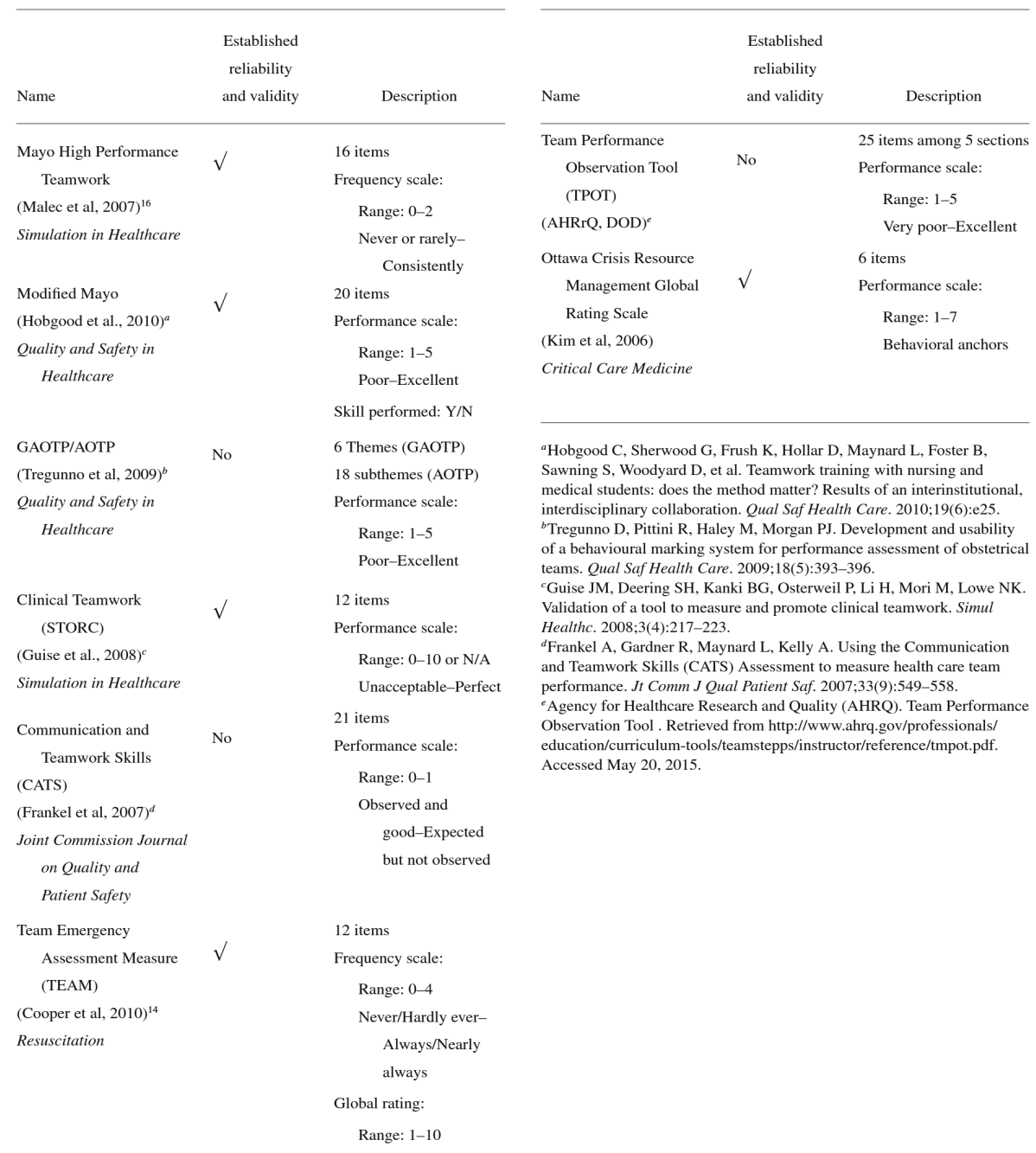

\section{Development and Implementation of a Rater Training Program}

To approach rater training, we designed and implemented a robust training program modeled after previously described high-stakes assessments. ${ }^{5}$ As opposed to conducting 1 training in the form of a single-day workshop, the rater training and recalibration occurred during 3 sessions over 16 weeks facilitated by a clinician educator with expertise in health care simulation, debriefing, and assessment. ${ }^{6,8}$ Multiple rater training methodologies were incorporated to optimize reliability, and 4 core training strategies served as the foundation of the program: rater error training (RET), ${ }^{7}$ performance dimension training (PDT), ${ }^{5-7}$ frame-of-reference training (FOR), ${ }^{5,7,19}$ and behavioral observation training (BOT)..$^{5,7}$ Since these strategies 
have been shown to improve raters' accuracy, ${ }^{5}$ we integrated them throughout the training in the form of (1) a didactic review of key team and teamwork concepts to establish a common understanding of terms; (2) a review and demonstration of common rating pitfalls to avoid; (3) a review of the basics of rating performance, including the TEAM and the relationship of each item to TeamSTEPPS principles; and (4) 3 rounds of rating practice wherein each rater-in-training used the TEAM to independently rate the same videotaped simulation, followed by a facilitated discussion of discrepancies in rating scores (TABLE 2).

Table 2 Components of rater training for assessing team performance

\section{Didactic Review}
(a) Key concepts of teams and teamwork
(b) Basics of rating performance
(c) Rating pitfalls

1 Round 1: Practice Rating (Example of poor performance)
(a) Group video review
(b) Independent rating
(c) Display of ratings
(d) Facilitated discussion focused on divergent rating scores

3 Round 2: Practice Rating (Example of excellent performance)
(a) Group video review
(b) Independent rating
(c) Display of ratings
(d) Facilitated discussion focused on divergent rating scores

4 Round 3: Practice Rating (Mixed performance)
(a) Group video review
(b) Independent rating
(c) Display of ratings
(d) Facilitated discussion focused on divergent rating scores

5 Additional rounds of independent, practice ratings as needed

\section{Development of a Rater Training Handbook}

In order to reduce the in-person training requirements and minimize training decay, we developed a rater training handbook to serve as a cognitive aid. The handbook (Appendix S1) includes behavioral anchors for each TEAM item to provide raters with specific, observable anchors at the extremes of the scoring range to provide a frame of reference. ${ }^{7,8,19}$ The anchors were primarily based on mapping TeamSTEPPS principles to TEAM items to illustrate the relationship with specific behavior anchors (Appendix S2). Additional handbook resources included pertinent teamwork definitions and team 
performance literature review, an outline of TeamSTEPPS principles, and review of common rater errors (eg, halo, leniency, central tendency and contrast effects). ${ }^{7}$

\section{Rater Selection}

Nine members of the multi-institutional research team participated in the rater training program. Raters' backgrounds include 5 pediatricians with general pediatric and subspecialty training, mostly in acute care fields; 3 pediatric nurses with work experience in research, emergency care, and general pediatrics, respectively; and 1 health services researcher with expertise in patient safety. The selected raters represented a convenience sample with a breadth of expertise in a variety of domains, including clinical practice and patient safety. These raters were drawn from the multiinstitutional research team. We included 1 non-clinician given her significant patient safety background; in other instances, a clinical background was a strict inclusion criterion.

\section{Rater Training}

To facilitate independent rating, a secure, password protected Web site was created to host the in-situ simulation videos and a Web-adapted version of the TEAM. Each in-situ simulation was divided into 3 predetermined "event sets," as shown in Table $3 .{ }^{20}$ All rounds of rating practice included a facilitated discussion of the similarities and differences in individual scores. If any training sessions were missed, raters were required to participate in a session via conference call with the training facilitator.

- Training Session 1. The first training session was an in-person meeting lasting nearly 4 hours and integrated the 4 core training strategies (i.e., RET, PDT, FOR, BOT). The session consisted of (1) a didactic review of the key concepts of teams and teamwork to help raters establish a common understanding, (2) a demonstration of common rating errors, (3) a review of the TEAM and of the relationship of each TEAM item to TeamSTEPPS principles, and (4) several rounds of practice rating. Raters independently rating 3 preselected videos that demonstrated examples of poor, mixed, and excellent team performance during emergent care situations using a paper-and-pencil version of the TEAM. The training facilitator then moderated a group discussion of the scores with special attention to items with less rating agreement. Raters whose score deviated substantially from the mean were asked to provide a rationale for their score ${ }^{5,21}$; a discussion ensued to resolve disagreements. Scores revealed inadequate interrater reliability, which was not formally assessed at this point.

- Training Session 2. All raters received the rater training handbook at the second session, which also lasted nearly 4 hours. The training facilitator led a 
review of handbook contents and encouraged raters to consult team performance behavioral anchors during rating. Rating practice consisted of trainees viewing and independently rating the same preselected videos of poor, mixed, and excellent teamwork from the previous session as well as 2 segments of a pilot simulation video that focused on patient evaluation (event sets 2 and 3). Independent ratings were documented using a paper-and-pencil version of the TEAM and also submitted via text message to Poll Everywhere* (http://www.polleverywhere.com), a free online polling software that provides instant display of scores for comparison and discussion of divergent ratings. Again, the training facilitator moderated a discussion of the scores focused on items with less rating agreement. The video from the pilot simulation was excluded from the analyses of the main study.

- Training Session 3. The third session was facilitated via a 2-hour webinar to accommodate rater availability. Prior to the session, each rater independently coded another segment of the pilot simulation video depicting patient deterioration and resuscitation, using a Web-adapted version of the TEAM. Rating scores were shared among the raters. The training facilitator focused the discussion on specific TEAM items with the greatest variability and divergence in scoring.

Table 3 Event set descriptions
Event set
General description of events

1

2

3

\author{
Patient transfer/handoff to ED or PICU team \\ Patient assessment \\ Patient deterioration and medical management
}

\section{Independent Rating: Pilot}

Prior to independent rating of all in-situ simulation videos, each rater was randomly assigned only 4 videos to rate over a 3-week period. Raters were encouraged to consult the rater training handbook when using the Web-based TEAM to rate (1) overall team performance and (2) each of the 3 event sets individually. Interrater agreement was determined to be adequate, and raters were assigned their remaining videos for rating.

\section{Assignment and Rating: All In-Situ Simulation Videos}

The remaining 42 in-situ simulation videos were then randomly assigned to 2 raters so that each rater received 9 or 10 videos for independent assessment. Raters were given 16 weeks to complete their ratings with an estimated total workload of 18 to 20 hours. 
Each rater used a unique identifier and password to access their assigned in-situ simulation videos and the web-adapted TEAM within a secure, password-protected server. Once logged in, raters were directed to a home page where they could monitor their progress and access their next assigned video. Raters were instructed to view each video in its entirety before rating. Raters could view the video as many times as needed and had the ability to change their ratings before submitting final scores. All scores were automatically recorded in an electronic database

\section{Data Analysis}

Given the relatively large number of raters $(N=9)$, the random assignment of videos, and the number of simulations $(N=42)$, adjacent agreement was selected as the measure of interrater reliability. ${ }^{22}$ Percent adjacent agreement is the percentage of times that 2 raters agree to within 1 unit of the score. Exact agreement of scores was also calculated. Ratings for each simulation's overall team performance and for the 3 individual event sets were determined by 2 independent raters and matched for each TEAM item in a nonrepeating, pairwise manner to calculate the percent of adjacent scores. Percent of adjacent agreement was determined at 4 time points:

1. Training Session 2: rating scores for event sets 2 and 3 of the pilot simulation;

2. Training Session 3: rating scores for event sets 2, 3, and overall team performance of the pilot simulation;

3. Four weeks posttraining: all rating scores of 8 randomly assigned simulation videos; and

4. At the conclusion of independent rating: rating scores of all 42 simulation videos.

\section{Results}

Table 4 shows the percentage of adjacent agreement and percentage of exact agreement of rating scores at the 4 previously described time points. Adjacent agreement increased from the second training session $(83.6 \%)$ to the third training session (85.6\%) when evaluating the same pilot video segments. Adjacent agreement for the rating of overall team performance was 78.3\%, which was added for the third training session. Four weeks posttraining, adjacent agreement was $97 \%$ and $90.6 \%$ at the end of all independent rating (42 simulation videos). These results indicate that raters maintained a consistently acceptable level of agreement during the 16 -week rating period after participating in the 3 -session training program. 
Chapter 5

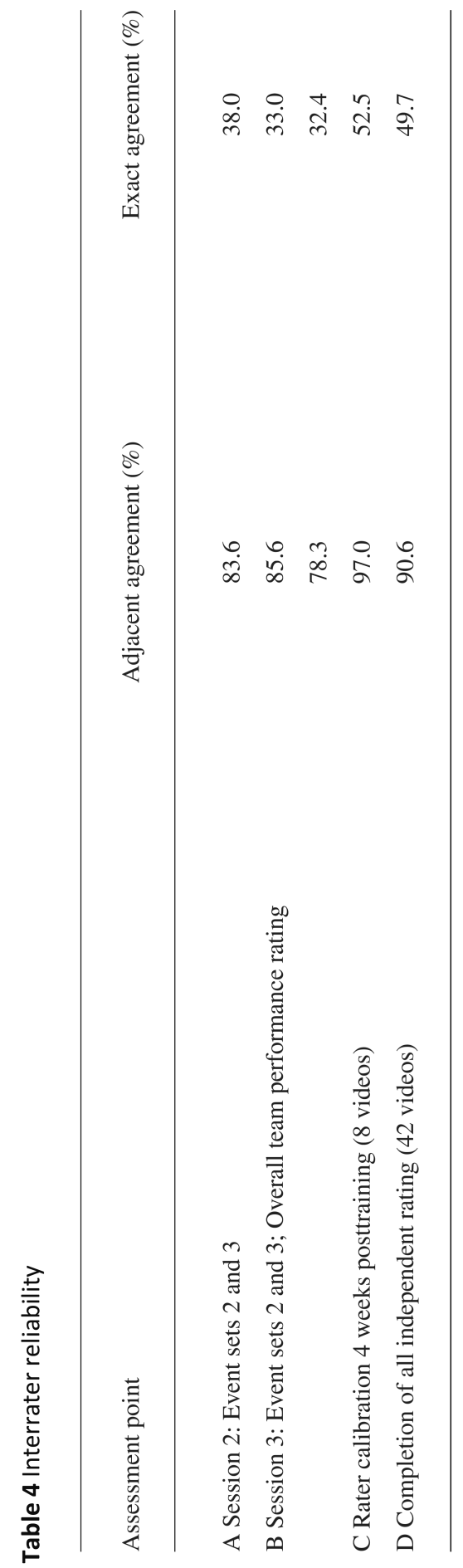




\section{Discussion}

Rating teamwork skills and behaviors, team communication, and overall team performance is difficult and requires specific knowledge and training. Use of a tool shown to yield valid and reliable data is a critical first step. However, rater training to use the tool in a calibrated manner is equally important to achieve reliability. The lack of well-defined models of rater training contributes to the paucity of rigorous assessment data about team performance. This article fills a void by providing a clear description of a rater training model and supporting results for training multiple raters.

We adhered to well-defined rater training strategies, provided a rater training handbook, and coordinated rating practice with facilitated feedback and discussion to train 9 raters to acceptable levels of agreement of at least $75 \%$ to approaching $90 \%{ }^{23}$ using adjacent agreement as the evaluation metric. Furthermore, the training strategies assured sustained, acceptable agreement among the raters over time. For specific event sets, raters achieved improved agreement between the second and third training sessions. Less agreement was achieved for rating of the overall team performance during the third session, which we attribute, in part, to a training artifact because raters were not adequately instructed to view the video in its entirety first.

Adjacent agreement increased for the independent ratings of the first 4 videos (pilot rating). We believe that this increase in agreement may be attributed to the facilitator's feedback and robust discussion during the third training session. In addition, due to the random assignment of videos, only 7 of the 9 raters participated in the third training session. Furthermore, high reliability (90\%) across all 9 raters was subsequently sustained for the independent coding of all videos.

Despite potential shortcomings, we used adjacent agreement to assess rating scores for several reasons. First, this method has been described as a means to assess interrater agreement and has been used by others to assess agreement of behaviorbased measures such as team skills, team communication, and overall team performance. ${ }^{22,24,25}$ Second, this metric was selected given the relatively large number of raters $(N=9)$ and since it relaxes criteria for exact agreement. ${ }^{26}$ Third, adjacent agreement is appropriate for multiple raters; 2 or more raters often need to be trained in order to rate multiple team performances (videos) in a timely manner. The relatively low number of points on the scale for nearly all items (5 points for TEAM items 1-11; 10 points for TEAM item 12) threatens finer discrimination among teams. ${ }^{26}$ However, the primary objective of the overall major study was to identify and describe characteristics of high- and low-performing teams; thus, we deemed that adjacent agreement was an acceptable measure interrater reliability. We also included a higher number of raters $(N=9)$, which likely reflects the approach that health care 
organizations will adopt to reduced individual rater workload, compared to the smaller group of 2 or 3 raters traditionally reported for research-based team assessments. As noted, the specific limitation of adjacent agreement relates to the potentially diminished discriminatory ability with a 5-point scale since we need to accept a possible higher level of error between raters. ${ }^{26}$ The fewer the number of items in the Likert scale, the greater the likelihood that agreement could be due to chance. Going forward, our research group would opt for rating with a 7-point or even 9-point scale to reduce the impact of this effect. In the current work, however, we believe that we were still able to differentiate between poorly and well-performing teams.

Since the TEAM was originally developed for expert clinicians, the mixed background of our raters may be a limitation. However, the raters for this project included both researchers and clinicians, which likely represents actual rating teams in health care organizations. Rater characteristics such as professional background have the potential to impact ratings; our convenience sample was to too small and the specialty background too varied to allow meaningful subgroup analysis of rater performance. Rater cognition and its influence on raters is an increasing area of focus for future work. ${ }^{27}$ Additionally, although the TEAM was designed to assess resuscitation events, not all event sets included in our analysis involved resuscitations. For those planning to implement a rater training program, several notable logistic considerations may drive the training process and depend on local resources as well as facilitator expertise and availability. Although costs and funding mechanisms (i.e., grant versus extramural funding) will vary, key components to develop the training program include training space with audiovisual capabilities and amenities, facilitator time, technological infrastructure and manpower to develop a web-based rating tool, and raters' time for training sessions and independent rating. Our approach to rater training and rating involved approximately 30 hours per rater.

In summary, the most important components of our rater training program were (1) facilitated, group discussion of ratings during each training session; (2) creation and use of the rater training handbook as a cognitive aid; and (3) measuring interrater reliability throughout the training and subsequent independent rating. During the training sessions, raters developed a shared understanding of teamwork skills and behaviors, team communication, and overall performance, as assessed by the TEAM, through facilitated discussion that allowed individuals to explain their scoring rationale. Discussion focused on items with the least agreement and contributed to raters' self-calibration. A second integral part of the training involved the development of the rater training handbook, which served as a reference guide during independent rating. Finally, it is important to track interrater reliability throughout training to determine when raters are ready to begin independent rating. It is not clear which of 
the outlined principles, if any, contributes the most to increasing and maintaining levels of agreement. Future research should focus on isolating each of these components to determine their effectiveness individually, and in combination with each other.

\section{Conclusions}

We provide a robust description of our rater training program for team performance in health care. This detailed example of a well-developed rater training program using 4 core rater training strategies (i.e., RET, PDT, FOR, BOT) can be replicated for training raters using other observational tools and instruments. For this program, key core rater training strategies were: (1) facilitated, group discussion of ratings of trigger videos with poor, intermediate and excellent performance during each training session; (2) creation and use of a rater training handbook to serve as a reference and cognitive aid; and (3) measuring interrater reliability throughout the training and subsequent independent rating.

\section{Lessons for practice}

Implementing a robust rater training program has several key components:

- Rating practice using trigger videos with examples of poor, intermediate and excellent performance with facilitated group discussions focused on divergent ratings. We recommend elimination of a paper-and pencil tool and adoption of an electronic database, as well as including a type of "polling" software for efficient sharing and visualization of raters' scores to promote discussion during training;

- Rating practice using trigger videos with examples of poor, intermediate and excellent performance with facilitated group discussions focused on divergent ratings. We recommend elimination of a paper-and pencil tool and adoption of an electronic database, as well as including a type of "polling" software for efficient sharing and visualization of raters' scores to promote discussion during training;

- Creation and use of a rater handbook to serve as a cognitive aid; and

- Measuring interrater reliability during training and subsequent independent rating to assess rater calibration.

\section{References}

1. Barrett J, Gifford C, Morey J, Risser D, Salisbury M. Enhancing patient safety through teamwork training. J Healthc Risk Manag. 2001;21:57-65.

2. Manser T. Teamwork and patient safety in dynamic domains of healthcare: a review of the literature. Acta Anaesthesiol Scand. 2009;53:143-151. 
3. Schmutz J, Manser T. Do team processes really have an effect on clinical performance? A systematic literature review. Br J Anaesth. 2013;110:529-54.

4. Rosen MA, Salas E, Wilson KA, King HB, Salisbury M, Augenstein JS, Robinson DW, Birnbach DJ. Measuring team performance in simulation-based training: adopting best practices for healthcare. Simul Healthc. 2008;3:33-41.

5. Feldman M, Lazzara EH, Vanderbilt AA, DiazGranados D. Rater training to support high-stakes simulationbased assessments. J Contin Educ Health Prof. 2012;32:279-286.

6. Evans LV, Morse JL, Hamann CJ, Osborne M, Lin Z, D'Onofrio G. The development of an independent rater system to assess residents' competence in invasive procedures. Acad Med. 2009;84:1135-1143.

7. Woehr DJ, Huffcutt Al. Rater training for performance appraisal: a quantitative review. J Occup Organ Psychol. 1994;67:189-205.

8. Yule S, Rowley D, Flin R, Maran N, Youngson G, Duncan J, Paterson-Brown S. Experience matters: comparing novice and expert ratings of non-technical skills using the NOTSS system. ANZ J Surg. 2009;79:154-160.

9. Borman WC. Format and training effects on rating accuracy and rater errors. J Appl Psychol. 1979;64:410421.

10. Castorr AH, Thompson KO, Ryan JW, Phillips CY, Prescott PA, Soeken KL. The process of rater training for observational instruments: implications for interrater reliability. Res Nurs Health. 1990;13:311-318.

11. Williams RG, Klamen DA, McGaghie WC. Special article: cognitive, social and environmental sources of bias in clinical performance ratings. Teach Learn Med.2003;15:270-292.

12. Rosen MA, Hunt EA, Pronovost PJ, Federowicz MA, Weaver SJ. In situ simulation in continuing education for the health care professions: a systematic review. J Contin Educ Health Prof. 2012;32:243-254.

13. TeamSTEPPS Home. Available at:http://teamstepps.ahrq.gov. Accessed April 13, 2014.

14. Cooper SJ, Cant RP, Porter J, Somers G, Kinsman L, Nestel D. Rating medical emergency teamwork performance: development of the Team Emergency Assessment Measure (TEAM). Resuscitation. 2010;81:446-452.

15. Kim J, Neilipovitz D, Cardinal P, Chiu M, Clinch J. A pilot study using high-fidelity simulation to formally evaluate performance in the resuscitation of critically ill patients: the University of Ottawa Critical Care Medicine, High-Fidelity Simulation, and Crisis Resource Management I Study. Crit Care Med. 2006;34:2167-2174.

16. Malec JF, Torsher LC, Dunn WF, Wiegmann DA, Arnold JJ, Brown DA, Phatak V. The Mayo High Performance Teamwork Scale: reliability and validity for evaluating key crew resource management skills. Simul Healthc. 2007;2:4-10.

17. Cooper SJ, Cant RP. Measuring non-technical skills of medical emergency teams: an update on the validity and reliability of the Team Emergency Assessment Measure (TEAM). Resuscitation. 2014;85(1):31-33.

18. Haidet KK, Tate J, Divirgilio-Thomas D, Kolanowski A, Happ MB. Methods to improve reliability of video recorded behavioral data. Res Nurs Health. 2009;32:465-474

19. Gorman CA, Rentsch JR. Evaluating frame-of-reference rater training effectiveness using performance schema accuracy. J Appl Psychol. 2009;94:1336-1344.

20. Rosen MA, Salas E, Wu TS, et al. Promoting teamwork: an eventbased approach to simulation-based teamwork training for emergency medicine residents. Acad Emerg Med. 2008;15:1190-1198.

21. Goldsmith T, Johnson P. Assessing and improving evaluation of aircrew performance. Int J Aviat Psychol. 2002;12:223-240.

22. Stemler SE. A comparison of consensus, consistency, and measurement approaches to estimating interrater reliability. Practical Assessment, Research \& Evaluation.2004;9:1-19. 
23. Graham M, Milanowski A, Miller J. Measuring and promoting interrater agreement of teacher and principal performance ratings. Washington DC: Center for Educator Compensation Reform. Available at:http://cecr.ed.gov/pdfs/InterÿRater.pdf. Accessed November 12, 2014.

24. Nicholson J, Konstantinidi E, Furniss F. On some psychometric properties of the questions about behavioral function (QABF) scale. Res Dev Disabil. 2006;27:337-352.

25. Peters-Scheffer N, Didden R, Green VA, Sigafoos J, Korzilius H, Pituch K, O'Reilly MF, Lancioni G. The behavior flexibility rating scale-revised (BFRS-R): factor analysis, internal consistency, interrater and intrarater reliability, and convergent validity. Res Dev Disabil. 2008;29:398-407.

26. Stemler SE, Tsai J. Best practices in interrater reliability: three common approaches. In: Osborne J, ed. Best Practices in Quantitative Methods. Thousand Oaks, CA: Sage; 2008:28-49.

27. Gingerich A, Kogan J, Yeates P, Govaerts M, Holmboe E. Seeing the "black box" differently from three research perspectives. Med Educ. 2014;48:1055-1068. 


\section{Appendix 1}

Rater Training Handbook: Behavioral Anchors; reprinted with permission

Leadership: It is assumed that the leader is either designated, has emerged, or is the most senior - if no leader emerges allocate a "0" to Questions $1 \& 2$.

1. Team leader let the team know what was expected of them through direction and command

\begin{tabular}{|l|l|}
\hline \multicolumn{1}{|c|}{ 0= Never/Hardly Ever } & \multicolumn{1}{c|}{ 4= Always/Nearly Always } \\
\hline $\begin{array}{l}\text { Team Leader: } \\
\text { - Not identifiable (i.e., multiple clinicians are } \\
\text { giving orders, unclear who is responsible for } \\
\text { medical decision making) }\end{array}$ & $\begin{array}{l}\text { Team Leader: } \\
\text { - Does not delegate roles or distribute } \\
\text { workload }\end{array}$ \\
$\begin{array}{l}\text { Does not articulate or share team goals } \\
\text { clearly (i.e., appears to assume the team } \\
\text { implicitly knows what he/she is thinking) } \\
\text { the Team Leader } \\
\text { Does not explicitly articulate or establish } \\
\text { priorities }\end{array}$ & $\begin{array}{l}\text { Clearly delegates roles and distributes } \\
\text { workload }\end{array}$ \\
\end{tabular}

2. The team leader maintained a global perspective

Prompts: Monitoring clinical procedures and the environment?

Remaining "hands off" as applicable? Appropriate delegation?

Team Leader:

- Does not share thought process

- Does not summarize or recap events for the team

- Assumes specific clinical tasks without explicitly handing off leadership; distracted or overly focused on tasks (i.e., intubation, chest compressions, performing patient care tasks, calling other clinicians on the phone)

- Appears to be unable to maintain an overview of situation (i.e., does not remain "hands off," does not step back, does not stand at the end of the bed or another location where global perspective is possible)

- Does not delegate tasks and distribute the workload to maintain a global perspective
Team Leader:

- Shares thought process; makes thinking transparent

- Summarizes and recaps events for the team

- Remains "hands-off" unless specific clinical expertise or correction is required

- Appears to maintain an overview of situation and steps back when situation allows (i.e., stands at the end of the bed or another location where global perspective is possible)

- Delegates tasks and distributes the workload to maintain a global perspective 
Team Work: Ratings should include the team as a whole (i.e., the leader and the team as a collective (to a greater or lesser extent)).

3. The team communicated effectively Prompts: Verbal, non-verbal and written forms of communication? \begin{tabular}{|l}
\hline 0= Never/Hardly Ever \\
\hline - Communication and/or instructions called out \\
into the air (i.e., not directed at a specific
\end{tabular} individual)

- Orders are complex and difficult to understand (e.g., several orders are given at once, non-standardized format, information missing)

- Communication is not purposeful (i.e., much extraneous talking, communication does not contribute to achieving team goals or priorities)

- No observable closed loop communication

- Confusion is not clarified

\section{4= Always/Nearly Always}

- Communication and/or instructions are clearly directed at a specific individual (e.g., use of name, eye contact)

- Orders are complete and given in a standardized or clear format

- Communication is clear, concise, easily understood, and purposeful (i.e., little/no extraneous talking, communication contributes to achieving team goals or priorities)

- Consistent use of closed loop communication (i.e., person receiving message confirms that it has been received and gives appropriate read-back)

- Any confusion is clarified

\section{The team worked together to complete tasks in a timely manner}

- Team appears inefficient and unorganized

- No evidence of coordination of activity

- Multiple people doing same task, leaving other tasks unattended

- People without assigned role are standing around

- Task saturation goes unnoticed by team members; team members do not offer support or help
- Team appears efficient and organized (i.e., a "well-oiled machine")

- Evidence of individual coordinating activity (e.g., distributing and delegating tasks)

- Work is distributed amongst the team

- Team members around the bed are engaged in purposeful activity (i.e., team members who are not needed are directed away from the bed)

- When task saturation of a team member is noted, other team members offer support or help

\section{The team acted with composure and control}

Prompts: Applicable emotions? Conflict management issues?

- Atmosphere appears chaotic

- Team members' voices are raised; yelling

- If conflict arises, there is long discussion rather than respectful and efficient resolution
- Atmosphere appears organized and controlled

- Team members exhibit calm tones of voices

- Alternating points of view are expressed and resolved respectfully and efficiently 
6. Team morale was positive Prompts: Appropriate support, confidence, spirit, optimism, determination?

- Team members seem unsure of themselves

- Team members do not assist one another with tasks

- Team members exhibit harsh and abrupt tone of voice

- Team members criticize each other

- Team appears confident

- Team members assist one another with tasks

- Team members exhibit collaborative, teamoriented behavior

- Team members express their viewpoints in a respectful way

\section{The team adapted to changing situations}

Prompts: Adaptation within the roles of their profession?

Situation changes: Patient deterioration? Team changes?

- Team members are not made aware of changing situation (i.e., when situation changes, no one reports the change to the group or it is noticed significantly late)

- Team members fixate on prior tasks and don't adapt to changing situation; new tasks remain unassigned

- In response to changing situations, team does not adapt or change focus to accommodate
- When situation changes, team member(s) report to the group in a timely fashion (i.e., change in patient hemodynamic stability, change of team roles, change of plan of care)

- Team roles change dynamically or may be reassigned within their profession because of change in team composition or to meet shifting priorities (e.g., $\mathrm{O}_{2}$ sats falling, significant rhythm change on monitor, drop in $\mathrm{BP}$, change in mental status)

- In response to changing situations, team adapts and changes focus to accommodate

\section{The team monitored and reassessed the situation}

- No verbalized reassessment of patient or situation

- Vital signs are not called out

- No team member appears to be or verbalizes who is watching monitor

- Team members do not exhibit situational awareness; do not verbalize changes to the team

- No evidence of shared mental model (i.e., no team members share thinking regarding the patient status)

\section{The team anticipated potential actions} Prompts: preparation of defibrillator, drugs, airway equipment?

- Team is playing "catch up" (i.e., significant delay in critical intervention because team was not prepared - e.g. airway equipment, meds, defibrillator)

- No team member verbalizes concern for potential changes in situation
- Team members continually reassess patient and trends or changes are verbalized (i.e., improvement or deterioration of patient status)

- Vital signs are called out

- Team members verbalize who is watching the monitor

- Team members exhibit situational awareness; verbalize changes to the team

- Evidence of shared mental model (i.e., team members share thinking regarding the patient status) 


\section{Task Management}

10. The team prioritised tasks

\begin{tabular}{|c|c|}
\hline $0=$ Never/Hardly Ever & 4= Always/Nearly Always \\
\hline $\begin{array}{l}\text { - Team is doing unnecessary activities } \\
\text { - Priorities are not clear } \\
\text { - Critical tasks remain undone or not } \\
\text { completed (e.g., } \mathrm{O}_{2} \text { sats are falling and team } \\
\text { member(s) remain focused on putting in a } \\
\text { Foley catheter) }\end{array}$ & $\begin{array}{l}\text { - Team is engaged in necessary activities } \\
\text { - Priorities are clear and team is focused on } \\
\text { tasks to achieve those goals } \\
\text { - Prioritized activity to care for the patient to } \\
\text { achieve value-added outcomes }\end{array}$ \\
\hline
\end{tabular}

\section{The team followed approved standards/guidelines}

\section{Prompts: Some deviation may be appropriate?}

- Significant deviation from critical elements and guidelines

- Adherence to appropriate standards and

- Many items need improvement

\section{guidelines}

- Few items need improvement

\section{Overall}

12. On a scale of $1-10$ give your global rating of the team's performance

\begin{tabular}{|c|c|c|}
\hline $1-3$ & 4-7 & $8-10$ \\
\hline $\begin{array}{l}\text { - Team is dangerous } \\
\text { - Team exhibits activities that } \\
\text { result in significant safety } \\
\text { concerns }\end{array}$ & $\begin{array}{l}\text { - Team appears competent } \\
\text { overall } \\
\text { - Some areas of } \\
\text { improvement needed } \\
\text { - Team gets the job done }\end{array}$ & $\begin{array}{l}\text { - Excellent, a model of good } \\
\text { teamwork } \\
\text { - Not many areas of } \\
\text { improvement }\end{array}$ \\
\hline
\end{tabular}




\section{Appendix 2}

TEAM/AHRQ TeamSTEPPS Map. Source: Rating medical emergency teamwork performance: development of the Team Emergency Assessment Measure (TEAM). Resuscitation 2010;81:446-452. Reprinted with permission from Elsevier.

\section{Team Emergency Assessment Measure (TEAM)}

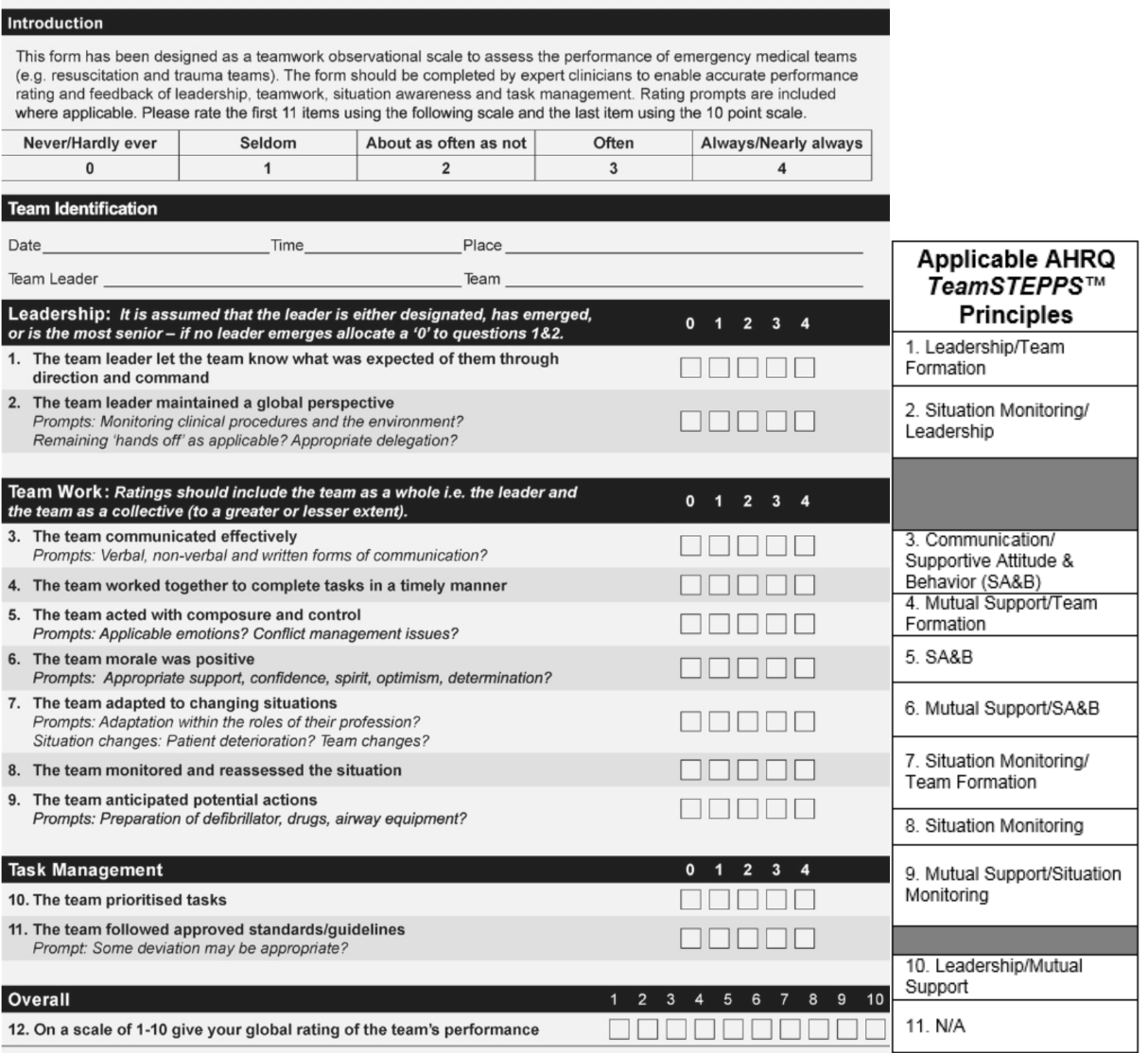

Comments: 


\section{CHAPTER 6}

\section{"Learning the lingo": A grounded theory study of telephone talk in clinical education}

Eppich WJ, Dornan T, Rethans JJ, Teunissen PW; under peer review 


\section{Abstract}

Purpose: Although the workplace learning literature has focused on 'doing', clinical practice involves 'talking' not only with patients but also about patients with other health professionals. Telephone talk is common, but its contribution to doctors' learning remains underexplored. Using a socio-cultural perspective, the authors examined how telephone talk influences physicians' clinical education.

Methods: Using constructivist grounded theory methodology, the authors conducted 17 semi-structured interviews with doctors from a variety of specialties and training levels from two American academic medical centers between 2015-2017. They collected and analyzed data iteratively using constant comparison to identify themes and explore their relationships. Theoretical sampling in later stages occurred until sufficiency was achieved.

Results: Participants reported speaking on the phone regularly to facilitate patient care and needing to learn how to tailor their talk based on goal(s) of the conversation and their specific conversation partners. Three common conversation situations highlighted the interplay between patient care context and conversation and created productive conversational tensions that influenced learning positively: (a) dealing with power differentials, (b) dealing with pushback, and (c) expressing uncertainty while still embodying trustworthiness.

Conclusions: Telephone talk contributes to postgraduate clinical education. Physiciansin-training learn both 'how to talk' and 'learn through talk' on the telephone mediated by productive conversational tensions that motivate them to modify their behavior to minimize future tensions. An evolution of 'how to talk' enables physicians-in-training to advocate for their patients and promote patient care. Preparing residents to deal with pushback could support their learning from this ubiquitous workplace activity. 


\section{Introduction}

While research on clinical workplace learning has focused primarily on how students and residents learn from 'doing', ${ }^{1-4}$ much of their clinical practice involves 'talking' not just with patients but about patients with other health professionals. As in other occupations 5,6, 'talk' encompasses verbal and nonverbal content and its accompanying social implications and comprises a significant component of clinical work. Moreover, according to both psychological and sociocultural theorists, talk mediates learning.,8 This central role of talk makes learning inseparable from patient care. Although researchers have examined how medical students learn oral presentation skills, ${ }^{9-12}$ we have much to learn about how talk shapes clinical education. A clearer understanding of workplace talk would help us delineate its specific contribution to clinical education.

Telephone conversations represent an everyday instance of workplace talk. Each day physicians-in-training speak with many conversation partners for a wide variety of reasons, e.g. to coordinate patient care across distributed teams or to seek/give advice about patient management. Telephone talk often plays an essential role in responding to acute situations, which demand that physicians manage remote interactions effectively to ensure safe and timely patient care. Given their ubiquity, these telephone conversations make up a substantive portion of residents' and fellows' workplace curricula. ${ }^{4,13}$ Thus, work-related telephone conversations represent a useful setting to study the learning that results from healthcare workplace talk. Limited research has outlined key strategies for successful telephone interactions between doctors seeking advice from subspecialist physicians. ${ }^{14-16}$ These studies do not explore the intrinsic learning potential of telephone conversations; further, they only touch on social elements and frame these interactions primarily as transactions of information between conversation partners. A need exists to incorporate these social aspects into research on the influence of telephone conversations on learning in graduate medical education.

Different perspectives illuminate different aspects of talk. Rather than an interindividual cognitive perspective, we chose a sociocultural lens that emphasizes the contributions of both social and individual dimensions of talk to human development and learning. ${ }^{17,18}$ Sociocultural speaking, talk mediates human thought, forms social structures, and gives people agency; all are integral to learning, ${ }^{18,19}$ Thus, as junior physicians-in-training progress in their clinical training, talk plays a vital role in their evolution from peripheral to full participants in their community of practice. ${ }^{19}$ Therefore, a socio-cultural perspective has particular advantages to examine how telephone talk influences this developmental trajectory during physicians' clinical education. 
We reason that better understanding of the role of residents' and fellows' telephone talk in workplace learning would yield valuable insights to promote practice improvements and clinical education. Thus, starting from the sociocultural assumption that talk simultaneously mediates practice and learning, we used residents' and fellows' accounts of their work-related telephone conversations as a model to study healthcare talk in order to answer the research question: How do telephone conversations contribute to postgraduate medical trainees' workplace learning?

\section{Methods}

Given the social nature of telephone conversations, we used constructivist grounded theory ${ }^{20,21}$, a qualitative methodology particularly well suited to explore complex social phenomena unexplained by pre-existing theory. Our goal was to derive a theoretical model about the role of work-related telephone conversations in resident and fellow clinical education. Since constructivist grounded theory encourages researchers to include their own backgrounds and perspectives into data collection and analysis, reflexivity is crucial. All four authors are physicians with significant experience in medical education research and WJE and PWT remain active in clinical practice. Additionally, PWT and TD have an extensive background in qualitative approaches to health professions education research.

The study took place at an accredited medical school in Chicago in the United States. Using targeted recruitment emails based on training program directors' suggestions for data rich informants, we invited residents and fellows across postgraduate years from various specialties from multiple residency and fellowship programs between 2015 and 2017. Several residents, including one at another large tertiary academic medical center in the United States, were invited via email at the suggestion of participants who had already been enrolled. Participants received no compensation or incentive for their involvement in the study. We obtained informed consent from each participant. The ethics committee at Ann \& Robert H. Lurie Children's Hospital of Chicago approved this study (IRB 2016-120).

One investigator (WJE) conducted all individual semi-structured interview with an initially purposive sampling of residents and fellows from December 2015 to February 2017. All interviews focused on patient care-related telephone conversations between doctors and other doctors, nurses, and health professions. Open ended questions invited participants to describe their experiences, including their last telephone conversation, one that stood out for them and why, particular challenges they experienced related to these telephone calls, and advice they would give more junior trainees about managing telephone interactions. Following grounded theory methodology, we collected and analyzed data iteratively using constant comparison. 
Interviews were audio-taped, transcribed, reviewed for accuracy, and de-identified.

The analysis proceeded in three phases, first with line-by-line coding and using constant comparative analysis of the initial interviews to create focused codes. Analytic meetings in pairs (WJE and TD or WJE and PWT) served to elevate and combine key concepts into identify major themes. Further analytic meetings with the entire team (WJE, TD, JJR, PWT) examined the relationships among major themes to theorize how work-related telephone conversations contributed to learning. As per grounded theory methodology, in latter stages of iterative data collection and analysis we recruited additional participants whose specialty and training level allowed us to refine aspects of our evolving theoretical model that remained unclear. Data collection ended when our analysis achieved theoretical sufficiency. ${ }^{20-22}$ We used MAXQDA (Berlin, Germany) to facilitate data management, interpretation, coding, and memoing.

\section{Results}

Seventeen physicians-in-training (11 male, 6 female) from post-graduate year 1 through 8 across a variety of specialties from three different academic hospitals participated. Training level also varied: 11 residents; 5 fellows in subspecialty training programs; and 1 chief resident. Roughly one third of participants were early in their training and were primarily supervised by others; one third both supervised others and were supervised by more senior physicians. About one third had significant supervisory experience since they were nearing the end of their fellowship training. In regard to specialty, 10 participants were from general or subspecialty pediatric programs, four from emergency medicine, and one each from orthopedics, surgery, and internal medicine. Anonymous participant codes identify representative quotations (e.g. P004).

All participants reported speaking on the phone regularly in order to facilitate patient care. They spoke with a wide variety of conversation partners depending on their role, practice domain, and urgency of clinical situations. For example, junior participants interacted frequently with other health professionals to seek help or guidance and to enact care plans established by the healthcare team. More senior participants provided advice, supervised more junior trainees, communicated with their attending physicians, and coordinated care of particularly complex or acutely unwell patients with a variety of other health professionals. Participants reported needing to learn how to tailor their talk efficiently and effectively based on goal(s) of the conversation and their specific conversation partners.

For participants, the dynamic interaction between clinical situations requiring telephone conversations and their respective conversation partners contributed to their learning potential. Young doctors learned how to talk in terms of 'what to say' 
related to informational and social content as well as the rhetoric of 'how to say it'. Our participants highlighted that both 'what to say' and 'how to say it' signified culturally sanctioned and expected ways of talking that were influenced by and reflective of their developmental trajectory from junior to more senior physician. This evolution in 'how to talk' directly enabled them to enact safe, effective, and efficient team-based patient care.

We now illustrate these findings using three common conversational situations that our participants encountered during work-related telephone talk that exemplify the interrelationship between context and conversation. These situations contributed both to how participants 'learned how to talk' and how they 'learned through talk' mediated in part by tensions that arose and seemed to exert positive influence on their learning. These included:

- Experiencing and dealing with power differentials

- Dealing with pushback

- Dealing with and expressing uncertainty while also embodying trustworthiness

\section{Experiencing and dealing with power differentials}

Many participants reported experiencing power differentials among conversation partners that seemed to both help and at times hinder learning. For example, a number of participants experienced emotional reactions when calling attending physicians. They used words like 'intimidating' and 'feeling nervous' that highlighted the role of 'hierarchy' in healthcare and the need to learn how to manage nervousness and threats to self-confidence.

When I'm calling an attending...there's some voice in the back of my head asking me whether or not that call should be made or if that's going to...be perceived negatively...or also just my own hang-ups about not wanted to feel weak. (P004)

Perceived asymmetry across hierarchical boundaries could influence learning positively. When presenting a patient to senior supervising physicians (attendings), participants wanted to be "as good as [they] can be" (P001) and embody trustworthiness by organizing their thoughts ahead of time. Participants often had an acute information need in the form of input from an attending physician or a consultant in order to advance patient care, at times under time pressure. In responding to this situational asymmetry in terms of role and information need, junior participants felt pressure to prepare ahead of time in order to deliver a concise oral presentation of relevant information to the best of their current abilities. 
You don't want to call your attending up in the middle of the night...and then clearly not [have] thought about what's going on with a case. It's just disrespectful to totally throw your hands up and wake them up without [giving it] any thought. Where's the learning if I don't actually think about this case first? And there's just a self-respect aspect of it--I don't want them to think I'm an idiot. (P009)

Participants mentioned how a lack of collegiality or "politesse" (P015) especially from someone up the hierarchy or from other medical specialties triggered strong emotional reactions and negatively impacted the conversations and thereby learning. When conversations became unpleasant, residents wanted to end the conversation, often to the detriment of their learning.

I always want to know 'why' this decision is being made. Knowing 'the why' helps me... respond [next time]. With negative conversations, you can sometimes lose 'the why' and not really care anymore... because the situation becomes frustrating. And then you're not really gaining that additional 'why' and knowledge. (P008)

Given these negative experiences, participants valued highly when perceived power differentials lessened, which enabled "sort[ing] through our thought processes at the same time" (P008). Participants at a similar training level often taught each other. For example, one pediatric fellow reported discussing the rationale or 'the why' for certain treatment decisions in particularly challenging cases with another subspecialty fellow, noting that "I come away from the conversations feeling like I now know something that I didn't before" (P009). Similarly, the importance of collegial working relationships-not only with peers but also across boundaries of hierarchy and medical specialty-came up repeatedly.

[Over time] you can be...more informal and still convey the relevant points, but joke around and have a little bit more fun...It's professional relationship but there's also a personal component to it...you have shared respect for each other. (P006)

\section{Dealing with pushback}

Most participants mentioned the experience of having to deal with "pushback" (P009) from conversation partners. 'Pushback' denotes situations when the doctor had a clear need or 'ask', but the conversation partner 'pushed back' and questioned the request or suggested course(s) of action. Some frequently mentioned examples of pushback included: 
- When calling for a consultation from a subspecialty service, the consultantusually another physician-in-training-expressed that formal consultation was unnecessary at that moment or inappropriate altogether

- When calling to admit a patient to the hospital ward or an intensive care unit, the admitting service (resident or fellow) responded that the admission was either unwarranted or inappropriate for their service

- When calling for urgent assistance, differing perceptions of relative urgency and priorities created tension

Participants highlighted the need to learn to deal with and even anticipate pushback depending on urgency and clinical requirements. Many of them advocated keeping the goal in mind "to get what you want" (P005) and working towards a mutually amenable solution by "continuing to be a rational, reasonable human being who may have a difference of opinion, but can talk through that with the other person" (P011). Depending on the circumstance, however, telephone pushback led to frustration “because I didn't necessarily get what I wanted [and] the team didn't necessarily get what they wanted" (P002). With increasing clinical experience, however, participants realized they didn't always need to get 'what they wanted'.

In medicine most of the time when there's a difference of opinion, it's kind of subjective... [so if] it's not going to hurt the patient, it's fine. You pick and choose those battles...you're storing up your ability to push your opinion harder when it really matters. (P011)

Participants reported multiple approaches to deal with pushback. These strategies included taking the conversation partner's perspective ahead of time, anticipating and pre-empting pushback, and keeping the goal of the conversation in mind. When pushback arose, participants recommended asking "what are you concerned about?" ... then "reason[ing] through those explanations" (P008) to solicit the conversation partner's perspective. Dealing with pushback in situations in which 'it really matters' required "all the tricks in your convincing playbook"; these tricks included being "really nice", then "firm", then a "little less nice....a little more direct" then "direct almost to the point of being rude about it" before "going up the chain" (P005). Several participants commented on the strategic use of "the higher-up's authority...[and] just say[ing] "the attending wants this, so please do this'" (P016). Especially for junior residents, 'the higher up in medicine is always a trump card' (P012). Finally, many participants emphasized that telephone communication had limits. When "you're not seeing eye-to-eye...you need to stand with the nurse [or] resident and look the patient together so that you can make sure that you're really on the same page" (P010). 
Many participants raised the issue of 'rambling' as a precursor to getting pushback since it magnified uncertainty and frustrated listeners. Rambling described a disorganized and unfocused mode of presenting information often without a recognizable purpose for the listener that made pushback more likely, especially for juniors. While pushback was most often viewed as something to overcome, unpleasant tensions associated with pushback also seemed to serve as implicit feedback. One resident reported that when conversation partners pushed back on the phone they could "get a little abrupt with questions and give [you] a hard time. [But when] you call them and they don't say anything and you're like 'that's what they want' -- that's better" (P016). Getting progressively less pushback over time, thus, indicated a moment in which young doctors were aware of their clinical progress.

\section{Dealing with and expressing uncertainty while embodying trustworthiness}

Many participants expressed having feelings of uncertainty. While uncertainty will always exist, participants worried about coming across as unsure of themselves and feared being viewed as "hedging" (P017), being "wish-washy" (P014), or "smelling like an intern" (P006). To this end, participants reported that, over time, they learned to be direct in expressing uncertainty while instilling confidence through "confident, adult, medical terms - not in scared, I'm still a student, terms" (P011). Participants commented on their efforts to embody trustworthiness, engender a sense of confidence in their telephone communications and "make a good impression" (P013) particularly with unfamiliar conversation partners.

Participants outlined important strategies for making a good impression and establishing trustworthiness, some of which we have already highlighted. First, many participants emphasized the essential nature of taking the conversation partners' perspective and information needs into account in order to achieve the goal of the exchange. With experience, participants learned to consider their audience and

...put myself in their shoes and think about what they want to know...and not really give anything else that they don't want to know about, cater your information towards their level and their specialty...(P008) and ...speak the language...these specialties want to hear. (P002)

Additional concrete strategies included: having a clear goal in mind, framing the conversation at the outset, and synthesizing information rather than merely being the "gatherer and reporter" of it (P010). For many participants, the first substantive sentence grabbed attention and anchored the rest of the conversation "because people won't listen unless they know what they're listening for" (P016). Participants also stressed the importance of "learning the lingo" (P008) in order to "paint a picture" 
(P003), through use of "buzzwords" (P007) that conveyed key information and urgency succinctly and persuasively. Crisp, organized presentations over the phone tailored to conversation partners were highly valued, especially when seeking advice from consultants or more senior physicians. Many participants identified the trial-and-error nature of gaining these rhetorical skills, which they viewed as a developmental process inextricably linked to caring for patients. As one upper level fellow noted, being more succinct is "partly because you're using fewer words, and partly that you sound more confident because you are more confident" (P011).

In addition, many participants reported that effective and efficient communication over the phone engendered trust. Importantly, a sense of being viewed as trustworthy contributed to an evolving sense of autonomy. In seeking attending input about a deteriorating patient, one participant recounted

[The attending was] asking me what's my assessment...and trusting what I'm telling her over the phone... [And her] asking, "What have you done so far and what do you want to do?" ... That represents telecommunication autonomy, 'Yes, I'm going to trust what you're giving me, right now, over the phone' (P007).

\section{DISCUSSION}

We explored the contribution of telephone talk to physicians' postgraduate medical education and found that work-related telephone talk represents a significant workplace activity for physicians-in-training. Given their highly social nature, a sociocultural lens offered particular advantages to examine telephone talk as physicians-intraining progressed along a developmental trajectory from more peripheral to more central members of their community. ${ }^{18}$ In doctors' communities of practice, learning how to talk and manage interactions skillfully conveys a sense of clinical and social competence ${ }^{9,10,23,24}$, which makes clear, concise, and persuasive communication highly desirable. However, not only did young doctors learn how to talk, our findings show that telephone talk also mediated learning as well.

Our analysis showed that tensions often arise during healthcare telephone talk. Reasons include the urgency of clinical situations requiring use of telephone communication, time-sensitive information needs, frequent boundary crossing between specialties and professions, varying abilities to communicate effectively and efficiently and a lack of visual nonverbal social cues. Although prior work has framed 'communicative tension' primarily as unproductive, ${ }^{25}$ our findings show that 'productive conversational tensions' contribute to physician workplace learning during telephone talk, even though doctors-in-training often find these tensions unpleasant. These productive tensions arise primarily from power differentials, dealing with 
pushback, and walking the line between expressing uncertainty while at the same time embodying trustworthiness. In line with work by Lingard et al. about 'tensions' in operating room teams, ${ }^{25}$ we purposefully use the term 'productive tensions' rather than conflict. Especially in healthcare, the term 'conflict' frequently has negative connotation, although recent calls encourage the healthcare field to take a more nuanced view of conflict in healthcare teams. ${ }^{26,27}$. Our study's main findings contribute to this more differentiated view.

'Productive conversational tensions' during telephone talk contribute to learning in several ways. First, these tensions help keep trainees 'on their toes' when speaking to people above them in the healthcare hierarchy. Second, by experiencing pushback, doctors-in-training must learn to articulate their thinking clearly, justify their point of view when differences of opinion and time pressure exist, accept alternate perspectives when appropriate, and choose their battles depending on patient care needs. Third, productive conversational tensions serve as valuable 'performance relevant information', ${ }^{28}$ by highlighting a lack of knowledge or an ability to assess a situation or communicate clearly and convincingly about it. For example, other authors have addressed how physicians' learn to express uncertainty, mostly through linguistic devices or rituals ${ }^{29}$ or using sanctioned language and particular grammatical structures, e.g. modal auxiliaries such as 'can, could, may' or adverbs like 'perhaps' or 'possibly'. ${ }^{10}$ Our work builds on these findings by emphasizing how the overall arc of a telephone conversation (how it is framed at the outset, its organization, its inclusion of only relevant information) enables doctors to express uncertainty with a 'manner of certitude'. ${ }^{10}$

Our findings suggest that physicians-in-training learn through their participation ${ }^{30}$ in work-related telephone calls and adapt their behavior in order to: (a) conform to the workplace culture and communication practices and (b) minimize tensions in future encounters. Indeed, by conforming to the way things are done, junior doctors participate in reproducing the community of practice ${ }^{18}$ and adopt established or reified communication patterns, ${ }^{4}$ with both desirable and undesirable consequences.

Of course, not all conversational tensions are productive, indeed some tensions create highly unproductive moments and even endanger patient safety. Telephone conversations can trigger strong emotional reactions for some residents, which heighten emotional activation and make some situations particularly memorable. ${ }^{31}$ Genuinely disruptive behavior falls well outside of the range of productive and even threatens patient safety. Such behavior includes yelling, abusive language, or a condescending tone ${ }^{32}$ that some of our participants also reported. Further, evidence indicates that rudeness has negative impacts on performance for individuals ${ }^{33}$ and teams. ${ }^{34}$ In addition, our data show how tensions of this nature impair learning since 
residents lose the desire to learn the 'why' behind recommendations from seniors and consultants since they are understandably keen to end unpleasant conversations. Although we show that tensions can be productive, clinical supervisors might infer that we should create 'productive' tension intentionally, which our data do not suggest. Such deliberate tensions during telephone talk may threaten supportive learning environments; on the contrary, we should work to find ways of minimizing any unproductive tensions or frank conflict.

Our study has important implications for physicians' clinical education with regard to their telephone talk. We replicate prior work that stresses the important role of effective oral presentation skills. ${ }^{9}$ For example, especially when junior residents 'ramble' on the phone, their unfocused presentation magnifies perceptions of their uncertainty and prompts others to others question their competence. Also, the extent to which physicians-in-training experience pushback adds to stress levels and perceived workload, which raises additional key questions. Should we help junior residents develop their communication skills and 'don a cloak of competence' 35 and 'disguise their uncertainty' ${ }^{10}$ as the community of practice seems to require? Or should we seek to create a learning environment where uncertainty is normalized? The way forward likely combines these two streams of thinking. Either way, we could achieve this aim by enhancing junior doctors' ability to articulate uncertainty in a way that promotes trustworthiness, to persuade and convince, to deal with pushback, and to mitigate rather than stoke unnecessary tensions. Medical educators could purposefully build learning experiences into post-graduate curricula to prepare young doctors for these situations.

With a stronger focus on telephone talk during clinical education, we foresee several benefits. First, junior physicians would better anticipate, pre-empt, and prevent possible pushback. ${ }^{36}$ Second, junior doctors may be better equipped to learn from their telephone talk, for example, by routinely seeking 'the why' behind a nurse's concern or a supervisor's clinical reasoning. Third, we could also prepare supervisors and consultants to support juniors in the telephone communication skills. Simulation-based strategies may serve as a useful means to this end. Finally, our sociocultural lens shines a light on the importance of collective processes in healthcare education to make sure our culture, as expressed in telephone conversations, promotes both safe and effective patient care and learning.

Several decisions related to our approach to data collection and analysis potentially impact our results. First, our decision to include solely physicians-in-training in our sample necessarily excludes the perspectives of attending physicians and other health professionals, such as nurses. This choice perhaps explains why the notion of 'tensions' as a contributor to learning featured prominently in our analysis. Alternately, by 
including only physicians-in-training across a breadth of specialties and training levels, we could explore key situations from various vantage points through the lens of a young doctor. Second, we chose interviews as a data collection method as opposed to audiorecording of actual telephone conversations. Our underlying assumption for our research was that both thought and social interaction are semantically mediated constructs, ${ }^{37}$ reflecting a continuous link between physicians' spoken interactions with work colleagues and how they manage themselves before, during, and after telephone conversations. Self-censorship, however, limits the extent to which individuals express their inner talk in social interactions. ${ }^{38}$ Therefore, our deliberate aim in using interviews as a data collection method was to solicit resident and fellow inner dialogue and interpretations related to their telephone talk experiences. Both valuable perspectives would remain inaccessible through analysis of audio recorded conversations. Of course, going forward we foresee that conversational analysis methods of audio-recorded telephone conversations would likely shed additional light on what more precisely characterizes the tensions that arise during telephone talk.

Future research on healthcare telephone talk should prioritize several key areas. First, a needs assessment for telephone talk would help determine what type of education physicians-in-training and supervisors require and how to design a robust curriculum. Second, we should seek a more fine-grained understanding of the various aspects of our findings, such how power differentials impact telephone conversations and what characterizes pushback on the telephone. Finally, as we have mentioned above, additional methodological approaches to this phenomenon would likely contribute additional insights to our understanding of this educationally rich workplace activity.

\section{Conclusions}

Telephone talk contributes to postgraduate clinical education since physicians simultaneously learn how to talk and learn through talk. Learning through telephone talk appears at least in part to be mediated through productive conversational tensions that can motivate physicians-in-training to modify their behavior to minimize future tensions they experience. Behavioral change across the developmental trajectory of clinical training manifests itself in part through an evolution of 'how to talk' that enables physicians-in-training to advocate for their patients and promote patient care. Education on 'how to talk' on the telephone could prepare residents to deal with the pushback they experience and support their learning from this ubiquitous workplace activity. 


\section{Chapter 6}

\section{References}

1. Dornan T, Boshuizen H, King N, Scherpbier A. Experience-based learning: a model linking the processes and outcomes of medical students' workplace learning. Med Educ. 2007;41(1):84-91.

2. Yardley S, Teunissen PW, Dornan T. Experiential learning: AMEE Guide No. 63. Med Teach. 2012;34(2):e102-e115.

3. Teunissen PW, Scheele F, Scherpbier AJJA, et al. How residents learn: qualitative evidence for the pivotal role of clinical activities. Med Educ. 2007;41(8):763-770.

4. Teunissen PW. Experience, trajectories, and reifications: an emerging framework of practice-based learning in healthcare workplaces. Adv in Health Sci Educ. 2015;20(4):843-856.

5. Scheeres H. Learning to talk: from manual work to discourse work as self-regulating practice. Journal of Workplace Learning. 2003;15(7/8):332-337.

6. ledema R, Scheeres H. From doing work to talking work: Renegotiating knowing, doing, and identity. Applied linguistics. 2003;24(3):316-337.

7. Vygotsky LS. Thought and Language (Rev. Ed.). Cambridge, Massachusetts: The MIT Press; 1986.

8. Wells G, Wells J. Learning to talk and talking to learn. Theory Into Practice. 1984;23(3):190-197.

9. Haber RJ, Lingard LA. Learning oral presentation skills: a rhetorical analysis with pedagogical and professional implications. J Gen Intern Med. 2001;16(5):308-314.

10. Lingard L, Garwood K, Schryer CF, Spafford MM. A certain art of uncertainty: case presentation and the development of professional identity. Soc Sci Med. 2003;56(3):603-616.

11. Lingard LA, Haber RJ. What do we mean by "relevance?" A clinical and rhetorical definition with implications for teaching and learning the case-presentation format. Acad Med. 1999;74(10 Suppl):S124S127.

12. Lingard L, Schryer C, Garwood K, Spafford M. "Talking the talk": school and workplace genre tension in clerkship case presentations. Med Educ. 2003;37(7):612-620.

13. Billett S. Learning through health care work: premises, contributions and practices. Med Educ. 2016;50(1):124-131. doi:10.1111/medu.12848.

14. Kessler C, Kutka BM, Badillo C. Consultation in the emergency department: a qualitative analysis and review. J Emerg Med. 2012;42(6):704-711.

15. Kessler CS, Chan T, Loeb JM, Malka ST. I'm clear, you're clear, we're all clear: improving consultation communication skills in undergraduate medical education. Acad Med. 2013;88(6):753-758.

16. Kessler CS, Tadisina KK, Saks M, et al. The 5 Cs of Consultation: Training Medical Students to Communicate Effectively in the Emergency Department. J Emerg Med. 2015;49(5):713-721.

17. Tsui A, Edwards G, Lopez-Real F. Sociocultural perspectives of learning. In: Learning in School-University Partnership Sociocultural Perspectives. New York: Routledge; 2009:45-71.

18. Lave J, Wenger E. Situated Learning: Legitimate Peripheral Participation. New York: Cambridge University Press; 1991.

19. Wenger E. Communities of Practice: Learning, Meaning, and Identity. New York: Cambridge University Press; 1998.

20. Watling $\mathrm{CJ}$, Lingard L. Grounded theory in medical education research: AMEE Guide No. 70. Med Teach. 2012;34(10):850-861.

21. Charmaz K. Constructing Grounded Theory. 2nd ed. London: SAGE Publications Ltd; 2014.

22. Varpio L, Ajjawi R, Monrouxe LV, O’Brien BC, Rees CE. Shedding the cobra effect: problematising thematic emergence, triangulation, saturation and member checking. Med Educ. 2017;51(1):40-50.

23. Atkinson P. Medical Work and Medical Talk: The Liturgy of the Clinic. London: Sage; 1995

24. Hunter KM. Doctors' Stories: The Narrative Structure of Medical Knowledge. Princeton, New Jersey: Princeton University Press; 1991.

25. Lingard L, Reznick R, Espin S, Regehr G, DeVito I. Team communications in the operating room: talk patterns, sites of tension, and implications for novices. Acad Med. 2002;77(3):232-237.

26. Eichbaum Q. Collaboration and Teamwork in the Health Professions: Rethinking the Role of Conflict. Acad Med. November 2017:1.

27. Greer LL, Saygi O, Aaldering H, De Dreu CKW. Conflict in medical teams: opportunity or danger? Med Educ. 
2012;46(10):935-942.

28. van der Leeuw RM, Teunissen PW, Van Der Vleuten CPM. Broadening the Scope of Feedback to Promote Its Relevance to Workplace Learning. Acad Med. October, 242017 [epub ahead of print]

29. Bosk CL. Occupational rituals in patient management. In: Vol 303. 1980:71-76.

30. Sfard A. On two metaphors for learning and the dangers of choosing just one. Educational Researcher. 1998;27(2):4-13.

31. McConnell MM, Eva KW. The role of emotion in the learning and transfer of clinical skills and knowledge. Acad Med. 2012;87(10):1316-1322.

32. Mullan CP, Shapiro J, McMahon GT. Interns' experiences of disruptive behavior in an academic medical center. J Grad Med Educ. 2013;5(1):25-30.

33. Porath $\mathrm{CL}$, Erez A. Does Rudeness Really Matter? The Effects of Rudeness on Task Performance and Helpfulness. Academy of Management Journal. 2007;50(5):1181-1197.

34. Riskin A, Erez A, Foulk TA, et al. The Impact of Rudeness on Medical Team Performance: A Randomized Trial. Pediatrics. 2015;136(3):487-495.

35. MacLeod A. Caring, competence and professional identities in medical education. Adv in Health Sci Educ. 2011;16(3):375-394.

36. Smith D, Edmondson A. Too hot to handle? How to manage relationship conflict. California Management Review. 2006; 49(1):6-31.

37. Wertsch JW. Voices of the Mind. Cambridge, MA: Harvard University Press; 1991.

38. Detert J, Edmondson A. Implicit Voice Theories: Taken-for-Granted Rules of Self-Censorship at Work. Academy of Management Journal. 2011;54(3):461-488. 


\section{Chapter 6}




\section{CHAPTER 7}

Learning how to learn using simulation: Unpacking disguised feedback using a qualitative analysis of doctors' telephone talk

Published as: Eppich WJ, Rethans JJ, Dornan T, Teunissen PW. Learning how to learn using simulation: Unpacking disguised feedback using a qualitative analysis of doctors' telephone talk. Medical Teacher. 2018;40(7):661-667. 


\section{Abstract}

Introduction: Telephone talk between clinicians represents a substantial workplace activity in postgraduate clinical education, yet junior doctors receive little training in goal-directed, professional telephone communication.

Aim: To assess educational needs for telephone talk and develop a simulation-based educational intervention.

Methods: Thematic analysis of 17 semi-structured interviews with doctors-in-training from various training levels and specialties.

Results: We identified essential elements to incorporate into simulation-based telephone talk, including common challenging situations for junior doctors as well as explicit and informal aspects that promote learning. These elements have implications for both junior doctors and clinical supervisors, including: (a) explicit teaching and feedback practices and (b) informal conversational interruptions and questions. The latter serve as "disguised" feedback, which aligns with recent conceptualizations of feedback as "performance relevant information".

Conclusions: In addition to preparing clinical supervisors to support learning through telephone talk, we propose several potential educational strategies: (a) embedding telephone communication skills throughout simulation activities and (b) developing stand-alone curricular elements to sensitize junior doctors to "disguised" feedback during telephone talk as a mechanism to augment future workplace learning, i.e. 'learning how to learn' through simulation. 


\section{Introduction}

Although telephone conversations between doctors and other health professionals represent a significant workplace activity, residents receive little if any training to engage in this professional conversational space. This lack of preparation can negatively affect patient care and potentially lead to patient harm due to incomplete information exchange $^{1-3}$ and paradoxically may even impair residents' clinical education. Most research in this area frames telephone conversations such as those related to "calling a consult", i.e. calling specialists for advice or consultation, as ones primarily about information exchange. ${ }^{4-6}$ This lens leads to training paradigms that necessarily highlight information exchange 7,8 and mnemonics that emphasize primarily monologic rather than dialogic communication protocols, e.g. SBAR (Situation, Background, Assessment, Recommendation). ${ }^{9,10}$ While such approaches can have significant clinical impact in the setting of patient handoff, ${ }^{11}$ standardization has limits. ${ }^{12}$ Recent work underscored the importance of familiarity and trust, ${ }^{13}$ the potential for unproductive tensions, ${ }^{14}$ and conflict. ${ }^{15}$

Building on the assumption that talk mediates learning, ${ }^{16-18}$ Eppich et al. outlined how healthcare talk contributes to both patient care and learning from patient care since talk forms the basis of inter-professional collaboration. ${ }^{19}$ Much of talk's intrinsic learning potential is "informal"20,21 and unplanned as opposed to formal curricular elements. As part of a larger research program, Eppich and colleagues interviewed medical trainees and used constructivist grounded theory methodology 22,23 to explore both (a) the role of telephone talk in physicians' clinical education and (b) what promotes learning during telephone talk. Eppich et al. (under review) interviewed 17 doctors-in-training who reported that telephone talk between clinicians, such as themselves and their clinical supervisors, featured prominently in their clinical work. Further, Eppich et al. used a sociocultural analytic lens and found that during telephone talk, doctors-in-training reported not only learning "how to talk", but also learning "through talk" partly driven by productive conversational tensions that they experienced. The authors also stressed the need for specific preparation in telephone talk in postgraduate medical education. This current study addresses this gap by further delineating these educational needs.

Simulating telephone talk is feasible, relatively easy to organize and requires no extensive equipment. Prior work has shown that simulation-based role play enhances telephone communication skills. ${ }^{24}$ However, the limited literature on educational interventions for telephone talk between providers focused primarily on monologic communication protocols. ${ }^{8,25}$ Therefore, we conducted a targeted needs assessment ${ }^{26,27}$ with several aims: (a) to clarify trainee doctors' perceived learning needs; (b) to use their experiences in workplace telephone talk to characterize both 
explicit and informal elements to incorporate them into realistic scenario design and implementation; and (c) to identify salient aspects to integrate into post-simulation debriefings.

\section{Methods}

We performed a secondary analysis of our existing dataset reported from our larger research program (Eppich et al. under review). Starting with portions of our initial analysis, we re-analyzed all interviews using principles of thematic analysis. ${ }^{28}$ Specifically, we sought evidence relevant for an educational needs assessment to inform scenario design, implementation and debriefing for both junior doctors and clinical supervisors.

\section{Study setting and participant sampling}

The study took place at an academic medical center in the Midwestern United States. We invited an initial group of physicians-in-training to participate through targeted recruitment emails based on suggestions from training program directors. Residents and subspecialty fellows were selected for interviews to ensure a spectrum of training levels and specialties. In addition, several residents were invited via email at the recommendations of participants who had already completed their interviews. One participant recruited in this manner was from another large tertiary academic center in the eastern United States. Participants, who provided informed consent before their interview, received no incentive or compensation. The ethics committee at the primary author's institution approved this study (IRB 2016-120).

In the spirit of reflexivity, we provide the authors' relevant background: (a) all authors are physicians who have significant medical education research experience; (b) WJE and PWT are active clinicians; (c) PWT and TD have extensive research experience using qualitative methodologies; and (d) WJE and JJR have substantial experience in simulation curriculum development.

\section{Data collection and analysis}

One investigator (WJE) performed all individual semi-structured interviews with a purposive sample of residents and subspecialty fellows across training levels and specialties between December 2015 and February 2017. All interviews explored doctors' patient care-related telephone conversations with other clinicians such as other doctors, nurses and health professionals. Open-ended items invited participants to describe their experiences related to telephone talk, including: (a) a recent telephone conversation that stood out and why; (b) challenging situations on the telephone; and (c) their advice to more junior physicians. Additional emergent themes were explored 
depending on participant responses, including what helped them attain their current abilities.

All interviews were audio-recorded, professionally transcribed, reviewed for accuracy, and de-identified. WJE performed a line-by-line coding of the initial three interviews using constant comparative analysis to create focused codes. TD and PWT reviewed initial focused codes independently to ensure agreement about coding and adequacy of the interview guide. Subsequent focused codes were developed jointly in the research team through independent review of data and collaborative discussion. We collected and analyzed our original data in an iterative fashion using constant comparison. At that time, we ended data collection when we identified no new themes and we had achieved theoretical sufficiency. ${ }^{29}$ For the current study, we applied principles of thematic analysis ${ }^{28}$ to our entire existing dataset beginning with focused codes we identified in the initial analysis related to: (a) challenging situations, (b) developmental trajectory from junior to senior doctor-in-training, and (c) what promotes learning on the telephone. Subsequent analytic meetings served to identify recurrent categories and provisional themes with particular relevance for an educational needs assessment. Data were reviewed jointly followed by collaborative discussion about the appropriateness of categories, which were then refined during asynchronous email exchanges. In line with the principles of thematic analysis, ${ }^{28}$ we incorporated additional data points into existing themes or organized them into new ones. We managed, interpreted, and coded our data using MAXQDA (Berlin, Germany).

\section{Results}

Seventeen physicians-in-training from postgraduate years 1 through 8 with an age range from 26 to 34 years (mean 29.6) from three academic hospitals participated. See Table 1 for an overview of relevant participant characteristics.

Table 1 Participant characteristics

\begin{tabular}{|c|c|c|c|c|c|c|c|c|}
\hline Participant characteristics & \multicolumn{8}{|c|}{ Proportion of total $(n=17)$ in absolute numbers } \\
\hline $\begin{array}{l}\text { Gender } \\
\text { Training level }\end{array}$ & \multicolumn{8}{|c|}{$\begin{array}{c}\text { Male (11) } \\
\text { Female (6) } \\
\text { Residents }{ }^{\mathrm{a}}(11) \\
\text { ubspecialty fellows }{ }^{\mathrm{b}}(5) \\
\text { Chief resident }^{\mathrm{c}}(1) \\
\end{array}$} \\
\hline \multirow{2}{*}{$\begin{array}{l}\text { Training years after graduation from medical school } \\
\text { i.e. post-graduate year (PGY) }\end{array}$} & PGY 1 & PGY 2 & PGY 3 & PGY 4 & PGY 5 & PGY 6 & PGY 7 & PGY 8 \\
\hline & 4 & 2 & 5 & 3 & 1 & 1 & 0 & 1 \\
\hline Specialty/Training Program & \multicolumn{8}{|c|}{$\begin{array}{c}\text { General or subspecialty pediatric programs (10) } \\
\text { Emergency medicine (4) } \\
\text { Orthopedics (1) } \\
\text { Surgery (1) } \\
\text { Internal medicine (1) }\end{array}$} \\
\hline
\end{tabular}

${ }^{a}$ Resident $=$ junior or senior house office in a general training program.

${ }^{b}$ Subspecialty fellow $=$ Registrar in a subspecialty training program.

${ }^{c}$ Chief resident $=$ training program graduate who helps administer training program. 
Given this diverse sample, our data reflect the varied experiences of physicians-intraining primarily being supervised (i.e. more junior doctors), those mostly supervising others (i.e. more senior doctors), or a mix of both. We identify representative quotations using anonymous participant codes (e.g. P007). The remainder of the results section addresses three major areas: (a) specific educational needs our participants reported in terms of situations and communication challenges, (b) helpful explicit feedback and teaching practices, and (c) informal aspects of telephone conversations that supported doctors' learning.

\section{Specific educational needs}

Despite the frequency of work-related telephone conversations during daily clinical work, nearly all participants specifically mentioned the lack of training in how to engage other clinicians over the telephone. Doctors gained telephone talk skills without "formal coaching" and they needed to "just stumble through" (P006). They learned as a result of "trial and error" (P007) through "experience at the school of hard knocks" (P005). As a result, junior doctors reported inefficient communication patterns that delayed patient care since decision- making required multiple phone calls instead of just one. More senior conversation partners also stressed multiple frustrating and inefficient patterns repeatedly, including:

- Omitting a "one-liner or a framework" (P009) at the outset to frame the conversation

- Giving "rambling" presentations in which "the severity of [the patient's] condition can get lost" (P001) with the result that "nobody's going to pay attention" (P006)

- Presenting irrelevant information while paradoxically leaving out critical details: "If you don't really know what [is] important, you're going to tell me everything....which maybe I don't care about... I care about the important things" (P011)

Our needs assessment further delineated areas of high educational need related to context and communication challenges. First, our participants raised specific situations that were particularly problematic early in their training: calling subspecialists for advice (i.e. calling a consult) or calling more senior colleagues on their team for guidance. One participant noted that as a junior doctor, he "struggled to call people for consults, or struggled to call my attendings" (P014). Second, our participants reported several particular challenges that contributed to this sense of "struggle" in these settings: (a) succinctly summarizing a complex clinical course; (b) conveying urgency effectively; and (c) dealing with pushback, i.e. when requests or proposed courses of action are initially questioned or even rejected without due consideration. 
Despite the lack of formal training in telephone talk, however, our participants described a developmental trajectory that eventually allowed them to gain the necessary telephone communication skills. Based on our participants' accounts, we identified several key elements that promoted learning directly and indirectly through workplace telephone talk. These included: (a) explicit teaching and feedback and (b) informal conversational interruptions and questions. Notably, informal conversational interruptions and questions served as valuable implicit feedback that influenced learning. Both explicit and informal elements have relevance for simulations designed to train both junior doctors and clinical supervisors to support and accelerate learning during telephone talk. We now expand on each of these main themes.

\section{Explicit teaching and feedback practices}

Participants shared helpful insights about explicit teaching and feedback interactions over the telephone that should inform how we prepare clinical supervisors for telephone encounters with juniors. Such teaching practices took various forms. First, participants appreciated when supervisors first provided some brief general background information about a given issue before giving specific advice, but without being "condescending" (P006) or using teaching as a "way to scold you" (P008). Second, participants valued when supervisors not only discussed what to do but also "explain why" (P002), which helped to "learn the thought process" by hearing "their clinical judgment" (P008). Third, more senior participants highlighted their use of questions as an explicit educational tool. Rather than simply telling a more junior colleague what needed to happen next, they sought to promote critical thinking.

[Residents] finish telling me the story and they just stop and I'm like, "So what do you think is going on? Okay, what would you like to do?" [If]... they have a plan that they want to present to me, then I ask, "Okay, so why do you want to do that? What's the reason for doing that?" (P009)

Multiple participants emphasized the value of explicit problem-focused teaching around an immediate patient care need. This perspective is an important one for clinical supervisors to appreciate. "Telephone conversations with a fellow or an attending...tend to be clinical snapshots that stay with me...more than PowerPoint lectures. Effective communication over the phone can be a great educational tool" (P007).

Both more senior and junior doctors-in-training discussed the role of specific feedback on the telephone. For example, supervisors at times explicitly "tend to let [junior doctors] tell their story, because they're learning... how to present a history.....and how to tell me their concerns, so I tend to let them go on for a bit. (P001). One senior resident noted that when giving feedback on presentation skills, he found that trying "to frame 
things that I need [from] them is a good way to teach and train them to know [what] to include in their presentation...over the phone [next time]" (P007). In addition, more junior doctors also valued feedback on their presentation skills, such as:

"You could be more organized and concise whenever you present...you could lead with the diagnosis and exactly what you think is going on with the patient" (P014). Further, in terms of clinical reasoning, one second year resident noted that when "calling someone...superior to me, my plan [of care] that I'm presenting is always a 'proposal' that I am asking for feedback on" (P004).

We also identified the potential to prepare junior doctors how to manage their own learning needs. For example, several participants mentioned situations in which they posed questions to solicit explicit teaching from either subspecialty consultants or supervising physicians since "physicians like

teaching for the most part... [and] tend to respond pretty positively to that, especially if you don't have any more work at the end of the question" (P015). Conversations grounded in immediate clinical questions also had the potential to lead to discussions around future hypothetical situations. One mid-level emergency medicine resident noted that when speaking with an orthopedic resident, he was asking about the management of a patient with a fracture:

'What would I typically do with this patient if I were the community and I didn't have an orthopaedic doctor that could see them?' People are really busy.... If you don't ask for it, most of the time they're not going to educate you. (P008)

\section{Informal learning through "disguised feedback": conversational interruptions and questions}

The notion of interruptions with relevance for learning featured prominently in our data: either being interrupted or interrupting someone else. Depending on the vantage point, participants framed interruptions as either unpleasant (juniors) or necessary (seniors). More junior doctors with a story to tell appreciated being given the chance to say their "entire piece before [others] step in and ask their questions or give their opinions" (P002).

Even though interruptions were unpleasant, junior participants highlighted their educational value, especially when they caught themselves rambling without a clearly stated purpose to the conversation: "Sometimes you get cut off, or you get a clarifying question, so you get to the

point" (P010). One second year resident noted, "as an intern you would have given this long-winded story" and not "have identified the reason for the consult...they interrupt you like, 'Why are you calling me?'” (P015). Alternatively, more senior physicians who 
listened to a presentation over phone expressed that "if I have no idea of what's going on with the history, then I'Il interrupt them and start asking questions" (P009).

Thus, for seniors the act of interrupting rambling residents appeared to be primarily a matter of efficiency with secondary educational benefit "if it seems like it would save time for me to interrupt" to "steer [rambling residents] back on track" (P011). Representative questions that help "the junior colleague really focus on what's most important..." included: "What are you really concerned about here?" or "What are you worried about could be a danger to this child's life in the next 24 hours?" (P010)

Importantly, multiple participants emphasized the degree to which they were aware of how spontaneous conversational interruptions and questions served as implicit or 'disguised' feedback. This emerging awareness highlighted the potential in making the educational value of this 'disguised feedback' explicit in order to: (a) accelerate junior doctors' learning, (b) prepare clinical supervisors to accentuate their benefit.

Even if they're not specifically giving you feedback...you can tell if they have all the information that they want, or if they feel like you've left out some things...You get better at unpacking the disguised feedback on the other end of the phone. (P013)

To further underscore its educational significance, our participants reported that implicit feedback in the form of interruptions and questions served as a potent motivator for changing future behavior. For example, juniors often became aware they were taking too long or providing too much information: "When you're talking longer than you should...there's also in-the-moment, inadvertent feedback... I'm like, 'Okay, I need to start wrapping this up'" (P009) which helps residents get "better at gauging how much information people want" (P013). One junior noted that when presenting over the phone and someone asks “'Okay, why are you calling me?' or 'What's the question?', then I know I did not say the correct thing in the first two sentences" (P016). As a result, "I would try to shape my [future]conversations...to avoid having them have to cut me off" (P006).

Participants experienced interruptions for questions as unpleasant, something about which clinical supervisors should be aware. For example, when calling a consult, "if [more senior physicians] are asking me more parts of the history or physical, that means that this information was relevant...that means that I have not prepared myself [for the call]" (P006). However, "those questions stuck with me...now I ask them" (P009). Thus, participants not only found general interruptions to prompt a more succinct presentation helpful, but also specific questions that helped them realize what information has relevance in a particular clinical context: 
"So, depending on how it's asked [and] what the question is, sometimes when I hang up - I'm like, this is what they care about, which is good to know about in the future... It helps me frame the patient in a way [the specialist] wants to know about them" (P016).

\section{Discussion}

Our findings contribute to a robust needs assessment of telephone talk in postgraduate medical education and complement existing approaches based on mnemonics or cognitive aids. ${ }^{8,9,25}$ Our study extends this prior work by delineating explicit and informal educational elements of these telephone conversation. We see multiple implications for the use of simulation-based approaches to augment telephone talk.

First, physicians-in-training reported particularly challenging situations to integrate into simulation scenarios, namely calling for subspecialty consultation or calling more senior supervising physicians for advice. Second, we recommend routinely integrating telephone communication into existing scenarios. For example, when caring for a simulated critically-ill patient, simulation participants must often call the critical care unit or other subspecialists for urgent assistance. We recommend that subsequent debriefings should integrate a discussion about the telephone calls embedded in these immersive manikin-based simulations. Third, our findings provide guidance as to how simulated conversation partners should portray their roles and embody both explicit and implicit feedback. See Table 2 for an overview about how our findings can inform development of a simulation-based telephone talk curriculum for junior doctors.

In addition to explicit feedback and teaching over the phone ${ }^{30}$ that has been previously described, our results show that much of the feedback residents receive during telephone talk is implicit or "disguised". Thus, our findings align with recent conceptualizations of feedback as "performance relevant information" (PRI). ${ }^{31}$ According to Leeuw and colleagues, PRI "focuses on how learners interpret their performance in the workplace in terms of what is relevant information for their learning" and "includes all potential sources of information for learning arising from the interpretation of one's performance and interaction in the workplace" (p. 2). ${ }^{31}$

Since much of PRI is implicit or "disguised", we rationalize that sensitizing residents to potential PRI during their telephone interactions would enhance their ability to learn from their workplace telephone talk. Thus, we envision an educational intervention that not only trains junior doctors in telephone communication skills, but also prepares them to: (a) identify and incorporate "disguised" feedback, and (b) respectfully solicit the "why" behind the conversation partners' clinical decision-making and management choices in order to enhance their own learning. Thus, such an educational intervention 
would potentially enhance junior doctors' abilities to learn from future workplace telephone encounters.

For a dedicated simulation telephone talk intervention, we propose using simulated patient methodology. ${ }^{32}$ Specifically, the goal would be to prepare physicians-in-training to recognize, integrate and act on "disguised" feedback or PRI that emerges during healthcare talk. Similarly, a faculty development or "residents-as-teachers" initiative could prepare clinical supervisors to deal with underperforming residents and make normally implicit feedback more explicit. These might include providing strategies to interrupt rambling residents respectfully ("Can I pause you for a second? It would help me to hear your clinical question") or to frame a series of additional questions ("In these situations I need additional information, so I have some more specific questions for you...").

Now we will focus the implication of our needs assessment for physicians-in-training and a curriculum that moves beyond a traditional simulation paradigm. In our view, participants traditionally perform and reflect in simulation with the goal of learning to perform in future clinical practice (i.e. "simulation-as-learning-to-perform"). Such approaches using deliberate practice have shown benefit for communication skills training. ${ }^{33,34}$ However, given that simulation may occur infrequently during busy resident clinical training, we plan an alternate yet complementary strategy. By using PRI as a conceptual framework, we propose a simulation intervention in which trainees perform and reflect with the goal of learning how to learn from clinical practice (i.e. "simulation-as-learning-how-to-learn") (Table 2). Thus, our proposed simulation curriculum would sensitize young doctors to the learning cues or PRI during workplace telephone talk to enhance their future learning. Of course, a fundamental prerequisite would involve establishing a supportive learning environment ${ }^{35}$ by sharing expectations in advance, i.e. "Your conversation partners will portray their role realistically, including interrupting you to ask questions, much like you may experience in your daily clinical work. We will discuss this phenomenon after the simulation ends".

Since the value of disguised feedback during workplace telephone talk represents one of our key findings, we recommend integrating the notion of PRI into simulation activities, including scenarios and debriefings. Short postsimulation debriefings could highlight these moments of potential PRI so that young doctors learn to recognize them explicitly and see their value for their own learning. This approach would inform reflective questions during the debriefing that could prepare residents to ask themselves: "What did I learn from this conversation, how does it impact my clinical reasoning, what would I do differently next time?" 


\section{Chapter 7}

Table 2 Key elements of a workplace-informed simulation-based telephone talk curriculum for junior doctors, including two complementary approaches

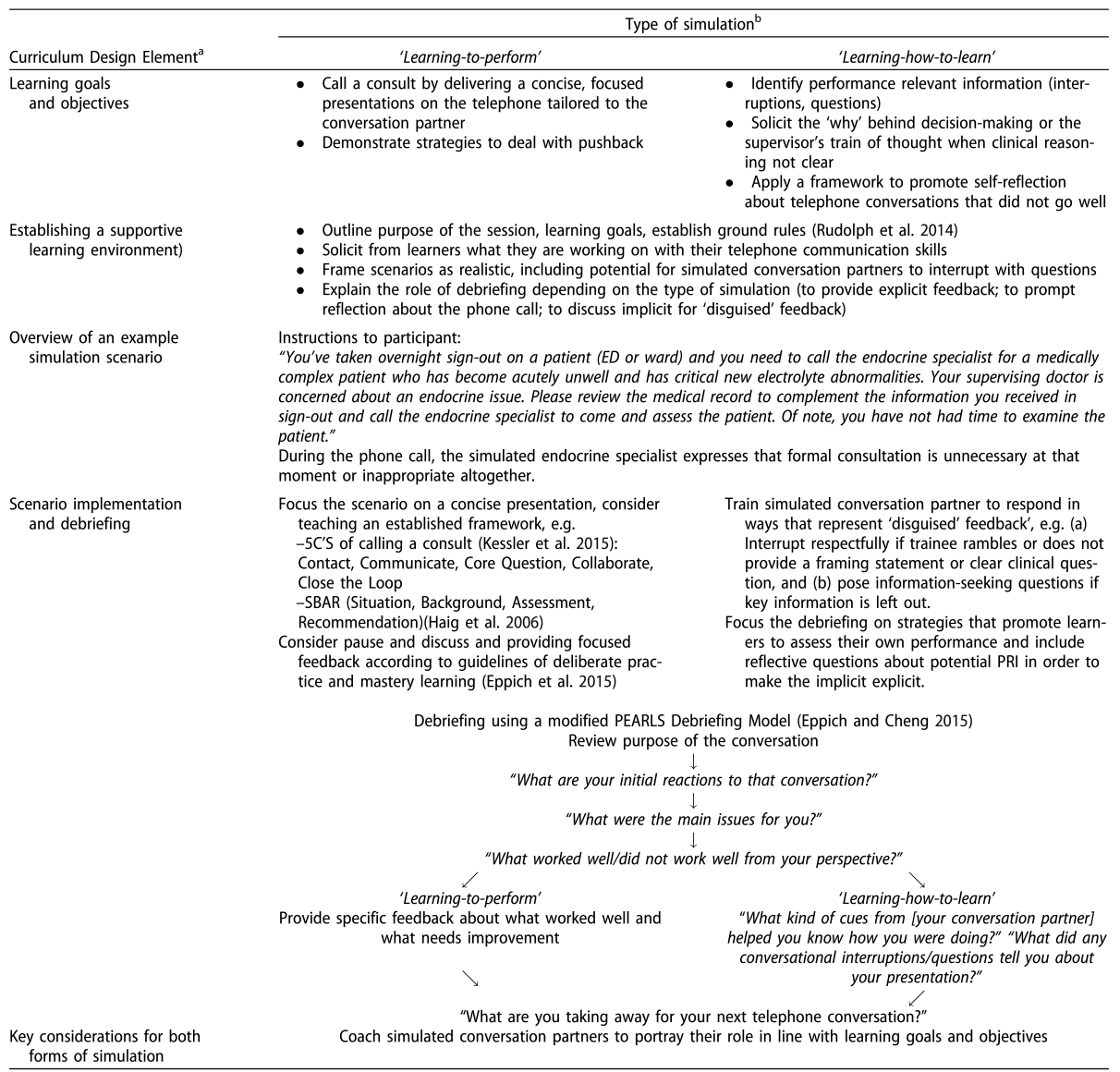
of simulation

${ }^{a}$ Curriculum design elements based on literature review and our findings.

${ }^{\mathrm{b}}$ May include both complementary types of simulation.

For this study, we recruited participants from primarily one academic medical center. This may limit transferability of our findings to other areas of practice influenced by differing relational and power dimensions. However, we believe that recruitment of participants from various specialties and from three different teaching hospitals mitigates this point to some extent, as each specialty and hospital engenders its own particular culture. It would be interesting to explore healthcare telephone talk in other geographic regions with their unique cultural differences, which also impact debriefings. ${ }^{36}$

This paper has focused on a needs assessment for simulation- based educational interventions for telephone talk. We plan to develop and implement a simulation-based telephone talk curriculum and assess its effectiveness. Future work is needed to 
delineate the extent to which the approach of "simulation-as-learning-how-to-learn" translates to workplace learning and performance. Another potential application of this revised educational paradigm might include deliberate training of team reflexive behaviors ${ }^{37,38}$ in order to enhance future individual and team workplace learning. Simulation-based team training may serve as an ideal venue to prepare teams to engage in these learning behaviors, ${ }^{38}$ for example, collective reflection before, during, and after patient care episodes).

\section{Conclusions}

Telephone talk between clinicians represents an underappreciated workplace activity in postgraduate clinical education. Our needs assessment identified essential elements to incorporate into a simulation-based curriculum to improve telephone communication skills. Common challenging situations for junior doctors include (a) calling subspecialists or more senior clinical supervisors for advice, and (b) structuring presentations succinctly while conveying urgency and the need for consultation convincingly. Simulation scenarios for junior doctors and their clinical supervisors should integrate both explicit and informal aspects, namely explicit teaching and feedback practices as well as disguised feedback or PRI in the form of conversational interruptions and questions. In addition to training telephone communication skills, we see potential in using telephone talk simulations two key ways: (a) to prepare clinical supervisors to support junior doctors' learning, and (b) to sensitize junior doctors to recognize disguised feedback they encounter as a mechanism to augment later workplace learning, i.e. 'learning how to learn' through simulation.

\section{References}

1. Phitayakorn R, Williams RG, Yudkowsky R, et al. Patient-care-related telephone communication between general surgery residents and attending surgeons. J Am Coll Surg. 2008;206(4):742-750.

2. Brannen ML, Cameron KA, Adler M, Goodman D, Holl JL. Admission handoff communications: clinician's shared understanding of patient severity of illness and problems. J Patient Saf. 2009;5(4):237-242.

3. Kessler C, Scott NL, Siedsma M, Jordan J, Beach C, Coletti CM. Interunit handoffs of patients and transfers of information: a survey of current practices. Annals of emergency medicine. 2014;64(4):343-349.e345.

4. Kessler C, Kutka BM, Badillo C. Consultation in the emergency department: a qualitative analysis and review. J Emerg Med. 2012;42(6):704-711.

5. Kessler CS, Chan T, Loeb JM, Malka ST. I'm clear, you're clear, we're all clear: improving consultation communication skills in undergraduate medical education. Acad Med. 2013;88(6):753-758.

6. Chan T, Orlich D, Kulasegaram K, Sherbino J. Understanding communication between emergency and consulting physicians: a qualitative study that describes and defines the essential elements of the emergency department consultation-referral process for the junior learner. CJEM. 2013;15(1):42-51.

7. Kessler CS, Kalapurayil PS, Yudkowsky R, Schwartz A. Validity evidence for a new checklist evaluating consultations, the 5Cs model. Acad Med. 2012;87(10):1408-1412.

8. Kessler CS, Tadisina KK, Saks M, et al. The 5Cs of Consultation: Training Medical Students to Communicate Effectively in the Emergency Department. J Emerg Med. 2015;49(5):713-721. 


\section{Chapter 7}

9. Haig KM, Sutton S, Whittington J. SBAR: a shared mental model for improving communication between clinicians. Joint Commission journal on quality and patient safety / Joint Commission Resources. 2006;32(3):167-175.

10. Pryor E, Woodward-Kron R.. International medical graduate doctor to doctor telephone communication: a genre perspective. Engl Spec Purp. 2014;35:41-53.

11. Starmer AJ, Spector ND, Srivastava R, et al. Changes in medical errors after implementation of a handoff program. N Engl J Med. 2014;371(19):1803-1812.

12. Hilligoss B, Moffatt-Bruce SD. The limits of checklists: handoff and narrative thinking. BMJ Qual Saf. 2014;23(7):528-533.

13. Chan T, Sabir K, Sanhan S, Sherbino J. Understanding the impact of residents' interpersonal relationships during emergency department referrals and consultations. J Grad Med Educ. 2013;5(4):576-581.

14. Wadhwa A, Lingard L. A qualitative study examining tensions in interdoctor telephone consultations. Med Educ. 2006;40(8):759-767.

15. Chan T, Bakewell F, Orlich D, Sherbino J. Conflict prevention, conflict mitigation, and manifestations of conflict during emergency department consultations. Acad Emerg Med. 2014;21(3):308-313.

16. Vygotsky LS. Thought and Language (Rev. Ed.). Cambridge, Massachusetts: The MIT Press; 1986.

17. Lave J, Wenger E. Situated Learning: Legitimate Peripheral Participation. New York: Cambridge University Press; 1991.

18. Wenger E. Communities of Practice: Learning, Meaning, and Identity. New York: Cambridge University Press; 1998.

19. Eppich W, Rethans J-J, Teunissen PW, Dornan T. Learning to Work Together Through Talk: Continuing Professional Development in Medicine. In: Supporting Learning Across Working Life. Vol 16. Professional and Practice-based Learning. Cham: Springer International Publishing; 2016:47-73.

20. Eraut M. Informal learning in the workplace. Studies in continuing education. 2004;26(2):247-273.

21. Swanwick T. Informal learning in postgraduate medical education: from cognitivism to 'culturism'. Med Educ. 2005;39(8):859-865.

22. Watling $\mathrm{CJ}$, Lingard L. Grounded theory in medical education research: AMEE Guide No. 70. Med Teach. 2012;34(10):850-861.

23. Charmaz K. Constructing Grounded Theory. 2nd ed. London: SAGE Publications Ltd; 2014.

24. Evens $S$, Curtis $P$. Using patient-simulators to teach telephone communication skills to health professionals. J Med Educ. 1983;58:894-898.

25. Podolsky A, Stern DT, Peccoralo L. The Courteous Consult: A CONSULT Card and Training to Improve Resident Consults. J Grad Med Educ. 2015;7(1):113-117.

26. Anderson JM, Aylor ME, Leonard DT. Instructional design dogma: creating planned learning experiences in simulation. Journal of Critical Care. 2008;23(4):595-602.

27. Thomas PA, Kern DE, Hughes MT, Chen BY, eds. Curriculum Development for Medical Education. a SixStep Approach. 3rd ed. Baltimore: The Johns Hopkins University Press; 2016.

28. Braun V, Clarke V. Using thematic analysis in psychology. Qualitative Research in Psychology. 2006;3(2):77-101.

29. Varpio L, Ajjawi R, Monrouxe LV, O'Brien BC, Rees CE. Shedding the cobra effect: problematising thematic emergence, triangulation, saturation and member checking. Med Educ. 2017;51(1):40-50.

30. Miloslavsky EM, McSparron JI, Richards JB, Puig A, Sullivan AM. Teaching during consultation: factors affecting the resident-fellow teaching interaction. Med Educ. 2015;49(7):717-730.

31. van der Leeuw RM, Teunissen PW, van der Vleuten CPM. Broadening the Scope of Feedback to Promote Its Relevance to Workplace Learning. Acad Med. 2018;93(4):556-559.

32. Cleland JA, Abe K, Rethans J-J. The use of simulated patients in medical education: AMEE Guide No 42. Med Teach. 2009;31(6):477-486.

33. Szmuilowicz E, Neely KJ, Sharma RK, Cohen ER, McGaghie WC, Wayne DB. Improving residents' code status discussion skills: a randomized trial. J Palliat Med. 2012;15(7):768-774.

34. Wayne DB, Moazed F, Cohen ER, Sharma RK, McGaghie WC, Szmuilowicz E. Code status discussion skill retention in internal medicine residents: one-year follow-up. J Palliat Med. 2012;15(12):1325-1328. 
35. Rudolph JW, Raemer DB, Simon R. Establishing a safe container for learning in simulation: the role of the presimulation briefing. Simul Healthc. 2014;9(6):339-349.

36. Chung HS, Dieckmann P, Issenberg SB. It is time to consider cultural differences in debriefing. Simul Healthc. 2013;8(3):166-170.

37. Schmutz JB, Eppich WJ. Promoting Learning and Patient Care Through Shared Reflection: A Conceptual Framework for Team Reflexivity in Health Care. Acad Med. 2017;92(11):1555-1563.

38. Schmutz JB, Kolbe M, Eppich WJ. Twelve tips for integrating team reflexivity into your simulation-based team training. Med Teach. 2018; 40(7):721-727. 


\section{Chapter 7}




\section{CHAPTER 8}

Promoting learning and patient care through shared reflection: A conceptual framework for team reflexivity in health care

Published as: Schmutz JB, Eppich WJ. Promoting Learning and Patient Care Through Shared Reflection: A Conceptual Framework for Team Reflexivity in Health Care. Acad Med. 2017;92(11):1555-1563. 


\section{Abstract}

Health care teams are groups of highly skilled experts who may often form inexpert teams because of a lack of collective competence. Because teamwork and collaboration form the foundation of effective clinical practice, factors that promote collective competence demand exploration. The authors review team reflexivity (TR), a concept from the psychology and management literatures, and how it could contribute to the collective competence of health care teams. TR captures a team's ability to reflect collectively on group objectives, strategies, goals, processes, and outcomes of past, current, and future performance to process key information and adapt accordingly. As an overarching process that promotes team functioning, TR builds shared mental models as well as triggering team adaptation and learning.

The authors present a conceptual framework for TR in health care, describing three phases in which TR may occur: pre-action TR (briefing before patient care), in-action TR (deliberations during active patient care), and post-action TR (debriefing after patient care). Depending on the phase, TR targets either goals, taskwork, teamwork, or resources and leads to different outcomes (e.g., optimal preparation, a shared mental model, adaptation, or learning). This novel conceptual framework incorporates various constructs related to reflection and unites them under the umbrella of TR. Viewing reflection through a team lens may guide future research about team functioning, optimize training efforts, and elucidate mechanisms for workplace learning, with better patient care as the ultimate goal. 


\section{Introduction}

Although health care teams usually represent collections of highly skilled individual experts, such teams are not necessarily competent ${ }^{1}$ or expert. $^{2}$ Indeed, communication breakdowns can occur, which threaten both patient safety ${ }^{3,4}$ and learning. ${ }^{5}$ These findings highlight the complex social environments of clinical medicine, in which teamwork, collaboration, and interprofessional collaborative practice ${ }^{6}$ are essential elements. ${ }^{7-10}$ In other words, competence in complex clinical settings is not only an individual but also a collective phenomenon. ${ }^{1,11}$ However, mechanisms for promoting collective competence are poorly understood.

Reflective practice is one such mechanism. ${ }^{12}$ Indeed, the discourse of reflection looms large for competent professional practice and lifelong learning ${ }^{13,14}$ within medicine and health professions education. ${ }^{15,16}$ Most literature, however, focuses on individual reflection ${ }^{14}$ and highlights competence as an individual construct. Unfortunately, a focus on reflection at an individual level neglects inadvertent gaps in patient care due to inadequate team-level reflection.

Team reflexivity (TR), a concept from psychology and management literatures, may contribute to collective competence and expert team performance, since health care providers reflect not only individually but collectively as well. TR (defined in the next section) captures a team's ability to reflect on group objectives, strategies, goals, processes, and outcomes of past and current performance and to adapt accordingly. ${ }^{17}$ As an overarching process, TR promotes good team functioning and learning. ${ }^{17,18}$ Therefore, in this article, we have three aims: (1) to explore TR as a driver for optimal health care team functioning and learning, (2) to develop a conceptual framework that illustrates mechanisms and moderating factors for TR in health care, and (3) to discuss areas for future TR research to delineate its mechanisms and potential impact on learning and health care delivery.

\section{Definition of TR}

Reflection and adaptation are central to the concept of TR. ${ }^{19}$ Reflection at the team level involves several key behaviors through which the team's reality is constantly renegotiated. Some TR behaviors mentioned in the literature ${ }^{19}$ include

- questioning,

- planning,

- analyzing,

- exploring alternatives, 
- using knowledge explicitly,

- reviewing past events with self-awareness, and

- digesting and incorporating new information.

TR is a team-level construct, which has been defined as the extent to which group members overtly reflect upon and communicate about the group's objectives, strategies (e.g., decision making) and processes (e.g., communication), and adapt them to current or anticipated circumstances. ${ }^{17}$

In contrast, nonreflexivity denotes a state of acting without awareness. ${ }^{20}$ Nonreflexive teams show little collective awareness of team objectives, of strategies about how to collaborate, and of the environment in which they operate. ${ }^{21}$

TR holds particular promise when clinicians are faced with uncertain and complex tasks demanding adaptation (e.g., nonroutine activities), ${ }^{22}$ which makes sense because information processing is an essential element of TR. TR becomes less important when team goals are clear and all tasks are coordinated on the basis of prelearned routines (e.g., routine elective surgery). With increasing ambiguity (e.g., complicated diagnostic tasks or unexpected complications), teams must process new information and use all available resources. Although TR has relevance beyond acute care settings, for clarity we locate our examples mainly in that domain.

During the care of a patient with asthma and severe respiratory distress, the team leader might initiate TR by saying, "At this point the patient is not responding to our treatments and the oxygen saturation remains borderline. Are we missing anything?" Similarly, the team may actively reflect on escalating treatment and question planned interventions-for instance, "Bronchodilators are having minimal effect. Should we try noninvasive ventilation strategies or do we need to move straight to endotracheal intubation?"

In addition, teams can reflect on team processes themselves to adapt them to current or anticipated circumstances-for instance, "Things seem a bit loud and chaotic at the moment; can we regroup and make sure we are clear about our priorities?" Through $T R$, the entire team may provide input through collective reflection about objectives, processes, or strategies. A related concept called leader inclusiveness denotes words and actions leaders exhibit that invite and show appreciation for others' contributions. ${ }^{23}$ Whereas leader inclusiveness focuses on leaders, TR encompasses communication between team members as well. Expressions that mirror certain behaviors in the team with the intention to invite team members to reflect (e.g., 
orders) are not considered as TR (e.g., "I have the feeling we are uncoordinated here; can we omit unnecessary talk, please?").

Team-level reflexivity differentiates itself from individual reflexivity, since TR necessarily requires communication (including nonverbal communication); TR is a relational behavior whose explicit interactions can be observed. Originally, West ${ }^{19}$ described TR as a construct comprising three parts-namely, reflection, planning, and action/adaptation. However, recent work ${ }^{21,24,25}$ views TR in a more uniform fashion, with information processing as an essential element of team reflection. Schippers et $\mathrm{al}^{25}$ conceptualize TR as an explicit information-processing activity in teams that precedes adaptation in rapidly changing situations and contributes to team learning. Also, Konradt et al ${ }^{18}$ present a dynamic framework where feedback represents a situational factor, triggering TR and adaptation to reduce discrepancies between a current and desired state.

Studies in other domains link TR with team effectiveness in TV production teams, ${ }^{26}$ innovation in organizational teams from the private sector, ${ }^{27}$ better communication and shared mental models (SMMs), ${ }^{28}$ and improved learning in student teams. ${ }^{24}$ To date, however, studies about TR in health care are scarce. Aspects of TR can be found in tools ${ }^{29,30}$ and frameworks for interprofessional collaboration. ${ }^{31}$ However, interprofessional collaboration is conceptualized more broadly (e.g., sharing, partnership, power, interdependency, process ${ }^{31}$ ) than are the explicit observable behaviors of TR. Collaboration itself includes more than reflection on a team level. Because of space limitations, we have not included an extensive literature review on interprofessional education or team training models. However, see Lapkin et al $^{32}$ for a review on this topic.

Here we present a framework in which TR occurs not only after team actions as a deliberate team learning process but also as a deliberate team process before, during, and after task execution. On the basis of preliminary findings from other domains, we suspect potentially significant benefits for team functioning, immediate and future patient care, and learning (see Chart 1).

\section{A conceptual framework for health care teams using TR}

Over time, teams pass through different phases, each focusing on different tasks. In action phases, teams engage in activities that directly contribute to goal achievement (e.g., providing patient care), whereas in transition phases, teams focus on evaluation and/or planning activities occurring before and after action phases. ${ }^{33}$ Compared with more stable teams in other industries, health care teams often change composition 
and exist only briefly with a strong emphasis on the action phase, hence the descriptor action teams. ${ }^{34}$ In action teams, essential transition phases are likely to suffer.

Most of the literature has viewed TR as a process occurring in transition phases with the purpose of evaluating the action process (e.g., debriefing). ${ }^{25}$ However, in line with others, ${ }^{18,35}$ we conceptualize TR as a beneficial team process in transition phases not only before and after task execution but also during action phases. Outcomes and targets of TR processes differ according to the temporal focus of reflection (i.e., past events, current actions, future activities). Depending on the situation, teams can reflect upon five elements: their goals, the available resources, taskwork, teamwork, and outcomes (see Chart 1).

Goals include main goals as well as subgoals. Defining goals and subgoals facilitates target-oriented actions during the process. However, inaccurate goals (e.g., in cases of incorrect working diagnoses) can lead teams down erroneous paths and prevent appropriate prioritization. In a patient with severe respiratory distress and hypoxia (as in the case illustrated in Chart 2), goals might include ensuring adequate oxygenation, with the following subgoals:

- Initiate effective bag-mask ventilation with $100 \%$ oxygen

- Prepare supplies for intubation

- Perform intubation and confirm airway placement

- Implement post-intubation management to ensure adequate oxygen saturation

- Diagnose underlying conditions and provide targeted therapy

Resources include personnel resources (e.g., team members' skills, experience, or fatigue levels) and system resources (e.g., available equipment, layout of ward).

Taskwork denotes a team's "interaction with tasks, tools, machines and systems" ${ }^{\text {"36 }}$ and represents what a team is doing (e.g., administering medications for rapid sequence intubation), whereas teamwork is how the members of a team are doing it with each other (e.g., giving a clear order, using closed loop communication). Thus, teamwork helps direct, align, and monitor taskwork. ${ }^{36}$

Finally, outcomes describe work outputs from the action phase. These include both patient and team outcomes (e.g., improved oxygenation, time to key interventions, team member satisfaction, burnout). ${ }^{37}$ By definition, reflection about outcomes occurs only after task completion. Depending on when a team reflects, TR 


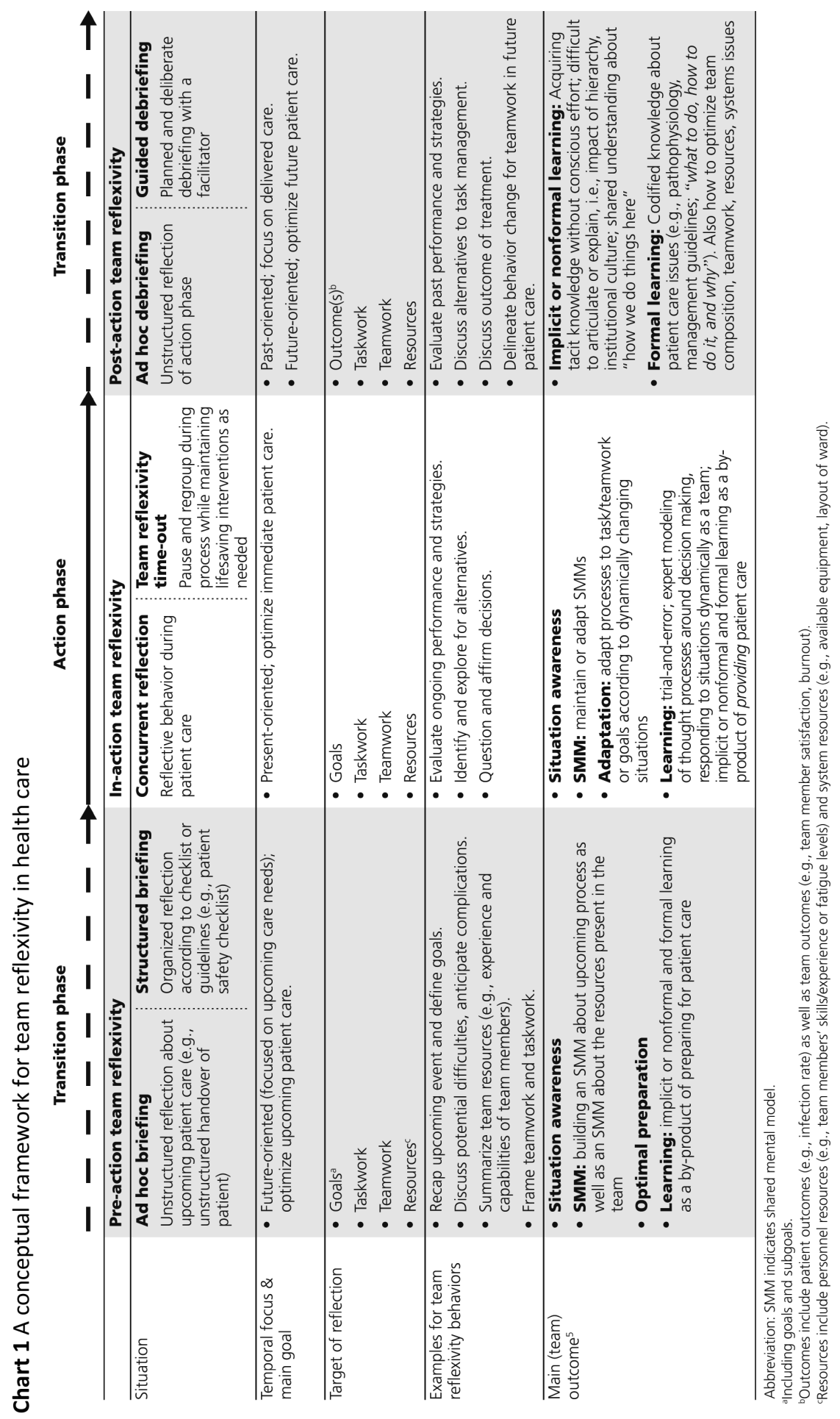




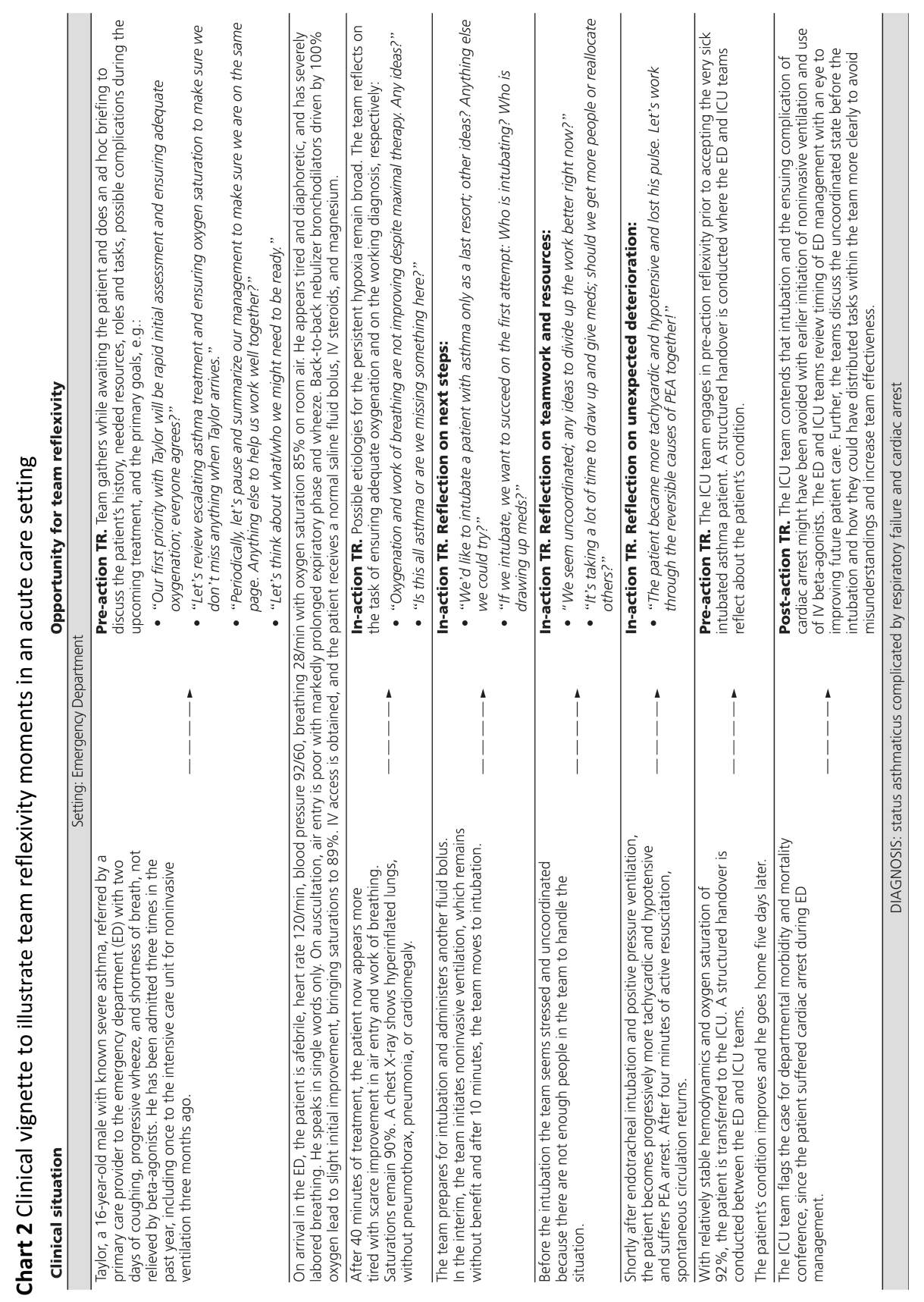


varies in scope and purpose, enabling different outcomes. In Chart 1 we present our TR framework with three types of TR-namely pre-action, in-action, and post-action TR. In addition, Chart 2 provides representative examples of behaviors that initiate TR from a patient's health care journey.

In the following and in Chart 2, we explain and illustrate the three stages of TR by discussing the case of Taylor (not his real name), a 16-year-old patient with severe asthma presenting to the emergency department (ED). TR is also relevant for non-acute care settings and educational environments, although in these settings, the distinction between action and transition phases is less clear. Such uses of TR also reflect the collaborative practice among team members in less leader-centered environments. Although these uses of TR are not the focus of our article, we discuss TR in team training in the Discussion section and also have provided two supplemental digital appendices to illustrate the potential of TR in a variety of settings and to present models of TR that are less "leader centered." (See Appendices 1 and 2 at at the end of Chapter 4). The first of these appendices illustrates the use of TR in a rehabilitation clinic; the second appendix shows TR during a simulation training course.

\section{Pre-action TR}

Pre-action TR focuses on upcoming care needs and occurs before the action phase. Teams can reflect upon goals, upcoming taskwork, teamwork, and personnel and system resources. Examples from Chart 2 include:

- Goals: "Our first priority with Taylor will be rapid initial assessment and ensuring adequate oxygenation; everyone agrees?"

- Taskwork: "Let's review escalating asthma treatment and ensuring oxygen saturation to make sure we don't miss anything when Taylor arrives."

- Teamwork: "Periodically, let's pause and summarize management to ensure we are on the same page. Anything else to help us work well together?"

- Resources: "Let's think about what/who we might need to be ready?"

Pre-action TR focuses on the future by collectively anticipating upcoming activities if leaders frame the team reflection episode as such. Framing refers to the process of creating meaning that is not a necessary or factual aspect of the current situation ${ }^{12,38}$ by explicitly stating why the discussion is happening, what dilemma needs solving, or what assumptions underlie decision making. ${ }^{39}$ Shared reflection before patient contact prepares teams for upcoming events and increases situational awareness, since all team members may not understand upcoming taskwork and teamwork in the same way. Leaders should collaborate with team members to frame 
expectations actively and provide opportunities to ask questions, clarify understanding, and give input, all of which also facilitates both individual and team learning. In addition, pre-action TR might promote a positive team climate and encourage speaking up about safety concerns because team members feel valued. ${ }^{40}$ Similarly, establishing a "safe container" before training events can maximize learning outcomes. ${ }^{41}$

Pre-action TR primes teams to deliver excellent care and sets the stage for optimal team functioning. It builds SMMs about upcoming tasks as well as knowledge and skills within teams. SMMs predict good team performance ${ }^{42}$ and provide a cognitive foundation for teamwork. ${ }^{43}$ Pre-action reflection may occur in ad hoc briefings-in some cases called huddle moments ${ }^{44}$-without a predefined structure or following a checklist, as is usual before incision in operative procedures. ${ }^{45}$ Perioperative checklists promote development of SMMs by focusing teams on patients and upcoming taskwork. However, perioperative checklists underemphasize teamwork aspects that might promote TR behaviors. This omission fails to address a potentially important predictor for improved patient care.

\section{In-action TR}

In-action TR focuses on immediate patient care needs during action phases. As ongoing management unfolds, teams can again reflect upon:

- Goals and subgoals to ensure they are following appropriate courses of action (e.g., a junior team member may ask, "Is our first priority in this moment really $X Y$ or shouldn't we do YZ? Can you clarify?"). In response, a team leader might initiate an opportunity for the team to reflect: "Okay, let us quickly summarize what we have here, our priorities, and management options."

- Specific taskwork (e.g., consider the necessity and timing of a procedure).

- Teamwork (e.g., "We seem uncoordinated; any ideas about how to divide up the work better right now?").

- Team resources to achieve their patient care objectives (e.g., from team member: "It's taking a lot of time to draw up and give meds; should we get more people or reallocate team members?").

In-action reflection serves to maintain or adapt SMMs, making it especially valuable when pre-action reflection was minimal or nonexistent or when additional team members arrive. TR catalyzes team adaptation in evolving and dynamic situations that require shifting focus and/or priorities during treatment ${ }^{19}$ (e.g., when unanticipated 
complications arise or key information emerges), thus promoting team situational awareness. Further, through explicit TR and building SMMs in specific situations-a form of situated learning ${ }^{46}$-less experienced team members may achieve deeper understanding of highly context-dependent patient care issues.

In-action TR achieves maximum impact particularly for complex tasks with high degrees of uncertainty. ${ }^{27}$ In these instances, teams may engage in a form of trial and error, going down one path that proves erroneous, but self-correcting through episodes of TR. Effective teams "organize to learn" ${ }^{47}$; collective trial and error including TR would be an example. However, for routine tasks with established team roles and division of labor, unnecessary or excessive in-action team reflection may distract or even impede care.

The primary goal of in-action TR is optimizing immediate patient care. This explicit team process may occur in two ways: (1) concurrently while providers execute patient care tasks, or (2) by briefly pausing the process through a TR time-out. During bursts of concurrent reflection, team members refine SMMs and establish clear immediate-term management priorities. However, some team members may miss relevant information during ongoing patient care (e.g., nurses focused on drawing up medications and who are not at the bedside). Thus, team leaders and/or team members may also trigger an explicit TR time-out to regroup, reevaluate, and summarize to get everyone on the same page. ${ }^{48}$ By pausing all but lifesaving resuscitative measures in highly dynamic and complex situations, this deliberate TR process ensures that most if not all team members listen; ideally, the process creates space for team members to contribute their perspectives.

A patient in cardiac arrest with pulseless electrical activity represents a classic example of this TR time-out approach: During ongoing resuscitation, the team must actively consider and search for possible reversible causes. Team input may not only be desirable but lifesaving. A brief pause gives teams critical time to evaluate their efforts, build or adapt an SMM, and avoid going down potentially wrong paths, ${ }^{48}$ highlighting the value of investing periodic short bursts of shared reflection to promote effective teamwork and minimize errors.

No empirical study has yet to explore the potential beneficial effect of in-action TR, but evidence from the expert judgment literature supports this notion. Expert clinicians know when to rely on either intuitive or deliberate, analytical approaches. ${ }^{49}$ Moulton et $\mathrm{l}^{50}$ refer to experts' ability to "slow down when you should" and shift to a more reflective, deliberative state. Similarly, this same assertion applies for teams. Truly expert teams heed cues when situations deteriorate, which allows them to adapt 
dynamically. In these moments, teams should actively shift into a brief reflective state through concurrent TR or, as needed, into a TR time-out. While team leaders most likely initiate TR, all team members must feel empowered to prompt reflection during suboptimal team coordination or to clarify shared understanding about what is going on or the priorities for care. As an example, in complex critical situations, a nurse may ask, "I don't think we are all on the same page here. What is our working diagnosis?" This triggers the team leader to say, "Yes, let's summarize all of what is going on and what our priorities are," to review the process.

Team leaders should invite collective reflective behavior, explicitly encouraging pauses in action if someone perceives that team actions are not yielding desired outcomes in terms of taskwork. ${ }^{51}$ Yet for team leaders, moments of TR prompted by team members may be especially helpful in situations with high cognitive load (e.g., complicated diagnostic situations with high time pressure). In such cases, leaders focused on integrating many sources of information may not recognize progressively uncoordinated team activity.

\section{Post-action TR}

Post-action TR centers both on past team activity related to delivered care and also on opportunities to improve future care. As post-action TR by its nature is deeper than preaction or in-action TR and encompasses a whole discussion, we have provided no concrete examples here. Teams typically evaluate their taskwork (e.g., appropriateness and timeliness of clinical management). However, post-action TR should also include evaluation of teamwork. What aspects of teamwork went well, and why? What aspects of teamwork need improvement, and why? If the team seemed uncoordinated at times, what contributed to that? Such questions initiate the reflective process about teamwork and improve future teamwork by evaluating past actions.

Increasingly strong evidence exists ${ }^{52-54}$ that post-action reflexivity also helps crystalize learning, either as a by-product or an explicit goal. This collective learning-a main goal of post-action reflexivity-serves to enhance future patient care by improving taskwork (e.g., clinical management) and teamwork (e.g., behaviors that improve team coordination). For example, the ICU team flags Taylor's case for a departmental morbidity and mortality (M\&M) conference because he suffered cardiac arrest during ED management. During the M\&M, clinical decision making, treatment strategies, and alternative treatment methods are discussed (e.g., "Earlier initiation of noninvasive ventilation and IV beta-agonists may have prevented intubation and the ensuing complication of cardiac arrest"). With skilled facilitators and a supportive learning culture, M\&Ms represent a form of post-event debriefing, creating a space for TR behaviors. Post- 
action reflexivity among interdisciplinary team members after in-hospital cardiac arrests can improve the quality of basic and advanced life support and positively impact survival outcomes. $^{55}$

Post-action TR can be planned and deliberate or occur ad hoc, without structure. Planned debriefings commonly occur after specific, often simulated, scenarios ${ }^{56,57}$ with trained facilitators who establish and maintain a supportive climate that promotes honest and critical reflection. Such debriefings are, however, time- and resourceintensive for busy clinical environments.

Spontaneous ad hoc debriefings on breaks or over lunch-also called post "huddles"58 - may offer at least some team members the opportunity to talk about a case and to review management, taskwork, and teamwork, and may benefit team functioning. ${ }^{44,58}$ Because they are ad hoc, these spontaneous and emergent discussions may not include critical team members. Further, they may occur in professional silos in a manner that hampers interprofessional collaboration. ${ }^{10}$ Finally, such ad hoc debriefings may also lack a safe, supportive, nonblaming climate needed for the degree of reflexivity that fosters team learning. Nonetheless, we maintain that-especially for teams that become practiced and regularly engage in structured post-event debriefings - such ad hoc debriefings may contribute to improved taskwork and teamwork. By deliberately reflecting about past situations and evaluating their actions, teams can minimize similar future mistakes and expressly identify and reinforce positive behaviors. Ideally, debriefings that promote post-action reflexivity will become integrated in the health care workplace. Guidelines exist to promote these discussions in an evidence-based fashion. ${ }^{56,59,60}$

\section{Discussion}

We have outlined a novel conceptual framework for TR in health care that incorporates various constructs related to reflection and unites them under the umbrella of TR. Thus, we hope to advance the understanding of what processes allow expert teams to function competently in the collective. Our framework integrates three essential phases of patient care with opportunities for TR: pre-action, in-action, and post-action.

Most literature about pre-action TR focuses on structured briefings (e.g., preoperative briefings, handovers ${ }^{61,62}$ ), although other reflective pre-action processes like planning or framing ${ }^{38}$ are equally essential. Many clinicians potentially underestimate the value of ad hoc pre-action reflection and do not devote time for quick briefings. However, here we emphasize the importance of pre-action TR because it aligns and prepares the 
team, increases situational awareness through developing an SMM, and sets the stage for optimal teamwork.

Most research focusing on post-action TR (i.e., debriefings) that guides practice stems mainly from the education and simulation literature. As post-event debriefings in clinical environments gain traction, ${ }^{59}$ the role of ad hoc post-action debriefings also demands further investigation. Short informal post-action reviews after actual patient management (e.g., during a break) or after shift change likely enhances both team functioning and workplace learning. ${ }^{5}$ Reviewing actions after team events fosters not only individual but also team learning while reinforcing effective behaviors and identifying aspects to change in the future. In addition, deliberate reflection about past cases may help identify helpful or harmful system factors (including equipment and personnel resources). As a result, teams can improve system factors to provide conditions for optimal patient care (e.g., location of key equipment or accessing help in emergency situations).

Studies about in-action TR during active patient management are rare. Research about related constructs stems mostly from the coordination or leadership literature. This work explores elements of TR-or initiators for TR phases only - as isolated, detached team processes such as situation assessment, planning, talking to the room, explicit reasoning, or speaking up. ${ }^{63-67}$ These team processes are often investigated on a micro level tied to specific team and task characteristics, making generalization to other tasks difficult. Of course, good teamwork behaviors depend on both team and task characteristics. Although team research provides strong evidence about collective or work group effectiveness, no one specific teamwork behavior generally predicts effective team performance. ${ }^{68}$ In fact, this line of research views team adaptability to specific tasks or changing circumstances within task work (e.g., sudden cardiac arrest of a patient during an operation) as a relevant performance variable. ${ }^{69}$

Less clear is which team processes need to be adapted when and by whom. Empirical studies fail to answer these questions uniformly. Instead of focusing on micro processes, research must target overarching processes that promote collective competence through good team functioning, including effective teamwork and team adaptation in various team constellations and situations. TR exemplifies one such overarching team process that manifests itself in observable behaviors. TR about upcoming, actual, or past situations enables teams to adapt current or future team processes. Future empirical studies should investigate the links between in-action TR and performance outcomes as well as the impact of TR on team functioning (e.g., adaptation) during the process. In addition to creating SMMs in the service of effective patient care, all forms of TR also promote highly contextualized workplace-based 
learning as an important by-product of authentic patient care experiences. Emergent and nonroutine situations serve as fodder for reactive learning tightly linked to ongoing work demands; deliberative learning occurs during post-action review. ${ }^{70}$ Thus, we view episodes of TR not only as promoting team functioning but also as key elements of a guided workplace curriculum. ${ }^{71,72}$ Edmondson ${ }^{47}$ highlights critical "teaming" behaviors that help teams "organize to learn"; for example, explicit, open communication forms the foundation of collaborative practice. ${ }^{6}$

Our TR framework provides a conceptual model for future research to help guide areas of focus. Significant research supports pre-action TR (e.g., team huddle, ${ }^{44}$ briefing $^{40,73}$ ) and post-action TR (e.g., after-action reviews, ${ }^{74}$ debriefings ${ }^{75,76}$ ). In-action TR is mostly unexplored. Therefore, we propose observational studies to investigate TR in both simulation and real, clinical settings. Studies with pre-post intervention design focused on in-action TR might identify effects on relevant patient outcomes like treatment time or treatment quality (checklist-based assessment ${ }^{77}$ ) as well as team outcomes (e.g., SMM, adaptation, psychological safety). So far, various self-report questionnaires for TR exist, ${ }^{21,26}$ but behavior marker systems or observation tools need to be developed. Further, research from a sociocultural perspective might shed important light on TR, such as exploring transition phases in transfer of care from one health care provider or one team to another, viewing handover as a time of co-constructing meaning ${ }^{78}$ using TR as a sensitizing lens.

Future team training should incorporate the principles of TR, and especially in-action TR. For example, teams may benefit from simple TR time-outs or concurrent reflection about ongoing processes using simulation-based methods. Brief reflective episodes during real-time patient care may prevent teams from working toward wrong goals or working diagnoses and promote adaptation to complex and changing health care environments.

Individual reflection is already a widespread topic in medical education. ${ }^{15}$ Within the discourse of interprofessional collaboration in health care, we must expand our thinking to include team-level reflection to exploit its positive effects on team functioning. Within health care teams, every team member represents a valuable resource; complex patient care requires that we tap this human potential. As a teamwork process, TR enables teams to optimize their capacity. Our framework will support future research to clarify the impact of TR behaviors on improved team functioning and enhanced workplace learning, with better patient care as the ultimate goal. 


\section{Chapter 8}

\section{References}

1. Lingard L. Rethinking competence in the context of teamwork. The Question of Competence: Reconsidering Medical Education in the Twenty-First Century. Cornell University Press, Ithaca, NY; 2012:42-69.

2. Burke CS, Salas E, Wilson-Donnelly K, Priest H. How to turn a team of experts into an expert medical team: Guidance from the aviation and military communities. Qual Saf Health Care. 2004;13(suppl 1):i96-i104.

3. Kohn LT, Corrigan J, Donaldson MS; Committee on Quality of Health Care in America. To Err Is Human: Building a Safer Health System. 1999.Vol 6. Washington, DC: National Academy Press.

4. Lingard L, Espin S, Whyte S, et al. Communication failures in the operating room: An observational classification of recurrent types and effects. Qual Saf Health Care. 2004;13:330-334.

5. Eppich W, Rethans J-J, Teunissen PW, Dornan T. Billet S, Dymock D, Choy S. Learning to work together through talk: Continuing professional development in medicine. In: Supporting Learning Across Working Life. New York, NY: Springer; 2016:47-73.

6. Suter E, Arndt J, Arthur N, Parboosingh J, Taylor E, Deutschlander S. Role understanding and effective communication as core competencies for collaborative practice. J Interprof Care. 2009;23:41-51.

7. Kitto S, Marshall SD, McMillan SE, et al. Rapid response systems and collective (in)competence: An exploratory analysis of intraprofessional and interprofessional activation factors. J Interprof Care. 2015;29:340-346.

8. Lingard L, Reznick R, DeVito I, Espin S. Forming professional identities on the health care team: Discursive constructions of the "other" in the operating room. Med Educ. 2002;36:728-734.

9. Burford B. Group processes in medical education: Learning from social identity theory. Med Educ. 2012;46:143-152.

10. Weller J, Boyd M, Cumin D. Teams, tribes and patient safety: Overcoming barriers to effective teamwork in healthcare. Postgrad Med J. 2014;90:149-154.

11. Boreham N. A theory of collective competence: Challenging the neo-liberal individualisation of performance at work. Br J Educ Stud. 2004;52:5-17.

12. Schön DA. The Reflective Practitioner: How Professionals Think in Action. New York, NY: Basic Books; 1983.

13. Sandars J. The use of reflection in medical education: AMEE guide no. 44. Med Teach. 2009;31:685-695.

14. Nguyen QD, Fernandez N, Karsenti T, Charlin B. What is reflection? A conceptual analysis of major definitions and a proposal of a five-component model. Med Educ. 2014;48:1176-1189.

15. Ng SL, Kinsella EA, Friesen F, Hodges B. Reclaiming a theoretical orientation to reflection in medical education research: A critical narrative review. Med Educ. 2015;49:461-475.

16. Embo MP, Driessen E, Valcke M, Van Der Vleuten CP. Scaffolding reflective learning in clinical practice: A comparison of two types of reflective activities. Med Teach. 2014;36:602-607.

17. West MA. Beyerlein MM, Johnson DA, Beyerlein ST. Reflexivity, revolution and innovation in work teams. In: Product Development Teams. Vol 5. Stamford, CT: JAI Press; 2000:1-29.

18. Konradt U, Otte KP, Schippers MC, Steenfatt C. Reflexivity in teams: A review and new perspectives. J Psychol. 2016;150:153-174.

19. West M. West MA. Reflexivity and work group effectiveness: A conceptual integration. In: Handbook of Work Group Psychology. New York, NY: John Wiley \& Sons, Ltd.; 1996:555-579.

20. Rennie DL. Toukmanian SG, Rennie DL. Qualitative analysis of the client's experience of psychotherapy: The unfolding of reflexivity. In: Psychotherapy Process Research: Paradigmatic and Narrative Approaches. Thousand Oaks, CA: Sage; 1992:427-437.

21. Schippers MC, Hartog Den DN, Koopman PL. Reflexivity in teams: A measure and correlates. Appl Psychol. 2007;56:189-211. 
22. West MA. Team reflexivity. Encyclopedia of Group Processes and Intergroup Relations. New York, NY: Sage Publications; 2009:1-3.

23. Nembhard IM, Edmondson AC. Making it safe: The effects of leader inclusiveness and professional status on psychological safety and improvement efforts in health care teams. J Organ Behav. 2006;27:941-966.

24. Schippers MC, Homan AC, Knippenberg D. To reflect or not to reflect: Prior team performance as a boundary condition of the effects of reflexivity on learning and final team performance. J Organ Behav. 2013;34:6-23.

25. Schippers MC, Edmondson AC, West MA. Team reflexivity as an antidote to team information-processing failures. Small Group Res. 2014;45:731-769.

26. Carter SM, West MA. Reflexivity, effectiveness, and mental health in BBC-TV production teams. Small Group Res. 1998;29:583-601.

27. De Dreu CK. Team innovation and team effectiveness: The importance of minority dissent and reflexivity. Eur J Work Organ Psychol. 2002;11:285-298.

28. Gurtner A, Tschan F, Semmer NK, Nägele C. Getting groups to develop good strategies: Effects of reflexivity interventions on team process, team performance, and shared mental models. Organ Behav Hum Decis Process. 2007;102:127-142.

29. Orchard CA, King GA, Khalili H, Bezzina MB. Assessment of Interprofessional Team Collaboration Scale (AITCS): Development and testing of the instrument. J Contin Educ Health Prof. 2012;32:58-67.

30. Tilden VP, Eckstrom E, Dieckmann NF. Development of the assessment for collaborative environments (ACE-15): A tool to measure perceptions of interprofessional "teamness." J Interprof Care. 2016;30:288294.

31. D’Amour D, Ferrada-Videla M, San Martin Rodriguez L, Beaulieu MD. The conceptual basis for interprofessional collaboration: Core concepts and theoretical frameworks. J Interprof Care. 2005;19(suppl 1):116-131.

32. Lapkin S, Levett-Jones T, Gilligan C. A systematic review of the effectiveness of interprofessional education in health professional programs. Nurse Educ Today. 2013;33:90-102.

33. Marks MA, Mathieu JE, Zaccaro SJ. A temporally based framework and taxonomy of team processes. Acad Manage Rev. 2001;26:356-376.

34. Vashdi DR, Bamberger PA, Erez M. Can surgical teams ever learn? The role of coordination, complexity, and transitivity in action team learning. Acad Manage J. 2013;56:945-971.

35. Schmutz J, Welp A, Kolbe M. Örtenblad A, Löfström CA, Sheaff R. Teamwork in healthcare organizations. Management Innovations for Health Care Organizations. London, UK: Routledge; 2016:359-377.

36. Bowers CA, Braun CC, Morgan BB. Brannik MT, Salas E, Prince C. Team workload: Its meaning and measurement. Team Performance Assessment and Measurement: Theory, Methods, and Applications. 1997:Mahwah, NJ: Erlbaum; 85-108.

37. Reader TW, Flin R, Mearns K, Cuthbertson BH. Developing a team performance framework for the intensive care unit. Crit Care Med. 2009;37:1787-1793.

38. Edmondson AC. Framing for learning: Lessons in successful technology implementation. Calif Manage Rev. 2003;45:34-54.

39. Torbert W. Reason $\mathrm{P}$, Brandbury $\mathrm{H}$. The practice of action inquiry. Handbook of Action Research: Participative Inquiry and Practice. Thousand Oaks, CA: Sage; 2008:207-218.

40. Phadnis J, Templeton-Ward $\mathrm{O}$. Inadequate preoperative team briefings lead to more intraoperative adverse events [published online ahead of print April 22, 2015]. J Pat Saf.

41. Rudolph JW, Raemer DB, Simon R. Establishing a safe container for learning in simulation: The role of the presimulation briefing. Simul Healthc. 2014;9:339-349.

42. Burtscher MJ, Manser T. Team mental models and their potential to improve teamwork and safety: A review and implications for future research in healthcare. Saf Sci. 2012;50:1344-1354. 


\section{Chapter 8}

43. Mesmer-Magnus JR, Dechurch LA. Information sharing and team performance: A meta-analysis. J Appl Psychol. 2009;94:535-546.

44. Glymph DC, Olenick M, Barbera S, Brown EL, Prestianni L, Miller C. Healthcare utilizing deliberate discussion linking events (HUDDLE): A systematic review. AANA J. 2015;83:183-188.

45. Haynes AB, Weiser TG, Berry WR, et al; Safe Surgery Saves Lives Study Group. A surgical safety checklist to reduce morbidity and mortality in a global population. N Engl J Med. 2009;360:491-499.

46. Lave J, Wenger E. Situated Learning: Legitimate Peripheral Participation. Cambridge, UK: Cambridge University Press; 1991

47. Edmondson AC. Teaming: How Organizations Learn, Innovate, and Compete in the Knowledge Economy. 2012.San Francisco, CA: Jossey-Bass.

48. Rall M, Glavin R, Flin R. The "10-seconds-for-10-minutes principle"-Why things go wrong and stopping them getting worse. Bull Royal Coll Anaesth. 2008;51:2614-2616.

49. Croskerry P, Petrie DA, Reilly JB, Tait G. Deciding about fast and slow decisions. Acad Med. 2014;89:197200.

50. Moulton CA, Regehr G, Mylopoulos M, MacRae HM. Slowing down when you should: A new model of expert judgment. Acad Med. 2007;82(10 suppl):S109-S116.

51. Eppich WJ. "Speaking up" for patient safety in the pediatric emergency department. Clin Pediatr Emerg Med. 2015;16:83-89.

52. HoegI M, Parboteeah KP. Team reflexivity in innovative projects. R\&D Manag. 2006;36:113-125.

53. Edmondson AC, Dillon JR, Roloff KS. Three perspectives on team learning: Outcome improvement, task mastery, and group process. Acad Manage Ann. 2007;1:269-314.

54. Tannenbaum SI, Cerasoli CP. Do team and individual debriefs enhance performance? A meta-analysis. Hum Factors. 2013;55:231-245.

55. Wolfe H, Zebuhr C, Topjian AA, et al. Interdisciplinary ICU cardiac arrest debriefing improves survival outcomes. Crit Care Med. 2014;42:1688-1695.

56. Lyons R, Lazzara EH, Benishek LE, et al. Enhancing the effectiveness of team debriefings in medical simulation: More best practices. Jt Comm J Qual Patient Saf. 2015;41:115-125.

57. Eppich W, Cheng A. Promoting excellence and reflective learning in simulation (PEARLS): Development and rationale for a blended approach to health care simulation debriefing. Simul Healthc. 2015;10:106115.

58. Kellish AA, Smith-Miller C, Ashton K, Rodgers C. Team huddle implementation in a general pediatric clinic. J Nurses Prof Dev. 2015;31:324-327.

59. Kessler DO, Cheng A, Mullan PC. Debriefing in the emergency department after clinical events: A practical guide. Ann Emerg Med. 2015;65:690-698.

60. Salas E, Klein C, King H, et al. Debriefing medical teams: 12 evidence-based best practices and tips. Jt Comm J Qual Patient Saf. 2008;34:518-527.

61. Koo K. Patient-centered operating room briefings to improve surgical quality. JAMA Surg. 2015;150:183.

62. Manser T, Foster S. Effective handover communication: An overview of research and improvement efforts. Best Pract Res Clin Anaesthesiol. 2011;25:181-191.

63. Manser T, Howard SK, Gaba DM. Adaptive coordination in cardiac anaesthesia: A study of situational changes in coordination patterns using a new observation system. Ergonomics. 2008;51:1153-1178.

64. Kolbe M, Burtscher MJ, Manser T. Co-ACT-A framework for observing coordination behaviour in acute care teams. BMJ Qual Saf. 2013;22:596-605.

65. Tschan F, Semmer NK, Hunziker S, Marsch S. Duffy VG. Decisive action vs joint deliberation: Different medical tasks imply different coordination requirements. In: Advances in Human Factors and Ergonomics in Healthcare. 2011:Boca Raton, FL: CRC Press; 191-200. 
66. Kolbe M, Grote G, Waller MJ, et al. Monitoring and talking to the room: Autochthonous coordination patterns in team interaction and performance. J Appl Psychol. 2014;99:1254-1267.

67. Kolbe M, Burtscher MJ, Wacker J, et al. Speaking up is related to better team performance in simulated anesthesia inductions: An observational study. Anesth Analg. 2012;115:1099-1108.

68. Schmutz J, Manser T. Do team processes really have an effect on clinical performance? A systematic literature review. Br J Anaesth. 2013;110:529-544.

69. Maynard MT, Kennedy DM, Sommer SA. Team adaptation: A fifteen-year synthesis (1998-2013) and framework for how this literature needs to "adapt" going forward. Eur J Work Organ Psychol. 2015;24:652-677.

70. Eraut M. Non-formal learning and tacit knowledge in professional work. Br J Educ Psychol. 2000;70(pt 1):113-136.

71. Billett S. Guided learning at work. J Workplace Learn. 2000;12:272-285

72. Billett S. Towards a model of workplace learning: The learning curriculum. Stud Contin Educ. 1996;18:4358.

73. Nundy S, Mukherjee A, Sexton JB, et al. Impact of preoperative briefings on operating room delays: A preliminary report. Arch Surg. 2008;143:1068-1072.

74. Derue DS, Nahrgang JD, Hollenbeck JR, Workman K. A quasi-experimental study of after-event reviews and leadership development. J Appl Psychol. 2012;97:997-1015.

75. Brett-Fleegler M, Rudolph J, Eppich W, et al. Debriefing assessment for simulation in healthcare: Development and psychometric properties. Simul Healthc. 2012;7:288-294.

76. Sawyer T, Eppich W, Brett-Fleegler M, Grant V, Cheng A. More than one way to debrief: A critical review of healthcare simulation debriefing methods. Simul Healthc. 2016;11:209-217.

77. Schmutz J, Eppich WJ, Hoffmann F, Heimberg E, Manser T. Five steps to develop checklists for evaluating clinical performance: An integrative approach. Acad Med. 2014;89:996-1005.

78. Cohen MD, Hilligoss B, Kajdacsy-Balla Amaral AC. A handoff is not a telegram: An understanding of the patient is co-constructed. Crit Care. 2012;16:303. 


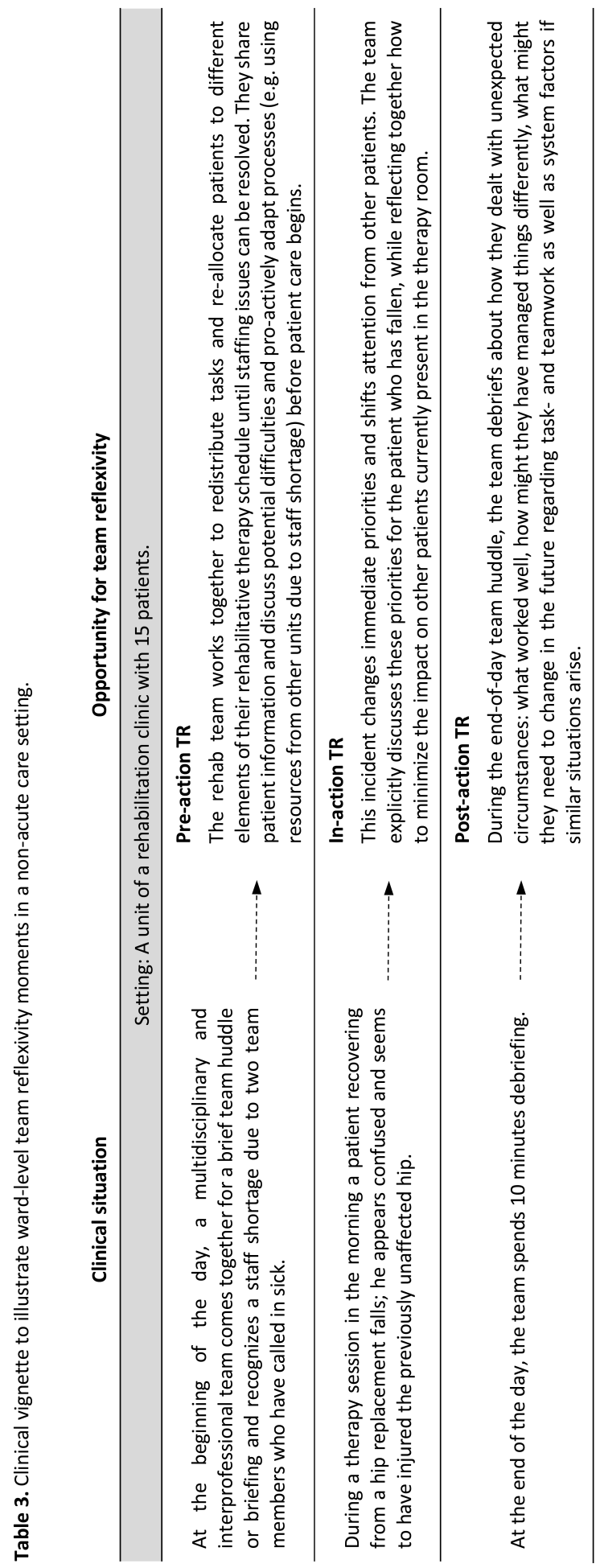




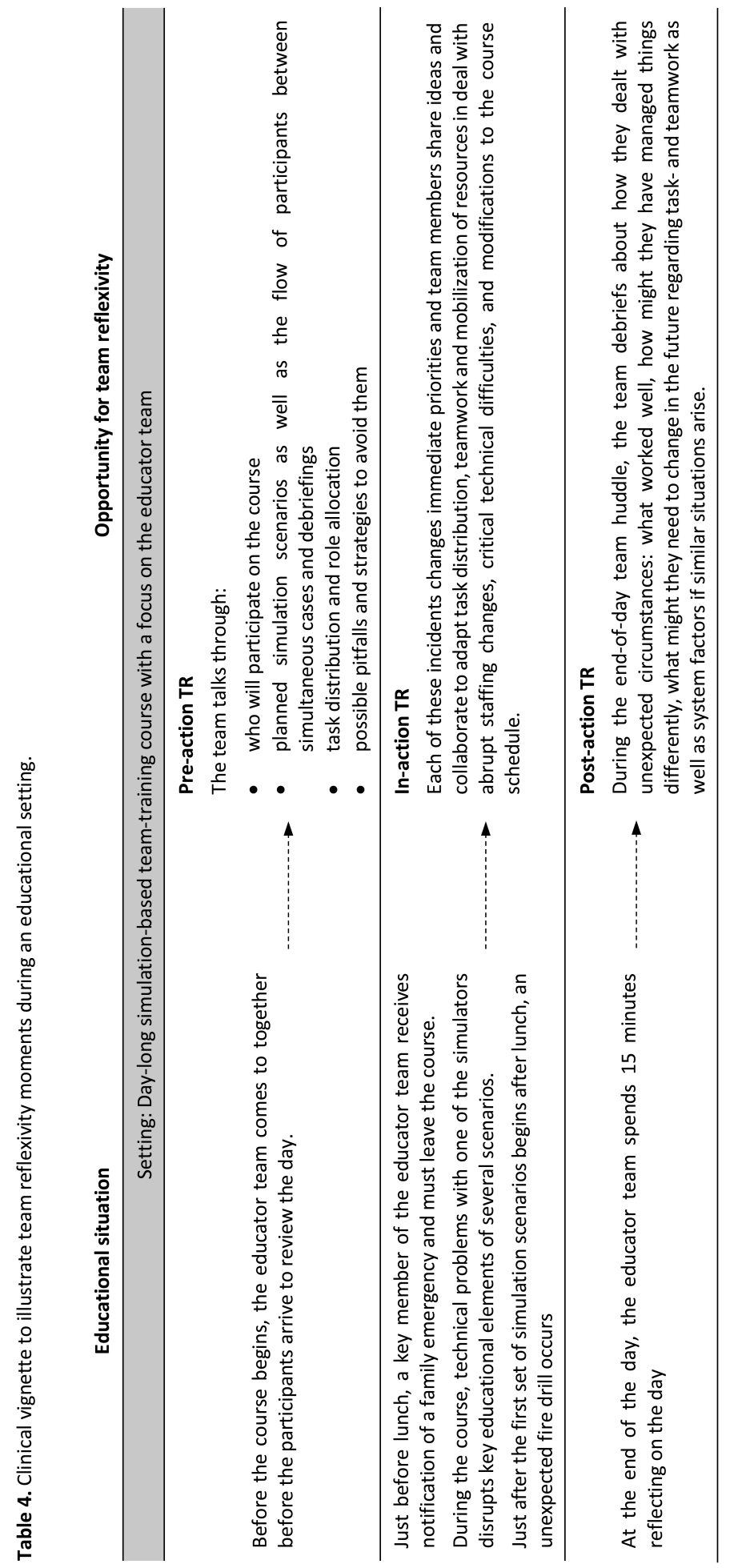


Chapter 8 
Discussion

CHAPTER 9

Discussion

157 


\section{Background}

This thesis addresses the following overarching research question: How does 'talk' contribute to learning in clinical education? Although talk as 'communicative competency' ${ }^{1}$ represents an important learning outcome in graduate medical education, talk as joint social activity ${ }^{2}$ contributes to both learning for practice as well as learning from practice.

The collective body of work in this thesis addresses my research question in two ways: (a) through integration of distinct literature streams in medical education and workplace learning, psychology and team science, and healthcare simulation debriefing, and (b) through contemporaneous research collaborations with experts in these domains. I explored healthcare talk in three specific instances: (a) healthcare simulation debriefing, (b) workplace telephone talk, and (c) team reflection at various timepoints related to patient care episodes. This discussion chapter outlines how main findings interrelate to form a clarifying line of research, explores strength and limitations of this thesis, and proposes implications for educational practice and research.

\section{Summary of findings}

In Part I of this thesis I argued for the central role of talk in clinical education and explored the potential alignments between workplace learning, continuous professional development and improved patient care quality. Chapter 2 presented proactive measures to steer the talk of practice by bringing together key actors in time and space to build shared understandings, promote collective competence, and augment collaborative learning processes.

Part II explored 'learning though talk for practice' with a focus on feedback and debriefing practices (Chapters 3 and 4) and reliable team performance assessment (Chapter 5 ) in simulation-based education. These chapters outlined how educators need to establish supportive learning environments, facilitate contextualized debriefings, and structure feedback and debriefing for specific settings such as simulation training for advanced life support (ALS) and team resuscitations. These chapters collectively addressed formal elements of talk in debriefing conversations that educators can steer deliberately. These formal elements of talk include two key dimensions: (a) process, i.e., what to say as well when, why, and how to say it, and (b) content, i.e., topics to discuss. Further, I highlighted a process to generate reliable performance assessment to inform the content of team debriefings. 
Part III explored 'learning through talk from practice', using two specific instances of workplace talk: telephone interactions (Chapters 6 and 7) and team reflection during various timepoints in relation to patient care episodes (Chapter 8). These chapters highlighted three main areas: (a) sociocultural aspects related to power and pushback, (b) formal aspects of talk related to process and content in the workplace, (b) informal conversational elements as 'disguised feedback'. I proposed a complementary approach to simulation, namely 'simulation as learning how to learn' in order to sensitize learners to disguised feedback and promote learning from future clinical work.

\section{General discussion}

The following discussion interprets my main findings in terms of how talk contributes to clinical education, relates them to the extant literature, and explores general implications for educational practice.

\section{Talk and formal educational practice}

Chapters 3 and 4 addressed formal elements of talk including two key dimensions related to process and content. With experience and faculty development, educators can deliberately steer the formal talk of debriefings to work collaboratively with learners and achieve explicit learning goals. Prior to PEARLS, the healthcare simulation literature largely advocated for adherence to one individual method. . $^{3-6}$ In contrast, PEARLS intentionally blends various educational strategies within a single debriefing. Additional blended approaches are emerging ${ }^{7}$ though not all have novice educators in mind. ${ }^{8}$ Krogh and colleagues found that expert simulation educators prefer flexible, blended approaches in their debriefing practice that allowed them to 'think on their feet ${ }^{\prime}{ }^{9}$ PEARLS adds to the literature by providing concrete strategies to achieve this aim.

Debriefing scripts provide specific formal language for novice educators with demonstrated benefit for learners. ${ }^{10}$ Debriefing frameworks and scripts represent reifications as Wenger conceptualizes them, ${ }^{11}$ namely ways of speaking in the community of practice in a broader sense. Over time, simulation participants become familiar with the process and language of the debriefing and become experienced with it. Of course, rigid adherence to debriefing scripts may strike learners as overly proscriptive, formulaic, and tokenistic; ${ }^{12}$ they also risk a paradoxical instructorcenteredness in situations which a learner-centered approach has more value. ${ }^{13}$ However, learners' familiarity with debriefing processes helps them manage expectations, which contributes to a sense of psychological safety. Psychological safety enables the interpersonal risk-taking ${ }^{14,15}$ that characterizes frank and open discussion about potentially uncomfortable topics such as error and other threats to patient safety. Such fit-for-purpose frameworks might also augment formal teaching and 
feedback practices on the telephone, which our study in Chapter 7 highlighted. Interested readers may also refer to my conceptual article ${ }^{16}$ entitled "Let's Talk About It": Translating lessons from healthcare simulation to clinical event debriefings and coaching conversations" which contextualizes my main findings for pediatric emergency medicine settings.

\section{Talk and relationships/rapport}

Supportive yet challenging learning environments are fundamental effective debriefing conversation ${ }^{17}$ and workplace talk. ${ }^{14,15}$ Recent research highlighted the role of building and managing rapport in facilitator-guided post-event debriefings to create and maintain a productive space for learning. ${ }^{18}$ Loo and co-authors used a rapport management model to critique debriefing frameworks identified through a systematic literature search. In their critical review, the authors assessed the extent to which existing debriefing frameworks integrated formal language to address main aspects of rapport management, namely (a) face sensitivities that deal with personal/social values like respect, status, and competence, (b) sociality rights and obligations related to personal/social entitlements such as being treated fairly, and (c) interactional goals in terms of tasks and relationships. Of 34 debriefing frameworks identified in this review, 15 of these - including PEARLS - considered all three components of the rapport management model. The authors noted that debriefing scripts should incorporate "culture-specific linguistic conventions" (p. 58) and phrases to manage rapport. ${ }^{18}$ Needless to say, debriefing scripts are only words on a page; how they are enacted in practice may be another matter. Yet these findings underscore the potential for scripts to help manage key aspects of the talk, especially for novice educators, until these important elements become second nature. Sargeant et al also highlighted relationship-building as a precursor to exploring reactions and content in their framework for facilitated feedback. ${ }^{19}$ Clinical event debriefings, ${ }^{20,21}$ a form of postaction team reflexivity (TR), ${ }^{22}$ also rely on rapport and relationships that promote psychological safety as a prerequisite to discussing otherwise undiscussable topics. ${ }^{23}$

\section{Talk and productive tensions}

While healthcare simulation values supportive learning environments, unfortunately the situation in clinical workplaces varies greatly. Although the term 'tension' generally invokes negative connotations, ${ }^{24-26}$ I identified productive components to conversational tensions. This notion adds a more nuanced view to our understanding of workplace talk. In my work, some tensions appeared to motivate junior doctors to change future behavior and craft their telephone talk in ways to minimize tensions while achieving patient care goals. Olmos-Vega et al also identified potentially beneficial tensions in clinical supervisor-supervisee dyads if safe learning environments allowed for productive negotiation. ${ }^{27}$ While team conflict is generally viewed negatively and something teams should avoid, ${ }^{26,28,29}$ certain collectivistic (rather than 
individualistic) conflict processes have benefits for team performance. ${ }^{30}$ These notions of productive tensions and constructive conflict processes have great relevance also for the discursive practice of TR from Chapter 8. The extent to which TR as a team process surfaces tensions and promotes productive collectivistic processes in the service of learning and patient care requires further study.

A fine line exists between productive and highly unproductive conversational tensions. Incivility in the workplace threatens psychological safety and social relations ${ }^{31,32}$ and thus hinders the dialogue that promotes learning and patient care. The relationship between communication breakdowns and patient safety is well documented. ${ }^{33-35}$ Even witnessing rudeness impairs cognitive functioning in onlookers, even when they are not party to the rude interactions, ${ }^{36}$ a finding with relevance for healthcare. ${ }^{37,38}$ Issues of civility most certainly impact clinical practice, for example during telephone conversations when clinical supervisors or subspecialists interrupt junior doctors abruptly or rudely question management decisions. Further, doctors-in-training face threats to supportive clinical learning environments from disjointed team interactions in traditional clinical rotational structures. ${ }^{39,40}$ By rotating to different clinical services every few weeks, doctors-in-training fail to build meaningful collegial relationships that enable the conversations that promote their clinical and professional development in team-based healthcare settings.

\section{Talk and competence}

Talk not only represents individual communicative competency, ${ }^{1}$ talk appears integrally linked to the development of competence, which aligns with the participatory metaphor of learning ${ }^{41}$ and sociocultural theories. ${ }^{11,42,43}$ Our findings on workplace telephone talk highlighted the challenges junior doctors faced when perceiving uncertainty whilst seeking to embody trustworthiness. This finding evoked the 'cloak of competence $^{\prime 44}$ and aligns with prior work about learning to deal with uncertainty ${ }^{45,46}$ and appearing competent ${ }^{47}$ while giving oral presentations. In Chapters 6 and 7, doctors-in-training conveyed competence over the telephone through sanctioned ways of talking in the community in line with Wenger's 'shared repertoires' ${ }^{11}$ Kennedy et al 2008 investigated the important role of language in clinical supervisors' assessment of trainee competence, both in structure and delivery as well as anticipated information provided without the need for supervisors to pose questions to seek relevant information. ${ }^{48}$ Thus, talk and competence interrelate at multiple levels: talk creates opportunities required to develop competency, talk allows junior doctors to appear competent, talk allows clinical supervisors to assess competence. These reflections apply to both simulated and workplace settings.

Collective competence ${ }^{49}$ has recently emerged as an important consideration for teams, ${ }^{50,51}$ which relates to team communicative processes. For example, debriefings 
have clear benefits for team performance ${ }^{10,52}$ and likely contribute to collective competence. More recent empiric work in our existing research program on TR demonstrated significant benefits of 'reflection in the heat of the moment' (i.e., inaction TR) on team performance, especially for larger healthcare teams. ${ }^{53}$ TR may serve as a useful lens to help guide future research on the development of collective competence and workplace learning. Elements of TR as a team learning process would also align with the 'simulation as learning how to learn' paradigm. Our recent "12 Tips" paper in Medical Teacher proposed strategies for integrating TR into simulation-based team trainings. ${ }^{54}$

\section{Talk and shared understandings}

Shared understandings contribute to collective competence. Existing relationships promote the development of intersubjectivity or shared understandings between clinicians. ${ }^{55-57}$ Recent research highlighted that working together over time contributes to intersubjectivity between clinical supervisors and their trainees through diverse adaptation patterns that result in working repertoires. ${ }^{57}$ Through processes of shared decision-making, complying with supervisors instructions and negotiating supervisors' preference, working repertories enabled coordination within these dyadic teams. ${ }^{57}$ Olmos-Vega et al located their findings within a participatory framework of communities of practice, highlighting the relevance for workplace talk. When we view clinical event debriefings as a discursive space to create shared understandings, these findings indicate the potential for TR and clinical event debriefings to contribute to intersubjectivity within clinical healthcare teams. Billett pointed out that intersubjectivity itself may be viewed as a learning outcome. ${ }^{55}$ Further study using intersubjectivity as a theoretical lens might shed light on this important question.

\section{Talk and structured clinical experiences}

My work supports recent developments in medical education that nurture relationships and culture to provide a fertile ground for supportive conversations and shared understandings. Chapter 2 outlined the role of structured interdisciplinary rounds as an example of how bringing interprofessional hospital teams in time and space while choreographing their talk promoted shared mental models. Recent innovations in medical student clerkships serve as an additional example. While traditional clerkships follow a rotating structure that negatively impacts relationship building, ${ }^{39}$ longitudinal clerkships ${ }^{58-61}$ have emerged as a partial solution to these concerns. In longitudinal clerkships, medical learners spend extended time with not only patients, but also with physician supervisors and non-physician members of the healthcare team. The convergence of key players in time and space supports informal learning ${ }^{62,63}$ by encouraging supportive relationships, ${ }^{60}$ promoting entrustment decisions, ${ }^{64}$, and supporting the development of intersubjectivity. ${ }^{55-57}$ At Northwestern University in the 
United States, an 'educationally centered medical home' brings together teams of medical students from all four years of training in one clinic setting for the whole of their undergraduate medical experience. ${ }^{58,59}$ This clinic structure not only fosters medical students' relationships with clinical supervisors, but also with fellow medical students who can provide valuable near-peer feedback. I surmise that the nature of the talk within these environments plays a significant role; future study will need to determine how and to what extent such talk contributes to learning in these longitudinal clinical experiences.

\section{Limitations and strengths of this thesis}

This thesis has several important limitations. Chapters 3 and 4 about debriefing focused primarily on educator behaviors related to feedback and debriefing practices while neglecting the learner perspective-future work should directly address this gap. Although debriefing scripts have been shown to enhance learning outcomes, ${ }^{10}$ this thesis did not delineate precise learning benefits of the PEARLS framework and debriefing script, nor does my thesis compare PEARLS with other debriefing models. And even though the rich description of feedback and debriefing practices for ALS adds to our understanding of how to structure feedback and debriefing for mastery learning, other approaches may also be of benefit; I made no comparison between alternative strategies.

An additional limitation relates to the methodologies used to study telephone talk. For example, conversational analysis of recorded conversations may have potentially yielded different results. I specifically chose interviews as a data collection strategy to solicit learner perceptions of their experiences, which would remain hidden in a study of recorded conversations. Naturally, one may assert the potentially flawed nature of recollections and perceptions of their telephone talk in participants' accounts. Our rigorous approach to this qualitative research, however, has yielded trustworthy results.

Although I took a reflexive approach, my background as a physician and simulation educator potentially influenced my research. My views were shaped by my own experiences working in the team-based pediatric emergency department where I engage in telephone talk. All collaborators on the telephone talk studies were also physicians. However, all were experienced researchers - two of whom have extensive backgrounds in qualitative methodologies and whose input augmented the rigor of my findings.

One of the main strengths of this thesis is the bringing together complementary perspectives to answer my research question. I reviewed various literature streams and 
collaborated with experts from workplace learning, healthcare simulation debriefing, and team science. The nature of these contemporaneous collaborations with scholars from Europe (Netherlands, United Kingdom, Switzerland) and North America meant that much of this work occurred in parallel, allowing fertilization amongst projects. My transdisciplinary approach identified fruitful synergies that have informed our understanding about talk in clinical education.

The originality of this work stems from an examination healthcare talk from two complementary vantage points, namely learning through talk for and from practice. This approach allowed a rich exploration of talk as the intersection between simulation and workplace learning. Bligh and Bleakley called for dialogue between these two domains of learning, ${ }^{65}$ and my thesis answers this call using talk as a lens. This thesis answers the overarching research question using various methodologies and conceptual frameworks and emphasizes real world implications for educational practice.

\section{Implications for future research}

My thesis explores the role of talk in clinical education and raises additional research questions.

- First, we need to use additional methodologies such as conversational analysis to study actual process of behavior during debriefings. ${ }^{66}$ This thesis outlines what the conversational processes may look like in a debriefing as well as how to structure feedback and debriefing in mastery learning and deliberate practice curricula. However, we still have much to learn about the formal and informal elements of these learning conversations that would provide a fine-grained understanding of what aspects of talk contribute to meaningful learning outcomes. For example, Allen et al outlined the need to study specific communication processes within debriefings, including who facilitates and how to facilitate effectively. ${ }^{66}$ The findings in chapters 3 and 4 begin to shed light on these formal communication practices, although we have much to understand about the informal elements of debriefing conversations that may have both beneficial and unintended harmful effects. Conversation analysis of video- and audio-recorded debriefings has potential to yield valuable insights, ${ }^{67}$ as would qualitative ethnographic approaches. ${ }^{68}$

- Second, we also need to examine debriefings in a variety of contexts - since the talk of debriefings is highly situated, we would need to study debriefings that occur after simulated events targeted various performance domains (decisionmaking, teamwork, etc.) in a variety of contexts (intensive care unit, emergency department, ward, outpatient setting). The talk of those workplaces may have subtle yet important differences that influence learning. Better understanding 
of these microprocesses would also have logically impact on team reflexive behaviors ${ }^{22,69}$ after actual patient care episodes, both formal structured clinical event debriefings ${ }^{20,21,70}$ as well as ad hoc unstructured informal conversations. ${ }^{22}$

- Third, our field needs to clarify the downstream implications of debriefing. Some work demonstrates the impact of debriefing on clinical outcomes after resuscitation events, ${ }^{71}$ however this immediate link to patient outcomes is not always possible.

- Fourth, we must examine the impact of the novel simulation paradigm introduced in Chapter 7, namely 'learning how to learn through simulation.' Future study would clarify the potential of this approach and refine strategies for sensitizing doctors and other health professionals to the affordances of workplace talk. Team reflexivity surrounding patient care episodes has potential, but we are only beginning to understand how pre-action and in-action TR promotes learning in clinical settings.

- Fifth, we need to study the impact of curriculum and organizational innovations such as longitudinal clerkships and structured interdisciplinary ward rounds on clinical workplace talk.

\section{Conclusions}

Talk as joint social activity represents a significant work activity in graduate medical education that impacts communication practices, learning, and patient care. My research adds to our understanding about the important role of talk in both simulation and clinical education. Medical educators should steer the talk of practice in several key ways:

- Through formal and informal means, such as (a) structured feedback and debriefings that attend to relevant process and content and (b) strategies that foster relationships and supportive learning environments

- Through simulations designed to sensitize clinicians to the affordances of future workplace talk

\section{References}

1. Hymes DH. On Communicative Competence. Sociolinguistics: Selected Readings,(Eds.) by John Bernard Pride \& Janet Holmes, 269-293. 1972.

2. Clark HH. Using Language. Cambridge: Cambridge University Press; 1996:1-436.

3. Rudolph JW, Simon R, Dufresne RL, Raemer DB. There's no such thing as 'nonjudgmental' debriefing: a theory and method for debriefing with good judgment. Simul Healthc. 2006;1(1):49-55. 


\section{Chapter 9}

4. Jaye P, Thomas L, Reedy G. "The Diamond": a structure for simulation debrief. The clinical teacher. 2015;12(3):171-175. doi:10.1111/tct.12300.

5. Zigmont JJ, Kappus $\mathrm{L}$, Sudikoff SN. The 3D model of debriefing: defusing, discovering, and deepening. Semin Perinatol. 2011;35(2):52-58.

6. Sawyer TL, Deering S. Adaptation of the US Army's After-Action Review for Simulation Debriefing in Healthcare. Simul Healthc. 2013;8(6):388-397.

7. Sawyer T, Eppich W, Brett-Fleegler M, Grant V, Cheng A. More Than One Way to Debrief: A Critical Review of Healthcare Simulation Debriefing Methods. Simul Healthc. 2016;11(3):209-217.

8. Kolbe $M$, Weiss $M$, Grote $G$, et al. TeamGAINS: a tool for structured debriefings for simulation-based team trainings. BMJ Qual Saf. 2013;22(7):541-553.

9. Krogh K, Bearman M, Nestel D. "Thinking on your feet"-a qualitative study of debriefing practice. Advances in Simulation, 2016 Apr 2;1:12.

10. Cheng A, Hunt EA, Donoghue $A$, et al. Examining pediatric resuscitation education using simulation and scripted debriefing: a multicenter randomized trial. JAMA Pediatr. 2013;167(6):528-536.

11. Wenger E. Communities of Practice: Learning, Meaning, and Identity. New York: Cambridge University Press; 1998.

12. Bearman M, Ajjawi R. Avoiding tokenism in health professional education. Med Educ. 2013;47(1):9-11.

13. Cheng A, Morse KJ, Rudolph J, Arab AA, Runnacles J, Eppich W. Learner-Centered Debriefing for Health Care Simulation Education: Lessons for Faculty Development. Simul Healthc. 2016;11(1):32-40.

14. Edmondson A. Psychological safety and learning behavior in work teams. Administrative Science Quarterly. 1999:350-383.

15. Edmondson AC, Lei Z. Psychological safety: The history, renaissance, and future of an interpersonal construct. Annu Rev Organ Psychol Organ. 2014;1:23-43.

16. Eppich WJ, Mullan PC, Brett-Fleegler M. "Let's talk about it": translating lessons from healthcare simulation to clinical event debriefings and clinical coaching conversations. Clin Ped Emerg Med. 2016;17(3):200-211.

17. Rudolph JW, Raemer DB, Simon R. Establishing a safe container for learning in simulation: the role of the presimulation briefing. Simul Healthc. 2014;9(6):339-349.

18. Loo ME, Krishnasamy C, Lim WS. Considering Face, Rights, and Goals: A Critical Review of Rapport Management in Facilitator-Guided Simulation Debriefing Approaches. Simul Healthc. 2018;13(1):52-60.

19. Sargeant J, Lockyer J, Mann K, et al. Facilitated Reflective Performance Feedback: Developing an Evidenceand Theory-Based Model That Builds Relationship, Explores Reactions and Content, and Coaches for Performance Change (R2C2). Acad Med. 2015;90(12):1698-1706.

20. Kessler DO, Cheng A, Mullan PC. Debriefing in the emergency department after clinical events: a practical guide. Annals of emergency medicine. 2015;65(6):690-698.

21. Rose $\mathrm{S}$, Cheng $\mathrm{A}$. Charge nurse facilitated clinical debriefing in the emergency department. CJEM. 2018;55:1-5.

22. Schmutz JB, Eppich WJ. Promoting Learning and Patient Care Through Shared Reflection: A Conceptual Framework for Team Reflexivity in Health Care. Acad Med. 2017;92(11):1555-1563.

23. Argyris $\mathrm{C}$. Making the undiscussable and its undiscussability discussable. Public Administration Review. 1980:205-213.

24. Lingard L, Reznick R, Espin S, Regehr G, DeVito I. Team communications in the operating room: talk patterns, sites of tension, and implications for novices. Acad Med. 2002;77(3):232-237.

25. Wadhwa A, Lingard L. A qualitative study examining tensions in interdoctor telephone consultations. Med Educ. 2006;40(8):759-767.

26. Chan T, Bakewell F, Orlich D, Sherbino J. Conflict prevention, conflict mitigation, and manifestations of conflict during emergency department consultations. Acad Emerg Med. 2014;21(3):308-313.

27. Olmos-Vega FM, Dolmans DHJM, Vargas-Castro N, Stalmeijer RE. Dealing with the tension: how residents seek autonomy and participation in the workplace. Med Educ. 2017;51(7):699-707.

28. Greer LL, Saygi O, Aaldering H, De Dreu CKW. Conflict in medical teams: opportunity or danger? Med Educ. 2012;46(10):935-942. 
29. Janss R, Rispens $S$, Segers M, Jehn KA. What is happening under the surface? Power, conflict and the performance of medical teams. Med Educ. 2012;46(9):838-849.

30. DeChurch LA, Mesmer-Magnus JR, Doty D. Moving beyond relationship and task conflict: toward a process-state perspective. Journal of Applied Psychology. 2013;98(4):559-578.

31. Pearson CM, Porath $\mathrm{CL}$. On the nature, consequences and remedies of workplace incivility: No time for “nice?" Think again. The Academy of Management Executive. 2005;19(1):7-18.

32. Porath CL, Pearson CM. The cost of bad behavior. Organizational Dynamics. 2010;39(1):64-71.

33. Kohn SC, Corrigan J, Donaldson M. To Err Is Human: Building a Safer Health System. Washington, D.C.: National Academy Press; 2000.

34. Eppich W. "Speaking up" for patient safety in the pediatric emergency department. Clin Ped Emerg Med. 2015;16(2):83-89.

35. Sutcliffe KM, Lewton E, Rosenthal MM. Communication failures: an insidious contributor to medical mishaps. Acad Med. 2004;79(2):186-194.

36. Porath CL, Erez A. Overlooked but not untouched: How rudeness reduces onlookers' performance on routine and creative tasks. Organizational Behavior and Human Decision Processes. 2009;109(1):29-44.

37. Flin R. Rudeness at work. BMJ. 2010;340:c2480.

38. Riskin A, Erez A, Foulk TA, et al. The Impact of Rudeness on Medical Team Performance: A Randomized Trial. Pediatrics. 2015;136(3):487-495.

39. Holmboe E, Ginsburg S, Bernabeo E. The rotational approach to medical education: time to confront our assumptions? Med Educ. 2011;45(1):69-80.

40. Bernabeo EC, Holtman MC, Ginsburg S, Rosenbaum JR, Holmboe ES. Lost in transition: the experience and impact of frequent changes in the inpatient learning environment. Acad Med. 2011;86(5):591-598.

41. Sfard A. On two metaphors for learning and the dangers of choosing just one. Educational Researcher. $1998 ; 27(2): 4-13$

42. Lave J, Wenger E. Situated Learning: Legitimate Peripheral Participation. New York: Cambridge University Press; 1991.

43. Wells $\mathrm{G}$. Language and education: reconceptualizing education as dialogue. In: Language Use in Professional Contexts. Vol 19. Cambridge: Annual Review of Applied Linguistics; 1999:135-155.

44. Haas J, Shaffir W. The Professionalization of Medical Students: Developing Competence And A Cloak of Competence *. Symbolic Interaction. 1977;1(1):71-88.

45. Lingard L, Garwood K, Schryer CF, Spafford MM. A certain art of uncertainty: case presentation and the development of professional identity. Soc Sci Med. 2003;56(3):603-616.

46. Lingard L, Schryer C, Garwood K, Spafford M. "Talking the talk": school and workplace genre tension in clerkship case presentations. Med Educ. 2003;37(7):612-620.

47. Erickson F. Appropriation of voice and presentation of self as a fellow physician: aspects of a discourse of apprenticeship in medicine. In: Sarangi S, Roberts C, eds. Talk, Work, and Institutional Order. Mouton de Gruyter; 1999:109-143.

48. Kennedy TJT, Lingard LA. Questioning competence: a discourse analysis of attending physicians' use of questions to assess trainee competence. Acad Med. 2007;82(10 Suppl):S12-S15.

49. Boreham N. A theory of collective competence: challenging the neo-liberal individualisation of performance at work. British Journal of Educational Studies. 2004;52(1):5-17.

50. Lingard L, McDougall A, Levstik M, Chandok N, Spafford MM, Schryer C. Representing complexity well: a story about teamwork, with implications for how we teach collaboration. Med Educ. 2012;46(9):869877.

51. Lingard L. Paradoxical Truths and Persistent Myths: Reframing the Team Competence Conversation. J Contin Educ Health Prof. 2016;36 Suppl 1:S19-S21.

52. Tannenbaum SI, Cerasoli CP. Do Team and Individual Debriefs Enhance Performance? A Meta-Analysis. Human factors. 2013;55(1):231-245.

53. Schmutz JB, Lei Z, Eppich WJ, Manser T. Reflection in the heat of the moment: The role of in-action team reflexivity in health care emergency teams. J Organiz Behav. 2018;39(6):749-765.

54. Schmutz JB, Kolbe M, Eppich WJ. Twelve tips for integrating team reflexivity into your simulation-based team training. Med Teach. 2018;40(7):721-727. 


\section{Chapter 9}

55. Billett SR. Securing intersubjectivity through interprofessional workplace learning experiences. J Interprof Care. 2014;28(3):206-211.

56. Sheehan D, Wilkinson TJ, Billett S. Interns' participation and learning in clinical environments in a New Zealand hospital. Acad Med. 2005;80(3):302-308.

57. Olmos-Vega FM, Dolmans DH, Guzmán-Quintero C, Stalmeijer RE, Teunissen PW. Unravelling residents' and supervisors' workplace interactions: an intersubjectivity study. Med Educ. 2018;52(7):725-735.

58. Henschen BL, Garcia P, Jacobson B, et al. The patient centered medical home as curricular model: perceived impact of the "education-centered medical home". J Gen Int Med. 2013;28(8):1105-1109.

59. Henschen BL, Bierman JA, Wayne DB, et al. Four-Year Educational and Patient Care Outcomes of a Team-Based Primary Care Longitudinal Clerkship. Acad Med. 2015;90(11 Suppl):S43-S49.

60. Cuncic C, Regehr G, Frost H, Bates J. It"s all about relationships : A qualitative study of family physicians" teaching experiences in rural longitudinal clerkships. Perspect Med Educ. 2018;7(2):100-109.

61. Hirsh DA, Ogur B, Thibault GE, Cox M. “Continuity” as an organizing principle for clinical education reform. N Engl J Med. 2007;356(8):858-866.

62. Eraut M. Informal learning in the workplace. Studies in continuing education. 2004;26(2):247-273.

63. Marsick VJ, Watkins KE. Informal and Incidental Learning in the Workplace. New York: Routledge; 1990.

64. Hirsh DA, Holmboe ES, Cate Ten O. Time to trust: longitudinal integrated clerkships and entrustable professional activities. Acad Med. 2014;89(2):201-204.

65. Bligh J, Bleakley A. Distributing menus to hungry learners: can learning by simulation become simulation of learning? Med Teach. 2006;28(7):606-613.

66. Allen JA, Reiter-Palmon R, Crowe J, Scott C. Debriefs: Teams learning from doing in context. Am Psychol. 2018;73(4):504-516.

67. Seelandt JC, Grande B, Kriech S, Kolbe M. DE-CODE: a coding scheme for assessing debriefing interactions. BMJ Stel. 2018;4(2):51-58.

68. Reeves S, Peller J, Goldman J, Kitto S. Ethnography in qualitative educational research: AMEE Guide No. 80. Med Teach. 2013;35(8):e1365-e1379.

69. Schippers MC, Edmondson AC, West MA. Team reflexivity as an antidote to team information-processing failures. Small Group Research. 2014;45(6):731-769.

70. Mullan PC, Wuestner E, Kerr TD, Christopher DP, Patel B. Implementation of an in situ qualitative debriefing tool for resuscitations. Resuscitation. 2013;84(7):946-951.

71. Wolfe $\mathrm{H}$, Zebuhr C, Topjian AA, et al. Interdisciplinary ICU cardiac arrest debriefing improves survival outcomes. Crit Care Med. 2014;42(7):1688-1695. 


\section{Summary}

Rather than viewing talk as 'communicative competency' and as a learning outcome, this thesis treats talk as joint social activity that contributes to both learning for practice as well as learning from practice. This thesis addresses the following overarching research question: How does 'talk' contribute to learning in clinical education? Three specific instances of healthcare talk serve as the point of departure for this exploration: (a) healthcare simulation debriefing, (b) workplace telephone talk, and (c) team reflection at various timepoints related to patient care episodes. The aim was two-fold: to identify lessons from these respective settings that might inform each other, and to articulate practical strategies to steer healthcare talk in order to promote both meaningful learning and patient care.

Chapter 1 defines 'talk' as joint activity between conversation partners and argues that in many respects, 'learning by doing' in graduate medical education involves 'learning by talking' in team-based healthcare settings. Discursive work characterizes clinical practice in a wide variety of patient care related contexts; talk also contributes to learning processes of becoming a doctor, in line with sociocultural perspectives.

Chapter 2, a published book chapter, makes an argument for the central role of talk in learning from clinical practice. Communication breakdowns not only threaten safe patient care, they also lead to breakdowns in learning. Current models of continuous professional development are divorced from the talk of authentic practice. The chapter outlines potential alignments between workplace learning, continuous professional development and patient care quality. Proactive measures steer the talk of practice by bringing together key actors in time and space to augment collaborative learning processes and promote collective competence. Examples include structured interdisciplinary ward rounds, use of checklists, and improved handoff processes. Finally, the chapter introduces the ideas of using simulation to promote productive discourse and aligning simulation-based and workplace-based learning.

Chapter 3 presents a novel conceptual framework and script for healthcare debriefing called PEARLS. This model is based on review of literature and iterative refinement through expert and end-user feedback. PEARLS integrates various educational strategies and provides specific guidance depending on the contextual factors such as available time, learner group, and performance domains. As a blended debriefing approach, PEARLS offers a context-specific and adaptable structure to steer the talk of post-event debriefing conversations primarily for groups of learners or healthcare teams. Prior to PEARLS, the healthcare simulation literature advocated primarily for adherence to a single method. In contrast, the PEARLS debriefing framework and script intentionally blend approaches within a single debriefing. Thus, PEARLS provides 
simulation educators guidance in terms of debriefing process: what to say as well as when, why, and how to say it.

Chapter 4 uses pediatric and advanced life support (ALS) resuscitation training as a case study and provided a rich description of empirically proven feedback and debriefing practices. Previous publications about mastery learning approaches to advanced life support (ALS) failed to provide sufficient guidance for educators seeking to reproduce the demonstrated positive learning outcomes. Prior descriptions of essential feedback and debriefing practices in mastery learning were vague and unhelpful. Chapter 4 describes rich, highly contextualized, and empirically proven feedback and debriefing practices for the algorithm-based learning objectives related to ALS. Specifically, we describe 'microdebriefings' integrated within two specific educational strategies: mastery learning and rapid cycle deliberate practice. Rather than traditional debriefings that prompt reflection and provide feedback after performance events, microdebriefings occur during performance events to allow learners to apply reflections and/or feedback immediately. This feedback should include performance data whenever possible.

Chapter 5 outlines a specific process for rater training previously lacking in the literature. We reported how we reliably trained raters to use the Team Emergency Assessment Measure (TEAM) to assess team performance in simulated resuscitation scenarios. Such reliable performance data could inform the content of team debriefings. The multistep approach to rater training included didactic review of key principles of teamwork concepts and rating performance, several rounds of rating practice with exemplars of poor, excellent, and mixed performance.

Chapter 6 describes a qualitative study using a constructivist grounded theory approach. In-depth interviews explored work-related telephone conversations as a social phenomenon. Doctors-in-training from various specialties and training years described their telephone interactions with other members of the healthcare team such as their clinical supervisors, fellow doctors-in-training, subspecialists, nurses and allied health professionals. Our sociocultural analytic lens highlighted conversational tensions that influenced learning positively: (a) dealing with power differentials, (b) dealing with pushback, and (c) expressing uncertainty while still embodying trustworthiness. In contrast to prior work that framed tensions negatively, we identified productive components to conversational tensions. These 'productive conversational tensions' led to moments of awareness that prompted additional reflection. For example, doctors reported the unpleasantness of dealing with subspecialists who initially pushed back over the telephone, i.e. questioning or even denying legitimate requests or disagreeing with proposed courses of action. Experiencing pushback served as a motivator to craft their future telephone talk in ways to prevent, mitigate or manage pushback in order to achieve the aim of the telephone call and advance patient care. 
Chapter 7 reports an educational needs assessment based on the dataset from Chapter 6. Using qualitative thematic analysis, we identified both formal and informal aspects of workplace telephone talk that contributed to learning. Formal educational practices such as teaching and explicit feedback provide a target for faculty development strategies. The main findings, however, related to informal aspects of these conversations. Specifically, conversational questions and interruptions served as 'disguised feedback' for doctors-in-training. For example, when junior doctors did not anticipate information needs for respective conversation partners, conversation partners (such as subspecialists or supervising doctors) posed information-seeking questions. Based on these questions, junior doctors identified which information to include in future telephone case presentations. Using a lens of 'performance relevant information', we surmised that sensitizing doctors-in-training to disguised feedback had potential to impact their future workplace learning. Thus, we proposed several potential educational strategies to enhance telephone talk: (a) embedding telephone communication skills in existing simulation activities and (b) developing stand-alone curricular elements to sensitize junior doctors to "disguised" feedback during telephone talk as a mechanism to augment future workplace learning. Rather than a traditional view of 'simulation as learning to perform' for future clinical work, we suggested a complementary and novel approach to simulation, namely 'simulation as learning how to learn' from future clinical work.

Chapter $\mathbf{8}$ used a theoretical construct from the psychology and management literature called team reflexivity (TR) to delineate the potential influences of team interactions on both performance and learning. TR describes a team process by which teams reflect on goals, processes, and strategies to improve current or future performance. Since TR captures a team-level phenomenon, shared reflection necessarily requires communication amongst team members, i.e. talk. Historically, TR captured only reflection after events occurred, akin to post-event debriefings. Chapter 8 extended this view and described a novel conceptual framework for TR in healthcare that encompasses three phases during which TR may occur: pre-action TR (briefing before patient care), in-action TR (deliberations during active patient care), and post-action TR (debriefing after patient care). Accordingly, TR addresses goals, taskwork, teamwork, or resources with various outcomes depending on the phase (e.g., optimal preparation, a shared mental model, adaptation, or learning). We theorized that the creation of shared understanding within teams before, during, and after active joint clinical care through the talk of TR-including among clinical supervisors and doctor-in-training-contributes to highly situated forms of clinical workplace learning and enables collective competence. 
Chapter 9 (Discussion) integrates the main findings from all chapters to answer the main research question in terms of how talk contributes to clinical education. The chapter also explores general implications for educational practice. Lessons from the structured talk of feedback and debriefing in healthcare simulation demonstrate the potential in deliberately steering the talk of practice by attending to both process and content of learning conversations. When viewed through a socio-cultural lens, talk represents social activity that drives learning. Thus, relationships and rapport enable learning through talk. 'Productive conversational tensions' add a more nuanced view to our understanding of workplace talk in recognizing that some tensions motivate junior doctors to adapt their telephone talk in ways to minimize future tensions. Along these lines, talk plays an integral role in conceptions of individual competence in clinical education, namely in developing competence, appearing competent, and assessing competence. Further, talk drives the development of shared understandings within healthcare team that promotes intersubjectivity and collective competence. Medical educators should steer the talk of practice in two ways: (a) through formal and informal means, such as structured feedback and debriefings that attend to relevant process and content, and strategies that foster relationships and supportive learning environments, and (b) through simulations designed to sensitize clinicians to the affordances of future workplace talk. 


\section{Samenvatting}

In plaats van gesprekken door zorgverleners onderling en met patiënten te zien als 'communicatieve vaardigheid' en als een leeruitkomst, behandelt dit proefschrift gesprekken als een gezamenlijke sociale activiteit die bijdraagt aan zowel leren voor de praktijk als leren uit de praktijk. Dit proefschrift behandelt de volgende overkoepelende onderzoeksvraag: Hoe dragen 'gesprekken' bij tot leren in klinisch onderwijs? Drie specifieke instanties van gesprekken in de gezondheidszorg dienen als vertrekpunt voor deze verkenning: (a) debriefing in het kader van simulaties, (b) telefoongespreken op de werkplek, en (c) teamreflectie, op verschillende tijdstippen, gerelateerd aan het uitvoeren van patiëntenzorg. Het doel was tweeledig: om lessen te trekken uit deze respectievelijke situaties die elkaar zouden kunnen informeren, en om praktische strategieën te formuleren om gesprekken in de gezondheidszorg te sturen om zowel zinvol leren en patiëntenzorg te bevorderen.

Hoofdstuk 1 definieert 'gesprekken' als een gezamenlijke activiteit tussen gesprekpartners en beargumenteert dat 'al doende leren' in de medische vervolgopleiding ook betekent dat men leert door met elkaar te spreken over werkgerelateerde situaties. Dit soort communicatieprocessen zijn kenmerkend voor een grote verscheidenheid aan contexten in de klinische praktijk; gesprekken dragen ook bij aan de leerprocessen om arts te worden, wat in lijn is met sociaal-culturele perspectieven.

Hoofdstuk 2, gepubliceerd als hoofdstuk in boek, beargumenteert de centrale rol van gesprekken in het leren in de klinische praktijk. Verstoringen in de communicatie bedreigen niet alleen veilige patiëntenzorg, maar leiden ook tot negatieve effecten op leren. De huidige perspectieven op voortdurende professionele ontwikkeling van zorgprofessionals hebben onvoldoende oog voor het belang van communicatie en gesprekken in het leren van de praktijk. Dit hoofdstuk schetst mogelijkheden voor betere afstemming tussen leren op de werkplek, voortdurende professionele ontwikkeling en kwaliteit van patiëntenzorg. Voorbeelden zijn proactief sturen op praten over de praktijk door het samenbrengen, in tijd en ruimte, van personen met sleutelfuncties, om samenwerkende leerprocessen te bevorderen en collectieve competentie te onder de aandacht te brengen. Gestructureerde interdisciplinaire afdelingsrondes, het gebruik van checklists, en verbeterde overdrachtsprocessen kunnen hierbij helpen. Tenslotte introduceert dit hoofdstuk ideeën voor het gebruik van simulatie om productieve communicatieprocessen te ondersteunen en simulatiegebaseerd en werkplaats-gebaseerd leren op elkaar af te stemmen.

Hoofdstuk 3 introduceert een vernieuwend conceptueel raamwerk en script voor debriefing in de gezondheidszorg, genaamd PEARLS. Dit model is gebaseerd op literatuuronderzoek en herhaaldelijke aanpassingen op basis van feedback van experts 
en gebruikers. PEARLS integreert verschillende educatieve strategieën en biedt specifieke begeleiding afhankelijk van contextuele factoren zoals beschikbare tijd, de leergroep, en de gedragsdomeinen waarop wordt getoetst. PEARLS biedt een contextspecifieke en aanpasbare structuur om gesprekken na simulaties maar ook na (indrukwekkende) gebeurtenissen in de praktijk te sturen, in de eerste plaats voor groepen lerenden of zorgteams. Voor PEARLS pleitte men in de literatuur voornamelijk voor het naleven van één enkele methode. Het PEARLS-model combineert juist opzettelijk verschillende benaderingen om de meeste geschikte aanpak voor elke individuele debriefing te vinden. PEARLS biedt dus begeleiding op het gebied van het nabesprekingsproces: zowel wat te zeggen als wanneer, waarom en hoe het te zeggen.

Hoofdstuk 4 gebruikt 'advanced life support' (ALS), ook reanimatietraining genoemd, in de kindergeneeskunde, als een casestudie. Het bevat een rijke beschrijving aan empirisch bewezen feedback- en nabesprekingspraktijken. Eerdere publicaties over ALS onderwijs volgens het 'mastery learning' lieten na om voldoende handvatten te bieden voor begeleiders die willen proberen om in de literatuur gerapporteerde positieve leerresultaten te reproduceren. Eerdere beschrijvingen van essentiële feedback en nabesprekingspraktijken in het kader van een 'mastery learning' aanpak waren vaag en onbehulpzaam. Hoofdstuk 4 beschrijft rijke, in hoge mate gecontextualiseerde, en empirisch bewezen feedback en nabesprekingspraktijken voor de leeruitkomsten die horen bij een ALS training. Concreet beschrijven we 'microdebriefings' die geïntegreerd worden in twee specifieke onderwijsstrategieën: 'mastery learning' en 'rapid cycle deliberate practice'. In plaats van traditionele nabesprekingen die aanleiding geven tot reflectie en feedback na een oefening, gebeuren microdebriefings gedurende een oefening om lerenden in staat te stellen reflecties en/of feedback direct in te zetten. Deze feedback moet, zoveel mogelijk, concrete observaties van gedrag bevatten.

Hoofdstuk 5 schetst een specifiek proces voor de training van beoordelaars, zoals begeleiders van simulatieonderwijs, dat eerder in de literatuur ontbrak. We hebben gerapporteerd hoe we beoordelaars hebben getraind om de 'Team Emergency Assessment Measure' (TEAM) te gebruiken om gesimuleerde reanimatiescenario's te beoordelen. Dergelijke betrouwbare beoordelingen van de prestaties van een team kan de inhoud van team debriefing informeren. De meerstappenbenadering van beoordelaarstraining omvatte onder meer onderwijs over de belangrijkste principes van teamwork concepten en de rol van beoordelaars, verschillende rondes van oefenen met beoordelen met voorbeelden van slechte, uitstekende, en gemengde prestaties.

Hoofdstuk 6 beschrijft een kwalitatief onderzoek op basis van 'constructivist grounded theory'. Middels diepte-interviews verkenden we werkgerelateerde telefoongesprekken als een sociaal fenomeen. Artsen-in-opleiding van verschillende specialiteiten en opleidingsjaren beschreven hun telefooninteracties met andere leden 
van het gezondheidszorgteam zoals hun klinische supervisors, mede artsen-inopleiding, subspecialisten, verpleegkundigen en paramedische gezondheidsmedewerkers. Onze socioculturele analytische lens benadrukte conversationele spanningen die het leren positief beïnvloedden: (a) omgaan met machtsverschillen, (b) omgaan met het krijgen van (kritisch) weerwoord, en (c) uiten van onzekerheid zonder dat het ten koste gaat van vertrouwen wat anderen in je hebben. In tegenstelling tot voorgaand werk waarin spanningen vaak als negatief werden omschreven, kwamen uit deze studie dus ook constructieve elementen die uit conversationele spanningen naar voren komen. Deze spanningen leidden tot momenten van bewustzijn die aanleiding gaven tot verdere reflectie. Bijvoorbeeld, artsen rapporteerden dat het onaangenaam is wanneer subspecialisten verzoeken tot medebeoordeling van een patiënt in twijfel trekken of zelfs weigeren. Het ervaren van weerwoord en weerstand diende echter ook als een motivator om hun toekomstige telefoongesprekken verder vorm te geven om dit te voorkomen, te verminderen of te beheren, om zo het doel van het telefoongesprek en adequate patiëntenzorg te bereiken.

Hoofdstuk 7 beschrijft een analyse van de onderwijsbehoeften van (sub)specialisten in opleiding op basis van de dataset uit hoofdstuk 6 . Met behulp van kwalitatieve thematische analyse hebben we zowel formele en informele aspecten van werkplekgerelateerde telefoongesprekken die bijdroegen aan leren geïdentificeerd. De belangrijkste bevindingen waren gerelateerd aan informele aspecten van deze gesprekken. Vragen en onderbrekingen dienden als 'verborgen feedback' voor artsenin-opleiding. Bijvoorbeeld, wanneer arts-assistenten niet anticipeerden op de behoefte om specifieke informatie van hun gesprekpartners, dan stelden die gesprekspartners (zoals subspecialisten of supervisoren) aanvullende vragen. Arts-assistenten gebruikten op hun beurt deze vragen als feedback om zo te bepalen welke informatie ze een volgende keer toe wilden voegen aan de manier waarop ze een casus presenteren. Gebruik makende van het concept 'performance relevant information', vermoedden we dat het sensibiliseren van artsen-in-opleiding voor verborgen feedback mogelijk invloed kan hebben op hun leren. Daarom hebben we verschillende mogelijke educatieve strategieën voorgesteld om telefoongesprekken te verbeteren: (a) het inbedden van telefooncommunicatievaardigheden in bestaande simulatie-activiteiten en (b) het ontwikkelen van modules voor bestaande curricula om arts-assistenten te bewust te maken van deze "verborgen" feedback en hoe ze daar zinvol mee om kunnen gaan om leren op de werkplek te verbeteren. In plaats van de traditionele kijk van 'simulatie om te leren presteren' voor toekomstig klinisch werk hebben we een complementaire en vernieuwende aanpak voor simulatie voorgesteld, namelijk 'simulatie om te leren van werk te leren'. 
Hoofdstuk 8 gebruikt een concept uit de psychologie en managementliteratuur, genaamd teamreflexiviteit (TR) om de mogelijke invloeden van teaminteracties op zowel gedrag als leren te doorgronden. TR houdt in dat teams gezamenlijk nadenken over hun doelen, werkprocessen en strategieën om hun prestaties te verbeteren. Aangezien TR een fenomeen op teamniveau vastlegt, vereist dit communicatie tussen teamleden. Historisch vatte TR deze reflectie alleen nadat de evenementen gebeurden, zoals bij debriefing. Hoofdstuk 8 breidt deze kijk uit en beschrijft een vernieuwend conceptueel raamwerk voor TR in gezondheidszorg, dat drie momenten identificeert voor TR: voor-de-actie TR (voorbespreking voor de patiëntenzorg), tijdens-de-actie TR (beraadslagingen gedurende de patiëntenzorg) en na-de-actie TR (nabespreking na de patiëntenzorg). Dienovereenkomstig benadert TR doelen, taken, teamwerk, of middelen, afhankelijk van de fase (bv., optimale voorbereiding, een gedeeld mentaal model, adaptatie). Dit hoofdstuk stelt dat het creëren van gedeeld begrip binnen teams voor, gedurende, en na actieve gezamenlijke klinische zorg door het spreken over TR waaronder tussen supervisoren en artsen-in-opleiding- bijdraagt aan een wijze van leren die zeer goed aansluit bij de klinische werkplek en tevens collectieve competentie mogelijk maakt.

Hoofdstuk 9 (Discussie) integreert de belangrijkste bevindingen uit alle hoofdstukken om de overkoepelende onderzoeksvraag te beantwoorden in termen van hoe gesprekken bijdragen aan leren in een klinische omgeving. Het hoofdstuk verkent ook algemene implicaties voor de praktijk van klinisch onderwijs. Feedback en debriefing in het kader van simulatie maken duidelijk dat er veel potentieel zit in het doelgericht vormgeven van communicatieprocessen om van en door te leren in de praktijk. Bekeken door een socioculturele lens, vertegenwoordigen gesprekken een vorm van sociale activiteit die het leren stuurt. Goede onderlinge relaties en wederzijds respect maken leren door gesprekken mogelijk. 'Productieve conversationele spanningen' geven een genuanceerder beeld van ons begrip van gesprekken op de werkplek door te erkennen dat soms spanningen arts-assistenten motiveren om hun telefoongesprekken aan te passen om ze in de toekomst beter te laten lopen. Op een vergelijkbare wijze vervullen gesprekken een integrale rol in opvattingen over individuele competenties in klinisch onderwijs, met name in het ontwikkelen van competentie, in het competent lijken, en in het beoordelen van competentie. Verder stimuleren gesprekken de ontwikkeling van gedeelde inzichten binnen het team van zorgprofessionals die intersubjectiviteit en collectieve competentie bevorderen. Opleiders en begeleiders in de kliniek zouden praktijkgesprekken op twee manieren moeten sturen: (a) met behulp van formele en informele middelen, zoals gestructureerde feedback en nabesprekingen die betrekking hebben op relevante processen en inhoud, en strategieën die relaties en ondersteunende leeromgevingen bevorderen, en (b) door middel van simulaties die ontworpen zijn om clinici in staat te stellen optimaal gebruik te maken van de kracht van gesprekken in de dagelijkse praktijk. 


\section{Valorisation}

In the discussion section, I outlined the implications of my main findings. Now I will extend those implications beyond their scientific relevance. Talk plays a central role in clinical education, both in structured educational experiences and in the workplace. Thus, logical consequences include: (a) how we prepare faculty to engage with trainees, (b) how we prepare trainees to engage with faculty, (c) how we design curricula and clinical workspaces, and (d) how we augment team behaviors that promote shared understandings as well as team and individual learning. A key question relates to strategies that encourage uptake and use of my findings in educational practice.

\section{Translating knowledge}

As my work highlights, structured debriefing conversations have both process and content elements that educators can learn and master over time, making this an issue for faculty development. Colleagues and I have sought to disseminate our knowledge about the PEARLS debriefing framework at simulation and medical education conferences around the world, including multiple times at the International Meeting on Simulation in Healthcare, the International Pediatric Simulation Symposium and Workshops, and Pediatric Emergency Medicine Days in Germany.

In addition, I teach actively on a number of basic and advanced simulation educator courses locally in Chicago, as well as the Harvard Center for Medical Simulation and EUSIM and PAEDSIM courses in Europe. We have integrated principles from the PEARLS blended debriefing approach into these curricula. Attendees of these courses and conference workshops include physicians, nurses, and health professions educators from a variety of clinical and educational domains. We have codified our approach to teaching the PEARLS method in an invited PEARLS faculty development guide in Clinical Simulation in Nursing. ${ }^{1}$ PEARLS has become the preferred debriefing approach in many undergraduate nursing programs in the United States and Canada.

For many simulation educators, traveling to simulation conferences or obtaining funding to attend simulation educator courses represents a significant financial challenge and time commitment, so we have strived to create online resources. To make our work more widely accessible, my PEARLS collaborator Dr. Adam Cheng and I have joined forces with other international simulation experts to create and manage a website called Debrief2Learn.org. ${ }^{2}$ Debrief2Learn is a not-for-profit online repository of healthcare debriefing resources for simulation educators around the world. As such, social media such as Twitter plays an important role in directing interested educators to our collated body of work. Further, in response to calls for an even more user-friendly PEARLS debriefing script, we recently published a PEARLS infographic in Academic Medicine. ${ }^{3}$ With permission of the editors at Academic Medicine, we have made the PEARLS Debriefing Tool accessible through Debrief2Learn in a number of formats for printing and posting in debriefing rooms and for display on smartphones or tablets. The PEARLS Debriefing Tool has also been translated into multiple languages, including German, Spanish, French Japanese and Mandarin Chinese to name a few. More are in the works. I have also been invited to participate in online podcasts ${ }^{4}$ and journal clubs, ${ }^{5}$ 
making these avenues important to disseminate my work since they create enduring resources educators can access anywhere at any time.

\section{Managing the talk}

My findings about the talk in clinical workplaces have implications for physician education, although these considerations likely have applicability for clinicians from other professions as well. As my work has shown, some conversational tensions can be productive. In my view we must prepare physicians-in-training for their clinical encounters and sensitize them to the implicit or disguised feedback that such productive conversational tensions represent. I have already implemented a Telephone Talk workshop for a mixed audience of clinical supervisors and physicians-in-training as a forum to encourage dialogue about these important clinical interactions. A more formal curriculum for postgraduate physicians is under development that integrates notions of 'simulation as learning how to learn' from Chapter 7.

I have the great fortune of serving as an invited speaker to a broad range of clinical faculty in academic and community settings. I have already started integrating these important lessons about formal and informal clinical talk into keynote speeches, courses and workshops. Examples of upcoming conference keynote speeches and workshops include the New Zealand Association for Simulation in Healthcare in Auckland in late 2018 and the Prato Clinical Skills Conference in Italy in spring 2019.

In terms of team reflexivity, the work presented in Chapter 8 has spawned not only a growing research program to delineate mechanisms for team reflexivity, we have already begun integrating these notions into simulation curricula for health professionals. Examples include local simulation courses at Ann \& Robert H. Lurie Children's Hospital of Chicago and in pediatric team training courses with PAEDSIM, a German-speaking pediatric simulation collaborative in Germany, Austria, and Switzerland. PAEDSIM courses are designed for a multidisciplinary and interprofessional spectrum of pediatric professionals. I have been co-directing the PAEDSIM train-the-trainer courses for the past 7 years, and we have incorporated principles of team reflexivity into simulation educator training. To spread these lessons beyond these contexts, I have collaborated with Jan Schmutz and others to publish practical and easy to understand papers in both German and English.

- "Teamreflexion: Belastende Notfallsituationen meistern und verarbeiten" in a German pediatric journal (2017). ${ }^{6}$

- A 12 Tips paper in Medical Teacher on integrating team reflexivity into simulation-based team training (2018). ${ }^{7}$

Simulation appears to be an ideal venue to give clinicians a chance to experience and reflect on team reflexive behaviors. Finally, I am currently working with collaborators in research, education and clinical practice to translate lessons learned from healthcare simulation to clinical event debriefings after real situations in the workplace. ${ }^{8}$ 


\section{Summary}

My collective body of $\mathrm{PhD}$ related scholarship has implications for educators in both simulated and clinical settings, making faculty development imperative. In addition, strategies to prepare trainees for the talk of practice could yield tangible benefits for their learning. Finally, when designing curricula, workflows, and workspaces, we must consider the impacts on the talk of practice, since it has great implications for learning and patient care.

\section{References}

1. Cheng A, Grant V, Robinson T,...Eppich WJ. The Promoting Excellence and Reflective Learning in Simulation (PEARLS) Approach to Health Care Debriefing: A Faculty Development Guide. Clinical Simulation in Nursing. 2016;12(10):419-428.

2. Bajaj K, Meguerdichian M, Thoma B, Huang S, Eppich W, Cheng A. The PEARLS Healthcare Debriefing Tool. Acad Med. 2018;93(2):336.

3. Debrief2Learn.org at www.debrief2learn.org accessed September 5, 2018.

4. Simulcast Podcast, an 'Eppich Debriefing' at http://simulationpodcast.com/eppich-debriefing/ accessed September 5, 2018

5. Simulcast Journal Club on PEARLS at http://simulationpodcast.com/simulcast-journal-club-march2018-pearls-snythe/ accessed September 5, 2018

6. Schmutz JB, Eppich WJ, Heimberg E. Belastende Notfallsituationen meistern und verarbeiten. Pädiatrie. September 2017:10-14.

7. Schmutz JB, Kolbe M, Eppich WJ. Twelve tips for integrating team reflexivity into your simulationbased team training. Med Teach. 2018; 40(7):721-727.

8. Eppich WJ, Mullan PC, Brett-Fleegler M. "Let's talk about it": translating lessons from healthcare simulation to clinical event debriefings and clinical coaching conversations. Clin Ped Emerg Med. 2016;17(3):200-211. 
Valorisation 


\section{Acknowledgements}

I am unable to name or express sufficiently my sincerest thanks to every single person who supported me on my PhD journey. However, I wish to convey my deepest gratitude to the following colleagues, friends, and family:

To Pim Teunissen, for his wisdom, exemplary mentorship, and friendship

To Tim Dornan, for sage guidance and steadfast support in navigating key phases

To Jan-Joost Rethans, for his critical eye in keeping my work grounded and pragmatic

To Debra Nestel, who provided tangible advice and support at just the right moments

To Steven Krug, for enabling my academic pursuits

To my colleagues in the Division of Emergency Medicine at Ann \& Robert H. Lurie Children's Hospital of Chicago, for their continual encouragement

To the Grainger Foundation and the Department of Pediatrics, Northwestern University Feinberg School of Medicine, for financial support on my PhD journey

To Bill McGaghie, Diane Wayne, and my colleagues in the Department of Medical Education at Northwestern University Feinberg School of Medicine, for their mentorship and support

To Jenny Rudolph, Dan Raemer, Robert Simon, Jeffrey Cooper and my colleagues at the Center for Medical Simulation, for teaching me so much about debriefing

To the young doctors who participated in my research, for their candor and trust

To Adam Cheng, for our most fruitful collaboration

To Jan Schmutz, whose discipline and work ethic inspires and motivates

To Christiane Rabe, for being there from the beginning

To Jens Schroeter, without whom I would not be a physician

To my father, who would be proud

To my 'Oma', who made everything possible

To Erica, who inspires and supports in ways no one else can 


\section{Curriculum vitae}

Walter Eppich is Associate Professor of Pediatrics and Medical Education and Director of the Feinberg Academy of Medical Educators at the Northwestern University Feinberg School of Medicine. He attended medical school at Heidelberg University in Germany. He completed a residency in pediatrics at Duke University (USA) and Oxford University (UK) and subsequently a fellowship in pediatric emergency medicine at Yale University (USA). He maintains active clinical practice in the pediatric emergency department at Ann \& Robert H. Lurie Children's Hospital of Chicago, in addition to his educational research and faculty development responsibilities.

Since 2010, Dr. Eppich has been teaching extensively on basic and advanced simulation educator courses around the world with the Harvard Center for Medical Simulation. He has been active in the Society for Simulation in Healthcare, including a 3-year stint on the Board of Directors from 2012 to 2014. In 2017, he became an inaugural Fellow in the Society for Simulation in Healthcare Academy.

Dr. Eppich loves to travel to visit family and friends and to explore new locales. 
